\title{
Collection and Storage of Solar Gains Incident on a Radiant Floor in Highly Glazed Houses
}

by

Sébastien Athanase Brideau, B.Sc., M.A.Sc.

\author{
A thesis submitted to the \\ Faculty of Graduate and Postdoctoral Affairs \\ in partial fulfillment of the requirements for the degree of
}

Doctor of Philosophy in Mechanical Engineering

Ottawa-Carleton Institute for Mechanical and Aerospace Engineering

Department of Mechanical and Aerospace Engineering

Carleton University

Ottawa, Ontario

November, 2016

(C)Copyright

Sébastien Athanase Brideau, 2016 


\section{Abstract}

Large amounts of south facing windows can help reduce heating demand in the winter and shoulder seasons by allowing high levels of solar radiation to enter the building. One problem that may arise from large areas of south facing glazing is overheating of the adjacent rooms, even in the winter.

Cooling of the floors may provide a means to prevent overheating in such a situation. Cooling a floor prevents the portion of solar gains absorbed by the floor to be transferred to the space by convection or infrared radiation. This cooling can be achieved with the use of water pipes in the floor. The heat removed, and upgraded to a higher temperature with a heat pump, can then either be stored in a thermal storage tank for later use, sent to another zone that requires it, or used to preheat domestic hot water. Such a system has the potential to greatly reduce space heating and domestic heating requirements in houses in Canada. This thesis investigates such a system for a house in Canada. In periods of overheating, the solar gains are absorbed by the floor cover and collected by the cold pipes in the floor. The heat is upgraded by a heat pump and stored in a hot storage tank.

Building simulation was used to evaluate the potential energy savings for such system. This active/passive radiant floor solar collection system was found to be able to reduce energy demands by as much as $27 \%$ compared to a typical house HVAC system.

In order to model the system, existing models for embedded tube radiant floor systems were compared to a finite element simulation. Additionally, an above-floor tube and plate radiant floor model was developed and validated. A transient waterwater heat pump model was also developed and validated. The controls of radiant floor heating under high solar gains variation was also studied for various floor constructions. 
À maman et papa 


\section{Acknowledgments}

First, thank you Ian and Michaël. I really appreciated your guidance, and honesty. I also really appreciated you giving me the freedom to make this project my own, make mistakes, and learn from them. Merci Maman et Papa pour votre support continue. Thanks Adam for being a good friend, for being my tech support, and for letting me bounce ideas off of you. Thanks to my previous supervisor Michael Collins for the help with testing of samples and guidance when I needed it with my teaching. Thanks also to John Wright and Lukas Swan for their guidance and words of wisdom regarding teaching. Thank you Curtis, Sarah, Isabelle, Ashley, Nina, Chris, Fred, and Briana for your help with my experiment in the CHEeR house. Thanks Steve for your help with ESP-r. Thanks Evan and Geoff for your help in the lab, couldn't have done it without you. Thanks Ahmed, Ifaz, Steve, Suzan, Skai, Adam, Yawen, and Curtis for making the office so much fun. Merci Amen Agbossou pour ton amitié et ton superbe travail de modélisation. Thank you Liam and Cynthia for your advice and friendship. Thank you Steve Truttman for all the help. I would like to thank the NSERC Smart Net-Zero Energy Buildings Strategic Research Network for the financial support and the great opportunities it has provided students like myself over the last five years. Additionally, I would like to thank the Ontario Graduate Scholarship program and Dr. J.Y. Wong for his contribution to the J.Y. and E.W. Wong Research Award. Finally, thank you Christie for your patience and support. 


\section{Table of Contents}

Abstract $\quad$ ii

Acknowledgments $\quad$ iv

Table of Contents $\quad$ v

List of Tables $\quad$ x

List of Figures $\quad$ xii

$\begin{array}{ll}\text { Nomenclature } & \text { xvii }\end{array}$

1 Introduction 1

1.1 Problem ............................. 2

1.2 Proposed solution . . . . . . . . . . . . . . 3

1.2.1 Potential of radiant floor cooling with incident solar gains . . 4

1.3 Background information ................. 6

1.3.1 Radiant floors . . . . . . . . . . . . . 6

1.3.2 Vapour compression heat pumps . . . . . . . . . . 9

1.3.3 Simulation .................... 9

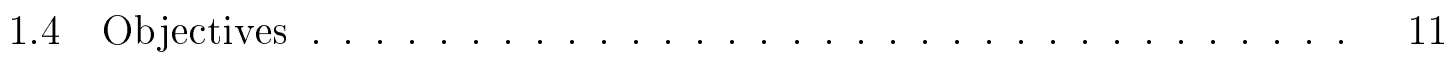

1.4.1 Structure of thesis ................ 12

2 Embedded tube inter-model comparison $\quad 14$

2.1 Introduction . . . . . . . . . . . . . . . . . . . 14

2.1.1 Literature review . . . . . . . . . . . . . 15

2.2 Heat transfer processes occurring with embedded-tube radiant floors . 18

2.3 Embedded-tube radiant floor models in BPS tools . . . . . . . . . 20 
2.3 .1 TRNSYS . . . . . . . . . . . . . . . . . . 23

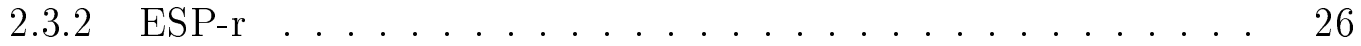

2.3 .3 EnergyPlus . . . . . . . . . . . . . . . . . . . . . 29

2.4 Inter model comparison . . . . . . . . . . . . . . . . . 31

2.4.1 Definition of test cases . . . . . . . . . . . . . 31

2.4 .2 Finite element analysis model . . . . . . . . . . . . 33

2.4.3 Making the three BPS tools equivalent . . . . . . . . . 36

2.5 Single step input results $\ldots \ldots \ldots \ldots \ldots$

2.5 .1 Thin slab case . . . . . . . . . . . . . . . 38

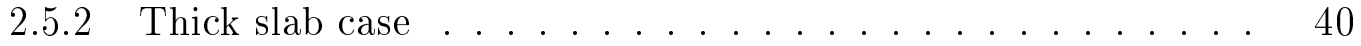

2.5.3 Steady-state solution . . . . . . . . . . . . . . . . 41

2.6 Double step input results . . . . . . . . . . . . . . . . . . . . . 43

2.6 .1 Thin slab case . . . . . . . . . . . . . . . . 43

2.6 .2 Thick slab case . . . . . . . . . . . . . . . . . . 44

2.6 .3 Time-step sensitivity . . . . . . . . . . . . . . . . . 44

2.7 Parametric Analysis . . . . . . . . . . . . . . . . 45

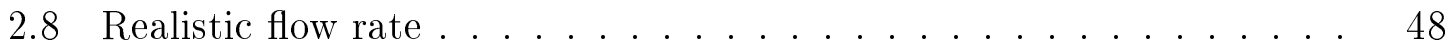

2.9 Closing remarks $\ldots \ldots \ldots \ldots \ldots \ldots \ldots \ldots \ldots \ldots \ldots$

3 Above-floor tube-and-plate (AFTP) radiant floor model development 54

3.1 Introduction . . . . . . . . . . . . . . . . . 54

3.1 .1 Literature . . . . . . . . . . . . . . . . . 55

3.2 Model development . . . . . . . . . . . . . . . . 55

3.2.1 ESP-r building domain solution method . . . . . . . . 55

3.2.2 Fin and cover finite difference conduction model . . . . . . . 56

3.2 .3 Tube model . . . . . . . . . . . . . . . . . . 60

3.2 .4 Implementation . . . . . . . . . . . . . . . . . 62

3.3 ESP-r model comparison with finite element analysis model . . . . . 62

3.3.1 Definition of test case . . . . . . . . . . . . . . 64

3.3 .2 Finite element analysis model . . . . . . . . . . . 65

3.4 Results . . . . . . . . . . . . . . . . . 66

3.4 .1 Parametric analysis . . . . . . . . . . . . . . 69

3.5 Experimental validation $\ldots \ldots \ldots \ldots \ldots \ldots \ldots$

3.5.1 Experimental apparatus . . . . . . . . . . . 70 
3.5.2 Experimental tests . . . . . . . . . . . . . 76

3.5 .3 Modelling . . . . . . . . . . . . . . . . . . 79

3.5.4 Experiment vs model comparison . . . . . . . . . . . . 81

3.5 .5 Sensitivity analysis $\ldots \ldots \ldots \ldots \ldots \ldots$

3.6 Closing remarks . . . . . . . . . . . . . . . . . . . . . . . . . . 89

4 Heat pump experimental testing and empirical model 91

4.1 Introduction . . . . . . . . . . . . . . . . . . . . . . . . 91

4.1 .1 Literature . . . . . . . . . . . . . . . . . . . . . . 91

4.1 .2 Context for this work . . . . . . . . . . . . . . . 93

4.2 Experimental setup . . . . . . . . . . . . . . . . . . . . 93

4.2 .1 Uncertainty analysis . . . . . . . . . . . . . . . 94

4.2 .2 Temperature measurements . . . . . . . . . . . . 95

4.2 .3 Flow meters . . . . . . . . . . . . . . . . 96

4.2.4 Electrical power measurement . . . . . . . . . . . 97

4.3 Steady state tests . . . . . . . . . . . . . . . . . 98

4.3 .1 Experimental results . . . . . . . . . . . . . . . . . 99

4.3.2 Influence of flow rate on performance . . . . . . . . . . 99

4.4 Transient tests . . . . . . . . . . . . . . . . . . . . . 102

4.5 TRNSYS model . . . . . . . . . . . . . . . . . . . . 103

4.5.1 Linear regression of empirical data . . . . . . . . . . 103

4.5.2 Steady state model . . . . . . . . . . . . . . . . 105

4.5.3 Steady state model applied to transient test . . . . . . . . 106

4.5.4 Development of transient heat pump model . . . . . . . . . 110

4.6 Closing remarks . . . . . . . . . . . . . . . . . 116

5 Controls of radiant floor heating with high solar gains 118

5.1 Introduction . . . . . . . . . . . . . . . . 118

5.1 .1 Objective . . . . . . . . . . . . . . . . . 119

5.2 Literature Review . . . . . . . . . . . . . . . . . . . . . . 119

5.2.1 Reactive radiant floor heating controls . . . . . . . . . . 119

5.2.2 Predictive radiant floor heating controls in housing . . . . . . 123

5.2 .3 Radiant floor models . . . . . . . . . . . . . . . . . . . . . . . 124

5.3 Control schemes examined . . . . . . . . . . . . . . . . . . . . 124

5.4 Simulation approach $\ldots \ldots \ldots \ldots \ldots \ldots \ldots$ 
5.5 Tube spacing . . . . . . . . . . . . . . . . . . . . . . 132

5.6 Response time . . . . . . . . . . . . . . . . . . . . 133

5.7 Parametric Analysis . . . . . . . . . . . . . . . . . . 134

$5.7 .1 \quad$ Predictive controller . . . . . . . . . . . . . . 138

5.8 Results . . . . . . . . . . . . . . . . . . . . . 138

5.8.1 6\% South Facing Glazing to Floor Area Ratio without Setback 138

5.8.2 6\% South Facing Glazing to Floor Area Ratio with setback . . 141

5.8.3 15\% South Facing Glazing to Floor Area Ratio without Setback 142

5.8.4 15\% South Facing Glazing to Floor Area Ratio with Setback . 145

5.8.5 Setback recovery time . . . . . . . . . . . . . . 148

5.9 Concluding remarks . . . . . . . . . . . . . . . . . . . . . . 148

6 Evaluation of active/passive solar collection system 151

6.1 Introduction . . . . . . . . . . . . . . . . . . 151

6.2 Models . . . . . . . . . . . . . . . . . . . . . . . 151

6.2 .1 Building model . . . . . . . . . . . . . . . . . . . 152

6.2.2 Plant model - solar collection system . . . . . . . . . . . 159

6.2.3 Plant model - typical house . . . . . . . . . . . . . . 161

6.2.4 Thermal comfort . . . . . . . . . . . . . . . . 161

6.3 Results . . . . . . . . . . . . . . . . . . . . 162

6.3 .1 Daily results . . . . . . . . . . . . . . . . . . . . 162

6.3 .2 Annual results . . . . . . . . . . . . . . . . . 166

6.3.3 Thermal comfort results . . . . . . . . . . . . . . . . 171

6.3.4 Latent heat removal . . . . . . . . . . . . . . . . 172

6.4 Concluding remarks . . . . . . . . . . . . . . . . . . . . . 172

7 Design and construction of active/passive radiant floor solar collection system in the Urbandale Center for Home Energy Research 174

7.1 Introduction . . . . . . . . . . . . . . . . . 174

7.2 Radiant floors . . . . . . . . . . . . . . . . . . . . 174

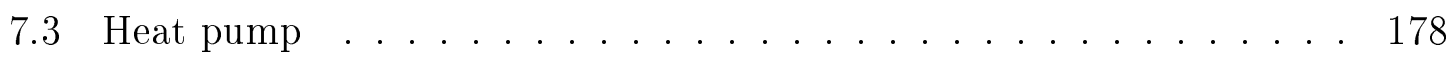

7.4 Hot water storage . . . . . . . . . . . . . . . . . . 178

7.4.1 Domestic hot water mimicry system . . . . . . . . . . . . 179

7.5 Cold water storage $\ldots \ldots \ldots \ldots \ldots \ldots$

7.6 Heat dump . . . . . . . . . . . . . . . . . . 180 
7.7 Electric backup heater . . . . . . . . . . . . . . . . 182

7.8 System operation . . . . . . . . . . . . . . . . . 183

7.8.1 Cooling mode . . . . . . . . . . . . . . 183

7.8 .2 Heating mode . . . . . . . . . . . . 186

7.8.3 Heating mode with domestic hot water draw . . . . . . . . 186

7.9 Concluding remarks . . . . . . . . . . . . . . 186

8 Conclusion $\quad 189$

8.1 Embedded-tube radiant floor inter-model comparison . . . . . . . . 189

8.2 Above-floor tube and plate radiant floor model development . . . . . 190

8.3 Heat pump experimental testing and empirical model . . . . . . . . . 191

8.4 Controls of radiant floor heating with high solar gains . . . . . . . . 191

8.5 Evaluation of active/passive solar collection system . . . . . . . . . 192

8.6 Design and construction of active/passive radiant floor solar collection system . . . . . . . . . . . . . . . . . 193

8.7 Major contributions . . . . . . . . . . . . . . 193

8.8 Recommendations . . . . . . . . . . . . . . 194

List of References 195

Appendix A Additional results for above-floor tube and plate radiant floor model 204

A.1 Geometry, construction, and test cases . . . . . . . . . . 204

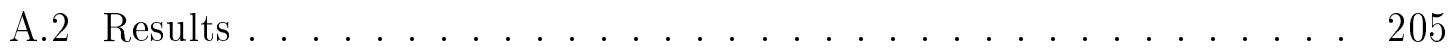

A.2.1 Finite element mesh sensitivity . . . . . . . . 205

A.2.2 ESP-r finite difference mesh sensitivity . . . . . . . . 205

A.2.3 Comparison . . . . . . . . . . . . 206

A.2.4 Parametric analysis .............. 209

$\begin{array}{lll}\text { Appendix B Laouadi radiant floor tube model } & 210\end{array}$

Appendix C Additional results for AFTP radiant floor experiment 212

C.1 Sensitivity analysis . . . . . . . . . . . . . . . . . . 214

Appendix D Parameters of tuned radiant floor heating controllers 218 


\section{List of Tables}

2.1 Construction for thin slab floor . . . . . . . . . . . . . . 32

2.2 Construction for thick slab floor . . . . . . . . . . . . . . . 32

2.3 Steady-state heat flux for thin slab case . . . . . . . . . . . . . . 42

2.4 Steady-state heat flux for thick slab case . . . . . . . . . . . . 42

3.1 Construction of floor . . . . . . . . . . . . . 65

3.2 RMSD for various parameters perturbation . . . . . . . . . 69

3.3 Construction of floor . . . . . . . . . . . . . . 70

3.4 Thermocouple calibration bias error sources . . . . . . . . . 73

3.5 Thermocouple bias error sources . . . . . . . . . . . . . 74

3.6 Pt100 bias error sources _..................... 74

3.7 Parameters for floor construction in model . . . . . . . . . . . . 80

3.8 Material sensitivity - RMSD - Test A . . . . . . . . . . 86

3.9 Material sensitivity - Percentage error for total energy transfer - Test A 86

3.10 Convective heat transfer coefficient sensitivity- RMSD - Test A . . . . 88

3.11 Convective heat transfer coefficient sensitivity - Percentage error for total energy transfer - Test A . . . . . . . . . . . . 89

4.1 Thermocouple bias error sources . . . . . . . . . . . . . 95

4.2 Thermopile bias error sources . . . . . . . . . . . . . . 96

4.3 Pt100 bias error sources . . . . . . . . . . . . . 96

4.4 Percent difference in performance at different flow rates . . . . . . . 102

4.5 Steady state heat pump equations coefficients . . . . . . . . . 105

4.6 Heat pump model inputs and outputs . . . . . . . . . . . . . . . 106

4.7 Parameters for transient heat pump model . . . . . . . . . . . 113

5.1 Tube-in-subfloor construction . . . . . . . . . . . . . . 131

5.2 Embedded tube construction . . . . . . . . . . . . . . 131

5.3 Slab thicknesses and tube locations . . . . . . . . . . . . . 131

5.4 Occupant Schedule . . . . . . . . . . . . . . . . . 132 
5.5 Effective steady state conductance for various floor constructions . . 133

5.6 Time constant for various floor constructions . . . . . . . . . . . 134

5.7 Parametric analysis . . . . . . . . . . . . . . 135

5.8 Objective function . . . . . . . . . . . . . 137

6.1 Construction of embedded tube floor . . . . . . . . . . . . 158

7.1 Construction of floor . . . . . . . . . . . . . 176

A.1 Construction of floor . . . . . . . . . . . . . . 205

A.2 RMSD for various parameters pertubation . . . . . . . . . . 209

C.1 Material sensitivity - Test B . . . . . . . . . . . . . 215

C.2 Convective heat transfer coefficient sensitivity- Test B . . . . . . . . 217

D.1 ON-OFF controls without temperature setback . . . . . . . 219

D.2 ON-OFF controls with temperature setback . . . . . . . . . 219

D.3 PWM controls without temperature setback . . . . . . . . . . 220

D.4 PWM controls with temperature setback . . . . . . . . . . 220

D.5 TR controls without temperature setback . . . . . . . . . . . 221

D.6 TR controls with temperature setback . . . . . . . . . . . 221

D.7 TRIF controls without temperature setback . . . . . . . . . . 222

D.8 TRIF controls with temperature setback . . . . . . . . . . 222

D.9 TRIF-Avg controls without temperature setback . . . . . . . . 223

D.10 TRIF-Avg controls with temperature setback . . . . . . . . . 223

D.11 Temperature Boost controls . . . . . . . . . . . . . . 224 


\section{List of Figures}

1.1 Schematic of incoming solar radiation in a room . . . . . . . . 3

1.2 Radiant heating and cooling system with heat pump . . . . . . . . 4

1.3 Radiant floor with embedded pipe . . . . . . . . . . . . 7

1.4 Above-floor tube and plate system . . . . . . . . . . . . . 7

1.5 Below-floor tube and plate system . . . . . . . . . . 8

2.1 Section of a fin . . . . . . . . . . . . . . . . . . . . . . . . . . . . .

2.2 Modes of heat transfer in embedded tube system . . . . . . . . . . 19

2.3 Water temperature profile along the pipe length . . . . . . . . . . 20

2.4 Plan view of serpentine configuration . . . . . . . . . . . 21

2.5 Example of temperature distribution in radiant floor . . . . . . . 21

2.6 TRNSYS model - delta to wye resistance network transformation . . 23

2.7 TRNSYS model series resistance circuit . . . . . . . . . . . . 24

2.8 Section of slab . . . . . . . . . . . . . . . . . 24

2.9 ESP-r model split construction . . . . . . . . . . . . . 28

2.10 Discretization of the EnergyPlus model . . . . . . . . . . . . 29

2.11 Single step input tube inner temperature profile . . . . . . . . . . 33

2.12 Double step input tube inner temperature profile . . . . . . . . . 34

2.13 Boundary of FEA model . . . . . . . . . . . . . . 35

2.14 FEA mesh and boundary conditions for thin slab . . . . . . . 35

2.15 Heat flux at top surface for thin slab with single step input . . . . . 39

2.16 Heat flux at top surface for thick slab with single step input . . . . . 41

2.17 Heat flux at top surface for thin slab with double step input . . . . . 43

2.18 Heat flux at top surface for for thick slab with double step input . . . 44

2.19 Effects of time-step on RMSD (thick slab) . . . . . . . . . . 46

2.20 Effects of time-step on TRNSYS results (thick slab) . . . . . . . . 46

2.21 Effects of time-step on ESP-r split construction results (thick slab) . . 47

2.22 Effects of time-step on EnergyPlus 2D results (thick slab) . . . . . 47 
2.23 Parametric analysis for thin slab FEA model . . . . . . . . . . . . . 48

2.24 Parametric analysis for thick slab FEA model . . . . . . . . . . . 49

2.25 Surface heat flux results for thick slab with realistic flow rate . . . . 50

2.26 Heat transfer between water and floor construction for thick slab with realistic flow rate . . . . . . . . . . . . . 51

3.1 Section of a AFTP radiant floor with boundaries of finite difference

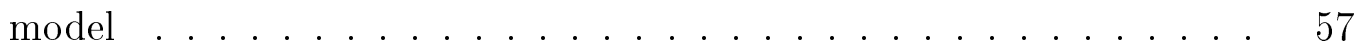

3.2 Finite difference model nodes and boundary conditions . . . . . . . 58

3.3 Equivalent circuit for conduction heat transfer coefficient calculations between nodes . . . . . . . . . . . . . . 59

3.4 Shift of finite element temperature field to match average ESP-r tem-

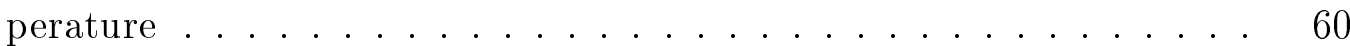

3.5 Energy balance on tube. Reproduced in part from Laouadi . . . . . . 61

3.6 Flow chart of model . . . . . . . . . . . . . . 63

3.7 Step input tube inner temperature profile . . . . . . . . . . . . 66

3.8 FEA mesh and boundary conditions AFTP floor . . . . . . . . . 67

3.9 Comparison of ESP-r model with finite element model for surface heat

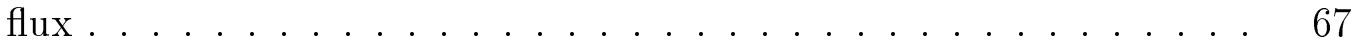

3.10 Comparison of ESP-r model with finite element model . . . . . . 68

3.11 Plan view of instrumented room with instruments locations (floor plan adapted from drawings by Urbandale Construction) . . . . . . . . . . 71

3.12 Picture of instrumented room with aspirated radiation shields, thermocouples, and flux meters . . . . . . . . . . . . 73

3.13 Picture of radiant floor manifolds with temporary flow meter and Pt100s 75

3.14 Experimental data (temperatures) for test A . . . . . . . . . . 77

3.15 Experimental data (heat flux and flow rate) for test A . . . . . . . 78

3.16 Location of measured and predicted heat flux surfaces . . . . . . . . 82

3.17 Experimental vs Modelled Results - Test A: Water Heat Transfer Rate 83

3.18 Experimental vs Modelled Results - Test A: Air and Floor Surface Temperature ................... 84

3.19 Experimental vs Modelled Results - Test A: Heat Fluxes . . . . . . 85

3.20 Comparison of convective heat transfer coefficient correlations over range of $\Delta T$ in tests f . . . . . . . . . . . . . 88

4.1 Transient heat pump model approach by Afjei et al. . . . . . . . . . 93 
4.2 Heat pump experiment apparatus schematic . . . . . . . . . . . 94

4.3 Heat pump in SBES lab . . . . . . . . . . . . . . 97

4.4 Current transformers . . . . . . . . . . . . . . . . 98

4.5 Condenser heat transfer rates - steady state experimental results . . . 100

4.6 Evaporator heat transfer rates - steady state experimental results . . 100

4.7 Electrical power consumption - steady state experimental results . . . 101

4.8 Heating COP - steady state experimental results . . . . . . . . . . . . 101

4.9 Transient experiment results . . . . . . . . . . . . . . 104

4.10 Percentage difference in energy between steady state model and experiment since start of cycle - cold start . . . . . . . . . . . . . . 107

4.11 Percentage difference in energy between steady state model and experiment since start of cycle - 3 hours since last cycle . . . . . . . . . . 108

4.12 Percentage difference in energy between steady state model and experiment since start of cycle - 1 hour since last cycle . . . . . . . . . . 109

4.13 Percentage difference in energy between steady state model and experiment since start of cycle - 33 minutes since last cycle . . . . . . . . . 109

4.14 Percentage difference in energy between steady state model and experiment since start of cycle - 15 minutes since last cycle . . . . . . . . . 110

4.15 Percentage difference in energy between transient model and experiment since start of cycle - cold start . . . . . . . . . . . . . . . 114

4.16 Percentage difference in energy between transient model and experiment since start of cycle - 3 hours since last cycle . . . . . . . . . . 114

4.17 Percentage difference in energy between transient model and experiment since start of cycle - 1 hour since last cycle . . . . . . . . . . . . 115

4.18 Percentage difference in energy between transient model and experiment since start of cycle - 33 minutes since last cycle . . . . . . . . . 115

4.19 Percentage difference in energy between transient model and experiment since start of cycle - 15 minutes since last cycle . . . . . . . 116

5.1 Example of pulse width modulation for heating mode. Adapted from Siegenthaler ..................... 125

5.2 Floor plan of modelled zone . . . . . . . . . . . . . . 128

5.3 Solar gains in the space and ambient temperature . . . . . . . . . 129

5.4 Embedded tubes construction . . . . . . . . . . . . 130

5.5 Tube-in-subfloor construction . . . . . . . . . . . . 130 
5.6 Heating demand of various floor constructions with typical solar gains without temperature setback . . . . . . . . . . . . . . . 139

5.7 Average supply temperature of various floor constructions with typical solar gains without temperature setback _ . . . . . . . . 140

5.8 Heating demand of various floor constructions with typical solar gains and temperature setback . . . . . . . . . . . . . . 141

5.9 Average supply temperature of various floor constructions with typical solar gains and temperature setback . . . . . . . . . . . . . . 142

5.10 Comfort of various floor constructions with high solar gains and without temperature setback . . . . . . . . . . . . . . . . 143

5.11 Heating demand of various floor constructions with high solar gains and without temperature setback . . . . . . . . . . . . 144

5.12 Average supply temperature of various floor constructions with high solar gains and without temperature setback . . . . . . . . . . 144

5.13 Comfort of various floor constructions with high solar gains and temperature setback

5.14 Heating demand of various floor constructions with high solar gains and temperature setback . . . . . . . . . . . . 146

5.15 Average supply temperature of various floor constructions with high solar gains and temperature setback . . . . . . . . . . . . 147

6.1 South elevation with high glazing area $\ldots \ldots \ldots \ldots$

6.2 South elevation with low (typical) glazing area . . . . . . . . . 154

6.3 Floor plan of first floor zone . . . . . . . . . . . . 156

6.4 Floor plan of first floor zone . . . . . . . . . . . . . . . 157

6.5 Results for February 2nd - Ottawa . . . . . . . . . . . . 163

6.6 Results for July 21st - Ottawa . . . . . . . . . . . . . . . . . 164

6.7 Results for November 15 th - Ottawa . . . . . . . . . . . 165

6.8 Annual simulation results for Ottawa - AFTP . . . . . . . . 167

6.9 Annual simulation results for Calgary - AFTP . . . . . . . . . 168

6.10 CWEC monthly average climate data . . . . . . . . . . . 168

6.11 Monthly simulation results for Ottawa - AFTP, $2 \mathrm{~m}^{3}$ hot storage tank, high south-facing glazing . . . . . . . . . . . . . 169

6.12 Monthly simulation results for Calgary - AFTP, $2 \mathrm{~m}^{3}$ hot storage tank, high south-facing glazing . . . . . . . . . . . . . . . 169 
6.13 Annual simulation results for Whitehorse . . . . . . . . . . . 171

6.14 Annual simulation results for various floor constructions in Ottawa . . 172

7.1 Roth radiant floor panels with tubes . . . . . . . . . . 175

7.2 Roth radiant floor with backing boards and thinset mortar . . . . . 176

7.3 Manifold on second floor . . . . . . . . . . . . . . . 177

7.4 Hot storage tanks . . . . . . . . . . . . . . . . 179

7.5 Heat dissipators . . . . . . . . . . . . . . . . . 180

7.6 Domestic hot water mimicry system storage tanks and flow control valves 181

7.7 Cold storage tank . . . . . . . . . . . . . . . . . . . 182

7.8 Electric backup boiler . . . . . . . . . . . . . . . . . 183

7.9 Symbol legend for plumbing schematics . . . . . . . . . . . . . . . 184

7.10 Schematic of system - Radiant floor cooling and active heat pump. Figure by Sarah Brown . . . . . . . . . . . . . . 185

7.11 Schematic of system - Radiant floor cooling and active heat pump. Figure by Sarah Brown . . . . . . . . . . . . . . 187

7.12 Schematic of system - Radiant floor cooling and active heat pump. Figure by Sarah Brown . . . . . . . . . . . . . . . . . . . . 188

A.1 Finite element mesh for tile cover . . . . . . . . . . . . . 206

A.2 Comparison of ESP-r model with finite element model for tile cover and 1280 minutes . . . . . . . . . . . . . . . 207

A.3 Comparison of ESP-r model with finite element model for tile cover and first 39 time steps $(78$ minutes $)$. . . . . . . . . . 207

A.4 Comparison of ESP-r model with finite element model for hardwood cover and 1280 minutes . . . . . . . . . . . . . . . . 208

A.5 Comparison of ESP-r model with finite element model for hardwood cover and first 39 time steps (78 minutes $)$. . . . . . . . . . . . 208

C.1 Experimental data (temperatures) for test B . . . . . . . . . . 213

C.2 Experimental data (heat flux and flow rate) for test B . . . . . . . . 213

C.3 Experimental vs Modelled Results - Test B: Water Heat Transfer Rate 214

C.4 Experimental vs Modelled Results - Test B: Air and Floor Surface Temperature . . . . . . . . . . . . . . . 215

C.5 Experimental vs Modelled Results - Test B: Heat Fluxes . . . . . 216 


\section{Nomenclature}

\begin{tabular}{|c|c|}
\hline$A$ & Area $\left[\mathrm{m}^{2}\right]$ \\
\hline$A_{\text {tube }}$ & Tube wall cross sectional area $\left[\mathrm{m}^{2}\right]$ \\
\hline$A U S T$ & Average uncontrolled surface temperature [K] \\
\hline$B_{I}$ & Bias error of derived quantity $I$ [various] \\
\hline$B_{X}$ & Bias error of single measurement $X$ [various] \\
\hline$C_{e f f}$ & Effective conductance $\left[\mathrm{W} \mathrm{m} \mathrm{m}^{-2} \mathrm{~K}^{-1}\right]$ \\
\hline$C_{p}, C$ & Specific heat $\left[\mathrm{J} \mathrm{kg}^{-1} \mathrm{~K}^{-1}\right]$ \\
\hline$C O P_{c}$ & Cooling coefficient of performance [-] \\
\hline$C O P_{h}$ & Heating coefficient of performance [-] \\
\hline$D$ & Diameter $[\mathrm{m}]$ \\
\hline$E$ & Energy $[\mathrm{J}]$ \\
\hline$F$ & Gain [-] \\
\hline$G$ & Incident thermal radiation $\left[\mathrm{W} \mathrm{m}^{-2}\right]$ \\
\hline$g$ & Gain $\left[K^{-1}\right]$ \\
\hline$h$ & Heat transfer coefficient $\left[\mathrm{W} \mathrm{m}^{-2} \mathrm{~K}^{-1}\right]$ \\
\hline$I$ & Derived quantity [various] \\
\hline$K$ & PID controller gain \\
\hline$k$ & Thermal conductivity $\left[\mathrm{W} \mathrm{m}{ }^{-1} \mathrm{~K}^{-1}\right]$ \\
\hline$L$ & Length of circuit $[\mathrm{m}]$ \\
\hline
\end{tabular}


M

$\dot{m}$

$N_{\text {cover }}$

$P$

$Q$

$q$

$R$

$R^{\prime}$

$S$

$T$

$T_{o}$

$T_{M R}$

$t$

U

$U P$

$\dot{V}$

W

X

$z$

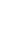

$\alpha$

$\Delta x$

$\Delta t$

$\delta$
Center to center tube distance [m]

Mass flow rate $\left[\mathrm{kg} \mathrm{s}^{-1}\right]$

Amount of cover layers [-]

Power [W]

Heat transfer rate $[\mathrm{W}]$

Heat flux $\left[\mathrm{W} \mathrm{m}^{-2}\right]$

Thermal resistance $\left[\mathrm{m}^{2} \mathrm{~K} \mathrm{~W}^{-1}\right]$

Thermal resistance per unit tubing circuit length $\left[\mathrm{m} \mathrm{K} \mathrm{W}^{-1}\right]$

Reset slope [-]

Temperature $[\mathrm{K}]$

Operative temperature $[\mathrm{K}]$

Mean radiant temperature $[\mathrm{K}]$

Time $[\mathrm{s}]$

Heat conductance $\left[\mathrm{W} \mathrm{m}^{-2} \mathrm{~K}^{-1}\right]$

Product of tubing overall heat conductance and perimeter $\left[\mathrm{W} \mathrm{m}^{-1} \mathrm{~K}^{-1}\right]$

Volumetric flow rate $\left[\mathrm{m}^{3} \mathrm{~s}^{-1}\right]$

Fin length $[\mathrm{m}]$

Measured quantity [various]

Distance in direction of fluid flow $[\mathrm{m}]$

\section{Greek Letters}

Absorptivity of thermal radiation [-]

Width of finite difference element [m]

Time step size $[\mathrm{s}]$

Thickness $[\mathrm{m}]$ 
$\epsilon$

$\Phi$

$\Lambda$

$\Theta$

$\rho$

$\tau$

$\Psi$

$\xi$

o

$b$

bead

$c$

coldstart

cond

condenser

corrected

$\operatorname{conv}$

cover

$d$
Effectiveness [-]

Deviation from average layer temperature $[\mathrm{K}]$

Coefficient in transient heat pump model $[\mathrm{s}]$

Temperature gradient between fluid and outer tube [K]

Density $\left[\mathrm{kg} \mathrm{m}^{-3}\right]$

Time constant $[\mathrm{s}]$

Heat pump steady state equation coefficient [various]

PID controller coefficient

\section{Subscripts and superscripts}

Immediately following the end of heat pump cycle

Between top zone and tube surface

Between bottom zone and tube surface

Between top and bottom zone

Air dry bulb

From boiler to circuit fluid

Thermocouple bead

From tubing to floor

Startup of heat pump after long period of time since last cycle

Conduction

Heat pump condenser

Corrected temperature

Convection

Floor cover

derivative 


\begin{tabular}{|c|c|}
\hline$e$ & Equivalent \\
\hline elec & Electrical compressor \\
\hline embed & Embedding material \\
\hline evap & Heat pump evaporator \\
\hline$f$ & Fluid \\
\hline$f-t u b e$ & From fluid to tubing \\
\hline$g$ & Between tube surface and average tube layer temperature \\
\hline$i$ & Integral \\
\hline in & Inlet \\
\hline $\max$ & Maximum \\
\hline measured & Measured value \\
\hline old & Previous time step \\
\hline out & Outlet \\
\hline outdoor & Outdoor air dry bulb \\
\hline$p$ & Pipe wall \\
\hline$r$ & Radiant \\
\hline return & Water return \\
\hline$s$ & Node nearest to tube \\
\hline setpoint & Air dry bulb setpoint \\
\hline steady & Steady state \\
\hline supply & Water supply \\
\hline surface & Floor surface \\
\hline$t i$ & Inner tubing \\
\hline to & Outer tubing \\
\hline
\end{tabular}




$t-1$
undisturbed
wire
$x$
$y$
$z$

Previous time step

Undisturbed measurement

Thermocouple wire

$\mathrm{X}$-axis, parallel to floor

Y-axis, perpendicular to floor

Between inlet water temperature and average water temperature 


\section{Chapter 1}

\section{Introduction}

In 2012, space heating of residential, commercial, and institutional buildings accounted for $16 \%$ of the total energy use in Canada. Space heating also accounted for $62 \%$ of the energy demand of residential buildings [1]. In order to improve energy efficiency in residential buildings such as houses, space heating demands must be lowered.

In highly insulated and air tight houses, the heating demands are usually much lower than conventional houses. Passive measures such as using south facing windows for solar gains during the heating season can be used to further lower the heating demand. Sander and Barakat [2] have shown that increasing the wall thermal resistance in a typical house in Ottawa from $3.5 \mathrm{~m}^{2} \mathrm{~K} \mathrm{~W}^{-1}$ to $6.4 \mathrm{~m}^{2} \mathrm{~K} \mathrm{~W}^{-1}$, increasing the thermal resistance of the roof from $5.2 \mathrm{~m}^{2} \mathrm{~K} \mathrm{~W}^{-1}$ to $10.5 \mathrm{~m}^{2} \mathrm{~K} \mathrm{~W}^{-1}$, and optimizing the south facing window area can reduce heating demand by almost half. For Canadian climates, they also showed that in highly insulated houses, the addition of thermal mass to the building has minimal impact on the heating demand and that changing windows from double pane to triple pane is the most effective way of decreasing heating demands in buildings with typical insulation levels and high insulation levels. Further, in highly insulated houses, they showed that the optimal south facing glazing area for reducing heating demand is approximately $4.8 \%$ of floor area for triple pane and $3.4 \%$ for double pane windows.

Previously, Barakat [3] had used modelling to evaluate the heat gains and losses through various window constructions in housing for every month of the year, in 13 Canadian locations, and at various orientations. It was found that although windows are typically energy gainers in the summer months, the winter months results are 
highly dependent on orientation, location, and window construction. During the winter months, south facing windows typically were the largest energy gainers and the north facing windows were typically the largest energy losers of all window orientations.

Later, Sander and Barakat [4] studied the utilization of solar gains through windows. A solar utilization factor was defined as the fraction of solar gains that reduce the heating demand. Those gains that do not decrease the heating load cause overheating. A graphical method to calculate the solar utilization factor based on a "gain-to-load ratio" and "thermal mass-to-gain ratio" was developed. These results were validated with experimental results. The various experimental results had seasonal utilization factors ranging between 0.62 and 0.97 . This means that, for those experiments, between $3 \%$ and $38 \%$ of the solar gains did not decrease the heating load in the space. The wide range of utilization factors is due to the experiments being run for various "gain-to-load ratios" and "thermal mass-to-gain ratios" (where the gain here is the amount of solar gains). For the same amount of solar gains, a higher amount of mass increases the the solar utilization factor. Similarly, for the same amount of solar gains, higher heating loads will increase the solar utilization ratio.

More recently, Proskiw [5] has shown that increasing the thermal mass in a Canadian house with a very heavy concrete construction may yield 2-7\% heating demand reduction, but that the cost involved is often prohibitive. Proskiw also presents a maximum south-facing glazing area of $6 \%$ of floor surface area after which additional glazing area yields minimal decrease in heating demand. This simple guideline has been used for low-energy houses for the past 25 years [5] but is still only a rule of thumb and may not provide the best design for all cases.

\subsection{Problem}

Although increasing south facing window area beyond the optimal point described previously will allow for more solar gains in the house, these gains will not be useful $[3,4]$. In single detached family house, one problem that can arise from highly glazed south facades and tight envelopes is overheating even in winter. Also, a mismatch of solar gains availability (day) and peak heating loads (night) means that heating will be required at night even for highly insulated houses. 


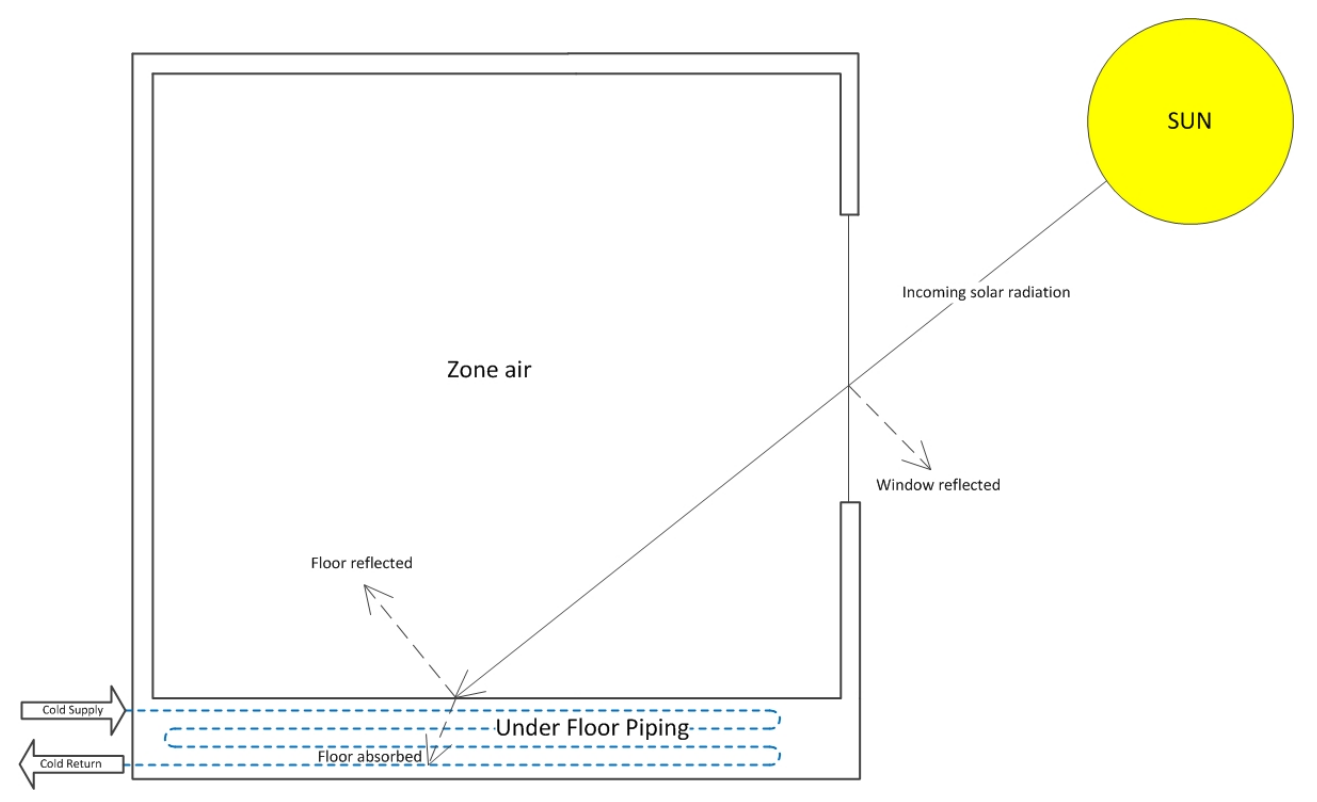

Figure 1.1: Schematic of incoming solar radiation in a room

\subsection{Proposed solution}

With the use of a radiant floor system, it may be possible to collect those solar gains incident on the floor in zones with a large amount of south facing windows, and store the heat collected for later release in the space, heating of another zone, or heating of domestic hot water. Figure 1.1 is a schematic of solar radiation entering a zone through a window, then being absorbed by the floor. As noted on the schematic, some of the incoming solar radiation is reflected by the window, and some is reflected by the floor. The absorbed solar radiation will cause the floor to warm up. Embedded pipes in the floor can be used to cool the floor and carry the heat away. A water-water heat pump would be used to supply cold water to the floor and hot water to a storage tank. Figure 1.2 shows a schematic of a potential system with cooling and heating in two zones, and domestic water heating. The proposed research sets to investigate the viability and design of such a system.

In order to study this type of system, simulation was used. There was however a lack of modelling tools and general knowledge to conduct the type of simulation required. First, existing models for embedded tube radiant floor systems (see Section 1.3.1) available in building performance simulation tools have never been validated adequately. Second, there was no existing model for above-floor tube and plate 


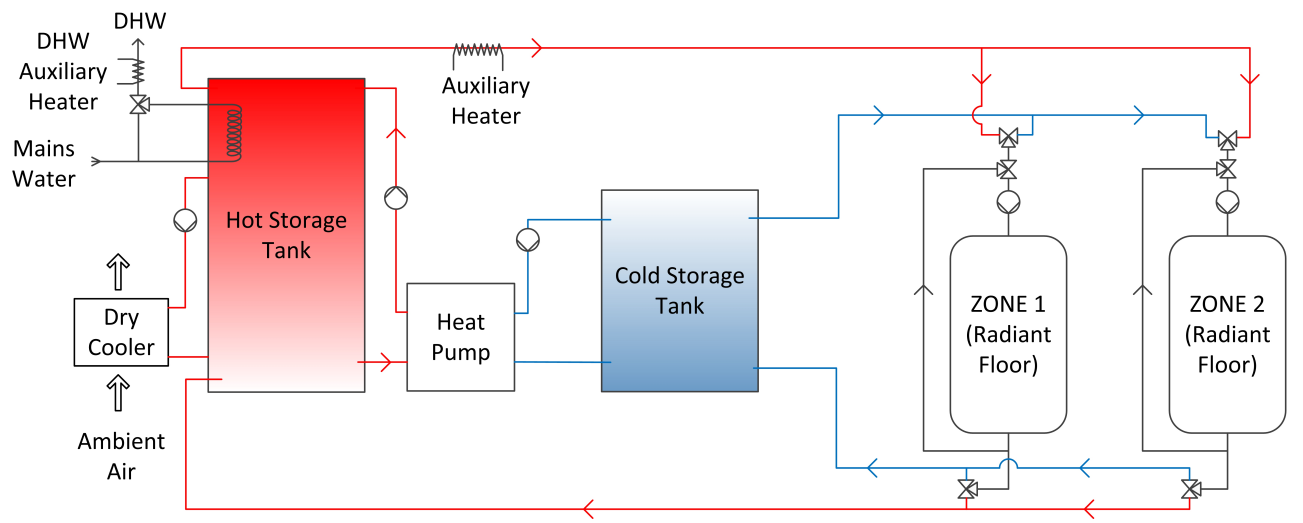

Figure 1.2: Radiant heating and cooling system with heat pump

radiant floor systems (see Section 1.3.1). Third, there was no existing transient model for house-scale water-water heat pumps (see Section 1.3.2). Finally, controls for hydronic radiant floors under high solar gains variability have not been investigated thoroughly. These knowledge gaps led to the specific objectives of this thesis. The current chapter gives an introduction to some of these topics, but these topics will be discussed in detail in the following chapters.

\subsubsection{Potential of radiant floor cooling with incident solar gains}

Beausoleil-Morrison [6] defined mixed convective heat transfer coefficients for floors based on correlations by Alamdari and Hammond [7] and Fisher [8]. With those correlations, it can be shown that for a room with typical conditions the heating convective heat transfer coefficient will be around $3.4 \mathrm{~W} \mathrm{~m}^{-2} \mathrm{~K}^{-1}$. For floor cooling, the convective heat transfer coefficient is approximately $0.4 \mathrm{~W} \mathrm{~m}^{-2} \mathrm{~K}^{-1}$. Radiative heat transfer coefficients are dependent on surface temperatures and optical properties, but are typically around $5.5 \mathrm{~W} \mathrm{~m}^{-2} \mathrm{~K}^{-1}$ for both heating and cooling $[9,10]$. It is obvious from those results that when the floor temperature is lower than the air temperature (cooling mode), the convection heat transfer becomes much smaller than the radiative heat transfer. For typical floor cooling without solar gains, Olesen reports a maximum cooling rate of $42 \mathrm{~W} \mathrm{~m}^{-2}[9]$ and a maximum heating rate around 100 $\mathrm{W} \mathrm{m}^{-2}[10]$ for typical conditions. These results show that radiant floors are normally much better suited for heating than cooling. If however solar gains are incident on the floor, the cooling capacity of the floor increases. 
Simmonds et al. [11] designed and modelled the mechanical system of an atrium at the Suvarnabhumi International Airport in Bangkok. The building envelope consisted of a combination of a membrane with a transmissivity of $2 \%$ and fritted glass (glass with surface treated with a very thin layer of ceramic, often in geometric patterns) with a transmissivity of $3.5 \%$. They found that the floor cooling capacity was approximately $80 \mathrm{~W} \mathrm{~m}^{-2}$ when solar gains were incident on the floor. The ventilation air cooling capacity was $17 \mathrm{~W} \mathrm{~m}^{-2}$. Børresen simulated an atrium with displacement ventilation and radiant cooling floor. He found that a floor with direct solar gains can have a cooling capacity as high as $150 \mathrm{~W} \mathrm{~m}^{-2}$. He also found that the cooled floor had little influence on the zone air temperature, but that the operative temperature was reduced significantly (qtd. in Olesen [9], p.44). These studies show that a large amount of cooling is possible with the use of radiant floors in atria. These results are however not necessarily valid for residential buildings such as houses.

De Carli and Tonon [12] modelled the effects of solar gains on a radiant floor cooling system on a room with a west facing window. The room was located at $42^{\circ}$ latitude, and exterior conditions were that of a city in the North of Italy, in July, during a clear-sky day. Sixteen different floor surface coverings were studied. Four radiation models were discussed. They used a variety of typical floor covering materials and showed that the thermal conductance of the cover material has a greater effect on the performance of the radiant floor than the absorptivity of the material. This is an important finding that can help guide the materials selection for the design of radiant floors with solar gains. They also found a $19 \%$ difference in floor heat flux between the most detailed and least detailed radiation models in the late afternoon. This finding shows the importance of properly modelling solar radiation in the space.

There is no mention in the literature of a potential for storing the extracted heat collected from radiant floors, or sending it to another zone in the building. However, similar work has been conducted with air based systems to move excess heat from one zone to another. In particular, Variable Refrigerant Flow (VRF) systems with heat recovery have been investigated for that purpose [13,14].

The main objective of this research work was to study the feasibility and performance of solar thermal collection through a radiant floor system in a single detached family house. This will give researchers and designers a better understanding of the performance of radiant floor cooling systems exposed to direct solar gains, and how to use those solar gains to reduce the overall energy consumption in a house. 


\subsection{Background information}

\subsubsection{Radiant floors}

Radiant panels are indoor surfaces like walls, floors, or ceilings, that are used for heating or cooling a space. In hydronic radiant panels, water is used to transport heat to, or away from, the panels. The American Society of Heating, Refrigerating, and Air-Conditioning Engineers (ASHRAE) defines a radiant panel as a temperaturecontrolled surface in which $50 \%$ or more of the design heat transfer to the space occurs by thermal radiation [15] (with the remaining heat transfer by convection). Figure 1.3 shows a section of a typical embedded-tube thin-slab radiant floor. Hot water is pumped through the pipes during periods of heating demand and the heat diffuses through the gypsum cement up to the floor covering. The heat is then radiated and convected in the space. Similarly, during periods of cooling demand, cold water is pumped through the floor pipes.

Other types of radiant floor systems include above-floor tube and plate, and belowfloor tube and plate, seen in Figures 1.4 and 1.5. Those types of radiant floors usually consist of a sheet metal fin attached to the tubes to improve heat conduction. The tubes and fin can be located below or above the subfloor. These systems are typically lighter and have a lower thermal mass than embedded-tube radiant floors, thus requiring a smaller structure to support them. They also typically exhibit lower thermal resistance between the heat transfer fluid and the space.

One of the advantages of hydronic radiant systems (over forced air or radiator systems) is that the return temperature can be lower for heating systems and higher for cooling systems. In heat pump systems, this increases the COP of the heat pump because of the lower temperature difference between the condenser and evaporator. The milder return temperatures required are due to the large surface area of the radiant panel (floor, ceiling, or walls), hence increasing the total potential heat transfer to the space and occupants. The large surface area also increases the radiant transfer to the occupants, with the potential of increasing comfort even if the zone air temperature could be considered uncomfortable on its own.

To account for radiant heat sources, an equivalent temperature felt by an occupant, 


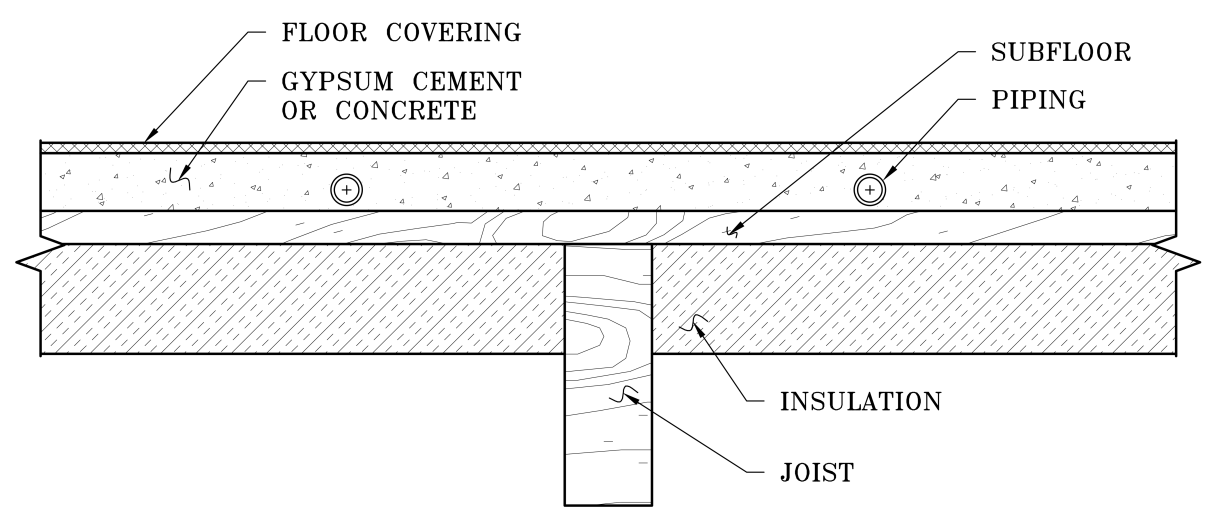

Figure 1.3: Radiant floor with embedded pipe

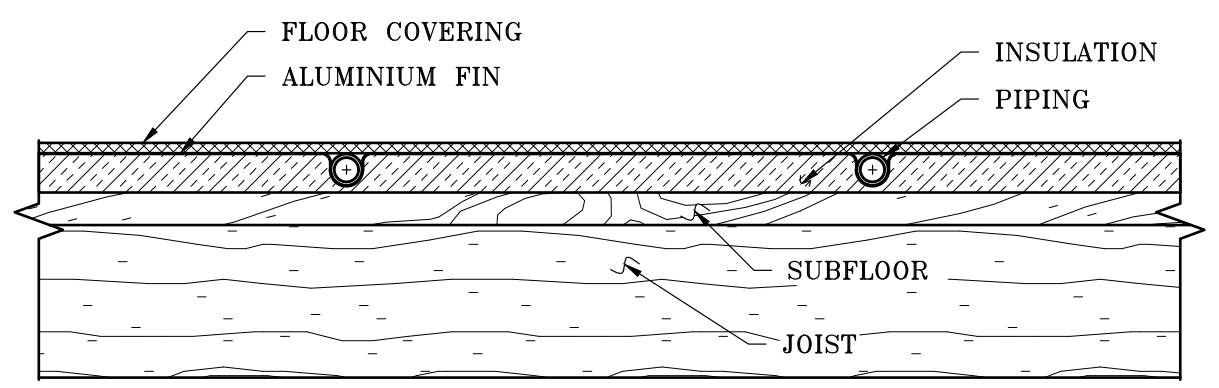

Figure 1.4: Above-floor tube and plate system 


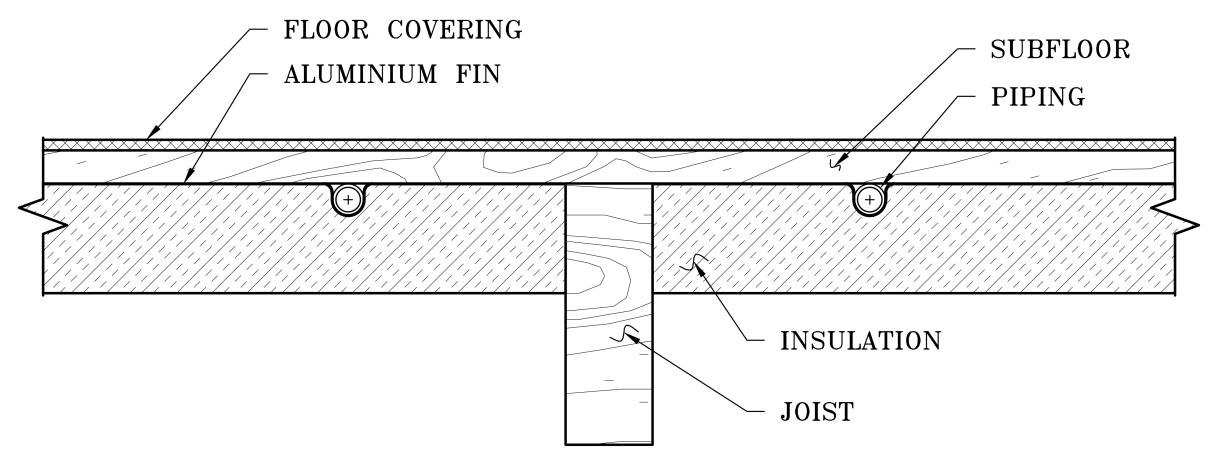

Figure 1.5: Below-floor tube and plate system

the operative temperature, is usually defined as in Equation 1.1 [16].

$$
T_{o}=\frac{h_{r} \cdot T_{M R}+h_{c o n v} \cdot T_{a}}{h_{r}+h_{c o n v}}
$$

where; $h_{r}$ and $h_{\text {conv }}$ are the radiative and convective heat transfer coefficients, $T_{a}$ is the air temperature, and $T_{M R}$ is the mean radiant temperature. The mean radiant temperature is approximately equal to the view factor weighted temperature of the surfaces in the space (the view factors are with respect to the occupant). $h_{\text {conv }}$ should be calculated using an appropriate correlation depending on the air velocity. Typical values for $h_{\text {conv }}$ in still air are between 3.1 and $5.1 \mathrm{~W} \mathrm{~m}^{-2} \mathrm{~K}^{-1} . h_{r}$ should be calculated based on the room geometry, surface temperatures, and emissivities. A typical value for $h_{r}$ is around $4.4 \mathrm{~W} \mathrm{~m}^{-2} \mathrm{~K}^{-1}$.

Equation 1.1 shows that an important aspect of the temperature felt by the occupant is the mean radiant temperature. As mentioned above, $T_{M R}$ is a function of the temperature of the various surfaces in a space. Therefore, all else being equal, a warmer floor will make an occupant feel warmer. 


\subsubsection{Vapour compression heat pumps}

A vapour compression heat pump is a device capable of transfering heat from a low temperature source to a high temperature sink using the vapour compression refrigeration cycle. There are other types of heat pumps that do not use the vapour compression cycle, but they will not be investigated in this work. For the purpose of this thesis, a heat pump refers to a vapour compression heat pump.

In heat pumps, usually the source and sink reservoirs are either air or water (sometimes mixed with glycol). A heat pump that moves heat from a cold air reservoir (such as outside cold air in the winter) to inside warm air (such as indoor air) is called an air-to-air heat pump (or air-air). A heat pump that uses two water reservoirs or loops is called a water-to-water heat pump (or water-water).

Heat pumps can be used to cool or heat the space. They can also be used to heat domestic hot water. Electrical power is required to drive the compression refrigeration cycle. A heating coefficient of performance (or $C O P$ ) is defined as the ratio of the heating rate to the electrical power input. These are usually higher or equal to unity. Similarly, a cooling $C O P$ is defined as the ratio of the cooling rate to the electrical power input [17]. In building performance simulation, heat pump performance is often simulated with steady state models that neglect the transient effects due to thermal mass and refrigerant migration. The modelling of heat pumps will be discussed in detail in a later chapter.

\subsubsection{Simulation}

In order to study the proposed system, simulation was used. Below is a brief description of the two main building simulation tools that were chosen for this study.

\section{Building simulation}

Many building simulation tools are readily available and their capabilities have been described by Crawley et al. [18] The use of building simulation software is typically required when attempting to accurately assess the performance of a building.

Heat gains and losses in buildings come from a variety of sources: heat transfer through the building envelope, infiltration through the building envelope, ventilation, solar gains through windows, and gains from occupants are a few examples. Every type of gain or loss is calculated using a model. For example, conduction heat transfer 
through walls may be solved using a finite difference method and the infiltration may be solved with the use of an empirical correlation. Additionally, environmental conditions that are not a part of the building may require some careful consideration. Prime examples are heat conduction through basements and surrounding soil, and the evaluation of incident solar radiation on an external surface. Both of those examples require models that deal with phenomena external to the building, but have a direct impact on the modelling accuracy. Building simulation software make use of many models to carry out simulation that would often be impossible for an individual to perform by hand, or even code (due to time constraints).

ESP-r was chosen as the building simulation tool for this project. ESP-r is a free, open source building simulation software that was created in the 1970s at the University of Strathclyde. ESP-r is mostly used as a research tool, and allows for modelling of heat transfer, moisture transfer, air flows, hydronic plants, and electrical power in buildings. The building domain energy balance is solved using the finite difference method. The default formulation of the finite difference method equation is the Crank-Nicholson formulation, but the user can define a different weighting of the implicit and explicit methods if required [19]. ESP-r has been validated by numerous studies [20].

By default ESP-r distributes solar radiation to surfaces in a zone with an area and absorptivity weighting scheme. However, the method selected to distribute solar radiation for this thesis was the most detailed method available in ESP-r. This method uses ray tracing to calculate the proportion of beam solar radiation transmitted through the windows that is absorbed by each surface. The incoming diffuse solar radiation and the reflected radiation are distributed to surfaces in the zones with an area and absorptivity weighting scheme. Once the solar radiation is allocated to a surface, the solar radiation absorbed by that surface is spread evenly over that surface.

Mechanical systems (plant network) can be also be modelled in ESP-r. However, the plant network can be quite difficult to use for complex systems, is not flexible in its use, and is limited in the types of models available. Further information regarding ESP-r's modelling methods can be found in [19], [21], and [22]. 


\section{Simulation of mechanical system}

Mechanical systems in houses can consist of multiple components such as pumps, fans, valves, boilers, solar thermal panels, thermal storage tanks, and controllers. Some of those can be modelled very simply, while others are quite complex. Developing all of the mechanical component models for a building could be a very tedious task. Luckily, many models are readily available for the TRNSYS simulation tool. TRNSYS was therefore chosen for the simulation of mechanical components in the building.

TRNSYS is a flexible simulation program that uses a modular approach to solve energy systems. The modular approach allows for the simulation of very complex system by breaking them up in many small components such as pumps, tanks, heat exchangers, controllers, or even a building model. TRNSYS takes an iterative and sequential approach to solving a system by solving each component individually based on inputs received from other components. These components are solved until convergence.

One of the components in TRNSYS is used for multi-zone building simulation. This component uses transfer functions to solve the building's energy balance [23]. This method is more computationally efficient than finite difference, however, the TRNSYS building model is less rigorous compared to ESP-r's model [24].

\section{Co-simulation tool}

Beausoleil-Morrison et al. [24] developed a coupling tool for ESP-r and TRNSYS. With the co-simulator, data can be passed between TRNSYS and ESP-r, allowing for use of models in both software. ESP-r is linked with the co-simulator through the plant domain, while TRNSYS is linked with the co-simulator through a TRNSYS type (or component). Data is passed between ESP-r and TRNSYS until convergence of both programs. The co-simulator then marches in time to the next time step. For this project, most of the mechanical system will be modelled with TRNSYS, while the building and radiant floors will be modelled with ESP-r.

\subsection{Objectives}

As discussed previously, the main objectives of this research work was to study the feasibility and performance of solar thermal collection through a radiant floor system 
in a single detached family house. In order to assess the system briefly described in Section 1.2, building simulation was used. To accurately model the system however, the following tasks were first addressed:

- Validation of current radiant floor models in building performance simulation tools

- Development of above-floor tube and plate radiant floor model

- Development of transient model for water-water residential heat pump

Additionally, controls for hydronic radiant floor heating under high solar gains variability have not been investigated thoroughly. This was examined as well.

\subsubsection{Structure of thesis}

This thesis is divided into eight chapters. Chapters 2 through 6 each contain topical literature reviews. Gaps in the literature are identified in the appropriate chapters.

The current chapter presented a brief overview of some general concepts and an introduction to the topics that will be discussed in this thesis. The second chapter discusses the validation of current embedded-tubes radiant floor models currently available in building performance simulation tools. These models had never been properly validated, and many problems were found with them. Solutions to these problems are proposed. The validation of these radiant floor models allows for them to be used with confidence in the evaluation of the system wide model. The third chapter presents the development of a new tube-and-plate radiant floor model and its experimental validation. Models for this type of radiant floor were not available so one is developed here for use in the simulation of the overall solar collection and storage system. The fourth chapter presents the development of a transient heat pump model for a residential water-water heat pump. This model will be used in the simulation of the overall solar collection and storage system. The fifth chapter discusses various reactive controls for radiant floor heating in periods of high solar gains. Controls of radiant systems with high solar gains is important to avoid overheating. This chapter compares various standard control systems and their effect on thermal comfort and energy consumption. The sixth chapter investigates the feasibility of a passive/active radiant floor solar collection system. Building performance simulation is used to estimate the energy savings incurred with this type of system in various 
Canadian climates. Chapter seven discusses the experimental apparatus that was built at Carleton University to test this passive/active system. Finally, Chapter eight is the conclusion. 


\section{Chapter 2}

\section{Embedded tube inter-model comparison}

\subsection{Introduction}

In order to accurately model the entire system described in Section 1.2 an accurate hydronic radiant floor model must be used. Based on a supply temperature, flow rate, and boundary conditions, radiant floor models calculate the heat transfer rate from the water to the floor (with the building model calculating the heat transfer in the floor construction) or the heat transfer in the entire floor construction. As discussed in Chapter 1, there are various types of hydronic radiant floor systems, one of which is the embedded tube type. Embedded tube systems are the most common type of radiant floor system, so it is important to be able to assess their performance when in use with the type of active/passive solar collection system described in Section 1.2.

This chapter discusses the embedded tube radiant floor models that have been implemented in the TRNSYS, ESP-r, and EnergyPlus building performance simulation (BPS) tools. The theory behind each model is discussed, along with their limitations. Additionally, previous validation attempts are reviewed. Two inter-model test cases were created for assessing the performance of radiant floor models are then described. Predictions made with the three BPS tools were contrasted to each other as well as with predictions made with a stand-alone transient finite element analysis (FEA) model. This work was previously published in The Journal of Building Performance Simulation [25]. Adam Wills, a fellow student in the Sustainable Buildings Energy Systems research group, helped with the literature review, and with the ESP-r modelling. 


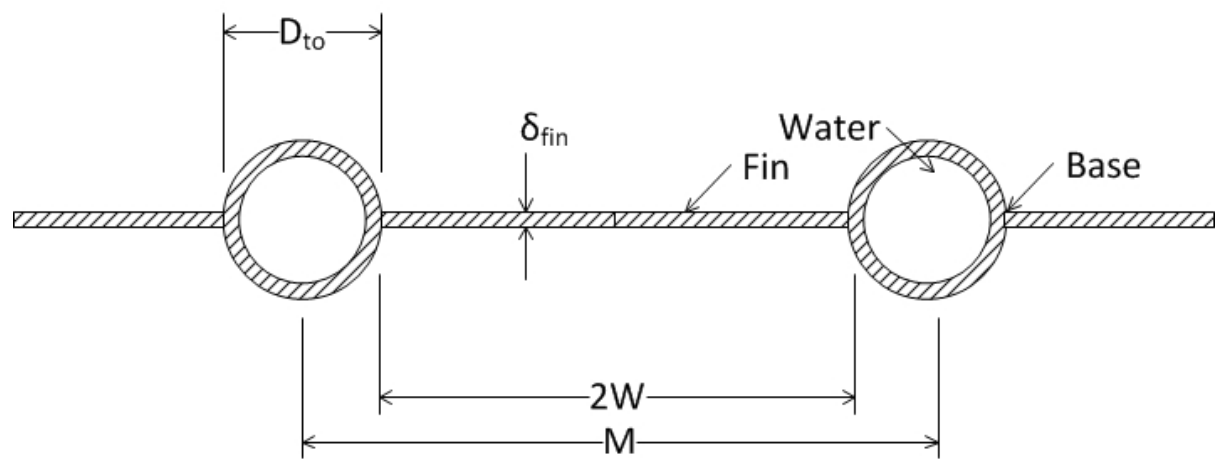

Figure 2.1: Section of a fin

\subsubsection{Literature review}

Historically, embedded pipe systems were the most common types of radiant floor systems. Therefore, most radiant floor models found in the literature, and all models implemented in BPS tools, were developed for embedded-tube systems.

A common approach is to model such radiant floors as fins. A fin is a surface that extends away from an object (sometimes referred to as an "extended surface") to increase the heat transfer from that object to its surroundings. Fins are usually modelled as a 1D steady-state conduction problem. Figure 2.1 shows a fin cross section. A fin efficiency can be defined as the ratio of the actual heat transfer rate between the fin and the environment to the potential heat transfer between the fin and the environment if the fin temperature equal to the base temperature. Equation 2.1 shows the resulting fin efficiency for an adiabatic fin tip [26].

$$
\eta=\tanh (m \cdot W) /(m \cdot W)
$$

where;

$$
m=\sqrt{U_{\text {total }} /\left(k_{e} \cdot \delta_{\text {fin }}\right)}
$$

In Equation 2.1 and 2.2, $U_{\text {total }}=h_{\text {conv }}+h_{r}$ where $U_{\text {total }}, h_{\text {conv }}$, and $h_{r}$ are the overall heat transfer coefficient, the convective heat transfer coefficient, and the radiative heat transfer coefficient respectively. $W$ is the fin length, $k_{e}$ is the equivalent radiant panel conductivity, and $\delta_{\text {fin }}$ is the thickness of the fin. The heat transfer rate to the space 
can then be calculated in the general form of [26]:

$q_{y} \cdot M=\left[2 \cdot W \cdot \eta+D_{t o}\right] \cdot h_{r} \cdot\left(T_{\max }-A U S T\right)+\left[2 \cdot W \cdot \eta+D_{t o}\right] \cdot h_{\text {conv }} \cdot\left(T_{\max }-T_{a}\right)$

where;

$M$ is the on center pipe distance, $D_{t o}$ is the pipe outside diameter, $q_{y}$ is the heat flux per unit area, $T_{\max }$ is the maximum panel surface temperature, $A U S T$ is the area-weighted average temperature of the uncontrolled indoor surfaces, and $T_{a}$ is the air temperature.

The ASHRAE recommended method for designing radiant surfaces [15] is based on a model by Kilkis et al. [26] The fin was modelled from the center of the pipes to the floor surface with an effective fin thermal conductivity defined in Equation 2.4.

$$
k_{e}=2 \cdot \frac{\sum_{i=1}^{n} k_{i} \cdot \delta_{i}+k_{\text {embed }} \cdot \delta_{\text {embed }}}{\delta_{\text {total }}}
$$

where;

$k_{i}$ is the thermal conductivity of floor coverings, $\delta_{i}$ is the thickness of floor coverings, $k_{\text {embed }}$ is the thermal conductivity of the embedding material, $\delta_{\text {embed }}$ is the thickness of the embedding material from the center of the pipe to the bottom of the floor covering, and $\delta_{\text {total }}$ is the thickness of the floor from the center of the pipe to the floor surface.

Kilkis et al. [26] calculated the maximum panel/radiant floor temperature $T_{\max }$ with the following equation:

$$
T_{\text {max }}=T_{t o}-q_{y} \cdot\left[R_{\text {cover }}+\left(\delta_{\text {embed }}-D_{\text {to }} / 2\right) / k_{\text {embed }}\right]
$$

where:

$R_{\text {cover }}$ is the thermal resistance of the floor covering material and $T_{t o}$ is the outer pipe temperature (calculated with an energy balance at the pipe).

Other similar fin models are present in the literature. Kollmar and Liese are reported in some literature $[26,27]$ as being amongst the first to develop a radiant slab model using this approach. They modelled the slab as a fin with a thickness equal to the tube diameter, and decreased the heat transfer coefficient between the space and the fin to account for the resistance of the material above and below the tube (qtd. by Ishino [28], p.1). Ishino [28] modified the Kollmar and Liese model and 
increased the fin thickness to account for most of the slab. An equivalent conductivity was calculated in a similar fashion as the Kilkis et al. model for multiple layers of material.

The fin models discussed above were all steady-state models. Carbonell et al. [29] developed a model based on the work of Kilkis et al. [26], coupled with a multilayer model to solve for the transient 1D conduction of the different layers. This model was not validated for transient conditions, however.

One dimensional fin models greatly simplify the heat transfer problem. They are based on the assumption that the entire thickness of the material is at the same temperature. Additionally, the models are derived for steady-state conditions and there is still no evidence that coupling a steady-state fin model with a $1 \mathrm{D}$ transient floor conduction will yield accurate results. Furthermore, all effects related to temperature gradients in the direction of water flow are ignored or approximated, and the effects of pipe bends, and temperature difference between adjacent pipes are ignored.

Many other radiant floor models can be found in the literature. They are typically more complex than fin models. Because of a lack of experimental validation for many of the models, it is unclear whether they produce more accurate results than fin models. Some of these models are discussed briefly here.

Some the the earliest efforts to model radiant floor systems was work by Hulbert et al. [30] and Nottage et al. [31]. They used steady-state two dimensional analytical models to analyse the effects of various parameters on the heat flow rates of the radiant floor. Zhang and Pate $[32,33]$ developed a 2D finite-difference method for ceiling and floor panels. They also developed a semi-analytical method for evaluating the performance of heating panels with embedded tubes [34]. Jin et al. [35] developed a calculation method for the floor-average surface temperature of radiant floor systems at steady-state conditions. Simple equations were used to calculate the floor temperature and heat transfer rates. Correlations for equivalent conductivity of the materials on the embedded tube layer were derived from numerical results. [36] used FEA to produce a single power function that predicts panel heating and cooling performance at steady-state.

Ho [37] and Ho et al. [38] modelled a radiant slab-on-grade using a finite difference model and a FEA model during transient conditions. They found that both models yielded similar results. They also validated the models experimentally.

Weber et al. [39] compared a 2D finite element model with experimental data and 
found an average difference in heat flux of around $3 \%$ and a maximum individual data point difference of $14 \%$. They also compared a simple RC (resistor-capacitor) model with experimental data. This $\mathrm{RC}$ model was an improvement on the model found in TRNSYS Type56 (as discussed in Section 2.3.1). The improved model combines a RC thermal circuit with a finite difference model of the concrete slab. They found that the $\mathrm{RC}$ model could predict the core temperature to within $0.2 \mathrm{~K}$ of experimental values.

The models described above are based on a 2D approach, and are therefore more detailed than the fin models. However, like the fin models, all effects related to temperature gradients in the direction of water flow are ignored or approximated, and the effects of pipe bends, and temperature difference between adjacent pipes are ignored.

Karlsson $[40,41]$ developed a 3D finite control volume model for a hydronic radiant slab, and compared results with a commercial 2D finite difference model and experimental data. The difference between the 3D finite control volume model and the $2 \mathrm{D}$ finite difference model was no more than $0.7 \%$ for transient conditions. A steady-state experiment showed a difference of $16 \%$ with the 3D finite control volume model. The difference between the modeled and the experimental results is believed to be caused by material properties, applied boundary conditions, and differences in actual and modeled construction geometry. The 3D finite control volume model of Karlsson $[40,41]$ takes into consideration the effects of temperature gradient in the direction of water flow. It does not however, account for bends in the pipe. Additionally, an adiabatic boundary is imposed halfway between adjacent pipes, preventing heat flow between them.

Some of the models discussed in this section have been used for the sizing of embedded-tube systems. Most of them have limited use to the average BPS practitioner or researcher however, as they have not been implemented in BPS tools.

\subsection{Heat transfer processes occurring with embedded-tube radiant floors}

All three modes of heat transfer are significant in embedded-tube radiant floors. Figure 2.2 shows two sections of a slab and the heat transfer processes that take place. All layers below the slab containing the tubes are represented in this figure 


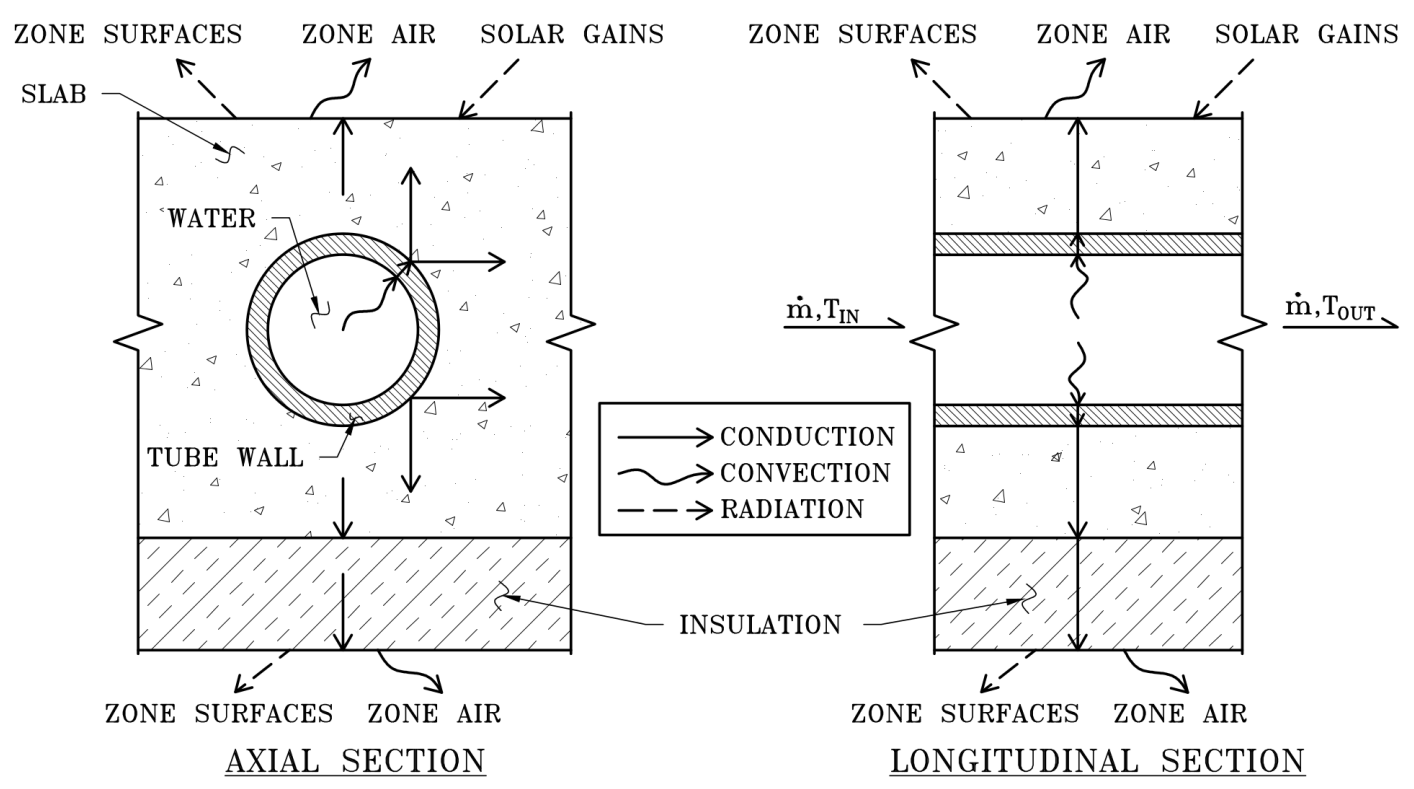

Figure 2.2: Modes of heat transfer in embedded tube system

with a single insulation layer. Furthermore, the figure does not illustrate the floor covering. In heating mode, heat is convected from the hot water to the inner tube wall. The heat is then conducted through the tube wall and through the slab to the floor surface. Convection exchange occurs between the floor surface and the zone air, and radiative exchange occurs between the floor surface and other surfaces in the room. These processes are transient, and occur in three dimensions.

The temperature profile along the length of the pipe is non-linear and approximately follows an exponential trend as shown in Figure 2.3 (when in heating mode). A serpentine layout of the radiant floor piping, as shown in Figure 2.4, is commonly employed. Other configurations are possible, such as the spiral configuration (pipes routed in a spiral pattern), and the serpentine counterflow configuration (serpentine layout with supply and return piping adjacent to each other). Because the temperature of the heat transfer fluid decreases along the length of the pipe, pipes located next to each other will be at different temperatures with these pipe layouts. Figure 2.5 illustrates the typical temperature distribution that can be expected in such a configuration. It shows the expected temperature distribution on the surface and at a horizontal layer beneath two adjacent pipes. As can be seen in the figure, the temperatures in the layer of the pipe and at the top surface tend to be higher on the 


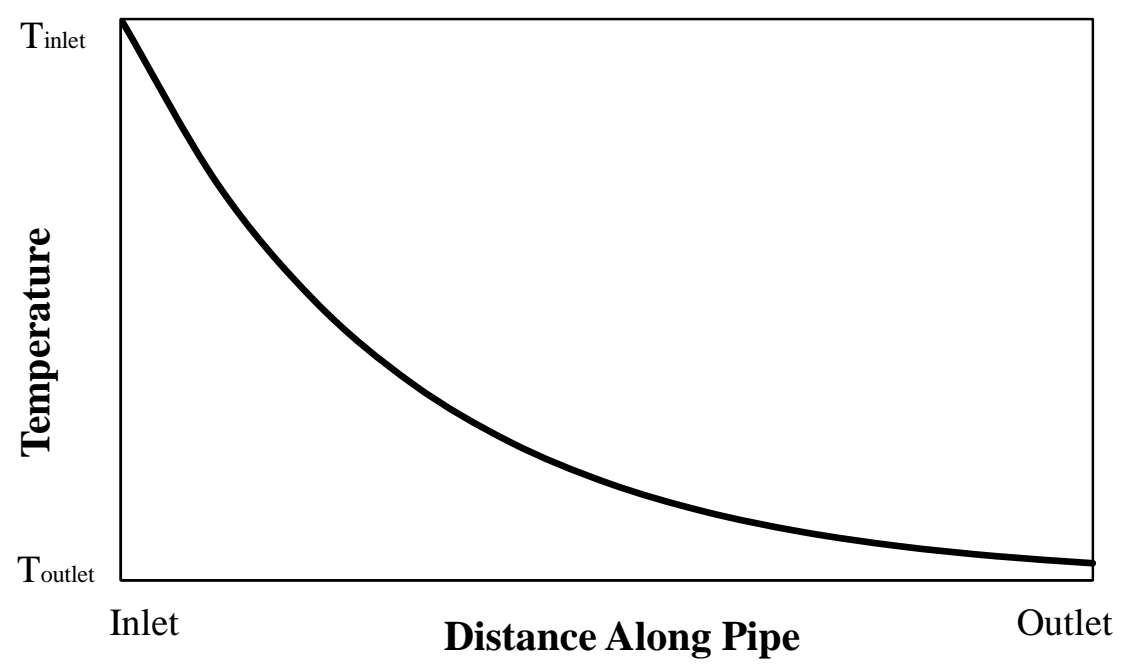

Figure 2.3: Water temperature profile along the pipe length

left side because this pipe is closer to the inlet of the heat transfer fluid.

Convection heat transfer in the tube typically occurs in the turbulent regime. The geometry of the tube, such as bends in the tubing, have an influence on the heat transfer coefficient between the tube and the water. Convection heat transfer between the floor surface and the room air is dependent on the surface temperature and the air temperature. Additionally, convection in the room can be driven buoyancy or forced flow caused by ventilation.

Radiation exchange is dependent on the geometry of the space, the radiative properties of the surfaces, and the temperature of the surfaces. Additionally, solar gains may be incident on the floor surface either directly or through reflection from another surface.

\subsection{Embedded-tube radiant floor models in BPS tools}

The heat transfer problem described in the previous section is non-trivial. In order to maintain relatively low computational cost, many assumptions and simplifications are made in BPS tools when solving this complex problem. 


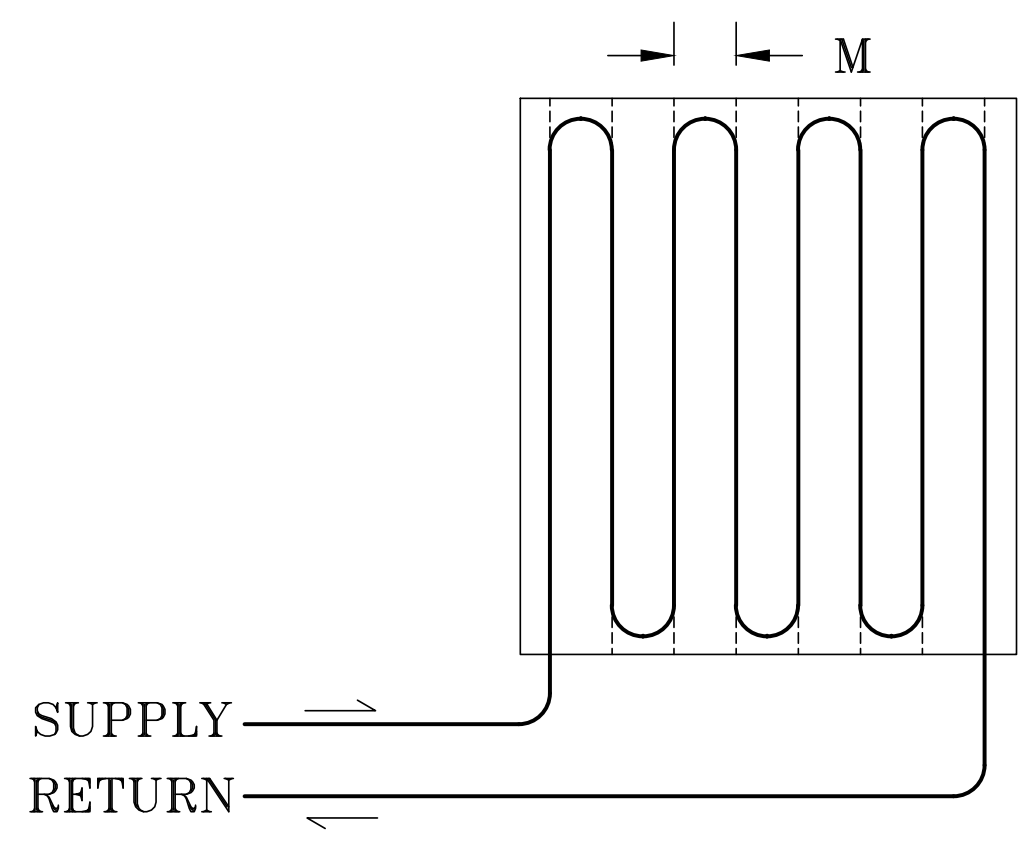

Figure 2.4: Plan view of serpentine configuration
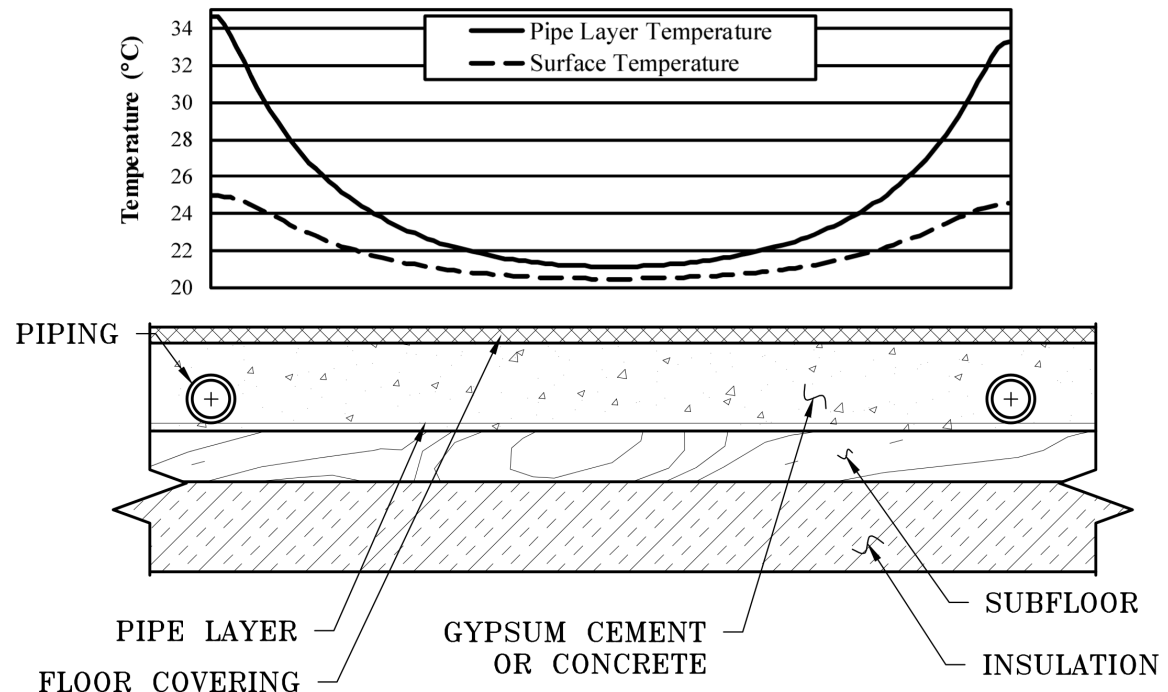

Figure 2.5: Example of temperature distribution in radiant floor 
The embedded-tube radiant floor models incorporated into BPS tools typically consider the floor, the tube, and the working fluid. The interaction of the slab with the rooms above and below is usually handled by the BPS tool's building thermal domain. In most BPS tools, users can select from many correlations for the convective heat transfer coefficients between the air and the floor surface. Radiant exchange between surfaces also typically requires input from the user for thermal optical properties and the determination of view factors.

Only a few BPS tools include models for embedded-tube radiant floors. The work in this chapter focuses upon the models included in three BPS tools used in research and practice: TRNSYS, ESP-r, and EnergyPlus.

There are some common assumptions made in the models employed by TRNSYS, ESP-r, and EnergyPlus:

1. The conduction in the slab along the length of the tube is ignored.

2. The tube bends are ignored.

3. Symmetry is assumed. As such, the temperature distribution is taken to be identical on both sides of the tube and adiabatic boundaries are assumed halfway between tubes. This essentially ignores the effects discussed in the previous section and illustrated in Figure 2.5.

With these assumptions, the models each use various methods of modelling the $2 \mathrm{D}$ conduction heat transfer in the floor with the average water temperature along the length of the tube taken as a boundary condition.

Tye-Gingras and Gosselin [42] found these assumptions to be appropriate for modelling radiant ceiling panels. However, there is no documented evidence assessing the appropriateness of these conclusions for embedded-tube radiant floors. Additionally, for all three BPS tools, the heat transfer coefficient between the tube wall and the fluid is calculated using correlations for a straight tube and fully developed flow, if the flow is in the turbulent regime.

The modelling approaches and associated limitations of the embedded-tube radiant floor models employed by TRNSYS, ESP-r, and EnergyPlus are described in the following three subsections. 

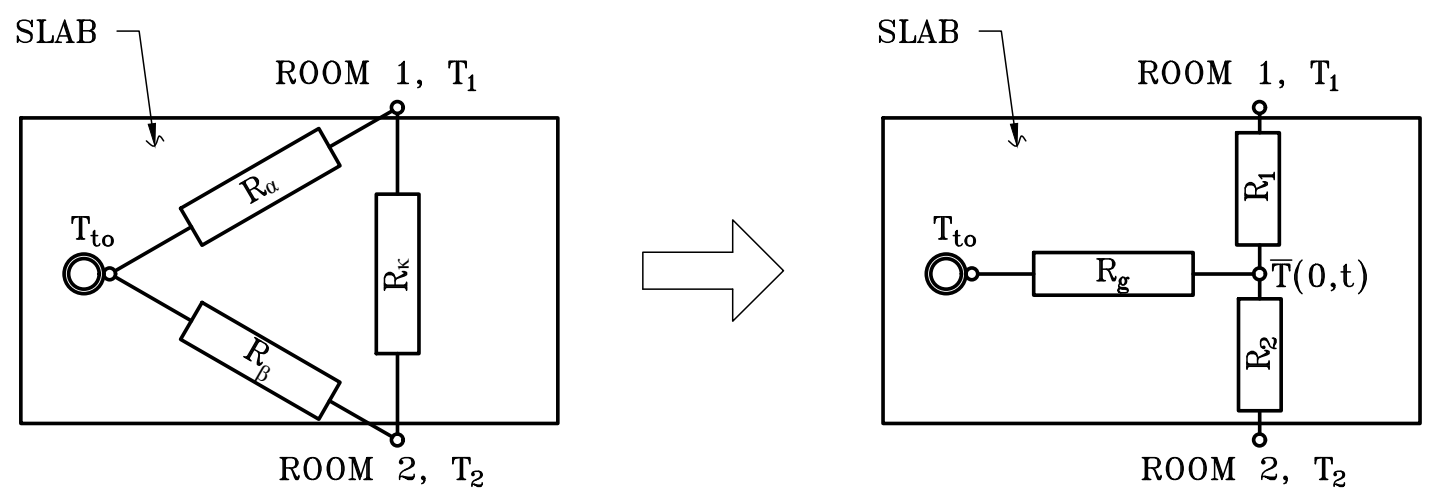

Figure 2.6: TRNSYS model - delta to wye resistance network transformation

\subsubsection{TRNSYS}

The radiant floor model in TRNSYS is defined in detail in the user manual [23]. The model uses a thermal resistance network to calculate the rate of heat transfer between the fluid in the tube and the so-called active layer of the construction. In the TRNSYS vernacular, the active layer is defined to be the construction layer in which the tubes are placed.

An analytical solution by Glück [43] is used to calculate a steady-state thermal resistance between the outer tube wall and the zones above and below the floor. A delta (or triangular) thermal resistance network is created, as shown on the left side of Figure 2.6. $R_{\alpha}$ and $R_{\beta}$ are the one dimensional thermal resistances between the tube layer and the rooms above and below respectively $\left(\mathrm{m}^{2} \mathrm{~K} \mathrm{~W}^{-1}\right) . R_{\kappa}$ is the one dimensional resistance between the two rooms $\left(\mathrm{m}^{2} \mathrm{~K} \mathrm{~W}^{-1}\right) . T_{1}$ and $T_{2}$ are the corresponding room air temperatures $(\mathrm{K})$. The delta network is then transformed to an equivalent wye (or tee) network, shown on the right side of Figure 2.6. $R_{g}$ is an equivalent resistance between the outer tube wall and the active layer $\left(\mathrm{m}^{2} \mathrm{~K} \mathrm{~W}^{-1}\right)$. Figure 2.7 shows the resistance network based on the inlet water temperature, $T_{f, i n}$, and the average active layer temperature, $\bar{T}(0, t)(\mathrm{K})$. The average active layer temperature, $\bar{T}(0, t)$, is the average temperature in the $\mathrm{x}$-direction of the active layer, which is located at $y=0$ (see Figure 2.8). $R_{p}$ and $R_{f}$ are the resistances to heat transfer by the tube walls and fluid flow $\left(\mathrm{m}^{2} \mathrm{~K} \mathrm{~W}^{-1}\right) . R_{z}\left(\mathrm{~m}^{2} \mathrm{~K} \mathrm{~W}^{-1}\right)$ is an equivalent resistance to account for the fact that the average water temperature, $\bar{T}_{f}$, is lower 


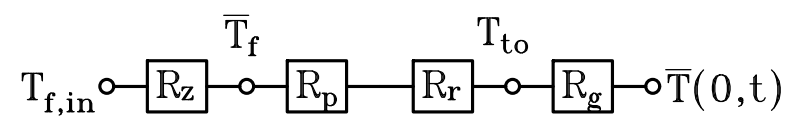

Figure 2.7: TRNSYS model series resistance circuit

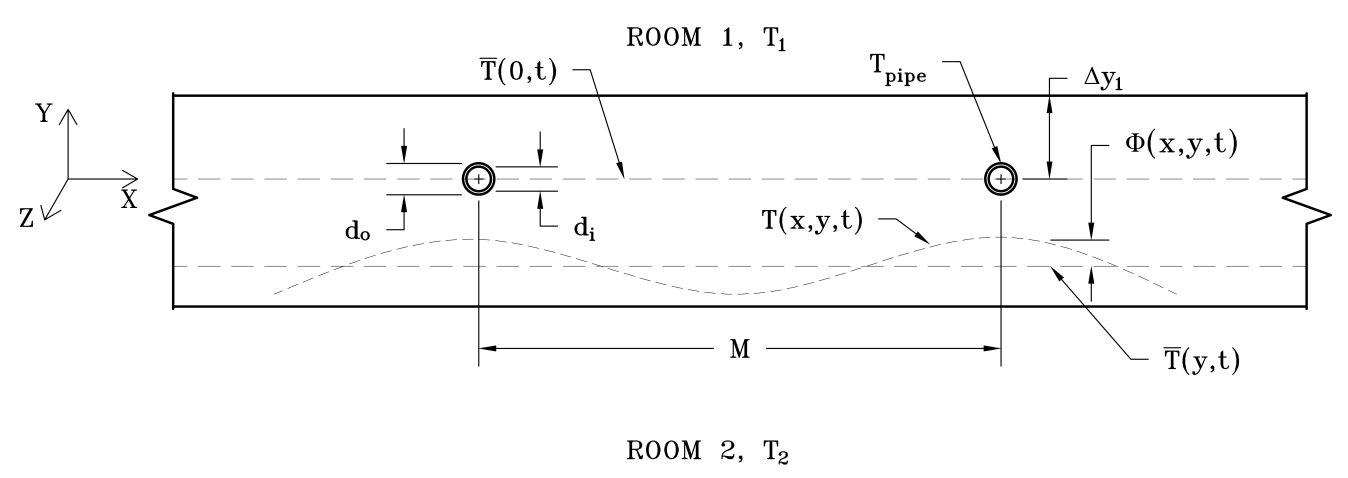

Figure 2.8: Section of slab

than the inlet water temperature, $T_{f, i n}$, during heating mode.

As shown previously in Figure 2.3, the water temperature profile along the pipe length is not linear. Because the TRNSYS model linearizes the temperature profile along the pipe, it can be necessary to subdivide a floor into a number of individual segments connected in series. With this, the heat transfer fluid exiting one segment becomes the inlet to the next segment. TRNBuild has an auto-segmentation function to automate this process.

The resulting heat flux is integrated with the building model as a heat generation term in a one dimensional conduction transfer function model for the appropriate surface and layer.

Other models are available for TRNSYS (such as Type360 [44], Type653, and Type993 [45]), but these are external to the Type56 building model and are not standard TRNSYS components. These models will not be further discussed here.

\section{Limitations}

The model implemented in TRNSYS has limitations that make it inappropriate for use in modelling certain floor constructions. The criteria given in Equations 2.6 and 2.7 must be met. These limitations result from simplifying assumptions made in 
the calculation of $R_{g}$.

$$
\begin{gathered}
\frac{\delta_{\text {embed,above }}}{M} \geq 0.3 \\
\frac{k_{\text {below }}}{\delta_{\text {below }}}<1.212 \mathrm{~W} \mathrm{~m}^{-2} \mathrm{~K}^{-1}
\end{gathered}
$$

where $\delta_{\text {embed,above }}$ is the thickness of the slab above the tubes $(\mathrm{m})$ and $M$ is the tube spacing $(\mathrm{m}) . k_{\text {below }}\left(\mathrm{W} \mathrm{m}^{-1} \mathrm{~K}^{-1}\right)$ and $\delta_{\text {below }}(\mathrm{m})$ refer to the thermal conductivity and thickness of the construction layer directly below the slab. This layer, typically an insulation layer for thick slabs, is not shown in Figures 2.6 and 2.8.

To put these limitations in perspective, the criteria given by Equation 2.6 requires a minimum slab thickness of $6 \mathrm{~cm}$ for a tube spacing of $20 \mathrm{~cm}$, which is a common spacing used in practice. Consequently, the TRNSYS model is limited to thick slabs. Furthermore, the criteria of Equation 2.7 limits the materials that can be used in the layer directly below the slab; the U-value of this layer must be below $1.212 \mathrm{~W} \mathrm{~m}^{-2} \mathrm{~K}^{-1}$ (e.g. at least $3-4 \mathrm{~cm}$ of polystyrene insulation).

It is possible to model floor constructions outside of the criteria described in Equations 2.6 and 2.7 by using the so-called expert mode to define the active layer. With this, the user overrides the calculations described above by prescribing an equivalent heat transfer coefficient between $T_{f, i n}$ and $\bar{T}(0, t)$ (refer to Figure 2.7). The expert mode however, is not well described in the TRNSYS manual [23] which makes it very difficult to use accurately.

\section{Model verification}

The TRNSYS manual [23] presents a verification of this model. A slab was simulated in TRNSYS and the solution was compared with results from a FEA model. The concrete slab was modelled with no floor cover. Additionally, the slab appears to be symmetrical around the horizontal axis. Two cases were studied with different inlet temperature profiles. FEA results were compared with the TRNSYS results. The results are presented graphically, and appear to show good agreement between the two models. However, the TRNSYS manual [23] does not quantify how well the models agreed. Furthermore, no information is provided on whether these results hold when there is a floor cover or for non-symmetrical slabs. 


\subsubsection{ESP-r}

ESP-r uses the finite difference method to solve transient conduction heat transfer across opaque constructions. The default and common treatment with ESP-r is to solve the problem 1-dimensionally. Consequently, this assumes that the temperature is homogeneous for a specific depth in the construction. In the case of radiant slabs however, the temperature changes with the depth (y-axis) and the distance from the tubes (x-axis) (refer to Figure 2.8).

Laouadi [27] developed a semi-analytical model ESP-r. This model does not solve the $2 \mathrm{D}$ temperature field, $T(x, y, t)(\mathrm{K})$, directly. Instead, it calculates a temperature perturbation field, $\Phi(x, y, t)(\mathrm{K})$, in the slab assuming a point source for heat flux. The temperature perturbation, $\Phi(x, y, t)$, is defined as the deviation in temperature at a point in the slab with respect to the average slab temperature, $\bar{T}(y, t)(\mathrm{K})$, at that depth. In other words, the temperature field, $T(x, y, t)$, is the sum of the $1 \mathrm{D}$ temperature solution, $\bar{T}(y, t)$, and a perturbation term. $\Phi(x, y, t)$. This can be seen in Equation 2.8 and Figure 2.8.

$$
T(x, y, t)=\bar{T}(y, t)+\Phi(x, y, t)
$$

To simplify the problem, the multi-layered construction is modelled as homogeneous. The conductivity, specific heat, and density of this homogeneous layer are determined by taking the thickness-weighted averages of the floor construction layers

The following steps are iterated to calculate the heat flux from the tube to the slab:

1. The temperature at the point source is calculated using the point source heat flux from the previous time-step or iteration.

2. That point source temperature is imposed on the tube outer wall.

3. The heat flux from the tube to the slab is calculated.

The tube model takes into account thermal mass of the tube material and is discretized in time using the Crank-Nicholson scheme. For sake of brevity, this will not be discussed further here. The tube solution and the 2D perturbation field are iterated using the Newton-Raphson method until convergence is achieved. This predicted heat flux is then communicated to the ESP-r building domain, where it is imposed as a heat source in its finite difference solution of the transient conduction problem. 
A unique feature of this model is its capability to output maximum and minimum surface temperatures (located directly above and halfway between the tubes). This can be useful to determine whether condensation could be a problem in cooling mode, or if the floor becomes uncomfortably hot directly above the tubes.

\section{Limitations}

The main limitation with the model in ESP-r is the use of average thermal properties for multi-layer constructions. If all layers have similar properties, this assumption is likely acceptable. However, if a thick insulation layer with low conductivity is used under a thin slab, the heat transfered to the slab will be underestimated. This is due to the fact that the average conductivity of the construction will be much lower due to the insulation's relatively low conductivity. When the semi-analytical 2D model solves the temperature perturbation field, it would do so with a lower conductivity than is actually present. In reality, the majority of the conduction heat transfer would occur in the slab and floor cover layers. When calculating the 2D temperature perturbation field, the conductivity, density, and specific heat values should be that of those layers.

In practice, this problem can be avoided by decoupling the insulation layer from the floor construction by creating a thin fictitious zone under the radiant slab as seen in Figure 2.9. The ceiling of this fictitious zone would be the radiant slab, and the floor would be the insulation layer. Walls would be adiabatic and high heat transfer coefficients would be used on the ceiling and floor. This ensures that only the thermal properties of the slab and floor covers would be included in the calculation of average thermal properties. For the purpose of this study, this method will be called the "split construction" method.

Modifications to the source code to allow the user to specify an insulation layer could also be implemented. These modifications would remove the insulation layer and any layer below it from the calculations of the average thermal properties. For the purpose of this study, these modifications will be called the "modified model". The aim of the "modified model" is the same as that of the "split construction" method, but the "modified model" does not require a fictitious zone. The "modified model" will be made available in a future ESP-r release. 


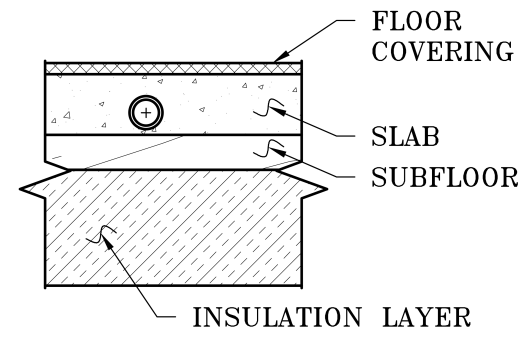

ACTUAL CONSTRUCTION

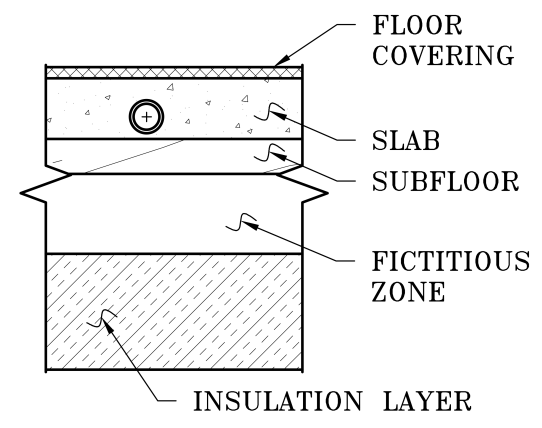

SPLIT CONSTRUCTION

Figure 2.9: ESP-r model split construction

\section{Model verification}

Laouadi [27] verified this model using a 2D finite volume model with a fully implicit scheme. The floor construction consisted of a floor cover, concrete slab, insulation, and gravel. Using a tube heat flux step input, the modelled average floor temperature was within $0.04{ }^{\circ} \mathrm{C}$ of the numerical solution after 12 simulation hours. The maximum floor surface temperature (directly above tubing) was within $0.21^{\circ} \mathrm{C}$ of the numerical solution, while the minimum floor surface temperature (between tubes) was within $0.17{ }^{\circ} \mathrm{C}$. The author also stated that an excellent agreement was obtained when modelling a uniform slab (without covering and insulation), but did not state the magnitude of the difference between the two models.

The models compared by Laouadi [27] matched very well despite not using the "split construction" method or the "modified model" described above. This can be explained by the fact that the layer of gravel used below the insulation had a relatively high thermal conductivity. The high conductivity of the thick gravel layer offset the low conductivity of the insulation layer when the thickness-weighted average thermal conductivity of the whole assembly was calculated by the model. The thicknessweighted average thermal conductivity with the gravel layer was $0.349 \mathrm{Wm}^{-1} \mathrm{~K}^{-1}$. By coincidence, this was close to the conductivity of the slab $\left(0.38 \mathrm{Wm}^{-1} \mathrm{~K}^{-1}\right)$. Had the gravel layer not been included in the construction, the thickness-weighted average thermal conductivity would have been $0.249 \mathrm{Wm}^{-1} \mathrm{~K}^{-1}$. This would have had a significant impact on the solution. 


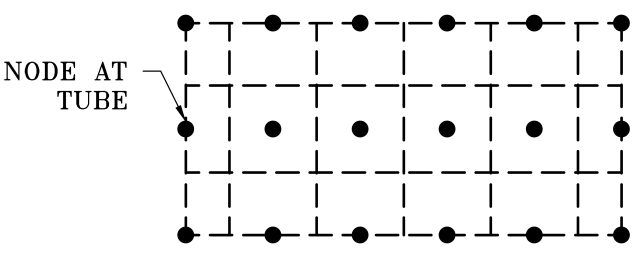

2D DISCRETIZATION

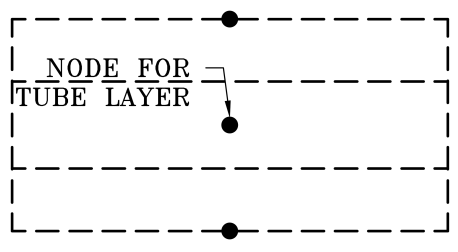

1D DISCRETIZATION

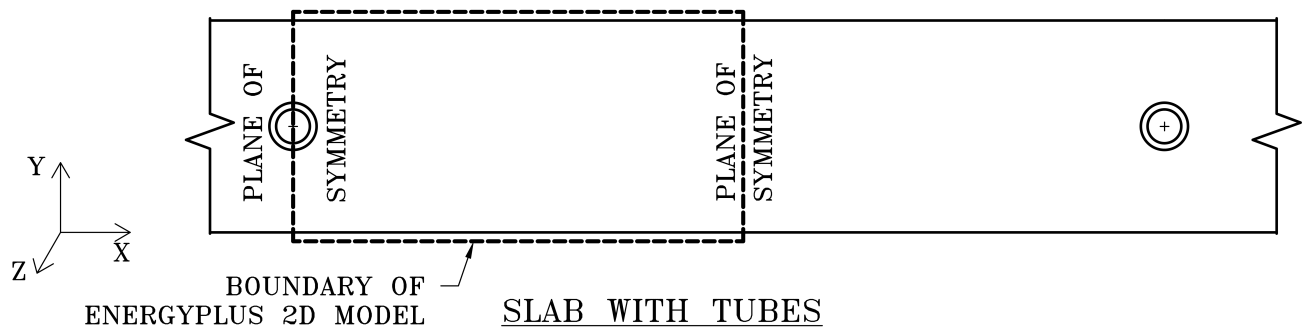

Figure 2.10: Discretization of the EnergyPlus model

\subsubsection{EnergyPlus}

Strand [46] developed separate 1D and 2D conduction transfer function models for radiant floor systems. These models were incorporated in EnergyPlus [47]. Both models are based on the conduction transfer function (CTF) method, where the CTF coefficients are calculated using the state-space method. The 1D model is discretized only in the main direction of heat flow (y-axis; see Figure 2.8), whereas the 2D model is further discretized in the $\mathrm{x}$-direction. Additionally, the 2D model uses symmetry to reduce the number of nodes used. The discretization of a single layer slab is shown in Figure 2.10. Both models assume that temperature of the floor materials is constant along the length of the tube.

A heat exchanger effectiveness is used to model the heat transfer between the water flowing through the tube and the floor construction:

$$
\epsilon=1-e^{-U A /\left(\dot{m} C_{p}\right)_{f}}
$$

where $\epsilon$ is the heat exchanger effectiveness (-). $U A$ is the product of the convective heat transfer coefficient between the flowing water and the inside surface of the tube, and the tube inside surface area $\left(\mathrm{W} \mathrm{K}^{-1}\right) .\left(\dot{m} C_{p}\right)_{f}$ is the product of the mass flow 
rate and specific heat of the water $\left(\mathrm{W} \mathrm{K}^{-1}\right)$.

The rate of heat transfer between the water flowing through the tube and the floor construction is then calculated using the effectiveness determined with Equation 2.9:

$$
q=\epsilon\left(\dot{m} C_{p}\right)_{f}\left(T_{f, i n}-T_{s}\right)
$$

where $q$ is the rate of heat transfer $(\mathrm{W}) . T_{f, i n}$ is the temperature of the water as it enters the radiant floor. For the $2 \mathrm{D}$ model, $T_{s}$ is taken as the temperature of the node nearest the tube. For the 1D model, $T_{s}$ is taken as the node temperature of the slab at the tube layer.

A pump, a diverting valve, and controllers are also packaged with the radiant floor model. The user has a choice between using a constant flow rate and constant temperature controller. Without modifying the EnergyPlus source code, there is no way for the user to circumvent these controllers, pumps, and diverting valves. This is unique to the EnergyPlus model. Additionally, for this work, the source code had to be modified in order to make the EnergyPlus model equivalent to the other models. This is discussed further in Section 2.4.3.

\section{Limitations}

The EnergyPlus models have a few limitations. First, the 2D model is not compatible with EnergyPlus's alternative finite difference solution algorithm. Second, the tube wall thermal resistance is assumed to be zero. Sattari and Farhanieh [48] have shown that tube thermal conductivity typically has little effect on the overall response of a radiant slab. However, if a thicker than usual tube with low thermal conductivity is used, this assumption may not be acceptable. Lastly, controllers in the floor model prevent water colder than the tube layer being sent to the floor in heating mode (and vice versa). In reality, these condition could conceivably happen as there are usually no controls implemented in real buildings to compare inlet water temperature and average slab temperature near the tubes.

\section{Model verification}

Strand [46] validated the 1D model with an experiment. This validation was not done using EnergyPlus, however the same model was later implemented into the software. Electric resistance heating wires were used to heat a slab. Temperature measurements 
were taken at 3 different layers in the slab, and deviations were found to be less than $0.5^{\circ} \mathrm{C}$ for all tested cases.

Chantrasrisalai et al. [49] compared in-situ measurements for a house with radiant capillary ceiling panels. The 1D model was used with seemingly good agreement, but no values were stated for average deviations. For this capillary systems, the tubes are closely spaced (every $0.0127 \mathrm{~m}$ ). It is therefore a good candidate for use of the 1D model, since the temperature in the tube layer was likely nearly homogeneous.

To the authors' knowledge, no validation or verification has so far been conducted for the 2D model in EnergyPlus.

\subsection{Inter model comparison}

This section describes the test cases that were created to contrast the predictions of the TRNSYS, ESP-r, and EnergyPlus models. The objective of these tests was to isolate the modelling of conduction heat transfer in the floor. As such, any prediction discrepancies could be attributed to the models described in the previous section. To accomplish this, the test cases were designed to impose boundary conditions at the inner tube and at the interface between the floor surface and the zone in such a manner that the three BPS tools could be made equivalent.

\subsubsection{Definition of test cases}

Two floor construction test cases were created: the thick slab test case and the thin slab test case.

For both cases, the distance between tubes (centre of tube to centre of tube) was set to $0.3048 \mathrm{~m}$. A zone of $3 \mathrm{~m}$ by $5 \mathrm{~m}$ by $2.7 \mathrm{~m}$ high was used. For both cases, a single circuit of tube in a serpentine layout was used. Given the above, the total length of the tube was $49.21 \mathrm{~m}$. The ESP-r and TRNSYS models calculate this length based on geometry. The EnergyPlus model requires the user to input the length. For a single loop serpentine tube configuration in a rectangular floor, shown in Figure 2.4, the length of tubing per loop can be calculated with Equation 2.11.

$$
L=\frac{A_{\text {floor }}}{M}
$$

where $L$ is the tube length, $M$ is the tube spacing, and $A_{\text {floor }}$ is the floor area. 
Table 2.1: Construction for thin slab floor

\begin{tabular}{lcccc}
\hline Material & $\begin{array}{c}\text { Thickness } \\
(\mathrm{m})\end{array}$ & $\begin{array}{c}k \\
\left(\mathrm{~W} \mathrm{~m}^{-1} \mathrm{~K}^{-1}\right)\end{array}$ & $\begin{array}{c}\rho \\
\left(\mathrm{kg} \mathrm{m}^{-3}\right)\end{array}$ & $\begin{array}{c}C \\
\left(\mathrm{~J} \mathrm{~kg}^{-1} \mathrm{~K}^{-1}\right)\end{array}$ \\
\hline Insulation & 0.0760 & 0.036 & 100 & 960 \\
Subfloor & 0.01905 & 0.1 & 450 & 1880 \\
Concrete $^{\mathrm{a}}$ & 0.03175 & 0.277 & 1461 & 840 \\
Hardwood $^{0}$ & 0.00794 & 0.14 & 600 & 1210 \\
\hline
\end{tabular}

a Tubes located in concrete layer, in contact with subfloor layer.

Table 2.2: Construction for thick slab floor

\begin{tabular}{lcccc}
\hline Material & $\begin{array}{c}\text { Thickness } \\
(\mathrm{m})\end{array}$ & $\begin{array}{c}\rho \\
\left(\mathrm{W} \mathrm{m}^{-1} \mathrm{~K}^{-1}\right)\end{array}$ & $\begin{array}{c}\rho \\
\left(\mathrm{kg} \mathrm{m}^{-3}\right)\end{array}$ & $\begin{array}{c}C \\
\left(\mathrm{~J} \mathrm{~kg}^{-1} \mathrm{~K}^{-1}\right)\end{array}$ \\
\hline Insulation $^{\text {Concrete }}$ & 0.0760 & 0.036 & 100 & 960 \\
Hardwood $^{\mathrm{a}}$ & 0.1308 & 0.277 & 1461 & 840 \\
\hline
\end{tabular}

a Tubes located in concrete layer, center of tube is $0.027051 \mathrm{~m}$ above insulation

The tubes were made of cross-linked polyethylene (PEX). The thermal conductivity of PEX was taken to be $0.38 \mathrm{~W} \mathrm{~m}^{-1} \mathrm{~K}^{-1}$, while the density and specific heat were taken to be $938 \mathrm{~kg} \mathrm{~m}^{-3}$ and $550 \mathrm{~J} \mathrm{~kg}^{-1} \mathrm{~K}^{-1}$ respectively. The tube inner and outer diameters were taken to be $0.0127 \mathrm{~m}$ and $0.016 \mathrm{~m}$ respectively. Tables 2.1 and 2.2 summarize the constructions for the two cases. Wood floor covers were used for both cases although other types of floor covers have a higher conductivity and may be more appropriate for radiant floors. This choice was made in order to stress the models by having different materials of varying thermal properties. Both constructions are more typical of residential applications.

No internal or solar gains were modelled in the zone. The convective heat transfer coefficient between the floor top surface and the air was fixed at a constant value of 11 $\mathrm{W} \mathrm{m}^{-2} \mathrm{~K}^{-1}$. While it would not be realistic to have a constant convection coefficient, 


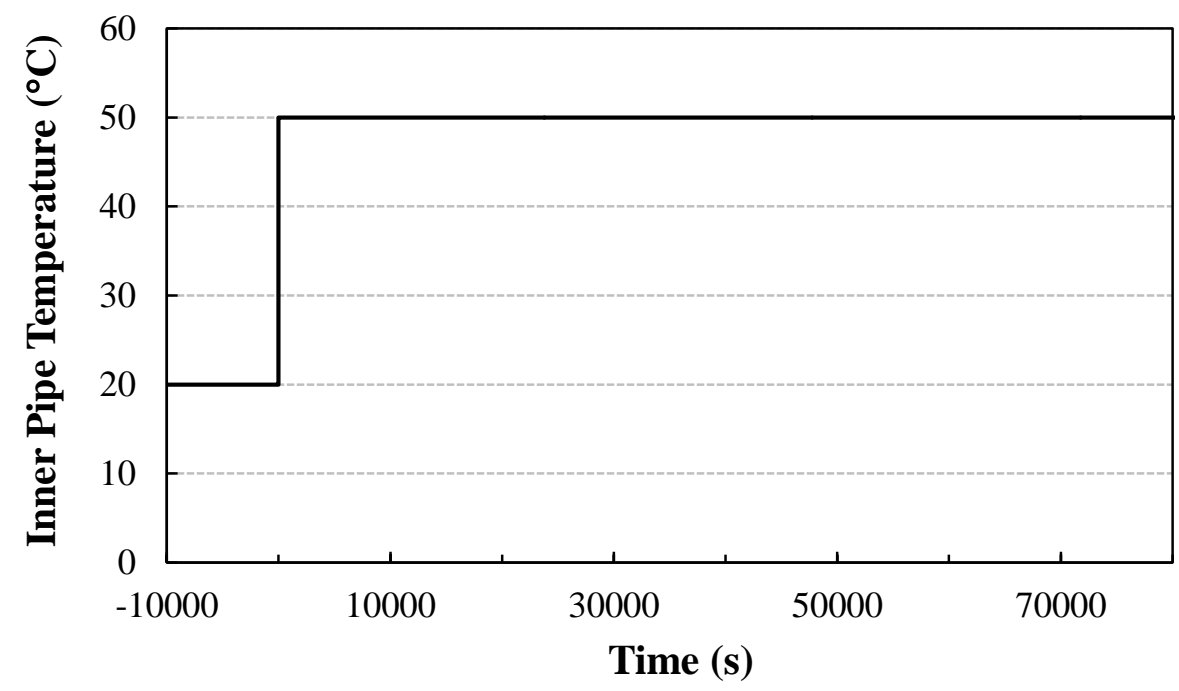

Figure 2.11: Single step input tube inner temperature profile

this is done to make the three BPS tools equivalent. The zone air temperatures above the floor was fixed at a constant $20^{\circ} \mathrm{C}$. There was no zone below the floor. Instead, a constant boundary condition was prescribed at $11 \mathrm{~W} \mathrm{~m}^{-2} \mathrm{~K}^{-1}$ and $20{ }^{\circ} \mathrm{C}$. Radiation heat transfer between the internal surfaces forming the zone was eliminated by setting the emissivity of all surfaces to zero. The initial floor construction temperature was set to $20^{\circ} \mathrm{C}$.

The inner tube temperature was made to vary in time using step functions, as illustrated in Figures 2.11 and 2.12. For the purpose of this work, the temperature profiles shown in Figures 2.11 and 2.12 will be called single step input and double step input respectively.

It is important to note that these test cases were not designed to be representative of current building practices, but rather conceived to stress and isolate particular aspects of the models. In this way, differences in simulation predictions could be attributable to the treatment of the transient conduction in the floor construction.

\subsubsection{Finite element analysis model}

A 2D transient conduction FEA simulation was performed for each floor construction using the LISA FEA package [50]. These predictions are used as a reference solution. 


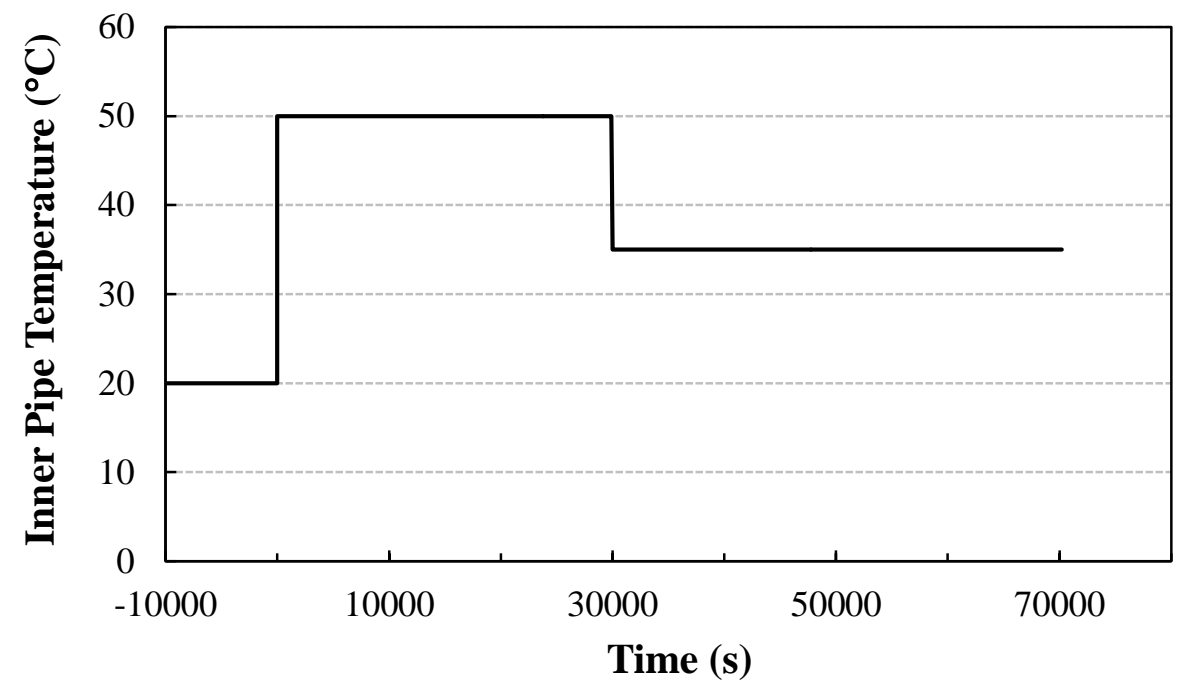

Figure 2.12: Double step input tube inner temperature profile

Although not exact, the FEA solution can help understand whether the simplifications and assumptions made in the TRNSYS, ESP-r, and EnergyPlus models are appropriate.

As shown in Figure 2.13, the FEA takes advantage of symmetry to limit the modelling of the radiant floor to only half of the distance between tubes. Figure 2.14 shows the mesh and boundary conditions for the thin slab case. The mesh contained 3991 nodes. Increasing the node count to 15678 changed the steady state heat transfer by $0.43 \%$. A single step input transient simulation as described in Section 2.4.3 was also run with both meshes. Increasing the node count to 15678 nodes (from 3991 nodes) changed the average heat transfer rate by $0.54 \%$. A similar mesh sensitivity analysis was done for the thick slab case, and a mesh of 5983 nodes was chosen. Refining the mesh to 23582 nodes resulted in a $0.057 \%$ change in steady state heat transfer. A single step input transient simulation as described in Section 2.4.3 was also run with both meshes. Increasing the node count to 23582 nodes (from 5983 nodes) changed the average heat transfer rate by $0.072 \%$.

The time-step size used for the transient FEA simulation was 2 minutes. For the single step input cases defined in Section 2.4.3, halving the time-step size changed the average heat transfer rate by $0.16 \%$ for the thin slab and $0.049 \%$ for the thick slab. 


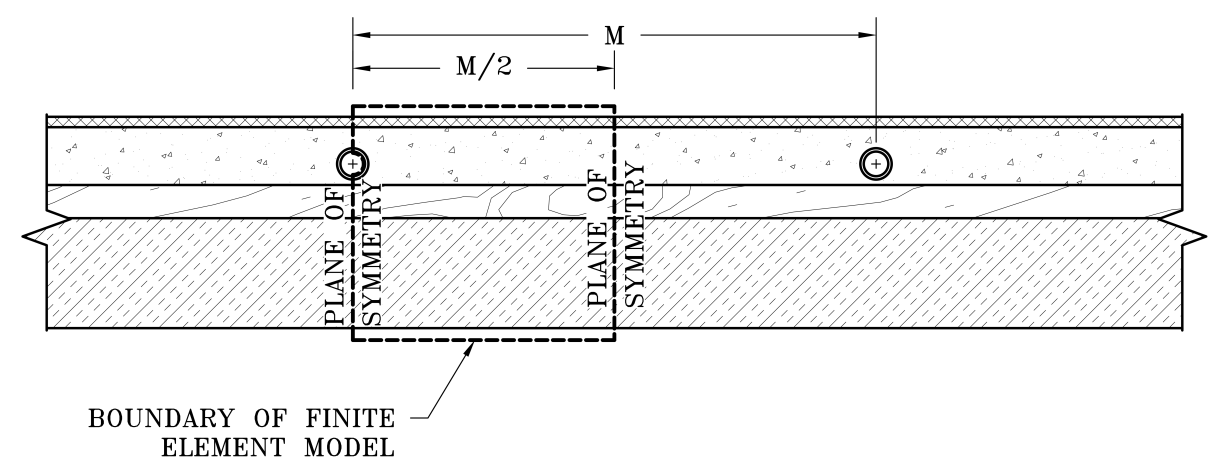

Figure 2.13: Boundary of FEA model

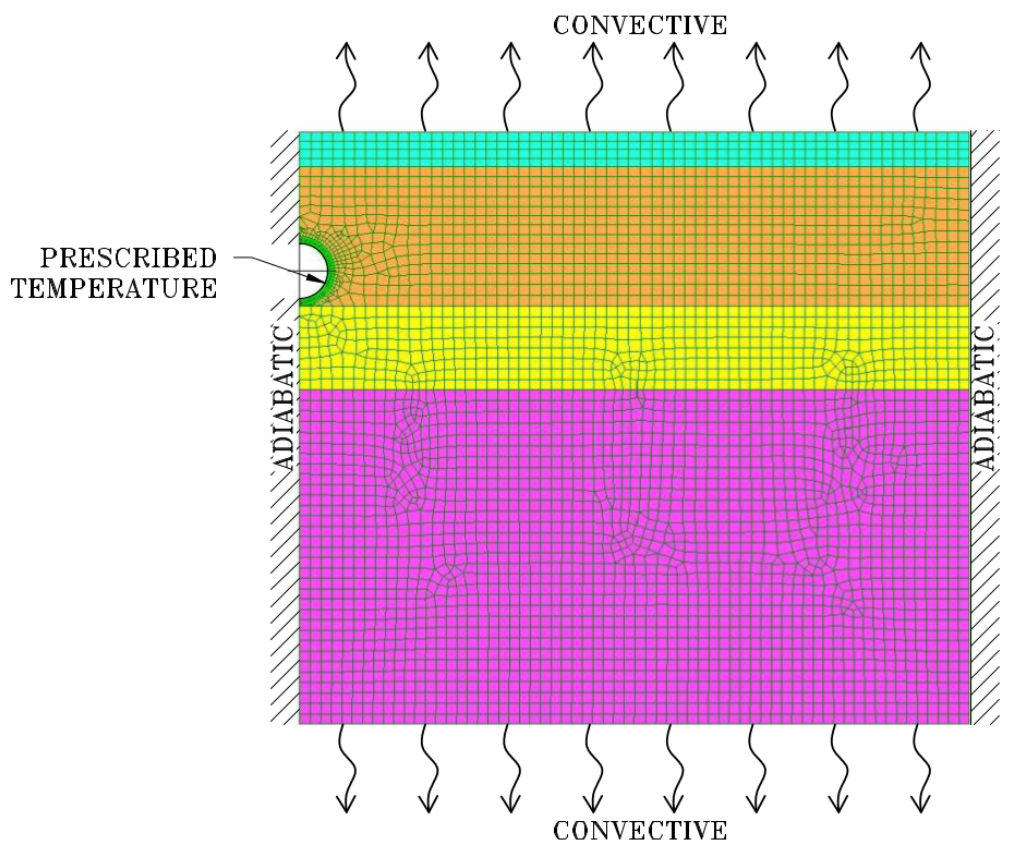

Figure 2.14: FEA mesh and boundary conditions for thin slab 


\subsubsection{Making the three BPS tools equivalent}

The two test cases were represented in TRNSYS, ESP-r, and EnergyPlus. With all three BPS tools, the zone air temperature was maintained at a constant value of 20 ${ }^{\circ} \mathrm{C}$.

The tube inner wall temperatures specified in Figure 2.11 or Figure 2.12 (depending on the case) were imposed by supplying a very high flow rate of water at the appropriate temperature. This flow rate would be physically impossible to achieve in a real scenario, but it resulted in a very large convection heat transfer coefficient between the flowing water and the inner tube wall. It also ensured a near uniform water temperature throughout the full length of the tube. As such, this approach ensured equivalent boundary conditions for comparing the predictions of the transient conduction models used by the three BPS tools and the FEA model. This way, the treatment of conduction heat transfer in the various models could be isolated and any differences in simulation predictions could be attributable to these aspects of the models.

A two minute time-step was employed for the ESP-r and EnergyPlus simulations. For the TRNSYS simulation, a building construction time-step of 3.6 minutes was used. Additionally, the overall simulation time-step was also set to 3.6 minutes because TRNSYS requires the overall simulation time-step to be a multiple of the timebase. In TRNSYS, the building construction time-step is called timebase. A timebase of 3.6 minutes was the lowest possible value allowed by the TRNSYS Type56 TRNBuild interface for the thick slab model. This limit is likely due to numerical instability as explained by Delcroix et al. [51]. The algorithm generating the transfer function coefficients is usually limited to relatively long timebase values (from a few minutes for relatively light construction types to several hours for very thick and heavy walls). In TRNSYS, the detailed radiation mode was used in order to suppress the radiant exchange.

For the single step input cases, the simulation duration is the time it takes for the top surface heat flux to reach $99 \%$ of steady-state. This is equivalent to 36480 seconds (10.13 hours) for the thin slab and 122040 seconds (33.9 hours) for the thick slab. For the double step input cases, the simulation length is 70200 seconds (19.5 hours).

The following versions of the three BPS tools were used:

- TRNSYS 17.01.0016 
- ESP-r 12.0 development_branch at revision 9329

- EnergyPlus 8.1.0.008 with modifications (see below)

Two modifications to EnergyPlus were required in order to conduct the work reported here:

1. The pump that circulates water through the radiant floor is embedded within the radiant floor model in EnergyPlus, in contrast to TRNSYS and ESP-r which treat these as distinct components. Consequently, the EnergyPlus user cannot impose a custom control law on this pump. One of the control laws implemented causes the pump to cycle off when the inlet water temperature drops below the tube layer temperature (in heating mode). Such situation temporarily occurs with the step-change employed in the double step input test cases. (refer to Figure 2.12). The source code was modified to force the pump to continuously circulate water during the test case.

2. This inter-model comparison revealed an error in the implementation of the EnergyPlus 2D radiant floor model that has a significant impact on simulation results. Specifically, an incorrect tube spacing is utilized by the EnergyPlus source code. This error was brought to the attention of the EnergyPlus developers and has since been corrected.

These above changes were accomplished by altering the EnergyPlus Fortran source code and then recompiling the program.

The TRNSYS model described in Section 2.3.1 could not be used for the thin slab case tested here due to the model's limitations (refer to Equation 2.6). Consequently, the so-called expert mode was utilized to override this limitation through the prescription of an overall heat transfer coefficient (refer to Section 2.3.1). As the TRNSYS manual [23] does not provide guidance on how this parameter should be prescribed, best efforts were employed to determine a value of $1.8529 \mathrm{~W} \mathrm{~m}^{-2} \mathrm{~K}^{-1}$ based upon a deduction of the model as described in the TRNSYS manual and in Koschenz and Dorer [52].

Additionally, TRNSYS calculates the average value over the time-step and not the instantaneous value at the end of the time-step. This effectively causes an apparent shift of half of one time-step in the solution compared with an instantaneous solution. 
The difference is small for small time-steps, but can cause discrepancies at larger timesteps. For this study, linear interpolation was used between TRNSYS output data points to approximate the instantaneous solution.

\subsection{Single step input results}

\subsubsection{Thin slab case}

Except where otherwise specified, results presented in this here are for the top surface heat flux. The top surface heat flux was calculated with Equation 2.12, where $q_{\text {surface }}$ is the top surface heat flux $\left(\mathrm{W} \mathrm{m}^{-2}\right), h$ is the heat transfer coefficient (set to 11 $\mathrm{Wm}^{-2} \mathrm{~K}^{-1}$ for this work), $T_{\text {surface }}$ is the top surface temperature $(\mathrm{K})$, and $T_{\text {zone }}$ is the zone temperatures (set to $293.15 \mathrm{~K}$, or $20{ }^{\circ} \mathrm{C}$ ). Because the zone air temperature and the heat transfer coefficient are imposed (and constant) through all tests, the surface heat fluxes reported are a function of the average top surface temperature only. Hence, comparing average top surface temperatures is redundant if the surface heat fluxes are already compared. For this reason, and in the interest of brevity, the surface temperature results were only compared for the single step cases. Results for the heat flux at the bottom surface are much smaller than that of the top surface and were found to follow similar trends to that of the top surface results. Therefore, they will not be discussed further.

$$
q_{\text {surface }}=h\left(T_{\text {surface }}-T_{\text {zone }}\right)
$$

The ESP-r, EnergyPlus and TRNSYS predictions for the single step input (as shown in Figure 2.11) thin slab case are illustrated in Figure 2.15. This figure plots the predictions of the top surface heat flux for both the 1D and 2D EnergyPlus models. It also plots two sets of predictions from ESP-r. For one ESP-r simulation, all material layers were represented in a single floor construction (see left side of Figure 2.9); the "split construction" approach was used in the other ESP-r simulation (see right side of Figure 2.9). The reference results produced with the FEA program are also plotted on Figure 2.15.

Figure 2.15 clearly illustrates that the EnergyPlus 1D model predicts significantly greater heat transfer from the water to the floor compared to the FEA solution and 


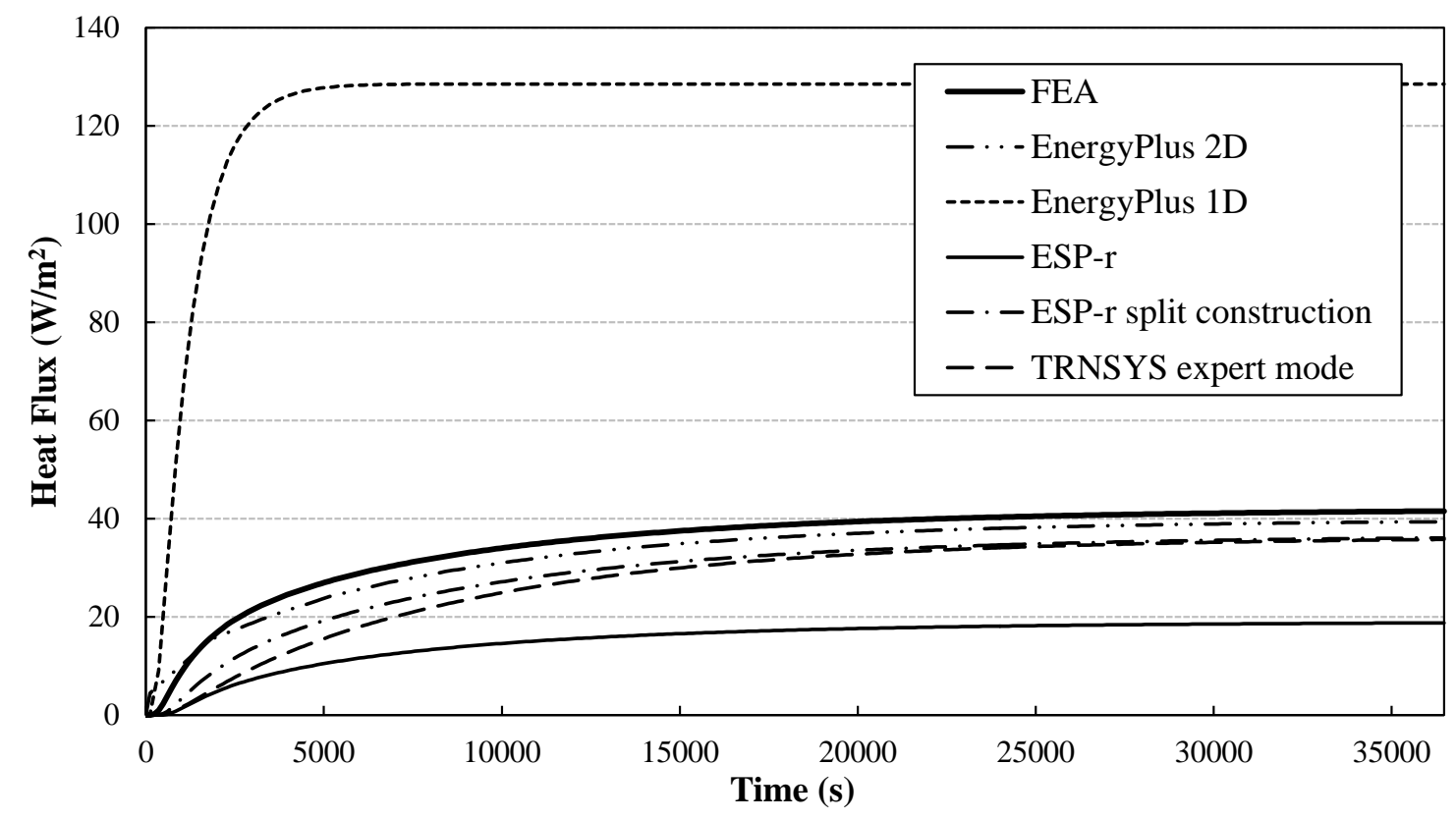

Figure 2.15: Heat flux at top surface for thin slab with single step input

the other models. It is well known that CTF solutions can become inaccurate at short simulation time-steps. Therefore, to explore the possibility that the short time-step employed here (2 minutes) contributed to this deviation, another simulation was run with the EnergyPlus 1D model, this one employing a 30-minute time-step. It was found that the EnergyPlus 1D model produced similar results with 2-minute and 30-minute time-steps, thus ruling out the possibility of the time-step-sensitivity of the CTF solution as the cause for the significant disagreement revealed in Figure 2.15. The EnergyPlus documentation [47] states that the 1D model is appropriate for electric resistance heating and hydronic heating when the performance of the heating equipment, such as a boiler, does not depend on supply or return temperatures. Strand [46] has shown this to be true for heating wire using an experiment. However, the results presented here show that the EnergyPlus 1D model should not be used for hydronic radiant floor systems.

The EnergyPlus 2D model predictions and FEA results are seen to be in close agreement. Over the time period of the test case $(36480 \mathrm{~s})$, the root mean square deviation (RMSD) between the EnergyPlus 2D model and FEA predictions is 2.57 $\mathrm{W} \mathrm{m}{ }^{-2}$. This is approximately $7 \%$ of the average heat transfer rate of $35.2 \mathrm{~W} \mathrm{~m}^{-2}$ 
over the test. The RMSD between the EnergyPlus 2D and FEA top surface temperature predictions is $0.23 \mathrm{~K}$. Not shown in Figure 2.15 are the results for the EnergyPlus 2D model without the tube spacing correction explained in Section 2.4.3. The EnergyPlus 2D model without the tube spacing correction was found to underestimate heat transfer by over $30 \%$ compared with the FEA solution.

When all material layers are represented in a single floor construction, the ESP$\mathrm{r}$ model is seen to significantly underestimate the heat transfer. This is because the ESP-r model uses average thermal properties of the floor construction for its calculations (see Section 2.3.2). In this test case, the low thermal conductivity of the insulation skews the average thermal conductivity. However, when the "split construction" method is utilized, the ESP-r model is found to agree more closely with the FEA solution; the RMSD is $6.22 \mathrm{~W} \mathrm{~m}^{-2}$, or approximately $18 \%$ of the average heat transfer rate over the test. The RMSD between the ESP-r "split construction" and FEA top surface temperature predictions is $0.57 \mathrm{~K}$.

The RMSD between the FEA predictions and TRNSYS expert mode predictions is $7.83 \mathrm{~W} \mathrm{~m}^{-2}$, or approximately $22 \%$ of the average heat transfer rate over the test. The RMSD between the TRNSYS expert mode and FEA top surface temperature predictions is $0.71 \mathrm{~K}$.

The "modified model" approach, as described in Section 2.3.2, showed no distinguishable difference with the "split construction" approach when plotted, so it was not shown in Figure 2.15. Similar results between the "split construction" approach and the "modified model" were expected, because both approaches were meant to remove the insulation layer from the average thermal properties calculations.

Because of their poor agreement with the FEA solution for this case, no further results for the the EnergyPlus 1D model and the ESP-r model (without the split construction approach) will be presented.

\subsubsection{Thick slab case}

The TRNSYS, ESP-r "split construction" method, and EnergyPlus 2D model predictions are illustrated in Figure 2.16, along with the reference predictions from the FEA model.

For this particular case, the ESP-r split construction model is seen to provide the closest agreement with the FEA solution: over the period of the test case (122040 s) 


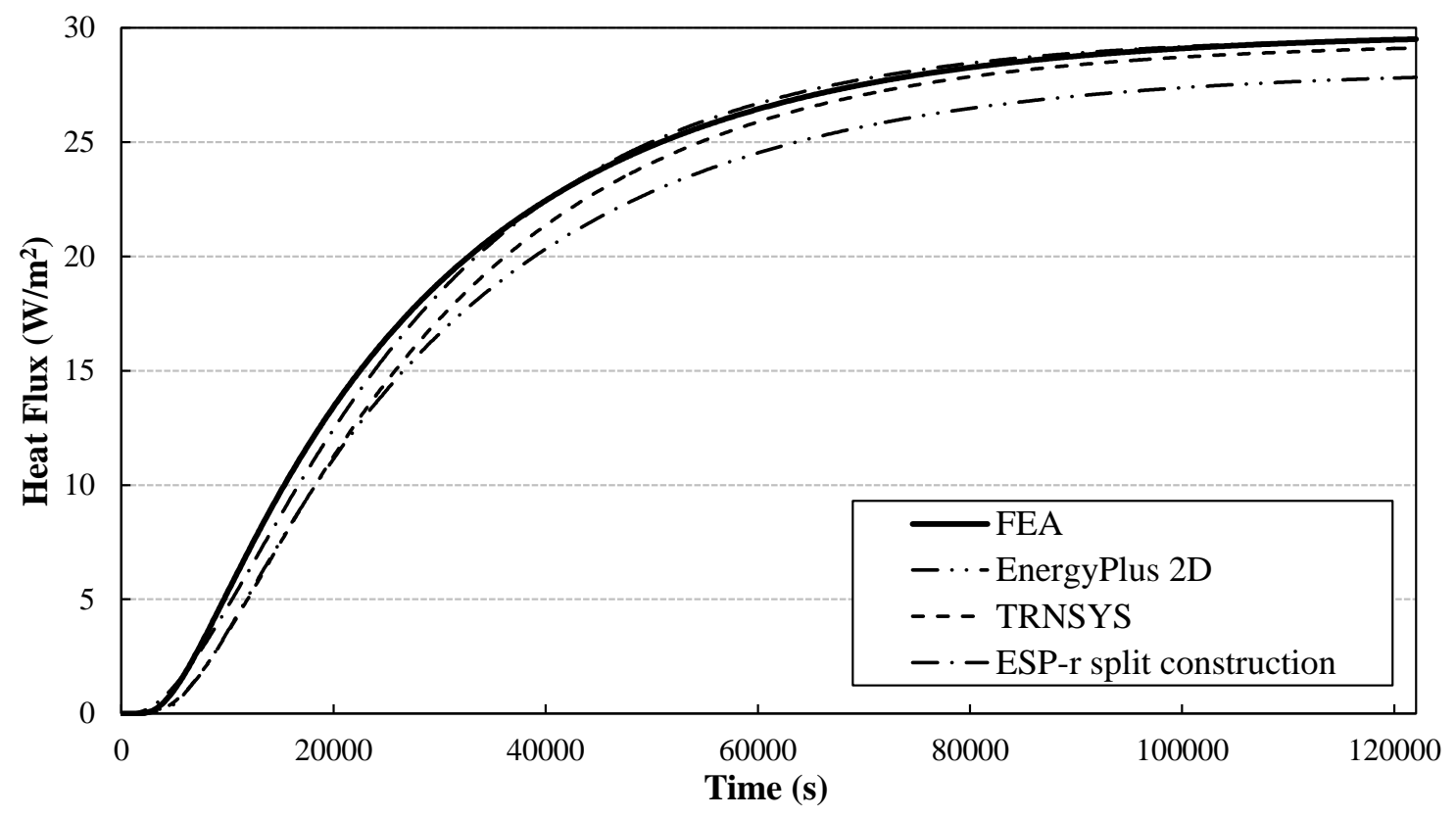

Figure 2.16: Heat flux at top surface for thick slab with single step input

the RMSD was $0.39 \mathrm{~W} \mathrm{~m}^{-2}$, which is $2 \%$ of the average heat flux of $22.5 \mathrm{~W} \mathrm{~m}^{-2}$. The RMSD of the TRNSYS model was $1.0 \mathrm{~W} \mathrm{~m}^{-2}$ (4\% of the average) and the RMSD of the EnergyPlus 2D model was $1.9 \mathrm{~W} \mathrm{~m}^{-2}$ ( $8 \%$ of the average). The RMSD between the FEA and BPS top surface temperature predictions is $0.04 \mathrm{~K}$ for ESP-r split construction, $0.09 \mathrm{~K}$ for TRNSYS, and $0.17 \mathrm{~K}$ for EnergyPlus 2D.

\subsubsection{Steady-state solution}

The previous results show differences in transient solutions. Comparing steady-state solutions can also be useful in contrasting the BPS models.

Tables 2.3 and 2.4 shows the steady-state heat flux and the absolute difference with the FEA solution for an inner pipe temperature of $50{ }^{\circ} \mathrm{C}$ for the thin and thick slab cases. These results show that for the thin slab case, the EnergyPlus 2D prediction is in much closer agreement with the FEA prediction than the ESP-r split construction and TRNSYS expert mode predictions. For the thick slab, the ESP-r split construction model prediction is the closest to the FEA, followed by TRNSYS prediction and EnergyPlus 2D prediction. 
Table 2.3: Steady-state heat flux for thin slab case

\begin{tabular}{lcc}
\hline Model & $\begin{array}{r}\text { Heat Flux } \\
\left(\mathrm{W} \mathrm{m}^{-2}\right)\end{array}$ & $\begin{array}{c}\text { Difference with FEA } \\
(\%)\end{array}$ \\
\hline FEA & 41.98 & - \\
TRNSYS expert mode & 36.29 & $15 \%$ \\
ESP-r split construction & 36.59 & $13 \%$ \\
EnergyPlus 2D & 39.83 & $5.1 \%$ \\
\hline
\end{tabular}

Table 2.4: Steady-state heat flux for thick slab case

\begin{tabular}{lcc}
\hline Model & $\begin{array}{r}\text { Heat Flux } \\
\left(\mathrm{W} \mathrm{m}^{-2}\right)\end{array}$ & $\begin{array}{c}\text { Difference with FEA } \\
(\%)\end{array}$ \\
\hline FEA & 29.81 & - \\
TRNSYS & 29.39 & $1.4 \%$ \\
ESP-r split construction & 29.68 & $0.44 \%$ \\
EnergyPlus 2D & 28.18 & $5.5 \%$ \\
\hline
\end{tabular}




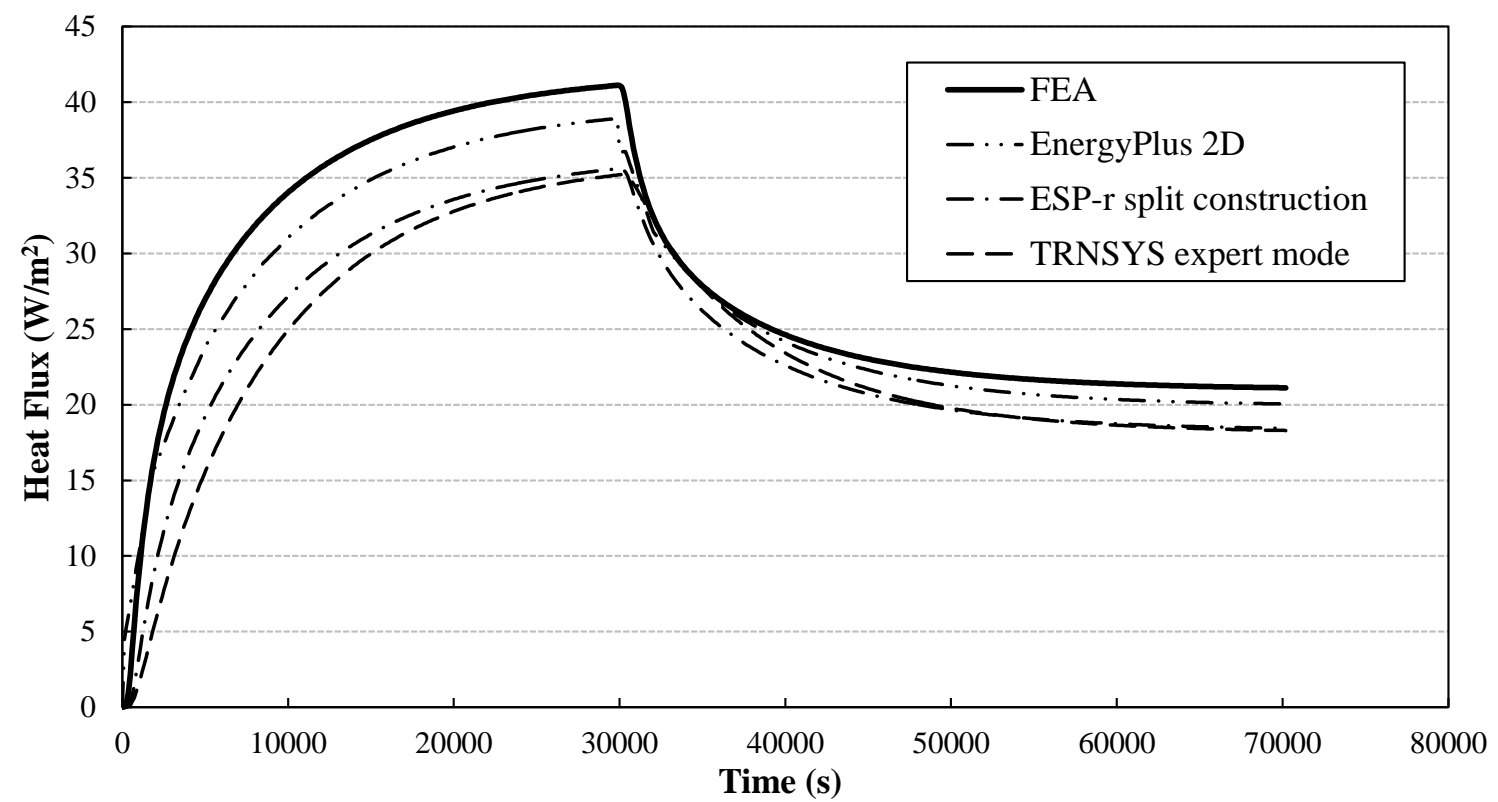

Figure 2.17: Heat flux at top surface for thin slab with double step input

\subsection{Double step input results}

In order to further stress the models, a double step input case was run. Similar types of test cases (double step input) have been previously used by others to compare radiant floor models $[23,27]$. The purpose of this double step input case was to test the model in transient conditions without allowing it to settle to a steady-state.

\subsubsection{Thin slab case}

The top surface heat flux predictions of the ESP-r "split construction", EnergyPlus 2D, and TRNSYS expert mode models for the double step input thin slab case are illustrated in Figure 2.17. The reference results produced with the FEA program are also plotted on Figure 2.17.

Over the time period of the test case $\left(7 \cdot 10^{4} \mathrm{~s}\right)$, the RMSD between the EnergyPlus $2 \mathrm{D}$ model and FEA predictions is $1.8 \mathrm{~W} \mathrm{~m}^{-2}$. This is approximately $7 \%$ of the average heat transfer rate of $27.7 \mathrm{~W} \mathrm{~m}^{-2}$ over the test. For the ESP-r "split construction" the RMSD is $4.6 \mathrm{~W} \mathrm{~m}^{-2}$, or approximately $16 \%$ of the average heat transfer rate over the test. The TRNSYS expert mode RMSD is $5.6 \mathrm{~W} \mathrm{~m}^{-2}$, or approximately $20 \%$ of the average heat transfer rate over the test. 


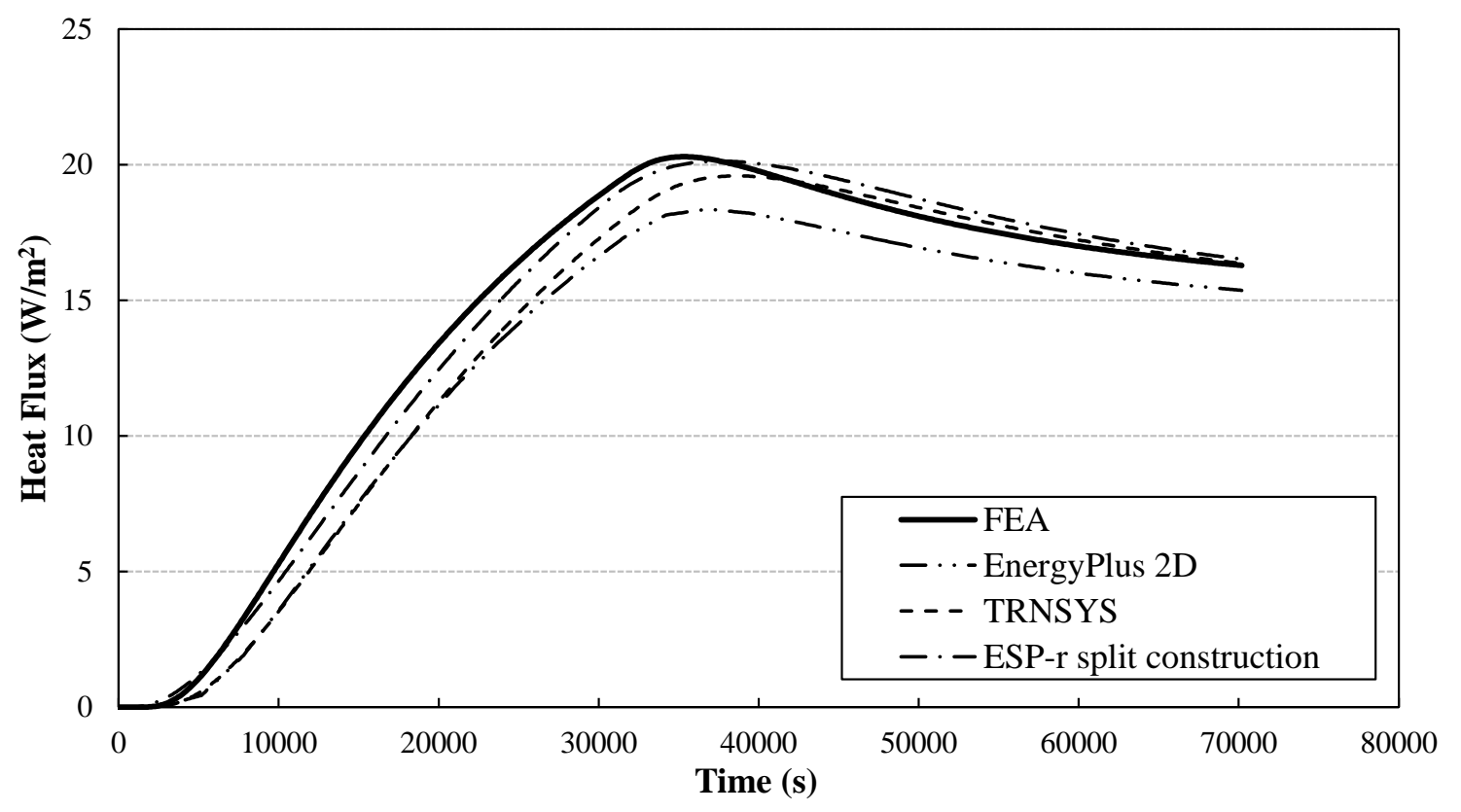

Figure 2.18: Heat flux at top surface for for thick slab with double step input

\subsubsection{Thick slab case}

The TRNSYS, ESP-r "split construction" method, and EnergyPlus 2D top surface heat flux model predictions are illustrated in Figure 2.18, along with the reference predictions from the FEA model.

As can be seen in Figure 2.18, all three models are seen to lag the FEA model solution following the step changes in the tube wall temperature at time $=0$ and at time $=3 \cdot 10^{4} \mathrm{~s}$ (refer to Figure 2.12). For this particular case, the ESP-r split construction model is seen to provide the closest agreement with the FEA solution: the RMSD was $0.6 \mathrm{~W} \mathrm{~m}^{-2}$, which is $4 \%$ of the average heat flux of $14.2 \mathrm{~W} \mathrm{~m}^{-2}$. The RMSD of the TRNSYS model was $1.2 \mathrm{~W} \mathrm{~m}^{-2}$ ( $8 \%$ of the average) and the RMSD of the EnergyPlus 2D model was $1.6 \mathrm{~W} \mathrm{~m}^{-2}$ (11\% of the average).

\subsubsection{Time-step sensitivity}

The previous results were generated using 2-minute time-steps for ESP-r, EnergyPlus, and the FEA, whereas a 3.6-minute time-step (and timebase) was used for TRNSYS. Additional simulations of the thick slab case were conducted to explore the sensitivity of model predictions to the choice of simulation time-step. This was accomplished by 
increasing the time-step (and timebase in TRNSYS) of the BPS tools simulations to 30 minutes.

The RMSD between these predictions and those from the FEA solution using a 2minute time-step were then calculated. The results, shown in Figure 2.19, reveal that the ESP-r and EnergyPlus solutions are quite sensitive to time-step. Interestingly, the ESP-r solution diverges from the FEA solution while the EnergyPlus solution does the opposite. Most of the variation between the 2-minute and the 30-minute timesteps for the ESP-r solution can be explained by its solution method. In ESP-r, the building domain is solved first, then the plant domain calculates the heat flux to the floor. This heat flux is then imposed to the floor at the next time step in the building model. This causes a shift of one time-step in the solution. This shift is insignificant for small time-steps, but can cause discrepancies at larger time-steps. Therefore, it is recommended to use a short time-step with the ESP-r model to minimize the effect of the shift. It is unclear why the EnergyPlus solution is sensitive to time-step, but it is possible that it is caused by a truncation of the conduction transfer function (CTF) coefficients. If this is the case, a longer time-step should be used with EnergyPlus to minimize the effect of the CTF coefficient truncation. The TRNSYS solution is not sensitive to time-step over the range of time-step (or timebase) tested here for the thick slab. The results of the TRNSYS, ESP-r, and EnergyPlus simulations at different time-steps are shown in Figures 2.20, 2.21, and 2.22 respectively. These results show that general conclusions cannot be made as to which of the BPS tools provides the closest results to the FEA model. If the cases in the previous sections had been simulated with a time-step other than 2 minutes, the various BPS tools would have performed differently. The results of the previous sections should therefore not be interpreted as a ranking system for the models. Rather, they are a verification of the suitability of the results under specific conditions.

\subsection{Parametric Analysis}

Building simulationists typically use tabulated thermo-physical properties when defining construction materials. These values come from many sources, including building 


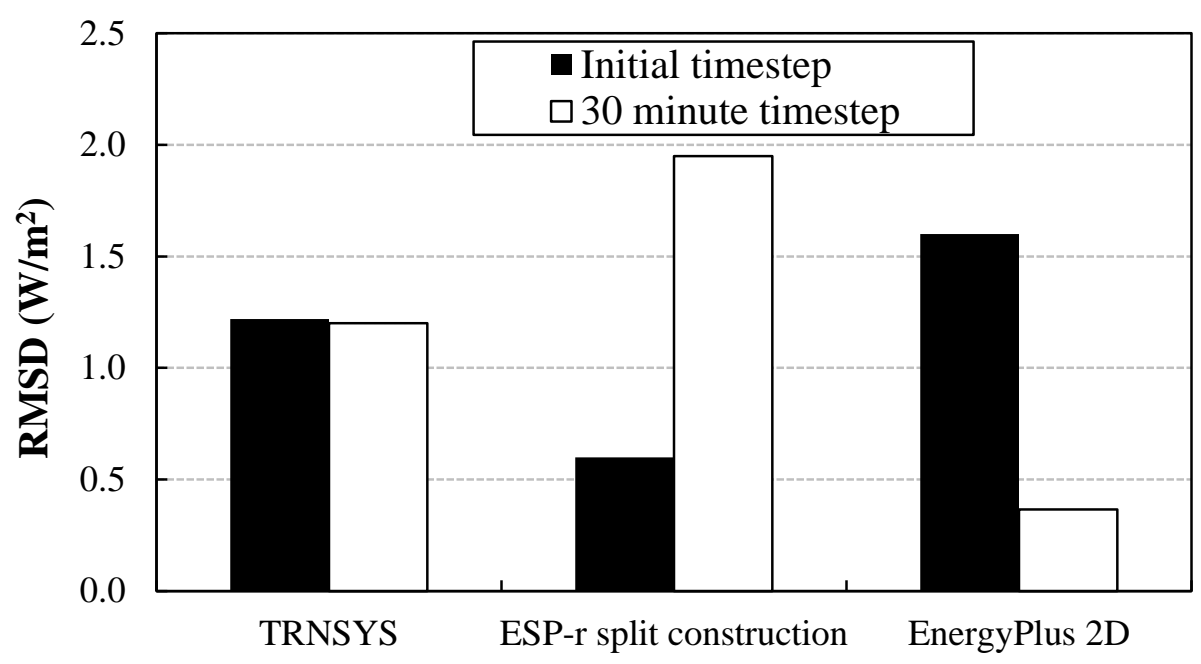

Figure 2.19: Effects of time-step on RMSD (thick slab)

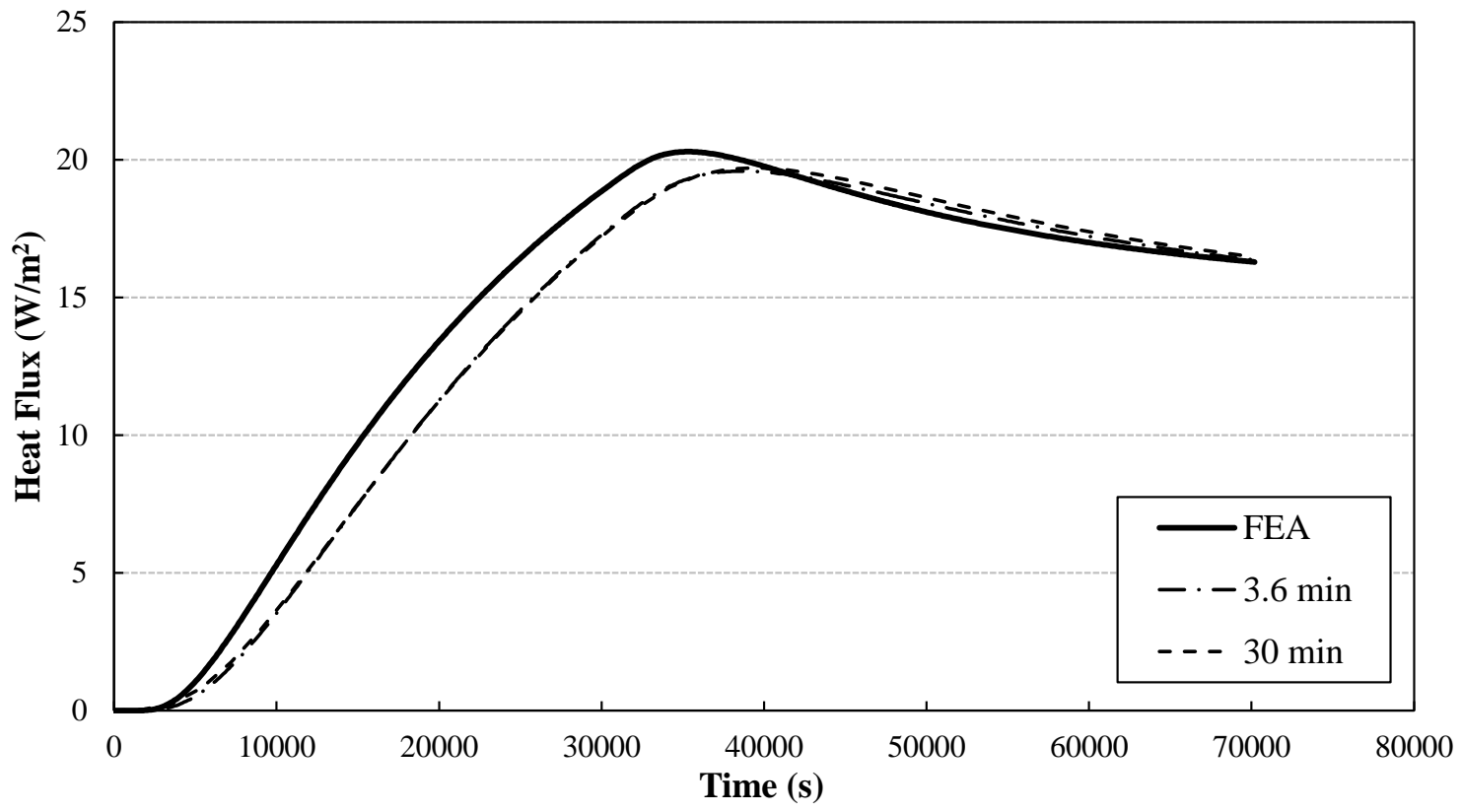

Figure 2.20: Effects of time-step on TRNSYS results (thick slab) 


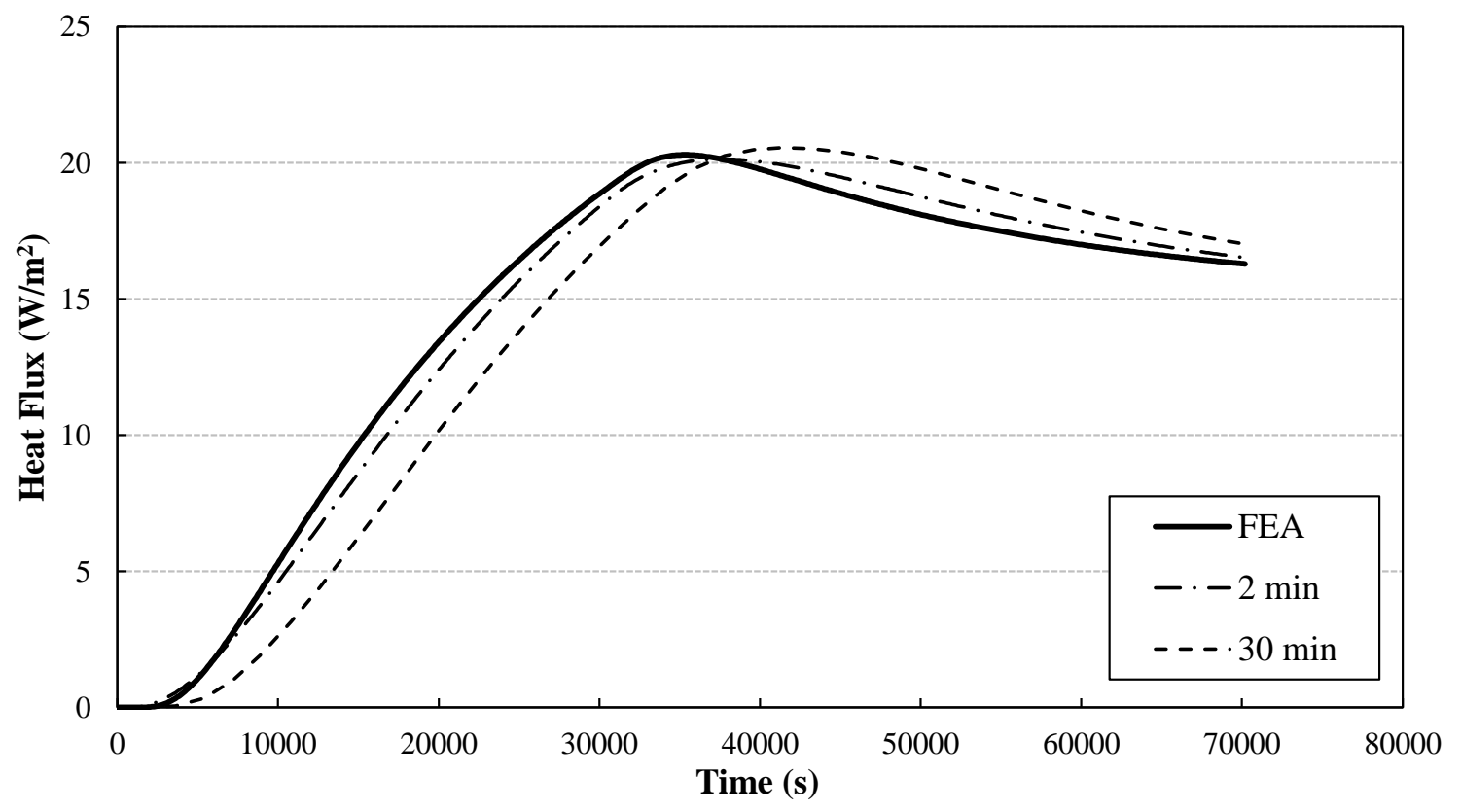

Figure 2.21: Effects of time-step on ESP-r split construction results (thick slab)

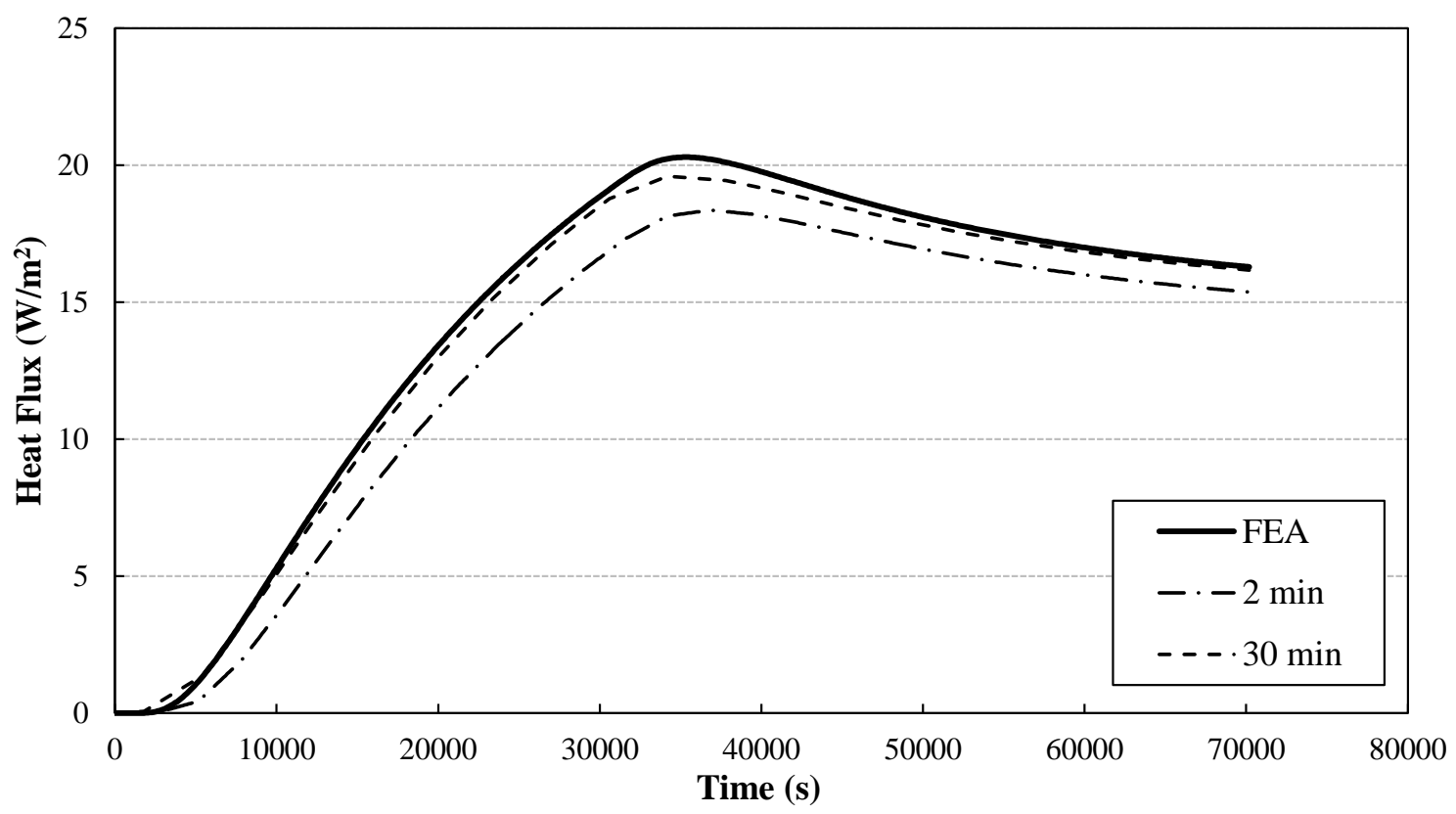

Figure 2.22: Effects of time-step on EnergyPlus 2D results (thick slab) 


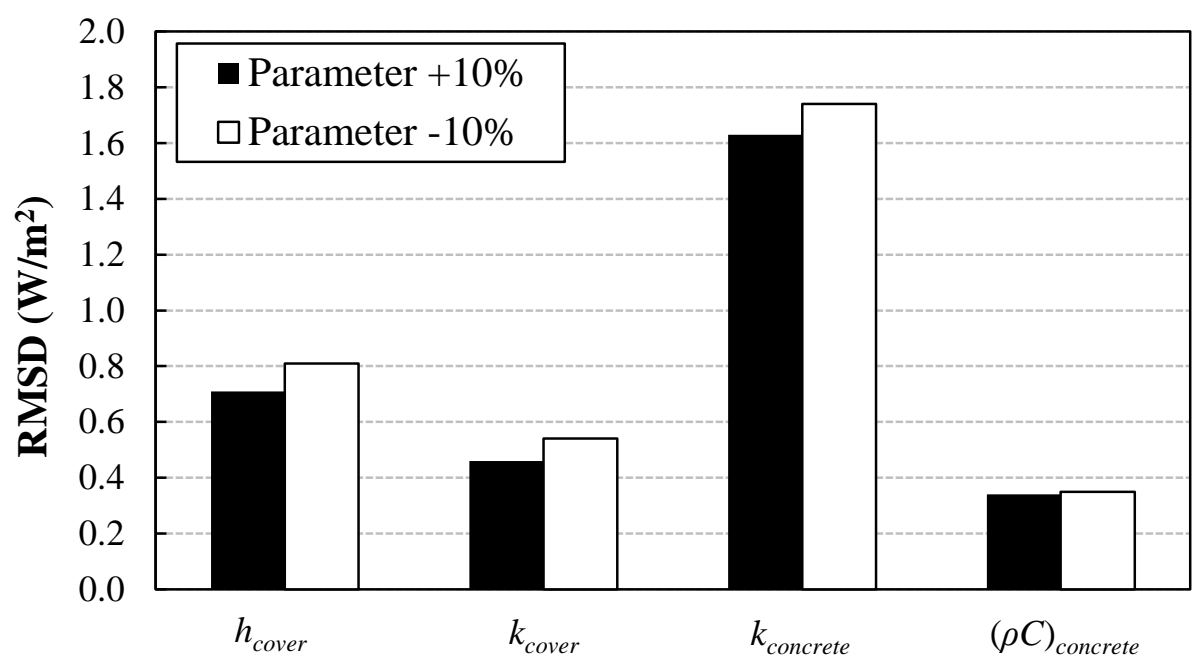

Figure 2.23: Parametric analysis for thin slab FEA model

guide books, BPS tools, and manufacturer's data [53]. Macdonald [54] reported uncertainties between $5 \%$ and $40 \%$ for thermal conductivities, over $1 \%$ for densities, and over $12.25 \%$ for specific heats. Additionally, Beausoleil-Morrison [19] reported differences of up to $20 \%$ between two heat transfer coefficient correlations for heated floors.

To put the deviations between the FEA solution and the BPS models in perspective, a parametric analysis was performed with the FEA model. The parameters investigated were: convective heat transfer coefficient, cover conductivity, concrete conductivity, and concrete thermal mass. Figures 2.23 and 2.24 show the results of the parametric analysis for the thin and thick slab models respectively. Each parameter was varied by $+10 \%$ and $-10 \%$ of its nominal value, and a RMSD was calculated between the base case and the varied parameter cases. These results show that the deviations found in all cases between the FEA solution and the three models fall within or near what would be expected from making typical modelling assumptions.

\subsection{Realistic flow rate}

In order to make the BPS models equivalent with the FEA model, an impossibly large water flow rate had to be used in the BPS tools. This effectively imposed a 


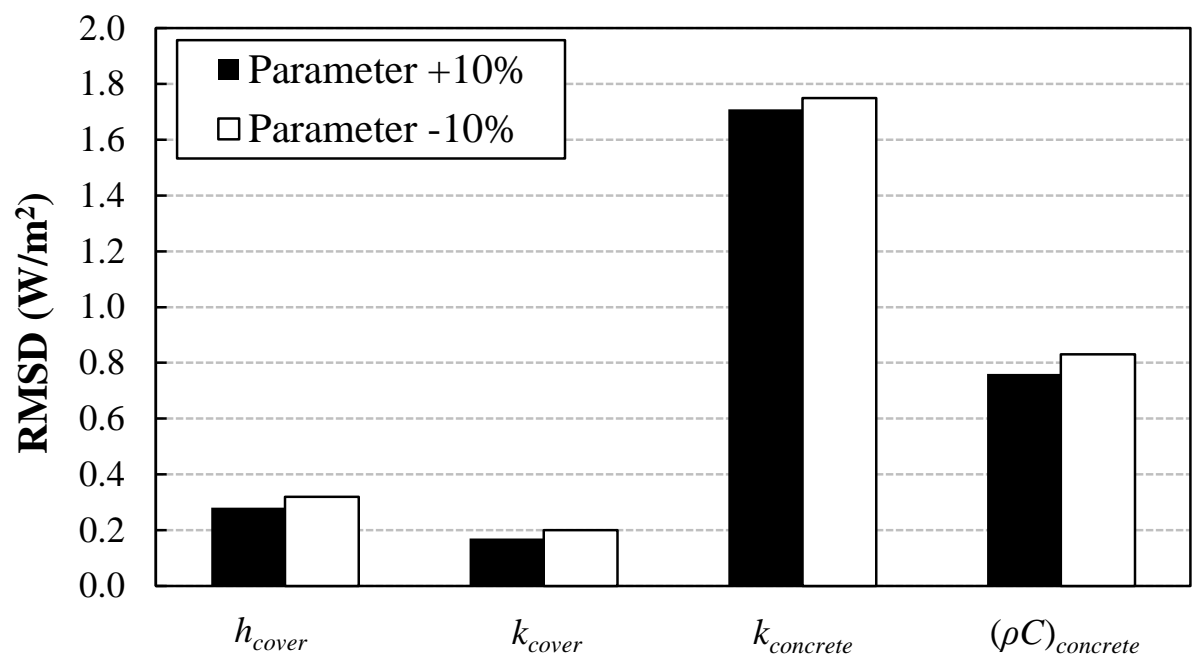

Figure 2.24: Parametric analysis for thick slab FEA model

temperature on the inner pipe wall.

The three BPS models can also be compared for a typical water flow rate. For this case, the FEA model cannot be made equivalent with the BPS models. For this reason, the FEA model was not used for this case. The inlet water temperature profile is shown in Figure 2.12. A two minute time-step was used in ESP-r and EnergyPlus and a 3.6 minute time-step (timebase) was used for TRNSYS (see Section 2.4.3). Figure 2.25 shows simulation results for a flow rate of $0.025 \mathrm{~kg} \mathrm{~s}^{-1}$ for the thick slab case. The RMSD between the ESP-r and TRNSYS solutions was $0.42 \mathrm{~W} \mathrm{~m}^{-2}$ while the RMSD between the ESP-r and EnergyPlus solutions was $1.4 \mathrm{~W} \mathrm{~m}^{-2}$.

Additionally, results for the heat transfer between the water and the floor construction per unit floor area are shown in Figure 2.26. The RMSD between the ESP-r and TRNSYS solutions is $8.0 \mathrm{~W} \mathrm{~m}^{-2}$ while the RMSD between the ESP-r and EnergyPlus solutions was $7.3 \mathrm{~W} \mathrm{~m}^{-2}$. These larger RMSDs compared with surface heat flux are likely caused by large temperature gradients in time at the beginning of the simulation, when the inlet water temperature jumps from $20{ }^{\circ} \mathrm{C}$ to $50{ }^{\circ} \mathrm{C}$, and again, when the temperature drops to $35^{\circ} \mathrm{C}$. These cause discontinuities that may not be handled well by the simulation tools. The ESP-r model predicts much higher heat transfer from the water to the slab compared to the EnergyPlus and TRNSYS models at the beginning of the simulation. It also predicts much higher heat transfer from the slab to the water compared to the other BPS models when the inlet water 


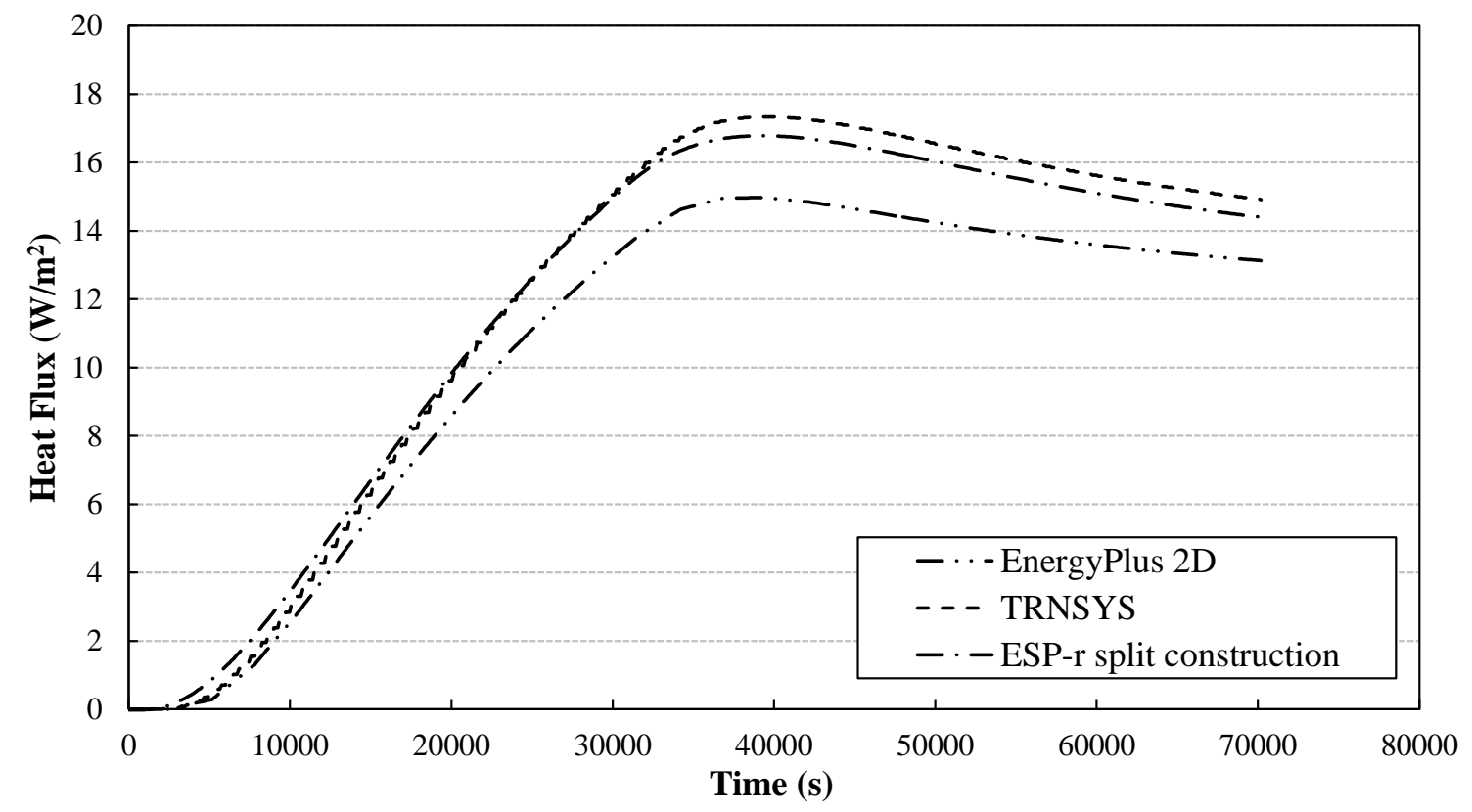

Figure 2.25: Surface heat flux results for thick slab with realistic flow rate

temperature drops to $35^{\circ} \mathrm{C}$. Furthermore, when the simulations are allowed to reach steady-state, the surface heat flux and the heat transfer between the water and the floor are within $0.1 \%$ of each other for all three models.

\subsection{Closing remarks}

In this chapter, the theoretical basis of the models used for predicting the performance of hydronic embedded-tube type radiant floors in TRNSYS, ESP-r, and EnergyPlus have been described. The problem is inherently three-dimensional and transient. But, the models in all three BPS tools necessarily introduce simplifications for computational reasons, in particular to the treatment of conduction between the embedded tubes and the upper surface of the floor.

Test cases based upon two floor constructions and two inner pipe temperature profiles used to isolate the modelling of conduction heat transfer between the embedded tubes and the floor surface were then created to perform an inter-model comparison. The inputs to the three BPS tools were made equivalent and simulations were conducted. The simulation predictions from the three tools were then contrasted to 


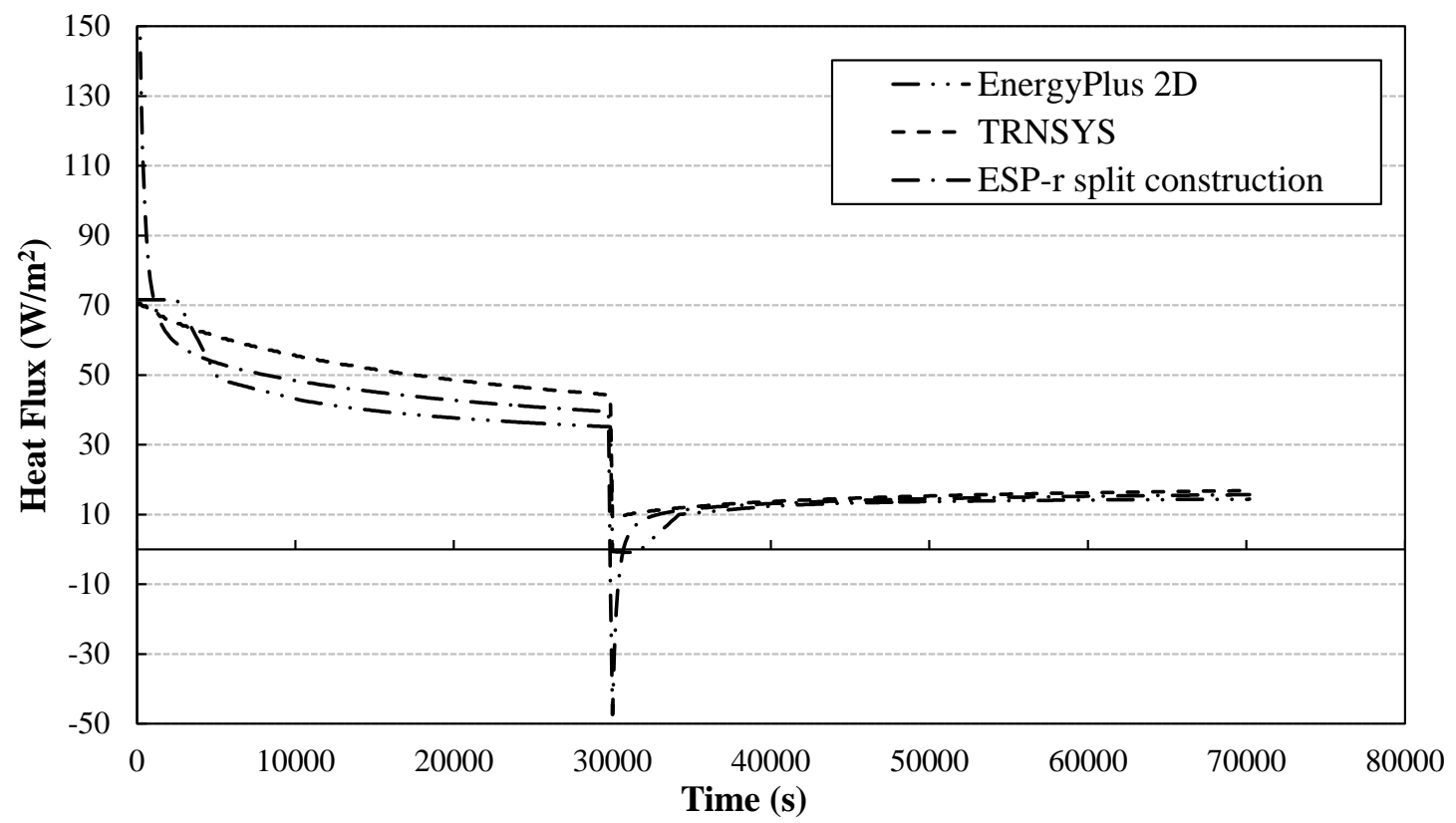

Figure 2.26: Heat transfer between water and floor construction for thick slab with realistic flow rate

each other, and compared to those from a reference finite element analysis tool which considered the transient conduction in a more rigorous fashion.

The test cases were not designed to be representative of current building practices, but rather conceived to stress and isolate particular aspects of the models. In this way, differences in simulation predictions could be attributable to the treatment of the transient conduction in the floor construction.

This analysis revealed serious issues with the radiant floor models in the three BPS tools. The TRNSYS model was unable to simulate one of the two test cases directly because that model's applicability is limited to relatively thick slabs. The expert mode was used for the thin slab case. This required the calculation of an equivalent heat transfer coefficient which is not well defined in the TRNSYS manual [23].

The ESP-r model employs a method which averages the thermal properties of multi-layered constructions. It was found that this could lead to important prediction errors when the construction layers have significantly different thermal properties (e.g. insulation versus concrete). A technique that could be employed by the tool user to mitigate this problem was assessed. Additionally, a more robust solution requiring a change to the ESP-r source code was also proposed and tested. Both methods 
were found to significantly improve the agreement between the ESP-r model and the reference FEA solution. As a consequence, it is recommended that the proposed source code changes be effected to the distributed version of ESP-r.

EnergyPlus' 1D model was found to significantly overestimate the heat transfer from the water to the floor: prediction differences up to $300 \%$ were found relative to the reference FEA solution. Furthermore, this analysis revealed a bug in the EnergyPlus 2D model that caused the model to significantly underpredict heat transfer: differences greater than $30 \%$ were found relative to the FEA solution. Once a correction was made to the source code, the EnergyPlus 2D model was found to be in much better agreement with the reference FEA solution. As a result of this work, the EnergyPlus developers were made aware of this error, and it has since been corrected in the general distribution.

Two inner pipe temperature profiles were used as a boundary condition. The first one was a single step input. The duration of the simulation was set as the time it took for the FEA solution to reach $99 \%$ of steady state. Top surface heat fluxes were compared. For the thin slab case, the RMSD between the ESP-r split construction model and the FEA solution was found to be $18 \%$ of the average top surface heat flux, the RMSD for the EnergyPlus 2D model (corrected as described above) was 7\% of the average heat flux, and the RMSD for the TRNSYS expert mode model was $22 \%$ of the average heat flux. For the thin slab, the worst RMSD found between the three models and the FEA top surface temperature predictions was $0.71 \mathrm{~K}$. Similarly, for the thick slab, the worst case was a RMSD of $0.17 \mathrm{~K}$.

For the thick slab case, the RMSD for ESP-r split construction was $2 \%$ of the average top surface heat flux, while it was 5\% for TRNSYS and 8\% for EnergyPlus 2D. When the simulations for the thick slab case were continued until steady-state conditions were achieved, the difference in top surface heat transfer between the FEA prediction and the TRNSYS, ESP-r, and EnergyPlus 2D model predictions were found to be $1.4 \%, 0.44 \%$, and $5.5 \%$ respectively.

The second inner pipe temperature profile consisted of two temperature step inputs such that conditions remained in a transient regime for 19.5 hours. For the thin $s l a b$ case, the root mean square deviation (RMSD) between heat transfer predictions from the EnergyPlus 2D model (corrected as described above) and the reference FEA solution was found to be $7 \%$ of average top surface heat flux, while the RMSD for the predictions from ESP-r split construction was 16\%, and $20 \%$ for the TRNSYS 
expert mode. For the thick slab case, the RMSD for ESP-r split construction was 4\%, while it was $8 \%$ for TRNSYS, and $11 \%$ for the EnergyPlus 2D model. Further to these differences, the ESP-r and EnergyPlus models were found to be sensitive to the choice of time-step. By increasing the time-step from 2 minutes to 30 minutes for the thick slab case, the RMSD increased for ESP-r, while it decreased for EnergyPlus. While the ESP-r predictions were the closest to the FEA solution with a 2 minutes time-step, they became the furthest of the three BPS tools when the time-step was increased to 30 minutes. The opposite happened with the EnergyPlus predictions. This shows that conclusions regarding which model is closest to the FEA solution for a particular test case should not be generalised. The time-step used will change which simulation tool predicts results closer to the FEA solution.

Tests with realistic flow rates were run and the surface heat flux and heat transfer between the water and floor construction were evaluated. The three BPS tools predicted similar results for surface heat flux. However, at periods of sharp changes in inlet water temperature, the ESP-r predictions deviated from that of TRNSYS and EnergyPlus for the heat transfer between the water and the floor construction.

These test cases (except for the realistic flow rate case) isolated the treatment of transient conduction between the embedded tubes and the floor surface. Many other factors can affect the accuracy of BPS predictions when simulating the performance of realistic radiant floor systems, such as uncertainty over thermophysical properties and the modelling of the convective heat transfer between the floor surface and the room air. A sensitivity analysis revealed that some of these factors can affect prediction accuracy as much as the transient conduction models examined by the test cases.

It would be interesting to expand this work to create additional test cases to examine other aspects of the models. As well, carefully designed and executed experiments that provide accurate empirical data for situations that can be made equivalent in the BPS tools would be invaluable as these would provide truth standards for comparison.

It is the author's opinion that the ESP-r split construction model presented in this chapter is adequate for modelling an embedded tube systems. With this validated model, and with a good understanding of its limitations, it was then possible to analyze the active/passive solar collection system presented in Chapter 1 with embedded-tube radiant floors. The next chapter will discuss a new AFTP radiant floor system model. This way, a comparison of the performance of the active/passive solar collection system with both types of radiant floors will be possible. 


\section{Chapter 3}

\section{Above-floor tube-and-plate (AFTP) radiant floor model development}

\subsection{Introduction}

As discussed in Chapter 2, in order to accurately model the entire system described in Chapter 1, there is a need for accurate radiant floor models. Models of embeddedtube systems were described and evaluated in Chapter 2. Another type of radiant floor that is becoming popular in housing is the Above-Floor Tube-and-Plate (AFTP). Embedded-tube systems are heavier than AFTP systems and may require a larger structure to support the extra weight. Additionally, because of the large thermal mass in typical embedded-tube radiant floors, controls can be problematic [55]. For example, during the heating season, a zone may be requiring heat at night. The floor will then be supplied with hot water all night and may be at relatively high temperatures come morning. If solar gains or other casual gains increase the space temperature in the morning, the supply of water will cease but the large amount of heat stored in the floor will still be released in the space for potentially a few hours, resulting in overheating. These problems typically get exacerbated with large variations in casual gains and solar gains.

AFTP systems can be used instead of embedded-tube systems to reduce thermal mass. Figure 1.4 shows a section an AFTP radiant floor. These systems consist of a thin conductive fin on top of a grooved high density insulation layer. The insulation layer is above a wooden subfloor. Tubes are laid in the grooves, and a floor cover is added on top. An alternative design is to use a grooved wooden subfloor and place the insulation below the subfloor. Models for these types of radiant floors are however 
not currently available in BPS software. This chapter discusses the development and implementation of such a model for ESP-r. The model was validated with a 2D finite element model and a full scale experiment. Part of this work was presented in [56].

\subsubsection{Literature}

The literature on AFTP models is minimal. Yeo and Kim developed a model for a fin radiant floor panel [57]. The model consisted of two layers of insulation, underneath a fin. This arrangement is very similar to a AFTP system, except that there was no floor cover. They modelled the floor using the finite difference method with an im-

plicit scheme, but it is not clear how the tube was modelled and coupled to the finite difference model. Additionally, the model was not implemented in a building performance simulation tool. Surface temperatures between the model and experimental results are reported to generally agree to within $0.5^{\circ} \mathrm{C}$.

Kattan et al. [58] developed a radiant floor model that used finite difference in the water flow direction. A fin was used at the bottom of the concrete layer to increase conduction. This model used a fin thermal resistance to calculate the heat transferred to the room. The fin thermal resistance was based on steady-state fin equations. The results were compared with transient experimental results by Cho and Zaheeruddin [59]. Although they stated that the model agreed with the experimental results, after reviewing the results provided in the paper it is the opinion of the author that this is not the case. Additionally, there are problems with the way errors are reported, specifically, percentage errors are reported for temperature measurements.

\subsection{Model development}

\subsubsection{ESP-r building domain solution method}

In order to solve for the transient heat transfer in a building's opaque fabric components, ESP-r uses a 1D finite difference approach (2D and 3D representations are possible, but rarely utilized). In 1D conduction, the direction of heat transfer is normal to the surface (or layer), and condution in other directions is ignored. Each layer in a wall, floor, ceiling, or other opaque fabric component is represented by three nodes. Each layer is assumed to be homogeneous. By default, thermophysical properties are treated as constant, although thermal conductivity can be made to vary 
with temperature and moisture content. By default, ESP-r uses the Crank-Nicholson scheme to solve the 1D heat balance problem. For sake of brevity, details are omitted here and the interested reader is directed to work by Clarke [22] for a detailed discussion.

\subsubsection{Fin and cover finite difference conduction model}

The approach taken for the new AFTP model is similar to that of Laouadi [27] discussed in Chapter 2. The difference lies in the solution of the temperature field in the floor. Laouadi used average floor properties (conductivity, specific heat, density) and solved the two-dimensional conduction equation in the floor. This approach works well when all layers in the floor have similar thermal properties. When a fin with a much higher thermal conductivity is introduced, the results become inaccurate.

A transient finite difference model was developed to evaluate the temperature distribution in the fin and floor cover. Figure 3.1 shows the boundaries of the finite difference model. The finite difference model considers only the layers of floor cover and the fin. The grooved layer (e.g. grooved subfloor or high density insulation) and layers below it are not considered in the model. The omission of those layers reduces the computational cost. Low computational cost is important in BPS. Often times, simulationists are performing analyses of large buildings at relatively small time steps for large period of simulation time. It is not rare for a simulation to run at a time step of 10 minutes for a simulation time of 1 year. This is a very large amount of time steps, therefore if it is possible to reduce the amount of operations in a model without sacrificing accuracy, a large amount of computational cost can be saved. This simplification means that the thermal mass is underestimated in the finite difference model. A method to account for this simplification is discussed later in this section.

Only half of the distance between the tubes is modelled as it is assumed that the temperature distribution in the floor is symmetrical at a point halfway between two tubes, and at the center of each tube. An adiabatic boundary condition is used at those points.

Figure 3.2 shows a diagram of the finite difference model nodes and boundary conditions. The model is discretized in two layers of nodes, representing the fin, and the cover. The finite difference nodes representing the fin layer are located in the centre of the elements, while the nodes representing the floor cover layer are located at 


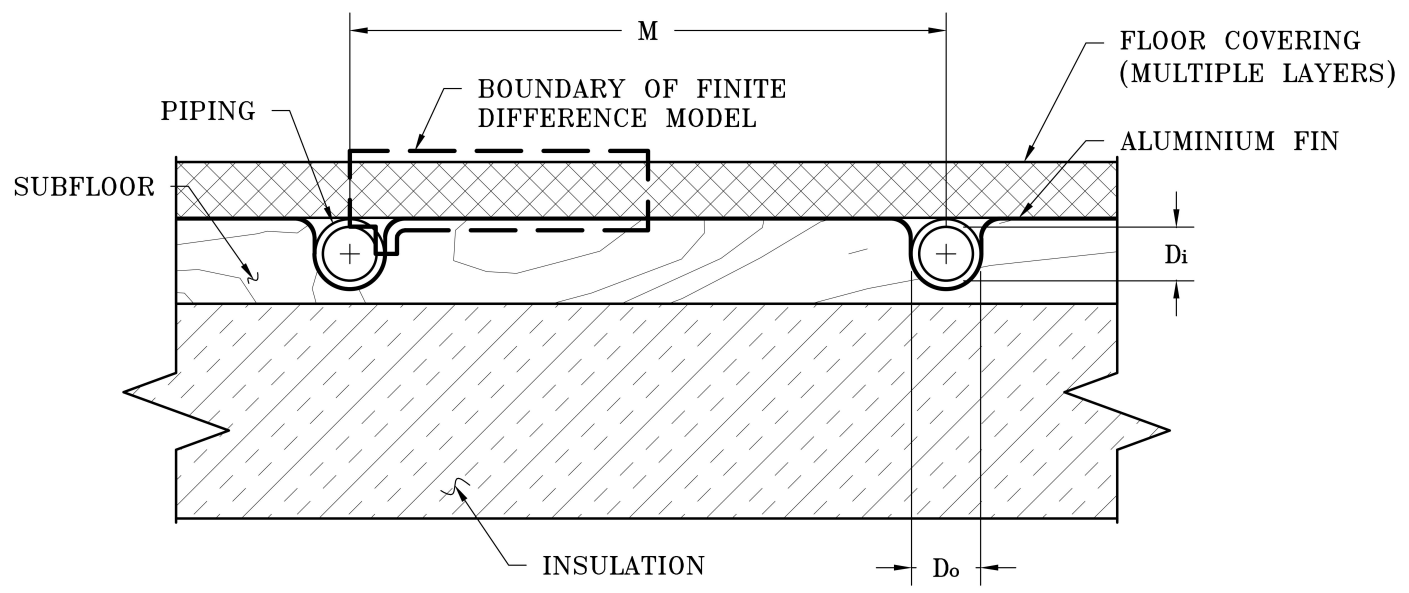

Figure 3.1: Section of a AFTP radiant floor with boundaries of finite difference model

the boundary between the zone air and the floor. The tube is considered to be a heat source or sink (indicated by $Q_{c}$ in the figure). The convective boundary conditions at the top surface are calculated based on the convective heat transfer coefficient calculated by the building domain. Since both the surface node temperatures and the air temperature are known, as well as the convective heat transfer coefficient, the convection term is easily calculated with Equation 3.1.

$$
Q_{\text {conv }}=A_{\text {floor }} \cdot h_{\text {conv }} \cdot\left(T_{\text {cover }}-T_{a}\right)
$$

where $A_{\text {floor }}$ is the floor area, $h_{\text {conv }}$ is the convective heat transfer coefficient, $T_{\text {cover }}$ is the floor surface temperature, and $T_{a}$ is the zone air temperature.

The longwave radiant heat flux and solar heat flux are calculated by the ESP-r building domain and passed to the finite difference model. In theory, the longwave radiant heat flux could be calculated using the calculated 2D model floor cover temperature and other surfaces temperatures and view factors. This would however add complexity to the model and add computational cost so the ESP-r building domain was left to handle that task, using the building domain 1D floor temperature instead.

To reduce the computational cost associated with the model, if there are multiple 


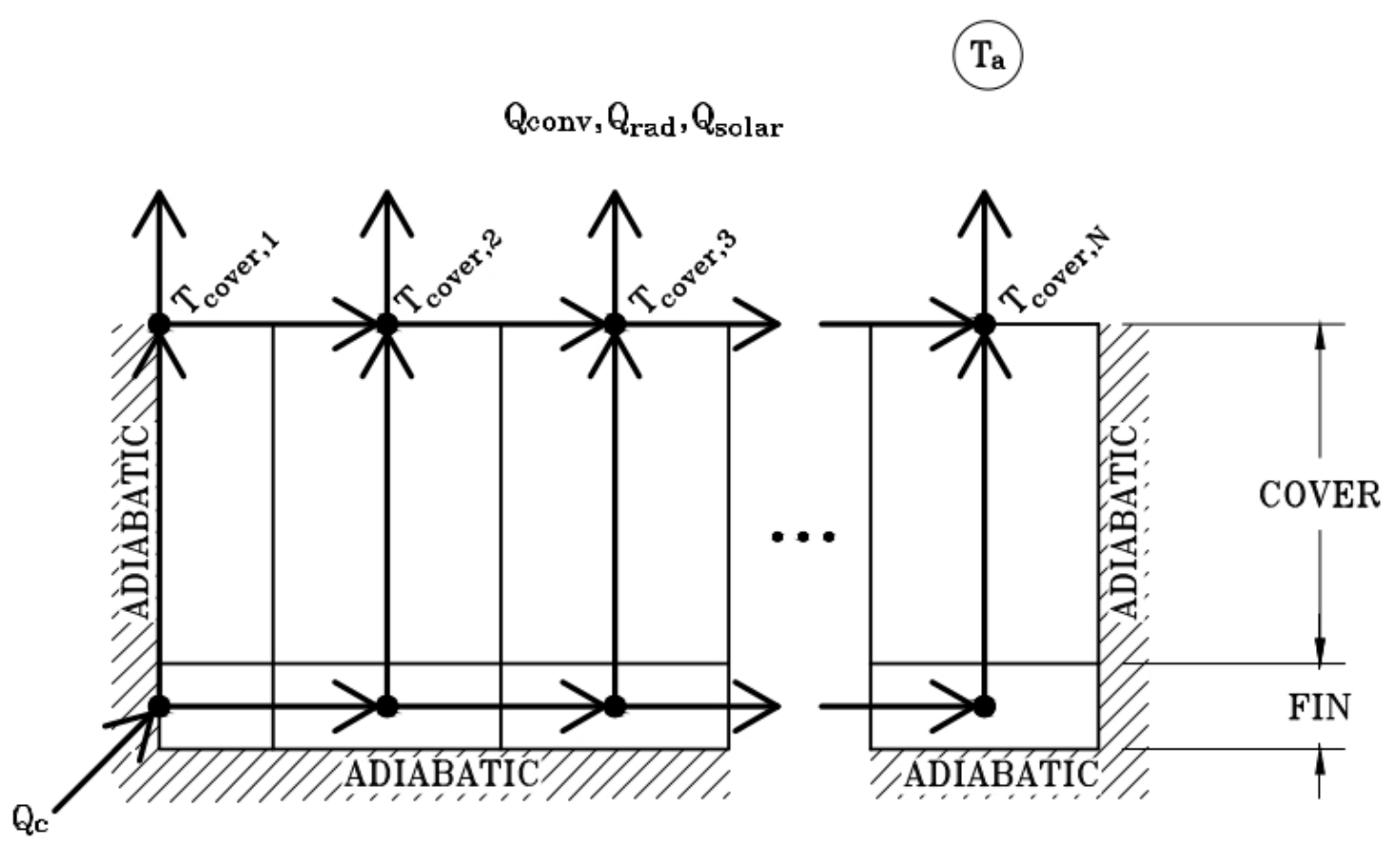

Figure 3.2: Finite difference model nodes and boundary conditions

cover layers, they are represented as a single node in the finite difference model. An equivalent y-direction conductive heat transfer coefficient between fin nodes and cover nodes is calculated using a series thermal circuit, as seen in Equation 3.2. An equivalent $\mathrm{x}$-direction conduction heat transfer coefficient between adjacent cover nodes is calculated using a thickness weighted average conductivity in the same fashion as a parallel thermal circuit. This is seen in Equation 3.3. Equivalent density and specific heat of the cover elements are also calculated as thickness weighted averages shown in Equations 3.4 and 3.5. An equivalent circuit showing side by side fin and floor cover nodes is shown in Figure 3.3.

$$
\begin{gathered}
h_{\text {cond }, y}=\left(\frac{\delta_{\text {fin }}}{2 k_{f i n}}+\sum_{i=1}^{N_{\text {cover }}} \frac{\delta_{i, \text { cover }}}{k_{i, \text { cover }}}\right) \\
h_{\text {cond }, x, \text { cover }}=\frac{\sum_{i=1}^{N_{\text {cover }}} \delta_{i, \text { cover }} k_{i, \text { cover }}}{\Delta x \sum_{i=1}^{N_{\text {cover }}} \delta_{i, \text { cover }}} \\
\bar{\rho}_{\text {cover }}=\frac{\sum_{i=1}^{N_{\text {cover }}} \delta_{i, \text { cover }} \rho_{i, \text { cover }}}{\sum_{i=1}^{N_{\text {cover }}} \delta_{i, \text { cover }}}
\end{gathered}
$$




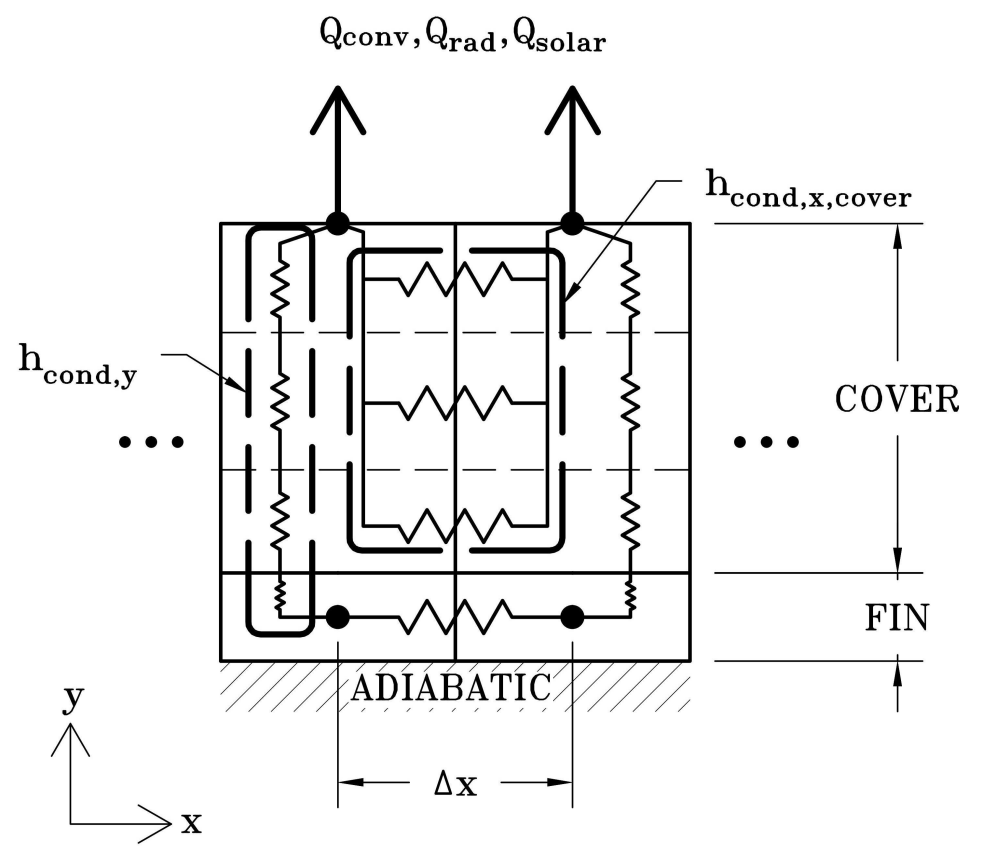

Figure 3.3: Equivalent circuit for conduction heat transfer coefficient calculations between nodes

$$
\bar{C}_{\text {cover }}=\frac{\sum_{i=1}^{N_{\text {cover }}} \delta_{i, \text { cover }} C_{i, \text { cover }}}{\sum_{i=1}^{N_{\text {cover }}} \delta_{i, \text { cover }}}
$$

The floor 2D finite difference model described so far is uncoupled from the building domain that solves the 1D conduction problem in building fabric. As mentioned previously, the omission of the layers below the fin underestimates the thermal mass in the floor. Therefore, to compensate for this modelling artifact, instead of using the $2 \mathrm{D}$ finite difference model temperature distribution as absolute values, the temperature distribution in the fin can be converted to deviations from the average layer temperature. As shown in Figure 3.4, the average fin temperature from the 2D model is calculated and the fin node temperatures are offset so that the 2D average fin temperature matches the ESP-r building domain 1D conduction model fin node temperature. The floor cover surface node temperatures are similarly shifted to match the building domain 1D model surface temperature.

This shifting technique is illustrated in Figure 3.4. The curved solid line is the temperature field from the 2D model for the fin or the cover. The solid horizontal 


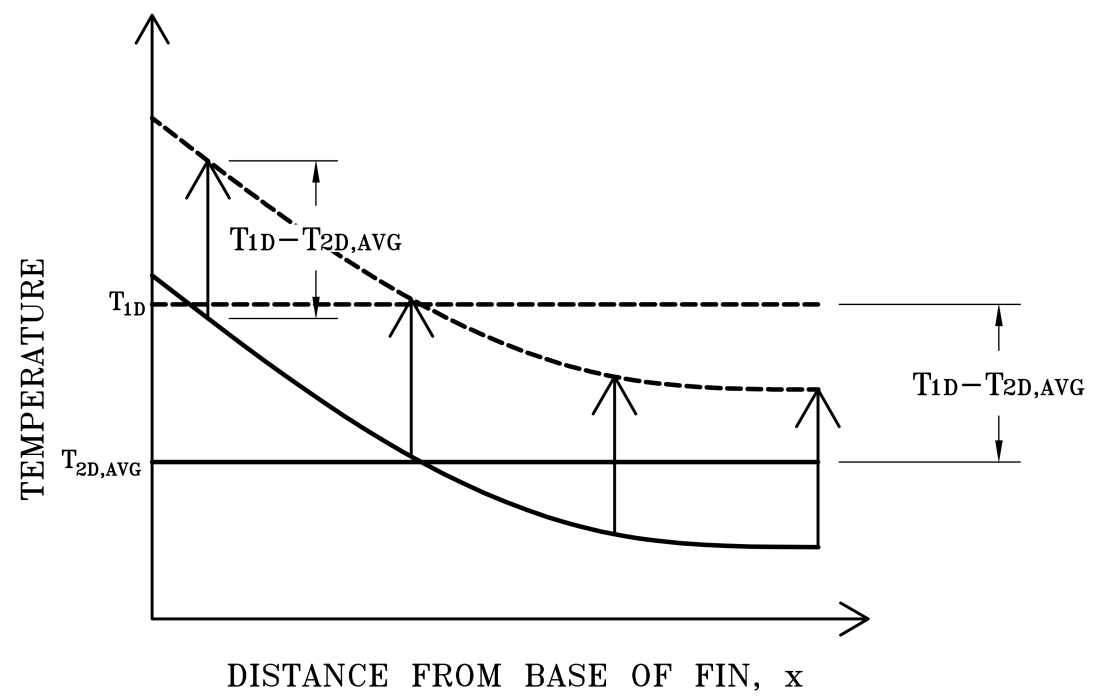

Figure 3.4: Shift of finite element temperature field to match average ESP-r temperature

line is the average for that 2D temperature field. The dashed horizontal line is the 1D ESP-r building domain temperature for that same layer (fin or cover). If average 2D temperature is not equal to the the 1D ESP-r building domain temperature, the entire 2D field is shifted to match the 1D temperature. This small adjustment is performed at every iteration and ensures that the 2D radiant floor model and the 1D building domain remain coupled. This means that the average fin and floor cover temperatures from the 2D model are forced to match the 1D building domain fin and floor cover temperatures. This prevents the two solutions from diverging from each other.

\subsubsection{Tube model}

Laouadi [27] described a detailed thermal model of a tube as part of a slab radiant floor model. The model is based on an energy balance. Figure 3.5 shows an energy balance on a discrete 1D element of a tube in a floor. At each iteration, the inputs to the tube model are the water inlet temperature and flow rate. The outputs are the heat transfer rate to the floor and the outlet temperature. For sake of brevity, only the resulting equations are included here and the interested reader is directed to Appendix B for a more detailed discussion of the model, or to the work by Laouadi 


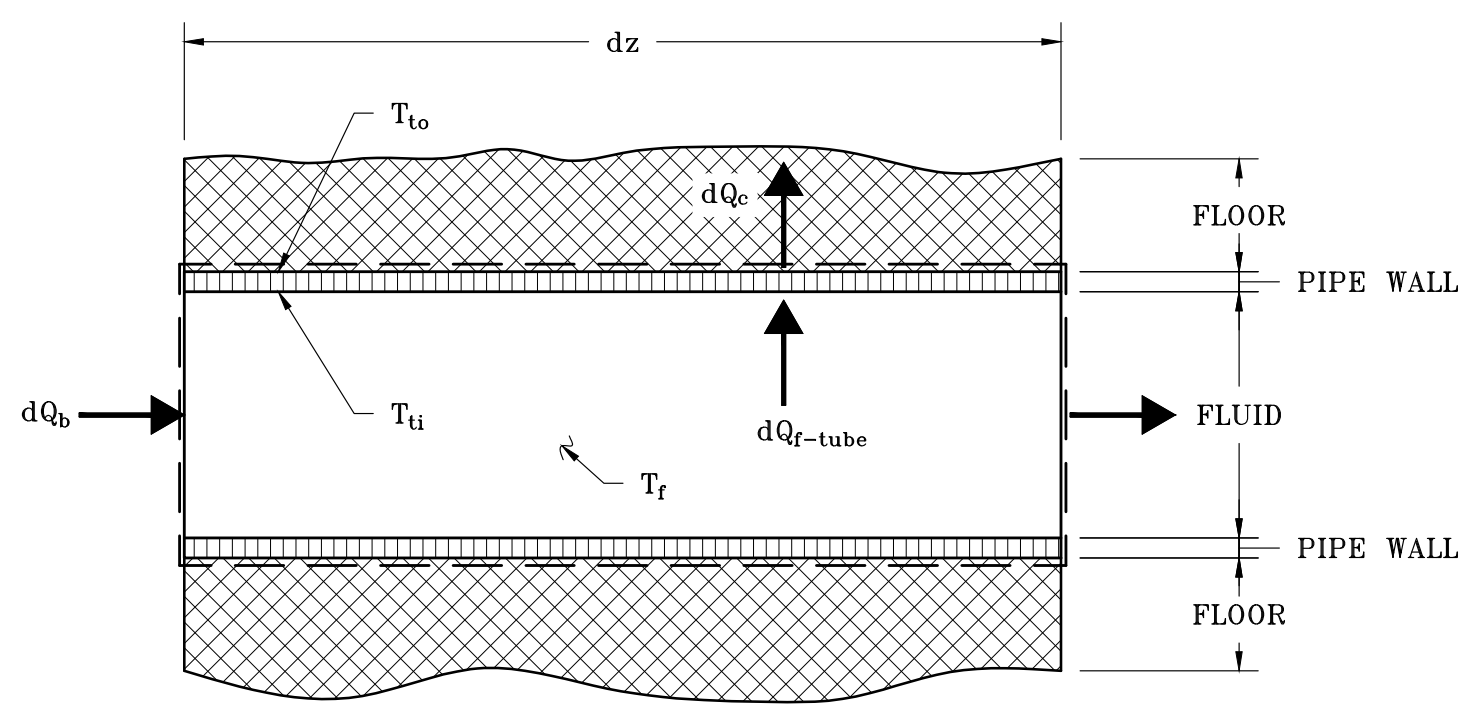

Figure 3.5: Energy balance on tube. Adapted (with permission) from Laouadi [27]

for a complete discussion of the pipe model.

Equation 3.6 shows the resulting discretized tube conduction model for the fully implicit method. This equation can be rearranged to solve for $\bar{\Theta}$.

$$
\left(\beta_{1}+\beta_{2} \Delta t\right) \bar{\Theta}-\beta_{1} \bar{\Theta}^{\text {old }}-\Delta t \gamma=0
$$

where $\beta_{1}, \beta_{2}$, and $\gamma$ are defined in Appendix $\mathrm{B}, \Delta t$ is the time step, the superscript old denotes the previous time step. $\bar{\Theta}$ is the average temperature difference between the fluid temperature and the tube temperature (Equation 3.7).

$$
\bar{\Theta}=\frac{1}{L} \int_{0}^{L}\left(T_{f}-T_{t o}\right) d z
$$

where $L$ is the length of the tube in a loop, $T_{f}$ is the fluid temperature, $T_{t o}$ is the tube temperature.

Equation 3.8 is used to calculate the heat transferred to the floor.

$$
Q_{c}=U P L\left[\bar{\Theta}-R_{c o n v, f-t u b e}^{\prime}(\rho C A)_{\text {tube }} \frac{d T_{t o}}{d t}\right]
$$


$\frac{d T_{t o}}{d t}$ is discretized with:

$$
\frac{d T_{t o}}{d t}=\frac{T_{t o}-T_{t o}^{o l d}}{\Delta t}
$$

\subsubsection{Implementation}

Solving the tube model requires knowledge of $T_{t o}$ which is not initially known. $T_{t o}$ is the tube outside wall temperature and can be approximated to be equal to the temperature of the fin node at which the heat is injected in the finite difference model. Equation 3.8 and the finite difference model described in the previous section then require iteration to solve for the heat flux delivered to the floor at every time step.

Figure 3.6 shows a simplified flow chart of the model and its interaction with the ESP-r building domain. At every time step, the ESP-r building domain calculates the 1D temperature distribution in the floor, using $Q_{c}$ calculated at the previous time step. $Q_{c}$ is imposed on the $1 \mathrm{D}$ model as a heat generation term in the layer corresponding to the aluminium fin. The plant domain is then called, and $Q_{c}$ is calculated based on previous time step or iteration values. The finite difference model is then solved using $Q_{c}$ and boundary conditions at the floor surface (from the building domain). Then the temperature distribution is shifted up or down to match the 1D node temperatures from the ESP-r building domain and $\bar{\Theta}$ is calculated. A convergence check is performed, and if the model has converged, it moves on to the next time step. If not, $\bar{\Theta}$ is used to recalculate $Q_{c}$.

\subsection{ESP-r model comparison with finite element analysis model}

The new model described in Section 3.2, which was implemented into ESP-r was compared with a solution from a 2D transient FEA simulation using the LISA FEA package [50]. The objective of these tests was to isolate the modelling of conduction heat transfer in the floor. As such, any prediction discrepancies could be attributed to the new model described in Section 3.2. To accomplish this, the test cases were designed to impose boundary conditions at the inner tube and at the interface between 


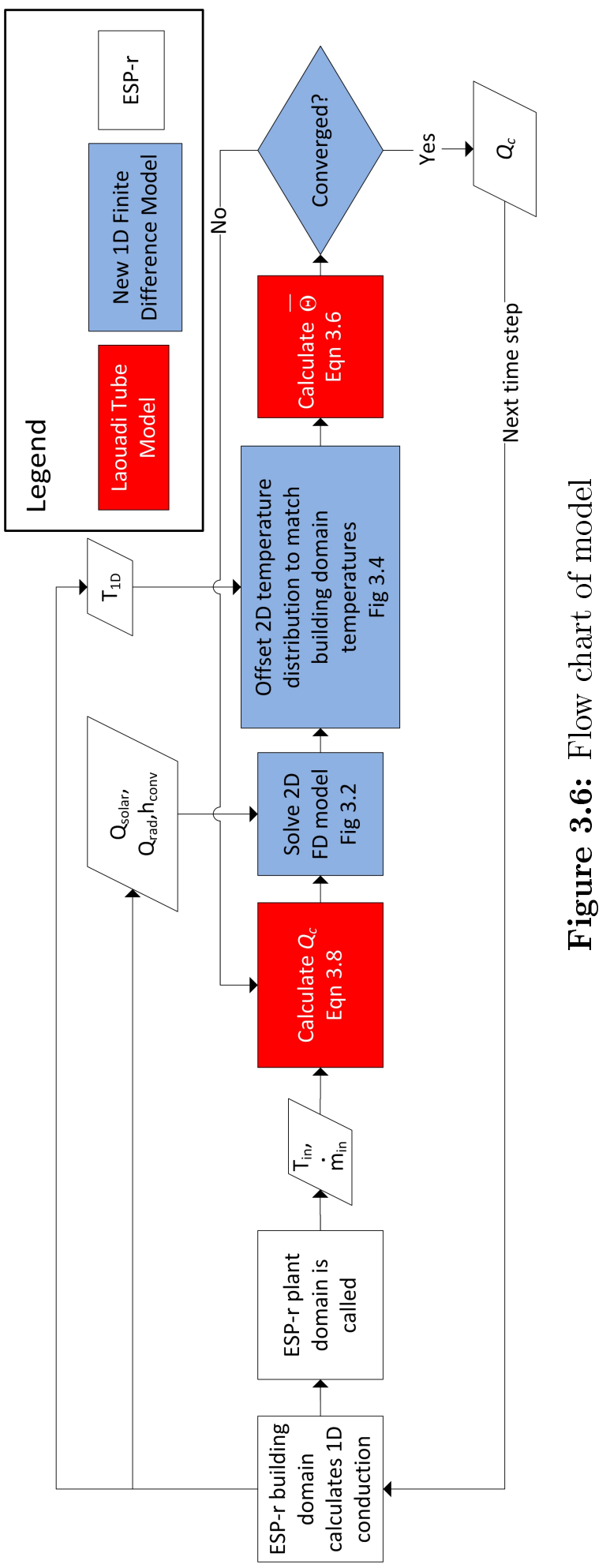


the floor surface and the zone in such a manner that the FEA model and the ESP$\mathrm{r}$ model could be made equivalent. Note that in the field of building performance simulation, a zone is usually defined as a well-mixed space represented with uniform air temperature.

\subsubsection{Definition of test case}

The test cases for the testing of the AFTP floors were similar to some of the test cases in Chapter 2, but for AFTP constructions. Three floor construction test cases were created. The floor construction discussed in this chapter included construction layers approximately equivalent to a product sold by Roth [60] and that was installed in the Urbandale Centre for Home Energy Research on the Carleton University campus. The other two floor construction test cases included construction layers that were approximately equivalent to a product sold by Warmboard [61], and a discussion of these results can be seen in Appendix A. Test cases were produced with the Warmboard product because it was a candidate product for installation in the Urbandale Centre for Home Energy Research.

The Urbandale Centre for Home Energy Research (CHEeR) is a research facility built on the Carleton University campus. Radiant floors were installed in the CHEeR facility, and approximate construction of the floors was used for the test case. Experimental testing of the radiant floor is reported later in this chapter.

The distance between tubes (centre of tube to centre of tube) was set to $0.1524 \mathrm{~m}$. A zone of $3 \mathrm{~m}$ by $5 \mathrm{~m}$ by $2.7 \mathrm{~m}$ high was used. For both cases, a single circuit of tube in a serpentine layout was used. Given the above, the total length of the tube was $49.21 \mathrm{~m}$. The ESP-r model calculates this length based on geometry. For a single loop serpentine tube configuration in a rectangular floor, shown in Figure 2.4, the length of tubing per loop can be calculated with Equation 2.11.

The tubes were made of cross-linked polyethylene (PEX). The thermal conductivity of PEX was taken to be $0.38 \mathrm{~W} \mathrm{~m}^{-1} \mathrm{~K}^{-1}$, while the density and specific heat were taken to be $938 \mathrm{~kg} \mathrm{~m}^{-3}$ and $550 \mathrm{~J} \mathrm{~kg}^{-1} \mathrm{~K}^{-1}$ respectively. The tube inner and outer diameters were taken to be $0.0127 \mathrm{~m}$ and $0.016 \mathrm{~m}$ respectively. Table 3.1 summarizes the construction of the floor.

No internal or solar gains were modelled in the zone in order to keep the test cases simple. This was to ensure that the ESP-r and FEA models could be made 
Table 3.1: Construction of floor

\begin{tabular}{|c|c|c|c|c|}
\hline Material & $\begin{array}{c}\text { Thickness } \\
\text { (m) }\end{array}$ & $\begin{array}{c}k \\
\left(\mathrm{~W} \mathrm{~m}^{-1} \mathrm{~K}^{-1}\right)\end{array}$ & $\begin{array}{c}\rho \\
\left(\mathrm{kg} \mathrm{m}^{-3}\right)\end{array}$ & $\begin{array}{c}C \\
\left(\mathrm{~J} \mathrm{~kg}^{-1} \mathrm{~K}^{-1}\right)\end{array}$ \\
\hline Subfloor & 0.01905 & 0.100 & 450 & 1880 \\
\hline High Density Insulation & 0.02489 & 0.029 & 45 & 1450 \\
\hline Aluminium Fin ${ }^{\mathrm{a}}$ & 0.00051 & 234.0 & 2700 & 900 \\
\hline Mortar & 0.0032 & 0.72 & 1860 & 780 \\
\hline Cement Backing Board & 0.0064 & 0.277 & 1461 & 840 \\
\hline Mortar & 0.0032 & 0.72 & 1860 & 780 \\
\hline Tile & 0.008 & 1.1 & 2100 & 837 \\
\hline
\end{tabular}

${ }^{a}$ Tubes located in grooves in Aluminium layer.

equivalent. The convective heat transfer coefficient between the floor top surface and the air was fixed at a constant value of $11 \mathrm{~W} \mathrm{~m}^{-2} \mathrm{~K}^{-1}$. While it would not be realistic to have a constant convection coefficient, this is done to make the ESP-r and FEA models equivalent. The zone air temperatures above the floor was fixed at a constant $20{ }^{\circ} \mathrm{C}$. There was no zone below the floor. Instead, a constant boundary condition was prescribed at $11 \mathrm{~W} \mathrm{~m}^{-2} \mathrm{~K}^{-1}$ and $20^{\circ} \mathrm{C}$. Radiation heat transfer between the internal surfaces forming the zone was eliminated by setting the emissivity of all surfaces to zero. The initial floor construction temperature was set to $20^{\circ} \mathrm{C}$.

The inner tube temperature was made to vary in time using step functions, as illustrated in Figure 3.7.

\subsubsection{Finite element analysis model}

A 2D transient conduction FEA simulation was performed for each floor construction using the LISA FEA package [50]. These predictions were used as a reference solution. Although not exact, the FEA solution can help understand whether the simplifications and assumptions made in the ESP-r model are appropriate.

The FEA takes advantage of symmetry to limit the modelling of the radiant floor to only half of the distance between tubes. Figure 3.8 shows the mesh and boundary conditions. The mesh contained 5465 nodes. Increasing the node count to 


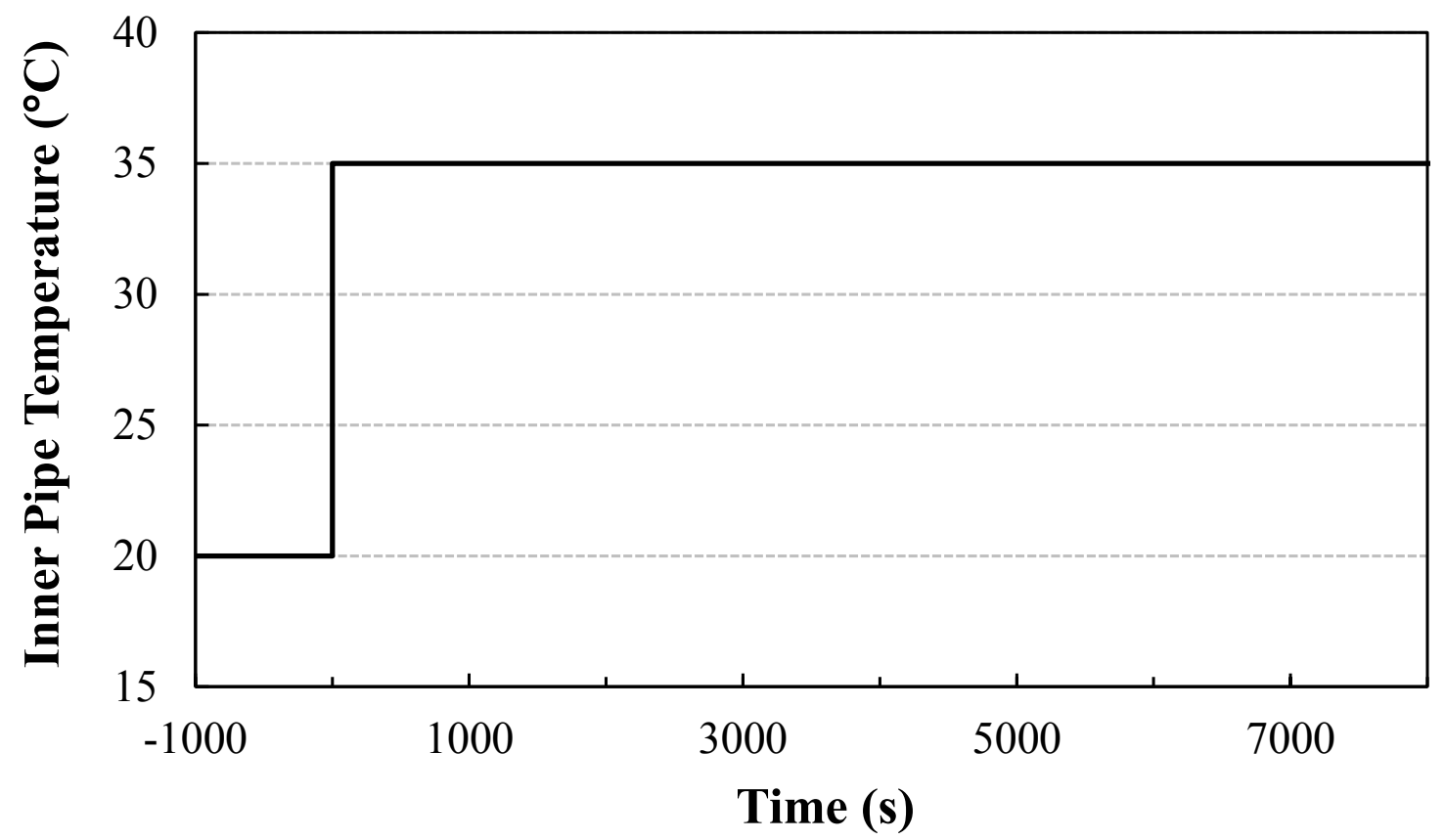

Figure 3.7: Step input tube inner temperature profile

21535 changed the steady state heat transfer by $0.03 \%$. A single step input transient simulation as described in Section 3.3.1 was also run with both meshes. Increasing the node count to 21535 nodes (from 5465 nodes) changed the average heat transfer rate by $0.05 \%$.

The time-step size used for the transient FEA simulation was 2 minutes. Halving the time-step size changed the average heat transfer rate by $0.82 \%$.

\subsection{Results}

The heat flux from the top floor surface to the surroundings as calculated by the finite element model and the ESP-r model are shown in Figure 3.9. The model was run to $99 \%$ of steady state value as calculated by the finite element model. This gave 39 time steps, or a total time of 4680 seconds. The root mean square deviation (RMSD) of the transient results was $1.68 \mathrm{~W} \mathrm{~m}^{-2}$. This result implies that the ESP-r model agrees well with the finite element model.

Additionally, the ESP-r model outputs the maximum and minimum floor surface 


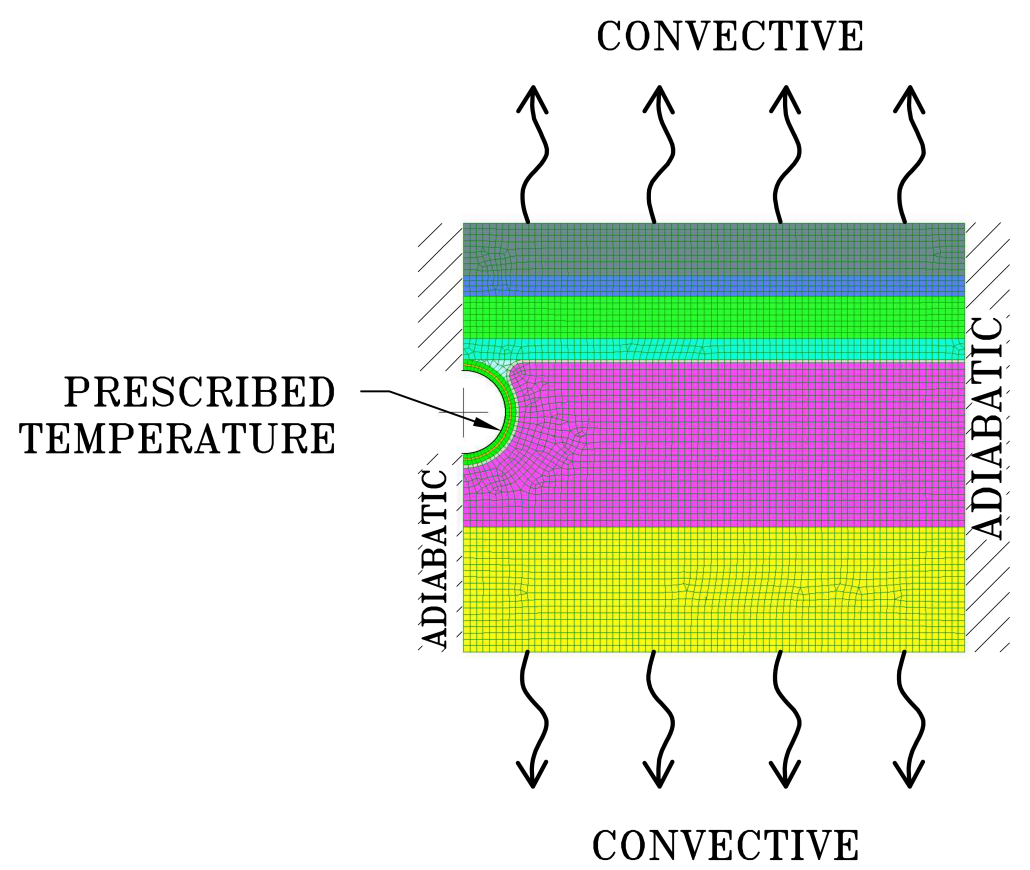

Figure 3.8: FEA mesh and boundary conditions AFTP floor

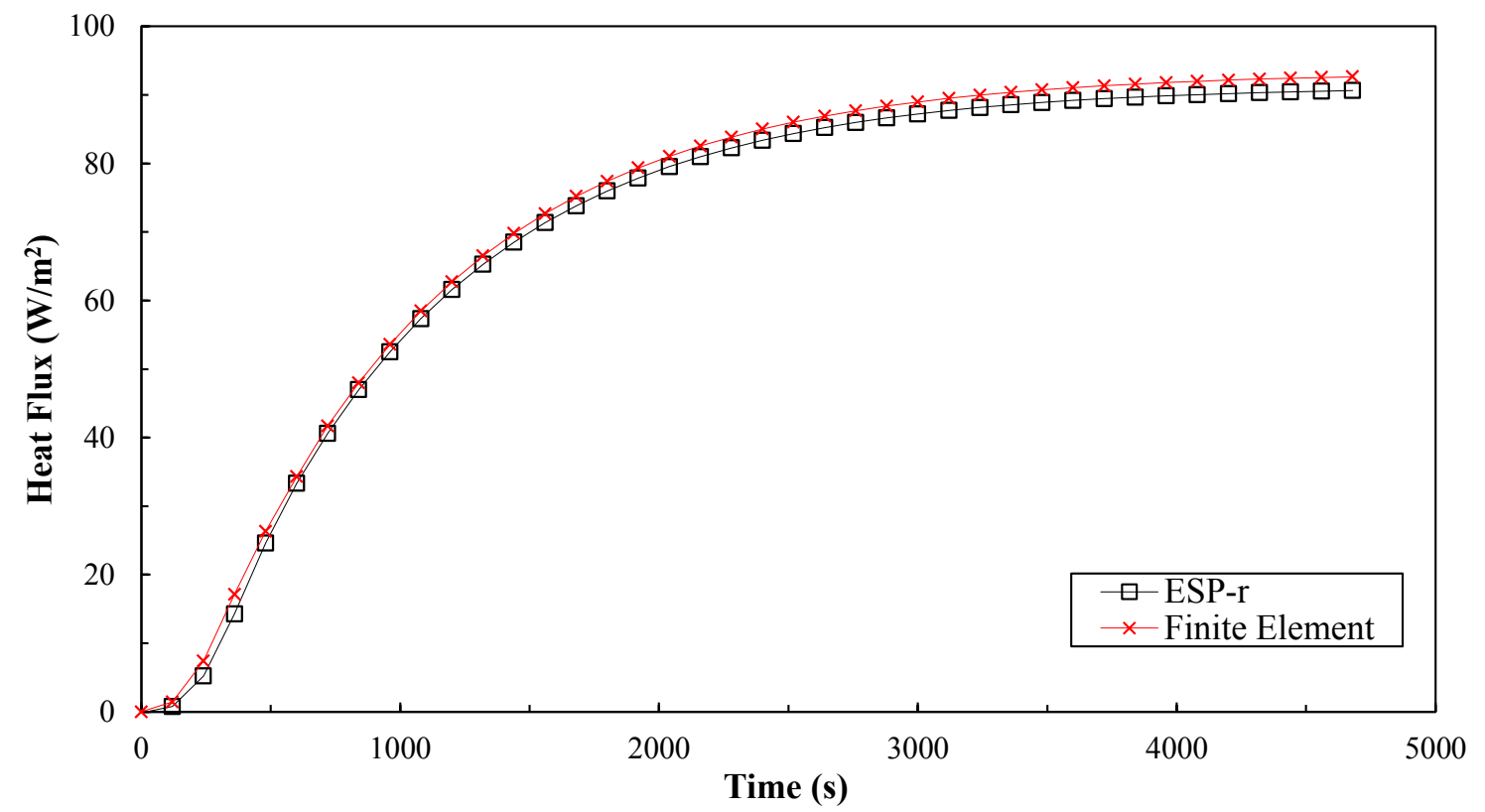

Figure 3.9: Comparison of ESP-r model with finite element model for surface heat flux 


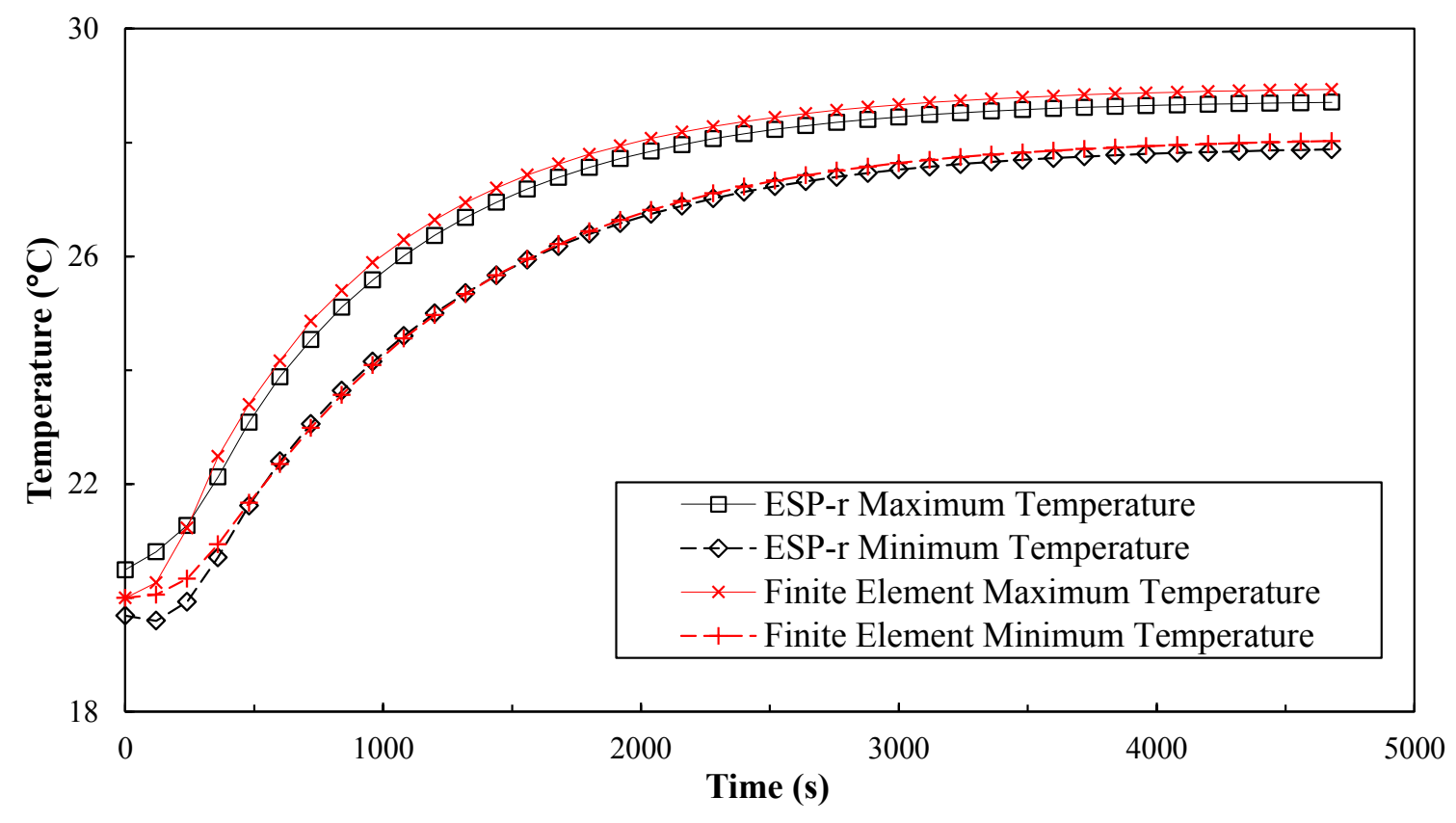

Figure 3.10: Comparison of ESP-r model with finite element model

temperatures. These temperatures are the temperatures directly above the tubes and halfway between the tubes respectively when in heating mode. Figure 3.10 shows the results of the ESP-r model predictions vs the finite element model. There is a problem with the solution when a rapid change in heat injection is applied, such as a step input, when the ESP-r model attempts to predict the maximum and minimum surface temperatures. This is caused by the fact that the ESP-r building model is not solved concurrently with the plant model. First, the building model (e.g. 1D floor conduction) is solved based on various boundary conditions, including heat injection calculated by the radiant floor model (which is part of the plant) at the previous time step. Then, the plant is solved. When a sudden large heat injection occurs in the radiant floor model, such as a large step input, the 2D finite difference model in the radiant floor model can account for this right away. However, the building model has still not been updated and the building model still does not see the heat input as a boundary condition. Therefore at the correction step of the 2D finite difference model, the values achieved for the maximum and minimum temperatures are non-physical. The problem lasts for approximately three time steps before resolving itself.

The steady state result of the ESP-r model was found by allowing the model to run for $427200 \mathrm{~s}$ (modelled time). The finite element solution gave a top surface steady 
Table 3.2: RMSD for various parameters perturbation

\begin{tabular}{lcc}
\hline Parameter & $\begin{array}{c}\text { RMSD for parameter } \\
+10 \%\left(\mathrm{~W} \mathrm{~m}^{-2}\right)\end{array}$ & $\begin{array}{c}\text { RMSD for parameter } \\
-10 \%\left(\mathrm{~W} \mathrm{~m}^{-2}\right)\end{array}$ \\
\hline$k_{\text {cover }}$ & 0.30 & 0.61 \\
$(\rho C)_{\text {cover }}$ & 1.19 & 1.12 \\
$k_{\text {tube }}$ & 0.98 & 1.20 \\
$k_{\text {fin }}$ & 1.30 & 1.42 \\
$t_{\text {mortar,bottom }}$ & 0.71 & 0.56 \\
$h_{\text {surface,top }}$ & 4.74 & 5.10 \\
\hline
\end{tabular}

state heat flux of $93.49 \mathrm{~W} \mathrm{~m}^{-2}$ while the ESP-r model gave a top surface steady state heat flux of $91.36 \mathrm{~W} \mathrm{~m}^{-2}$. This is a difference of $2.3 \%$.

\subsubsection{Parametric analysis}

A parametric analysis was performed with the ESP-r model. The parameters investigated were: cover conductivity, cover thermal mass, tube conductivity, fin conductivity, bottom mortar layer thickness, and surface convective heat transfer coefficient. Each parameter was varied by $+10 \%$ and $-10 \%$ and a RMSD was calculated for all data points between the base case and the varied parameter case. Simulations were run in ESP-r with the same conditions as described previously. Table 3.2 shows the results.

Considering that the RMSD between the FEA model and the ESP-r model was $1.68 \mathrm{~W} \mathrm{~m}^{-2}$ for the transient simulation, it can be seen that varying some parameters by $10 \%$ would yield results that diverge approximately as much as the error of the model. Typically, in BPS, the various construction parameters, and heat transfer coefficients are not known with a high degree of certainty. This analysis shows that the difference between the FEA results and the ESP-r results is similar or smaller to the uncertainty one would get from the input parameters or heat transfer coefficient. 
Table 3.3: Construction of floor

\begin{tabular}{|c|c|}
\hline Material & Thickness (m) \\
\hline Gypsum Board & 0.0127 \\
\hline Air space & 0.3048 \\
\hline Plywood Subfloor & 0.0159 \\
\hline Roth Panel $^{\mathrm{a}}$ & 0.0254 \\
\hline Mortar & 0.0032 \\
\hline Cement Backing Board & 0.0064 \\
\hline Mortar & 0.0032 \\
\hline Tile & 0.009 \\
\hline
\end{tabular}

${ }^{a}$ Roth panel is made of High Density Insulation overlaid with an aluminium sheet $(0.0005 \mathrm{~m}$ thick $)$. Tubes located in grooves in Aluminium sheet.

\subsection{Experimental validation}

The inter-model comparison can only validate certain aspects of the model. For example, the finite element model was not equipped to deal with the flow rate and longwave radiation, so idealized conditions were simulated. In order to further verify the ESP-r model under real conditions, an experiment was conducted in the Urbandale CHEeR. The objective of the experiment was to be able to predict the experimental conditions (mainly water heat transfer rate and top surface heat flux) in ESP-r given a set of inputs (including supply temperature and flow rate). The middle bedroom of the second floor was instrumented. This room was used because of its small size and the simple geometry of the serpentine layer in the floor, making it simpler to instrument and analyze.

\subsubsection{Experimental apparatus}

The floor construction is shown in Table 3.3. The PEX tubes have a spacing of $0.1524 \mathrm{~m}$.

Twelve thermocouples were installed on the floor surface. These were organized 


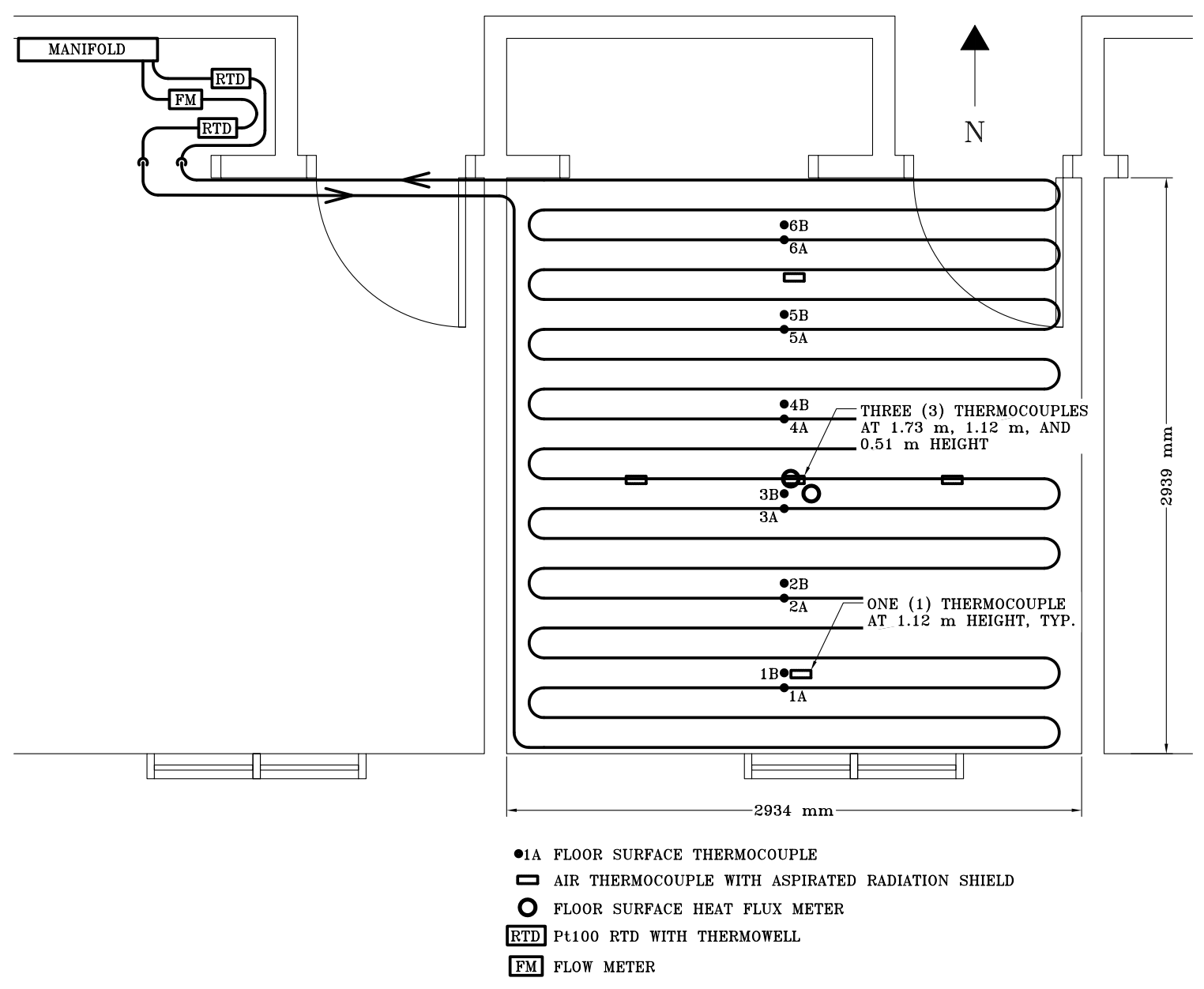

Figure 3.11: Plan view of instrumented room with instruments locations (floor plan adapted from drawings by Urbandale Construction)

in pairs of two; one above the tubes and one between the tubes. Seven thermocouples with aspirated radiation shields (as per design found in [62]) were installed at various locations in the space to get an accurate measurement of average room air temperature. Two Hukseflux HFP01 heat flux sensors were installed on the floor surface, near the centre of the room; one above the tube and one between the tubes. Figure 3.11 shows the location of the instruments described above.

After gathering the data, it was found that floor surface thermocouple $1 \mathrm{~A}$ was giving erroneous data. This data was therefore ignored. The average temperature of the floor can be assumed to be near the center of the floor. To ensure that the average of all of the floor thermocouples was giving an approximation for the average 
floor temperature, the average location of the thermocouple should therefore be as close as possible to the center of the floor. In order to approximate the average floor temperature accurately, the floor surface thermocouple $6 \mathrm{~B}$ was therefore also ignored to "balance" the missing thermocouple. A simple test was later run (after fixing the broken thermocouple) and it was found that the average of all twelve thermocouples (1A through $6 \mathrm{~B}$ ) agreed with the average of the ten closest to the center (1B through $6 \mathrm{~A})$ within less than $0.1{ }^{\circ} \mathrm{C}$.

Two thermocouples and two heat flux sensors were installed under the subfloor, approximately in the center of the floor. One set of thermocouples and heat flux sensor was located between tubes and the other directly below the tube. The underside of the gypsum board (the bottommost layer of the floor construction; located in the room below), was also equiped with a single thermocouple and heat flux meter. The installation of these sensors occurred from underneath the radiant floor construction.

Additionally, thermocouples and Hukseflux HFP01 heat flux sensors were installed on the North, East, West, and South walls, as well as the window and the ceiling. Two thermocouples and heat flux sensors were installed on the South wall and ceiling, one in line with the insulation cavity and the other in line with a wood stud/joist to account for thermal bridging effects. Thermocouples and heat flux sensors were also installed on the other side of the North, East, and West interior walls. A thermocouple was installed in the attic to measure the attic temperature. Figure 3.12 shows a picture of the room with the instruments described above.

The uncertainty for the measurements was calculated using the method defined by Moffat [63]. The bias error $B$ of a single measurement $X$ with multiple sources of errors $j$ is found using Equation 3.10.

$$
B_{X}=\left\{\sum_{j=1}^{n}\left(B_{j}^{2}\right)\right\}^{1 / 2}
$$

The spool with which thermocouples were made was calibrated by Geoff Johnson [64]. The bias error for thermocouples considering all sources was $0.47{ }^{\circ} \mathrm{C}$. A National Instruments cFP-TC-125 module was used to measure the $\mathrm{mV}$ signal from the thermocouples and heat flux sensors. The sources of bias error for the thermocouple calibration are listed in Table 3.4. Table 3.5 shows the total calibration and $\mathrm{read} /$ cold junction compensation (CJC) bias. The bias error of the heat flux sensors 


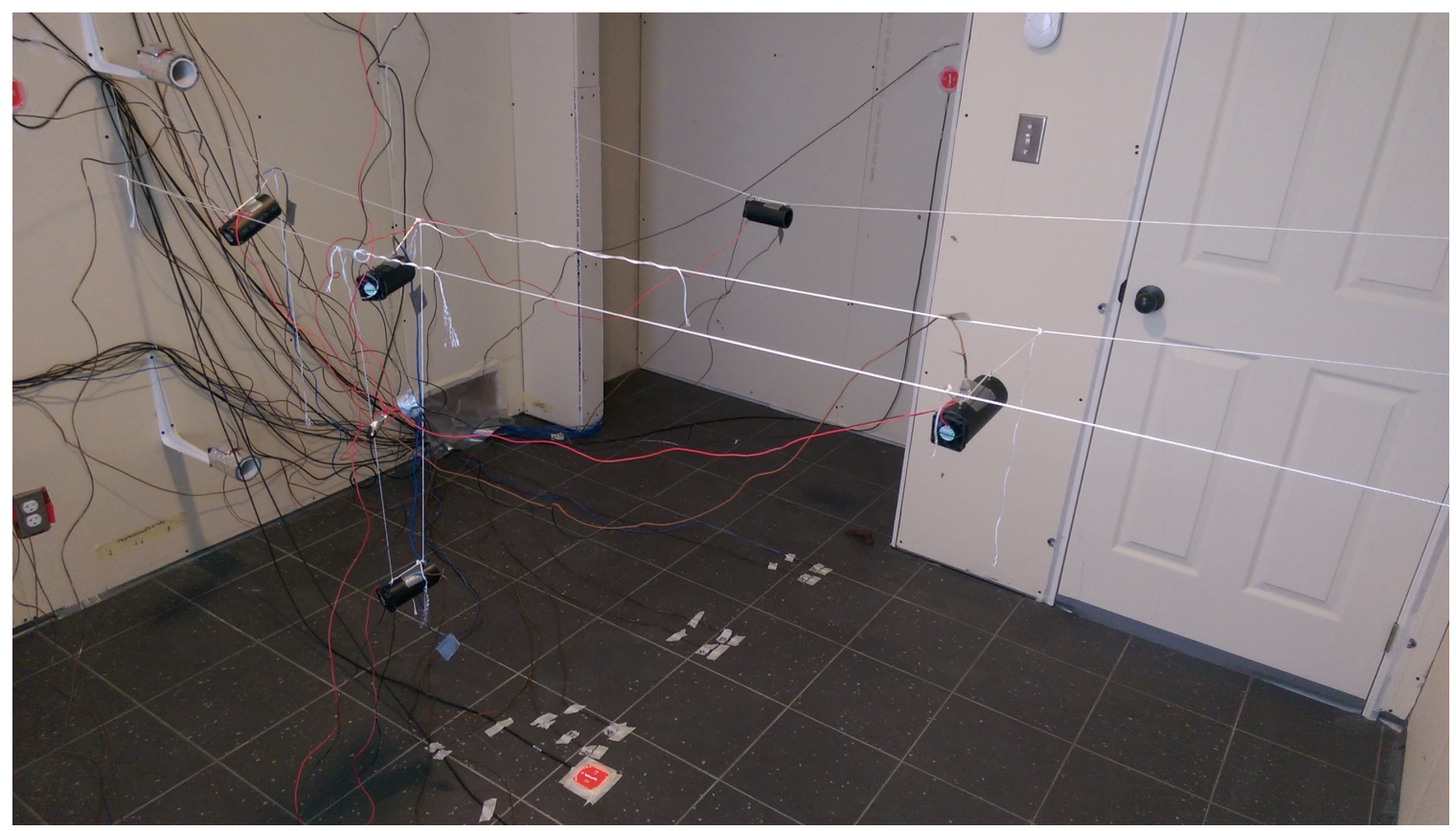

Figure 3.12: Picture of instrumented room with aspirated radiation shields, thermocouples, and flux meters

is $3 \%$ while the cFP-TC-125 module adds a marginal amount of bias to this in most cases.

The heat flux meters consist of calibrated thermopiles within a thin thermally conductive puck of known thermal conductivity. The heat flux across the sensor creates a small temperature difference across the thermopile, which then creates a $\mathrm{mV}$ signal proportional to the heat flux. The manufacturer has calibrated each individual heat flux sensor and provides a sensitivity coefficient for each of them.

Water inlet and outlet temperatures were measured with platinum resistance thermometers (Pt100) in thermowells. Previous work by Geoffrey Johnson, a member of

Table 3.4: Thermocouple calibration bias error sources

\begin{tabular}{lccccc}
\hline $\begin{array}{l}\text { Bias } \\
\text { Sources }\end{array}$ & Error & $\begin{array}{c}\text { Regression } \\
\text { Residual }\end{array}$ & $\begin{array}{c}\text { Cold } \\
\text { Junction } \\
\text { Drift }\end{array}$ & $\begin{array}{c}\text { Calibration } \\
\text { Reference } \\
\text { RTD }\end{array}$ & $\begin{array}{c}\text { Read } \\
\text { Error }\end{array}$ \\
\hline $\begin{array}{l}\text { Bias Error Val- } \\
\text { ues }\left({ }^{\circ} \mathrm{C}\right)\end{array}$ & 0.084 & 0.15 & 0.03 & 0.2 \\
\hline
\end{tabular}


Table 3.5: Thermocouple bias error sources

\begin{tabular}{lcc}
\hline Bias Error Sources & Calibration & $\begin{array}{c}\text { Experiment } \\
\text { Read and CJC }\end{array}$ \\
\hline Bias Error Values $\left({ }^{\circ} \mathrm{C}\right)$ & 0.27 & 0.38 \\
\hline
\end{tabular}

Table 3.6: Pt100 bias error sources

\begin{tabular}{lccc}
\hline Bias Error Sources & Sensor & $\begin{array}{c}\text { Resistance } \\
\text { Measurement }\end{array}$ & Calibration Fit \\
\hline Bias Error Values $\left({ }^{\circ} \mathrm{C}\right)$ & 0.02 & 0.02 & 0.008 \\
\hline
\end{tabular}

the SBES lab, had shown that the thermowells had no significant impact on steady state measurements with the Pt100s. Further investigation showed that the time constant of the themowell and Pt100 was approximately $23 \mathrm{~s}$. Since this is much smaller than the time constant of the floor and the minimum simulation time step, it should not affect the results. A Fluke 1524 reference thermometer was used to read the resistance from the Pt100s. The total bias error considering all sources for the Pt100s was $0.03{ }^{\circ} \mathrm{C}$ each. The sources of bias error for the Pt100s are shown in Table 3.6.

A Brooks BM02 positive displacement flow meter was used to measure flow rate. A National Instruments cFP-CTR-502 data acquisition module was used to count pulses coming from the flow meter. The bias error of the flow meter was $1 \%$ of measured flow rate. If it is assumed that one pulse is missed or one too many pulses is counted, at the end or beginning of the measurement period, this would yield a bias error of $0.00025 \mathrm{~L} \mathrm{~s}^{-1}$ or $1 \%$ of each individual measurement at every 10 seconds (experiment sampling rate). Figure 3.13 shows a picture of the second floor manifold for the radiant floor system, as well as the flow meter and Pt100s inside thermowells. The manifold, flow meter, and Pt100s are located approximately $2 \mathrm{~m}$ from the room in which the testing is taking place. Some heat will be transfered from the water to the floor in the area in the room adjacent to the test room, however this will be minimal as the section of tubes running in that area were installed without the heat transfer promoting aluminium fins. 


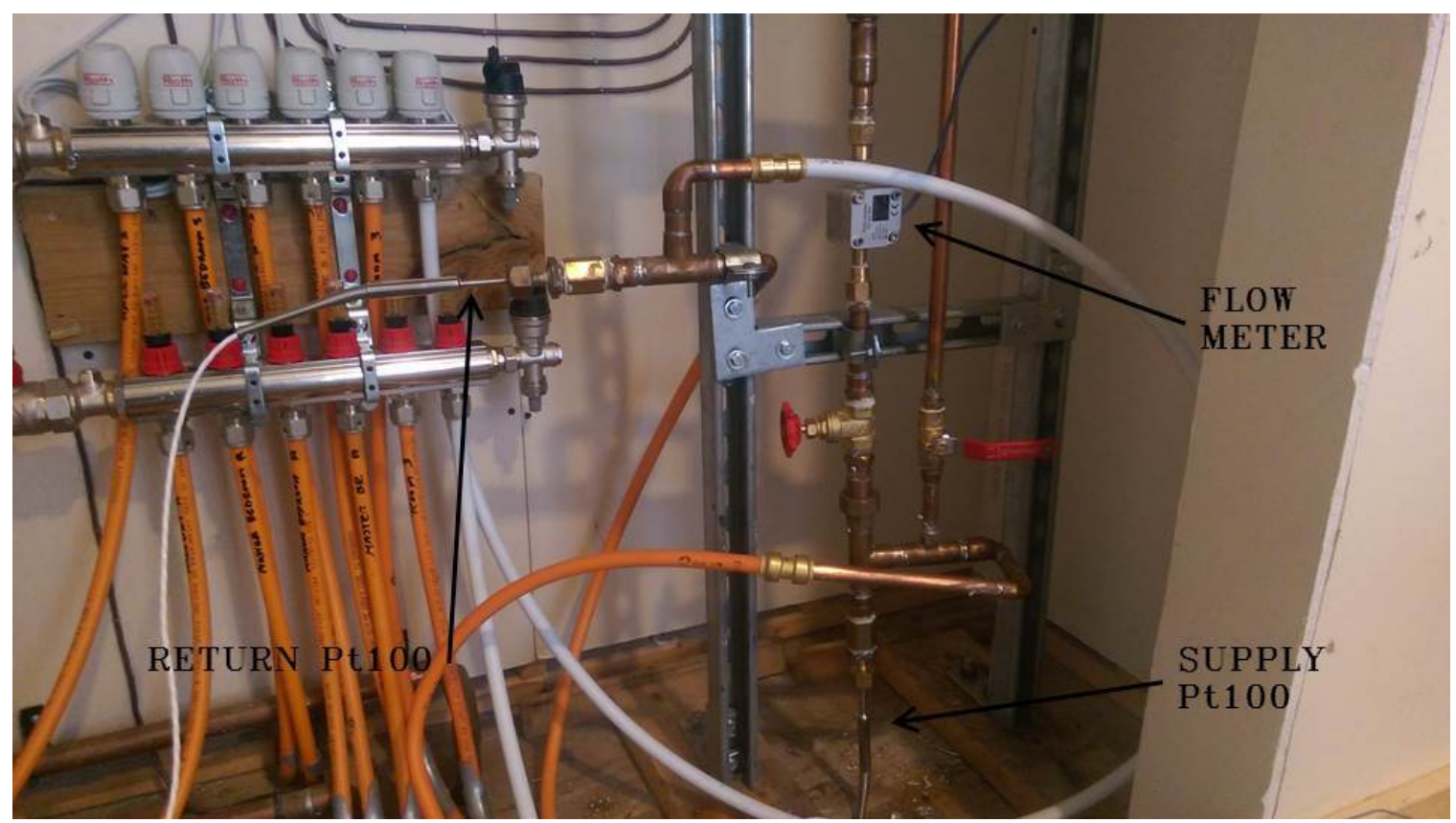

Figure 3.13: Picture of radiant floor manifolds with temporary flow meter and Pt100s

The heat transfer rate between the water and the floor was calculated with Equation 3.11.

$$
Q_{\text {water }}=\dot{V} \rho C_{p}\left(T_{\text {in }}-T_{\text {out }}\right)
$$

The density and specific heat vary with temperature. Data from the CRC Handbook of Chemistry and Physics [65] was used to fit sixth order polynomials for both properties. The resulting residuals were negligible. The CRC Handbook of Chemistry and Physics quotes uncertainties of $0.001 \%$ and $0.1 \%$ for density and specific heat at $1 \mathrm{~atm}$. The bias error from the calculation of the heat transfer rate between the water and the floor was then evaluated by propagating the bias errors of the Pt100s and the flow meter with Equation 3.12 [63].

$$
B_{I}=\left\{\sum_{i=1}^{n}\left(\frac{\partial I}{\partial X_{i}} B_{i}\right)^{2}\right\}^{1 / 2}
$$

where $X_{i}$ is measured data used to calculate the derived value $I$ (in this case heat transfer rate), with $I=f\left(X_{i}\right)$. 


\subsubsection{Experimental tests}

Tests were performed during the nights of May 14th to May 15th (test A), 2016 and May 15th to May 16th (test B), 2016. Night time tests were done in order to eliminate all solar gains. The elimination of solar gains in the experiment simplifies the simulation and removes uncertainty from modelling of the solar radiation when comparing the AFTP radiant floor model with the experimental results. Although the radiant floors were kept active after sunrise, those data points are ignored for the analysis below. All radiant floors in the house were heated simultaneously to achieve similar temperatures in all zones. The goal was to reduce heat transfer between zones through the walls. Additionally, the door to the test room was kept shut, and an attempt was made to make the room more air tight by taping gaps around the door and bottom of the walls. No ventilation systems were in use during the tests. All windows in the house were sealed for the duration of the test. The front door of the house remained sealed for the duration of the test, except for a few seconds within the first 30 minutes of the test to allow the author to leave for the night.

In order to recreate the same type of step input temperature profile as used for the inter-model comparison previously described, a constant temperature water source is required. An electric boiler with a PID controller was used for this purpose. However, the boiler was unable to provide a constant temperature water supply required to create a step input. Nevertheless, the experimental data can still be used and the appropriate boundary conditions can be applied to the model for comparison with the experiment.

Figure 3.14 shows the inlet, outlet, average floor surface, and average room air temperatures for test A. Figure 3.15 shows the corresponding top surface heat flux and volumetric water flow rate. Time 0 on the $\mathrm{x}$-axis corresponds to 23:00 in the evening of the first day. The sampling rate was 10 seconds for all instruments, but continuous lines are shown for clarity. Test B showed similar results to test A, so all data and analysis for test B can be seen in Appendix C.

\section{Measurement of surface temperature by contact method}

Accurate temperature measurement of a surface surrounded by a gas (or liquid) is problematic. Michalski et al. [66] describe three sources of error when measuring a 


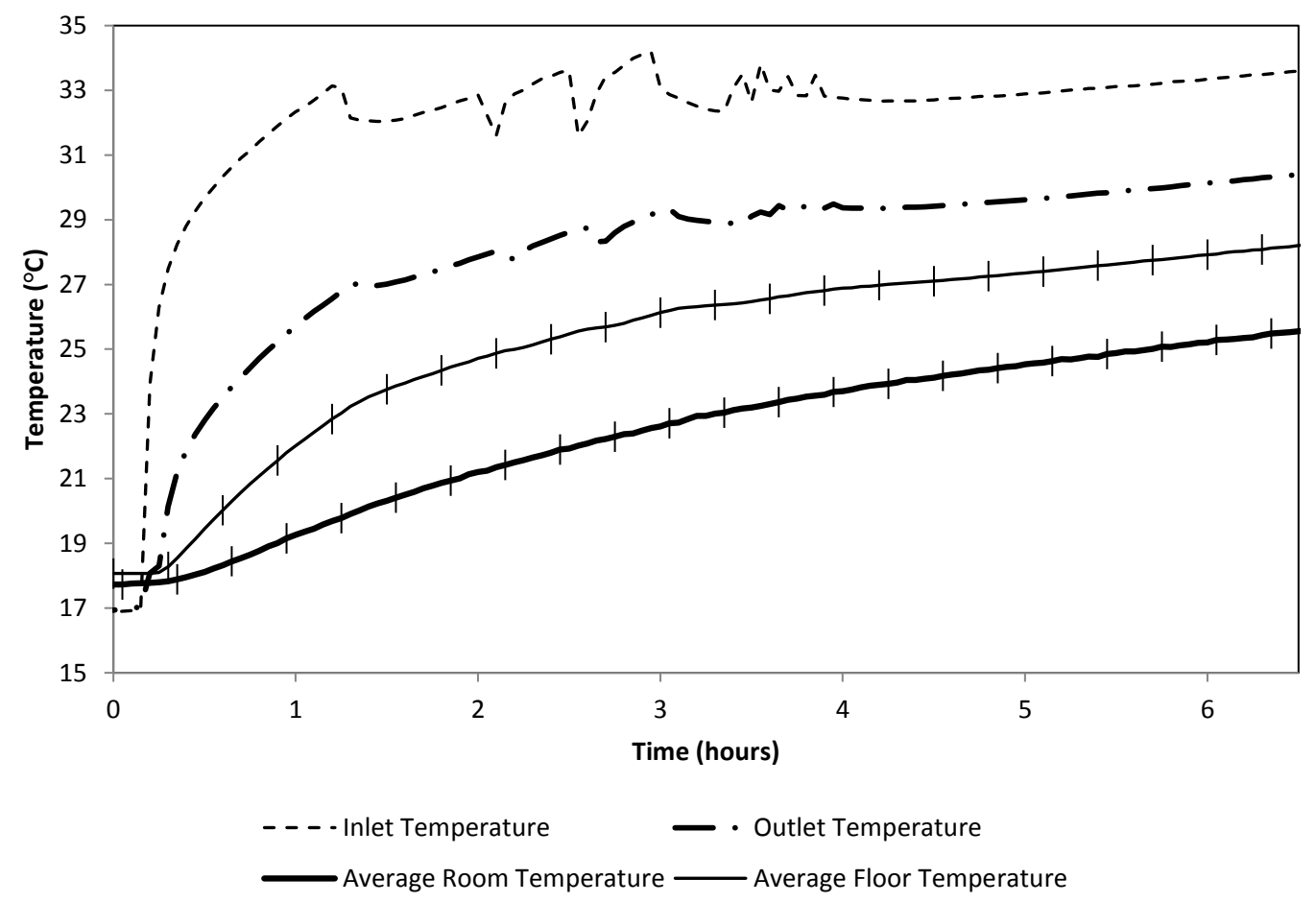

Figure 3.14: Experimental data (temperatures) for test A

surface temperature: The first is caused by the deformation of temperature field due to the temperature sensor. The second is caused by the contact resistance between the temperature sensor (in this case thermocouple bead) and the surface. The third is caused by the distance between the sensitive point of the temperature sensor and the surface being measured. In all three cases, the greater the difference in temperature between the surrounding fluid and the surface, the greater the error. In the case of the walls and ceiling, this should be a minor issue as the surface temperatures should be close to the air temperature. However, the floor temperature gets much warmer than the air temperature and this can cause a larger error than what is accounted for with typical error analysis.

Moffat proposed a simple correction for surface measurements with thermocouples [67] as shown in Equation 3.13. This correction only accounts for the deformation of the temperature field. The results of this correction for Test A are discussed later.

$$
\frac{T_{\text {measured }}-T_{\text {undisturbed }}}{T_{a}-T_{\text {undisturbed }}}=\frac{\left(\frac{\sqrt{h D_{\text {bead }} k_{\text {wire }}}}{2 k_{\text {surface }}}\right)}{1+\left(\frac{\sqrt{h D_{\text {bead }} k_{\text {wire }}}}{2 k_{\text {surface }}}\right)}
$$




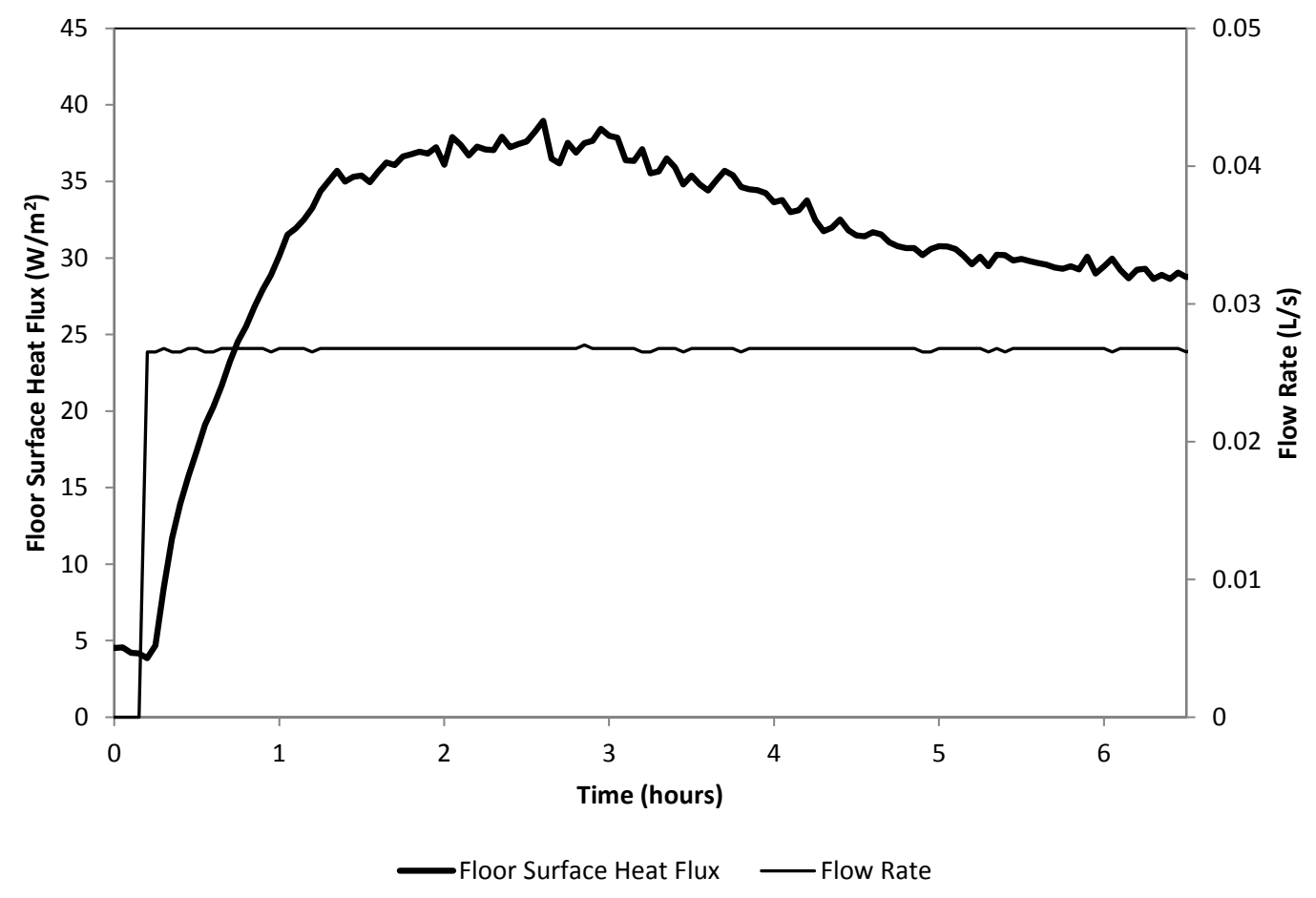

Figure 3.15: Experimental data (heat flux and flow rate) for test A

where $T_{a}$ is the air temperature, $T_{\text {undisturbed }}$ is the undisturbed floor temperature (to be solved for), $T_{\text {measured }}$ is the measured floor temperature, $h$ is the heat transfer coefficient, $D_{\text {bead }}$ is the thermocouple bead diameter, $k_{\text {wire }}$ is the thermocouple wire conductivity and $k_{\text {surface }}$ is the floor cover conductivity.

\section{Energy balance of experimental results}

An energy balance on the floor was conducted as a way to verify that the experiment was performed properly. Equation 3.14 shows the energy balance on the floor.

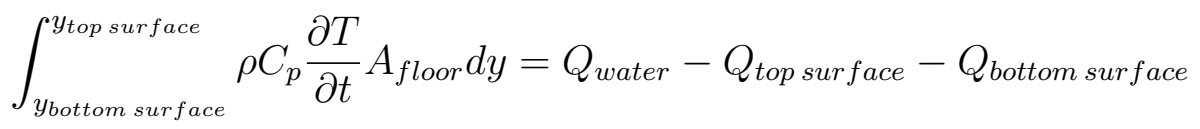

where $y_{\text {top surface }}$ and $y_{\text {bottom surface }}$ denote the positions of the top and bottom surfaces of the floor on the y-axis, $\rho$ and $C_{p}$ are the density and specific heat of the various floor construction layers, $A_{\text {floor }}$ is the floor surface area, $\frac{\partial T}{\partial t}$ is the rate of change of temperature (dependent on position $y$ ) with time, and $Q_{\text {water }}, Q_{\text {top surface }}$, 
and $Q_{\text {bottom surface }}$ are the heat transfer rates from the hydronic tubing to the floor, from the top surface to the zone above, and from the bottom surface to the zone below.

An energy balance was performed between 5 and 6 AM (before sunrise). This time period was used because the floor was nearest steady conditions at that point. Since the floor had not reached steady conditions, the energy storage term on the left hand side of Equation 3.14 was required. The energy storage term is more difficult to evaluate accurately than the other terms. First, not all $\rho$ and $C_{p}$ were known from manufacturer data, so typical values were found in the litterature. These values typically have a high level of uncertainty. These are discussed in the next section. Additionally, the spatial temperature distribution in the floor was not known with

high resolution. This could cause uncertainty in the evaluation of the $\frac{\partial T}{\partial t}$ term as temperature $T$ is a function of position $y$.

The energy balance was integrated over the hour ( 5 to $6 \mathrm{AM}$ ). The energy storage term was calculated to be $197.8 \mathrm{~kJ}$, while the water, top surface, and bottom surface terms were $1362.1 \mathrm{~kJ}, 965.3 \mathrm{~kJ}$, and $127.6 \mathrm{~kJ}$ respectively. The energy storage term was therefore $71.4 \mathrm{~kJ}$ lower than expected from the right hand side of the energy balance equation. This is equivalent to $5 \%$ of the total amount of energy entering the floor through the water. Part of this error may be attributed to experimental uncertainty. Additionally, the uncertainty in the material properties and spatial temperature distributions may have caused some errors in the calculation of the energy storage term. Nevertheless, this energy balance shows that the experiment was likely performed properly.

\subsubsection{Modelling}

A representation of the test room was created in ESP-r. Although the floor construction was known, the thermal properties of those materials were not. Table 3.7 shows the material properties used in the model for the floor construction. The joist space between the first and second floor was modelled as a separate zone with the gypsum board layer on the bottom of this zone.

The subfloor (plywood) properties were taken from a buiding load calculation manual [68]. The insulation conductivity was calculated from manufacturer's data. Other properties were taken from an ASHRAE handbook [16]. The thinset mortar 
Table 3.7: Parameters for floor construction in model

\begin{tabular}{|c|c|c|c|c|}
\hline Material & $\begin{array}{c}\text { Thickness } \\
\text { (m) }\end{array}$ & $\begin{array}{c}k \\
\left(\mathrm{~W} \mathrm{~m}^{-1} \mathrm{~K}^{-1}\right)\end{array}$ & $\begin{array}{c}\rho \\
\left(\mathrm{kg} \mathrm{m}^{-3}\right)\end{array}$ & $\begin{array}{c}C \\
\left(\mathrm{~J} \mathrm{~kg}^{-1} \mathrm{~K}^{-1}\right)\end{array}$ \\
\hline Subfloor & 0.0159 & 0.120 & 540 & 1210 \\
\hline High Density Insulation & 0.0250 & 0.032 & 40 & 1470 \\
\hline Aluminium Fin ${ }^{\mathrm{a}}$ & 0.0015 & 70.0 & 900 & 880 \\
\hline Thinset Mortar & 0.0032 & 0.72 & 1860 & 780 \\
\hline Cement Backing Board & 0.0064 & 0.2835 & 1300 & 840 \\
\hline Thinset Mortar & 0.0032 & 0.72 & 1860 & 780 \\
\hline Tile & 0.009 & 1.5 & 2089 & 730 \\
\hline
\end{tabular}

${ }^{a}$ The thickness of the aluminium layer was tripled in the model due to numerical issues. To account for this, the conductivity and density were divided by three. Since the resistance to conduction is very small in the y-axis (see Figure 3.2 ), the reduction in conductivity should not affect the model's results.

was Mapei Ultraflex 3. Properties were taken for cement mortar in a heat transfer textbook [69] as no data was found for the thinset mortar. It was assumed that the layers of mortar were $0.0032 \mathrm{~m}$ thick however this may vary. The cement backing board was a HardieBacker backerboard. The conductivity was taken from the manufacturer [70]. The density and specific heat were estimated based on values found in a ASHRAE handbook [16] however these may vary greatly in reality. The tile density was estimated based on the weight and dimensions. The tile material was porcelain. García et al. [71] have measured the thermal properties of various types of ceramic tiles including two types of porcelain tiles. The two types of porcelain tiles they measured had densities of 2380 and $2410 \mathrm{~kg} \mathrm{~m}^{-3}$. This is higher than the calculated value for the tile installed at the CHEeR facility. However, since this is the only data available, the specific heat and thermal conductivity of the lighter porcelain tile measured by García et al. [71] (at room temperature) were used.

The longwave emissivity of the tile and drywall were measured by Pr. Michael Collins at the University of Waterloo with the use of a Gier Dunkle DB-100 reflectometer. The tile had a hemispheric emissivity of 0.80 and the drywall 0.83 . Glass 
was assumed to have a hemispheric emissivity of $0.87^{1}$.

The aim of the model discussed earlier in this chapter is the calculation of the heat transfer rate between the water and the floor. The ESP-r building domain (1 dimensional finite difference model) then calculates the average temperatures at every layer of the floor and the heat fluxes at the top and bottom surfaces. In order to isolate the radiant floor model from the rest of the room model, the measured room air temperature, the various measured walls and ceiling temperatures, and the measured bottom subfloor surface temperature were imposed on ESP-r. Imposing these temperatures allowed for the isolation of the radiant floor model from the rest of the room.

In ESP-r, imposing the surface temperatures was accomplished with the use of the existing ESP-r embedded-tube radiant floor model. Each of the surfaces was given a high conductivity and low thermal mass, as well as high flow rate and small tube spacing. The supply temperatures were set to the measured surface temperatures. The room air temperature was imposed to ESP-r by supplying a very large amount of air at the measured air temperature. The bottom subfloor surface temperature was imposed by supplying a very large amount of air at the same temperature as the measured bottom subfloor surface temperature to the joist space below the floor, and imposing a very large convective heat transfer coefficient to the surface.

\subsubsection{Experiment vs model comparison}

The simulation time step was 3 minutes. As mentioned earlier, the experimental sampling rate was 10 seconds. In order to be able to compare them with the simulated results, only the experimental data corresponding with a 3 minute time interval was considered (i.e. no averaging of the experimental data for the time step; instantaneous values were used). The modelled and the experimental results for test A are shown in Figures 3.17 through 3.19. Figure 3.16 shows the location of the top surface heat flux and below subfloor heat flux on a section of floor.

The RMSD of the modelled vs experimental floor surface temperature was $0.54{ }^{\circ} \mathrm{C}$. The RMSD of the top and bottom floor surface heat flux were $2.42 \mathrm{~W} \mathrm{~m}^{-2}(7.7 \%$ of average heat flux of $31.54 \mathrm{~W} \mathrm{~m}^{-2}$ ) and $1.17 \mathrm{~W} \mathrm{~m}^{-2}$ (38\% of average heat flux of 3.10

\footnotetext{
${ }^{1}$ Reported values for emissivity of glass vary greatly in the literature. The ASHRAE Fundamentals Handbook [16] reports a value of 0.84, while Clarke [22] report values as high as 0.937.
} 


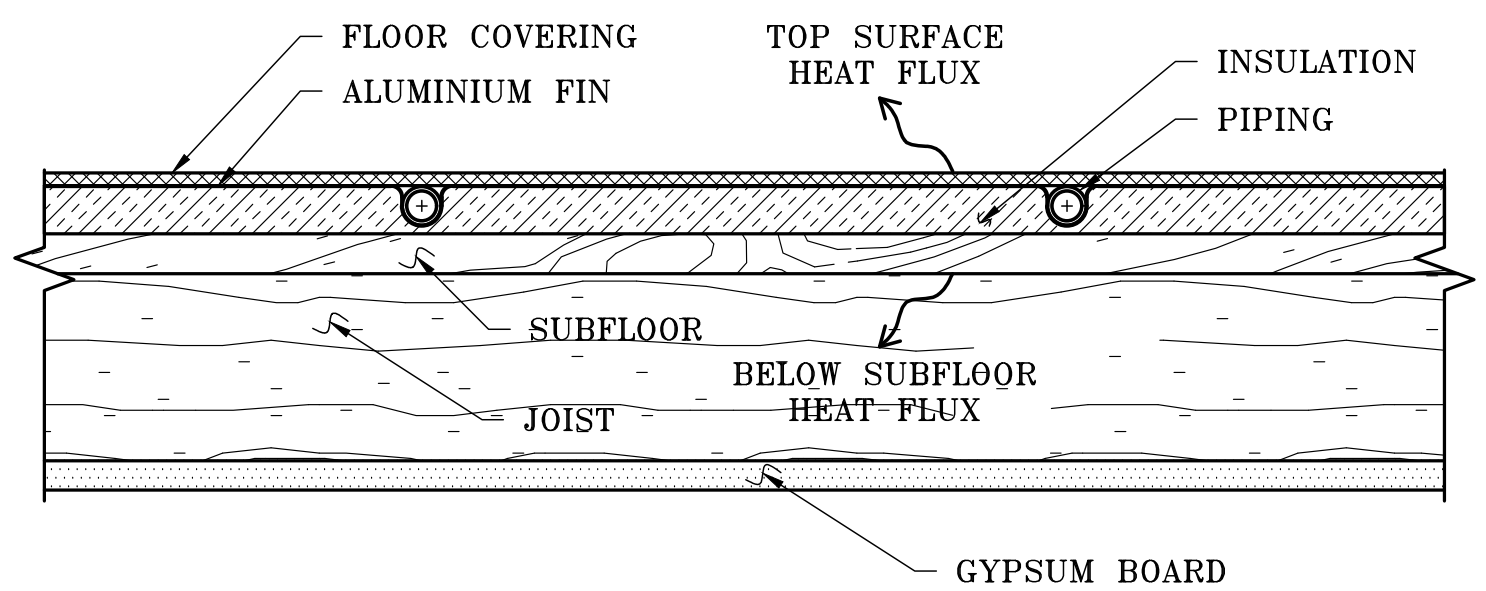

Figure 3.16: Location of measured and predicted heat flux surfaces

$\mathrm{W} \mathrm{m}^{-2}$ ) respectively. Finaly, the RMSD of the water heat transfer rate was $19.5 \mathrm{~W}$ (4.0\% of average heat transfer of $485 \mathrm{~W}$ ).

As can be seen in Figure 3.17, the model predicted the heat transfer rate between the water and the floor quite well. There was however an initial under-prediction for the first few time steps followed by an over-prediction of the heat transfer rate. Following approximately the first hour, the model consistently slightly under-predicted the heat transfer rate, but tended to capture the transient effects relatively well. Most of the data points were not within the experimental error bars.

Figure 3.18 shows measured floor temperature, as well as the corrected (or undisturbed) floor temperature as per Equation 3.13. The average value of the right hand side of Equation 3.13 for the duration of the test was 0.22. The modelled floor temperature and corrected results seem to agree very well. The modelled air temperature is not shown as the measured experimental values were imposed on the model. The error bars on the uncorrected floor temperature measurements are only shown every 6 time steps for clarity.

Figure 3.19 shows the surface heat fluxes. As can be noticed, there was a lag between the modelled top surface heat flux and the experimental value at the beginning of the test. This may have been caused by inaccurate model inputs (thermal properties of materials) or it could have been caused because of the simplifications 


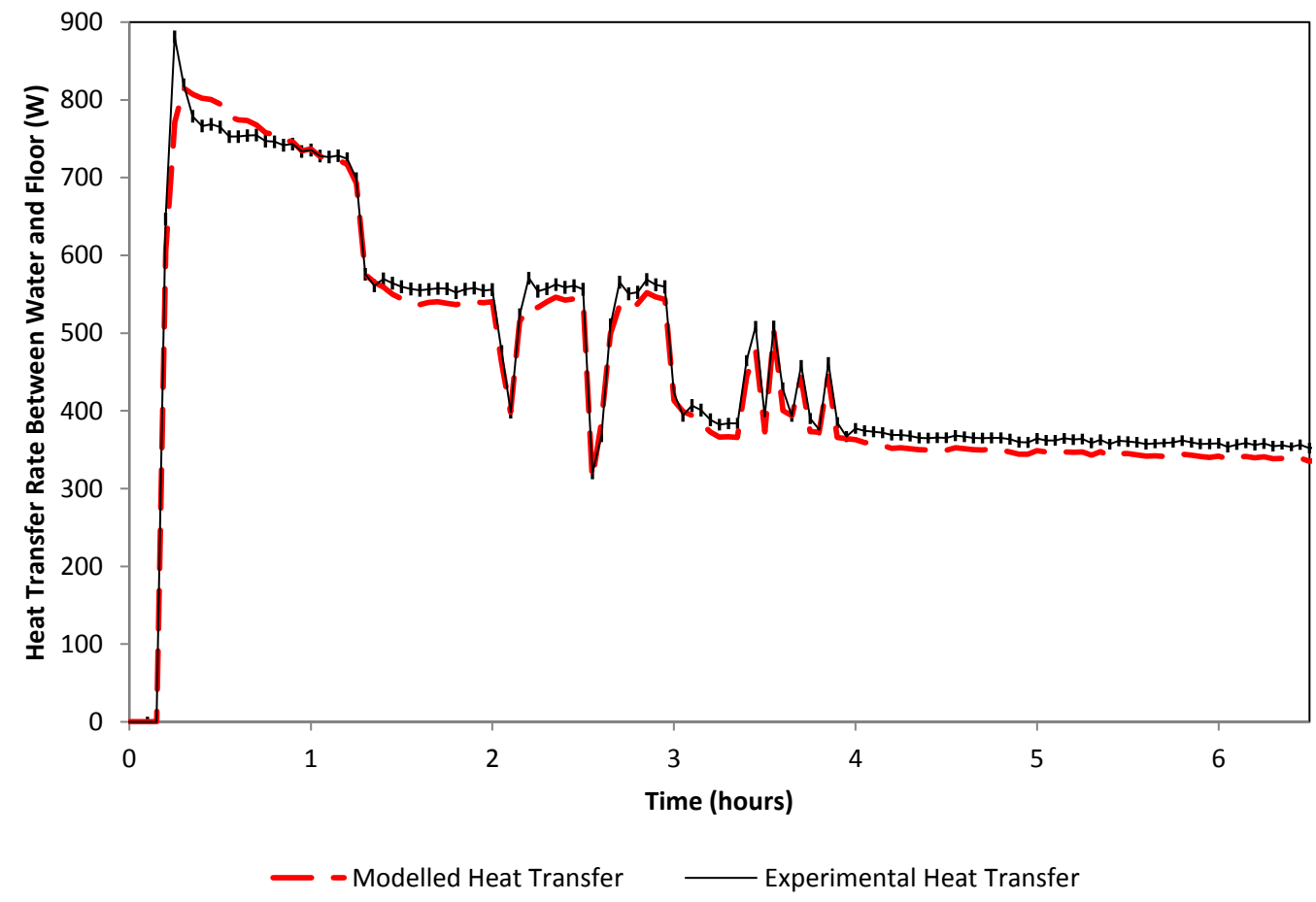

Figure 3.17: Experimental vs Modelled Results - Test A: Water Heat Transfer Rate

in the model. The latter is however unlikely as the finite element inter-model comparison discussed earlier in this chapter showed no such lag. Most of the modelled points did not fall within the error bars and were under-predicting the experimental results. Additionally, the heat flux below the subfloor was greatly inaccurate when evaluated in terms of percentage error. As mentioned earlier, the RMSD was $38 \%$ of the average. In absolute value however, it was very small due to the small amount of heat flux flowing downwards. The error bars for the heat flux from the subfloor are not shown for clarity as they were very small (less than $0.2 \mathrm{~W} \mathrm{~m}^{-2}$ ).

With the parameters described in Table 3.7, the model under-predicted the heat transfer from the water to the floor, from the top surface to the room, and from the bottom surface to the joist cavity.

\subsubsection{Sensitivity analysis}

As discussed in Section 3.5.3, many of the floor construction thermal properties were not known, and were approximated with general handbook or textbook data. To 


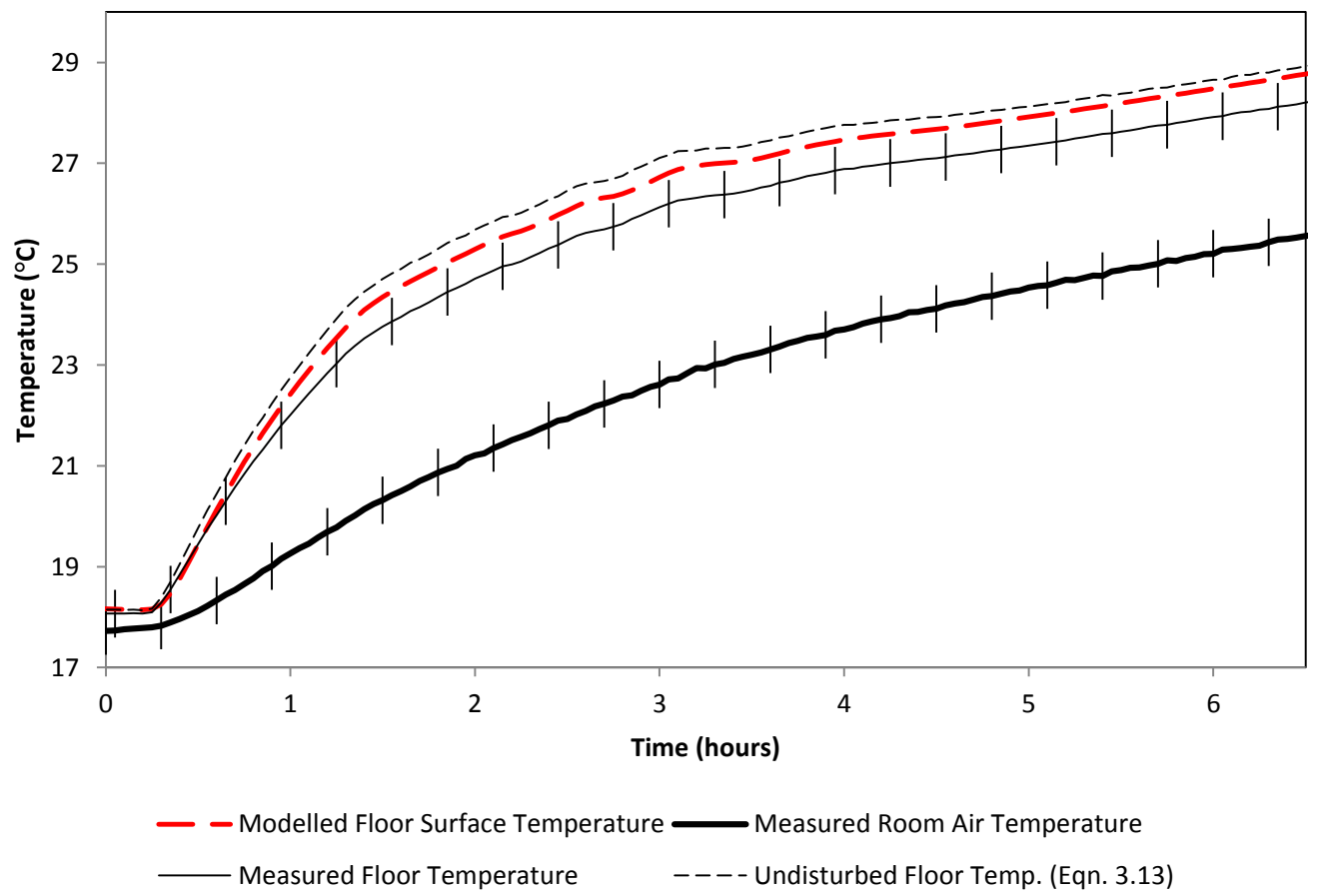

Figure 3.18: Experimental vs Modelled Results - Test A: Air and Floor Surface Temperature 


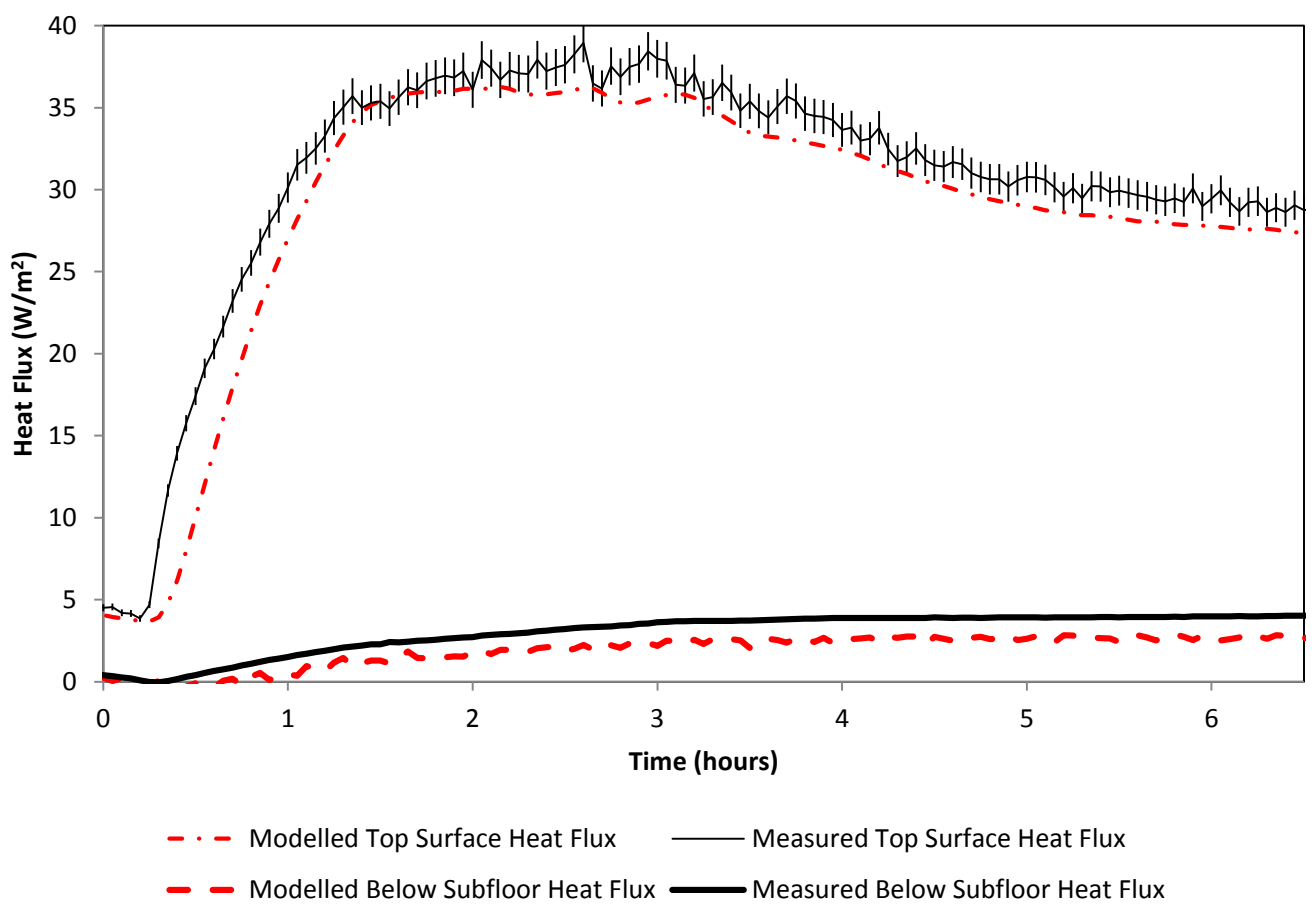

Figure 3.19: Experimental vs Modelled Results - Test A: Heat Fluxes

investigate the effect of the sensitivity of the model to some of the parameters, additional simulations were run. For both tests (A \& B), a low diffusivity and a high diffusivity case were defined. In the low diffusivity case, the conductivities of the tile and thinset mortar layers was reduced by $10 \%$ while the thermal mass of those layers was increased by 10\%. For the high diffusivity case, the conductivities of the tile and thinset mortar was increased by $10 \%$ and the thermal mass of those layers was reduced by $10 \%$. The model described in Section 3.5.3 was used as the base case.

Table 3.8 shows the results of the RMSD for the various model outputs for test A. Those results show that the material properties can have an impact on the results, especially for the top surface heat flux. In the following sections, the corrected (or undisturbed) temperature, as defined in Equation 3.13 is used when discussing the floor temperature.

Not shown in Table 3.8 is the fact that, similar to the base case, the simulated results for the low diffusivity and high diffusivity cases also under-predicted the heat transfer from the water to the floor, from the top surface to the room, and from the bottom surface to the joist cavity. This can be seen by looking at the percent error 
Table 3.8: Material sensitivity - RMSD - Test A

\begin{tabular}{|c|c|c|c|c|}
\hline & \multirow{3}{*}{$\begin{array}{c}\text { Average } \\
\text { Experiment } \\
\text { Value }\end{array}$} & \multicolumn{3}{|c|}{ RMSD: Experiment vs Model } \\
\hline & & Base & Low & High \\
\hline & & Case & Diffusivity & Diffusivity \\
\hline $\begin{array}{l}\text { Temperature Top Floor Surface } \\
\left({ }^{\circ} \mathrm{C}\right)\end{array}$ & 26.3 & 0.29 & 0.39 & 0.21 \\
\hline $\begin{array}{l}\text { Heat Flux Top Surface } \\
\left(\mathrm{W} \mathrm{m}^{-2}\right)\end{array}$ & 31.5 & 2.42 & 3.05 & 2.01 \\
\hline $\begin{array}{l}\text { Heat Flux Bottom Surface } \\
\left(\mathrm{W} \mathrm{m}^{-2}\right)\end{array}$ & 3.10 & 1.17 & 0.99 & 1.29 \\
\hline $\begin{array}{l}\text { Water to Floor Heat Transfer } \\
\text { (W) }\end{array}$ & 485 & 19.5 & 19.6 & 20.3 \\
\hline
\end{tabular}

Table 3.9: Material sensitivity - Percentage error for total energy transfer - Test A

\begin{tabular}{|c|c|c|c|}
\hline & \multicolumn{3}{|c|}{ Model Percentage Error (\%) } \\
\hline & Base & Low & High \\
\hline & Case & Diffusivity & Diffusivity \\
\hline Heat Flux Top Surface & -5.9 & -8.2 & -4.0 \\
\hline Heat Flux Bottom Surface & -37 & -31 & -41 \\
\hline Water to Floor Heat Transfer & -2.5 & -1.9 & -2.9 \\
\hline
\end{tabular}

of the simulated results in the total energy transfered over the entire test. The total energy transfered is simply the heat flux (in $\mathrm{W} \mathrm{m}^{-2}$ ) or heat transfer rate (in $\mathrm{W}$ ) integrated over time (to give $\mathrm{J} / \mathrm{m}^{2}$ or $\mathrm{J}$ ). This is shown in Table 3.9 where a negative value means that the experiment produced a higher energy transfer than the model.

As is seen from the results in Tables 3.8 and 3.9, there is not one case that improves all aspects of the model. Additionally, depending on the metric used (percentage error for total heat transfer, or RMSD) one might come to a different conclusion as to which case better predicts the experimental data. The goal of this exercise was to show that a change in material properties by an amount that is within the uncertainty of what 
is typical in BPS could yield significantly different results.

Similarly, convective heat transfer coefficients have a high level of uncertainty. The convective heat transfer coefficient used for the base case simulation was taken from a correlation by Awbi and Hatton [72]. This is just one of many heat transfer correlations available for a heated floor with buoyancy driven heat transfer. A sensitivity analysis was conducted to study the sensitivity of the heat transfer coefficient on both tests. The other convective heat transfer coefficients investigated were formulated by Alamdari and Hammond [7] and Khalifa and Marshall [73]. Figure 3.20 shows the convective heat transfer coefficients $h_{\text {conv }}$ for a range of difference in temperature between the floor surface and the air $(\Delta T)$ for the three correlations. The figure is for a $3 \mathrm{~m}$ by $3 \mathrm{~m}$ room.

Table 3.10 shows the RMSD between the experiment and the model with the various convective heat transfer coefficients (Awbi and Hatton is the base case). Table 3.11 shows the percentage error for the total energy transfered (water to floor, floor to room, subfloor to joist space) over the entire test period associated with the heat transfer coefficients. In Table 3.11, a negative value shows that the experiment produced a higher energy transfer than the model. The choice of heat transfer coefficient seems to have some impact on the accuracy of the model. In this case, the Khalifa and Marshall correlation gave results that are in closer agreement with the measured data. That correlation also happened to give higher heat transfer coefficients in the range of $\Delta T$ encountered in the tests discussed here. Because the Khalifa and Marshall model produces higher heat transfer coefficients, it may artificially counteract the suboptimal choices of material properties as input to the model. Therefore, it should not be thought as the more accurate correlation. 


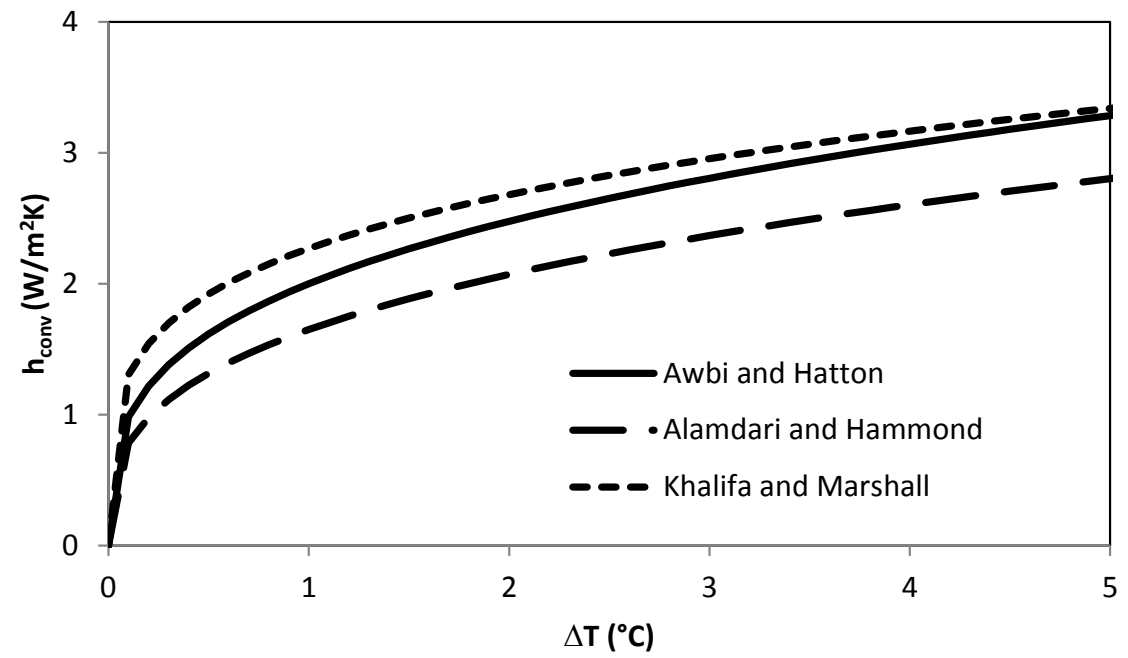

Figure 3.20: Comparison of convective heat transfer coefficient correlations over range of $\Delta T$ in tests

Table 3.10: Convective heat transfer coefficient sensitivity- RMSD - Test A

\begin{tabular}{|c|c|c|c|c|}
\hline & \multirow{2}{*}{$\begin{array}{c}\text { Average } \\
\text { Experiment } \\
\text { Value }\end{array}$} & \multicolumn{3}{|c|}{ RMSD: Experiment vs Model } \\
\hline & & $\begin{array}{c}\text { Awbi and } \\
\text { Hatton }\end{array}$ & $\begin{array}{c}\text { Alamdari and } \\
\text { Hammond }\end{array}$ & $\begin{array}{c}\text { Khalifa and } \\
\text { Marshall }\end{array}$ \\
\hline $\begin{array}{l}\text { Temperature Top } \\
\text { Floor Surface }\left({ }^{\circ} \mathrm{C}\right)\end{array}$ & 26.3 & 0.29 & 0.17 & 0.33 \\
\hline $\begin{array}{l}\text { Heat Flux Top } \\
\text { Surface }\left(\mathrm{W} \mathrm{m}^{-2}\right)\end{array}$ & 31.5 & 2.42 & 3.05 & 2.28 \\
\hline $\begin{array}{l}\text { Heat Flux } \\
\text { Bottom Surface }\left(\mathrm{W} \mathrm{m}^{-2}\right)\end{array}$ & 3.10 & 1.17 & 1.08 & 1.19 \\
\hline $\begin{array}{l}\text { Water to Floor } \\
\text { Heat Transfer }(\mathrm{W})\end{array}$ & 485 & 19.5 & 24.5 & 18.5 \\
\hline
\end{tabular}


Table 3.11: Convective heat transfer coefficient sensitivity - Percentage error for total energy transfer - Test A

\begin{tabular}{lccc}
\hline & \multicolumn{3}{c}{ Model Percentage Error (\%) } \\
\cline { 2 - 4 } & $\begin{array}{c}\text { Awbi and } \\
\text { Hatton }\end{array}$ & $\begin{array}{c}\text { Alamdari and } \\
\text { Hammond }\end{array}$ & $\begin{array}{c}\text { Khalifa and } \\
\text { Marshall }\end{array}$ \\
\cline { 1 - 4 } Heat Flux Top Surface & -5.9 & -8.5 & -5.3 \\
\cline { 1 - 1 } Heat Flux Bottom Surface & -37 & -34 & -37 \\
\cline { 1 - 1 } Water to Floor Heat Transfer & -2.5 & -3.8 & -2.1 \\
\hline
\end{tabular}

\subsection{Closing remarks}

In this chapter, the development of an above-floor tube-and-plate radiant floor heating and cooling model in ESP-r was discussed. The model consists of an analytical solution to the tube heat transfer coupled with a 2D finite difference conduction model. A RMSD of $1.68 \mathrm{~W} \mathrm{~m}^{-2}$ was found between this new model and a 2D transient finite difference analysis for the tested case. Additional cases are found in Appendix A with similar results. A parametric analysis performed in ESP-r showed that changing model parameters by $10 \%$ can change the results by a larger amount than the difference between the FEA and ESP-r results.

An experiment was conducted to further validate the model. Two tests were run and one was discussed in this chapter. The other test is discussed briefly in Appendix C.

RMSD between the experiment and the model for top surface heat flux was 2.42 $\mathrm{W} \mathrm{m}^{-2}$ (7.7\% of the average top surface heat flux). The percentage error of the total energy transfered at the top surface was $5.9 \%$. Similarly, the RMSD for the heat transfer between the water and the floor construction was $19.5 \mathrm{~W}(4.0 \%$ of the average heat transfer rate). The percentage error of the total energy transfered between the water and the floor was $2.5 \%$.

It was found that the model was sensitive to construction thermal properties with total water to floor total energy transfered percentage error varying between $2.9 \%$ and $1.9 \%$ for high and low diffusivity floor construction cases. The convective heat transfer coefficient also affected the model results. The total water to floor total energy transfered percentage error varied between $3.8 \%$ and $2.1 \%$ for the Alamdari 
and Hammond, and the Khalifa and Marshall correlations.

It is the author's opinion that the model presented in this chapter is adequate for modelling AFTP systems. With this new validated model, it is now possible to analyze the active/passive solar collection system presented in Chapter 1 with confidence in the AFTP radiant floor model. Before being able to investigate the entire system, a transient model for a house-scale water-water heat pump is discussed in the next chapter. 


\section{Chapter 4}

\section{Heat pump experimental testing and empirical model}

\subsection{Introduction}

In Chapter 1, one of the tasks mentioned as required in order to analyze the active/passive solar collection system was the development a transient water-water heat pump model. This chapter reviews the relevant literature on the modelling of heat pumps in the BPS context, and then presents a new model derived and calibrated from laboratory experiments. This work was presented at the eSim2016 conference [74].

\subsubsection{Literature}

Heat pumps are usually rated using steady-state experimental data and performance studies are typically based on that data [75]. The standard heat pump models in TRNSYS use user defined performance maps to interpolate steady-state conditions and therefore ignore transient effects.

Henderson [76] has shown that steady-state models tend to predict higher seasonal $C O P$ than transient models for a air to water heat pumps used for space heating. The transient models used in that study simply consisted of the steady-state model with a time constant as in Equation 4.1.

$$
\frac{d Q_{\text {transient }}}{d t}=\frac{1}{\tau}\left[Q_{\text {steady }}-Q_{\text {transient }}\right]
$$

where $Q_{\text {transient }}$ is the transient model heat transfer rate, $Q_{\text {steady }}$ is the steady-state 
model heat transfer rate, $t$ is time, and $\tau$ is the time constant.

The time constants used were $55 \mathrm{~s}$ and $133 \mathrm{~s}$ in order to bracket the range of available experimental data. It was found that compared to the steady-state model, the transient models calculated 3.4 and $9.8 \%$ increases in seasonal energy consumption and a 3.3 and $7.1 \%$ reduction in COP. Others have also worked on the concept of modelling transient heat transfer rates in heat pumps as linear systems with a time constant [77] while some improved on the model by adding a second time constant to better capture the transient effects $[78,79]$. The models that have been developed were for water-air heat pumps, but the general concepts of the models should also work for a water-water heat pump.

Some heat pump models that account for transient effects have been developed for TRNSYS, but they do not come with the standard library of models [80,81]. These models also use a time constant approach but are for water-air and air-air heat pumps. The approach by Afjei et al. [81] is particularly interesting because it accounts for the time elapsed between cycles. This model is however not intended for a water-water heat pump (icing and defrosting are included in the model) and it does not seem to account for transients in the evaporator. Additionally, the model requires a cool down time constant which describes the speed at which the condenser cools down after the heat pump is turned off. The model assumes that the heat pump will have the same time constant once turned on no matter how long since the last cycle, but that the starting heat transfer rate changes. This is seen in Figure 4.1. The second time the heat pump is turned $\mathrm{ON}$, the transient heat transfer is calculated to be non-zero (and positive) at the very instant the heat pump is turned ON. This is a questionable assumption for a water-water heat pump. There could be situations when, for a short time, the heat transfer on the condenser or evaporator side is close to zero, or even negative at the beginning of a cycle (e.g. if the supply water sent to the heat exchanger is very close in temperature to the average temperature of the heat exchanger at the beginning of the cycle).

Transient heat pump models used for building simulation typically neglect transient effects in electrical power supply during start-up periods. Garde et al. [82] state that this assumption is reasonable since the power surge only lasts a few seconds. These findings are important and seem to point to a need for modelling of transient effects in order to increase the accuracy of the heat pump model results. 


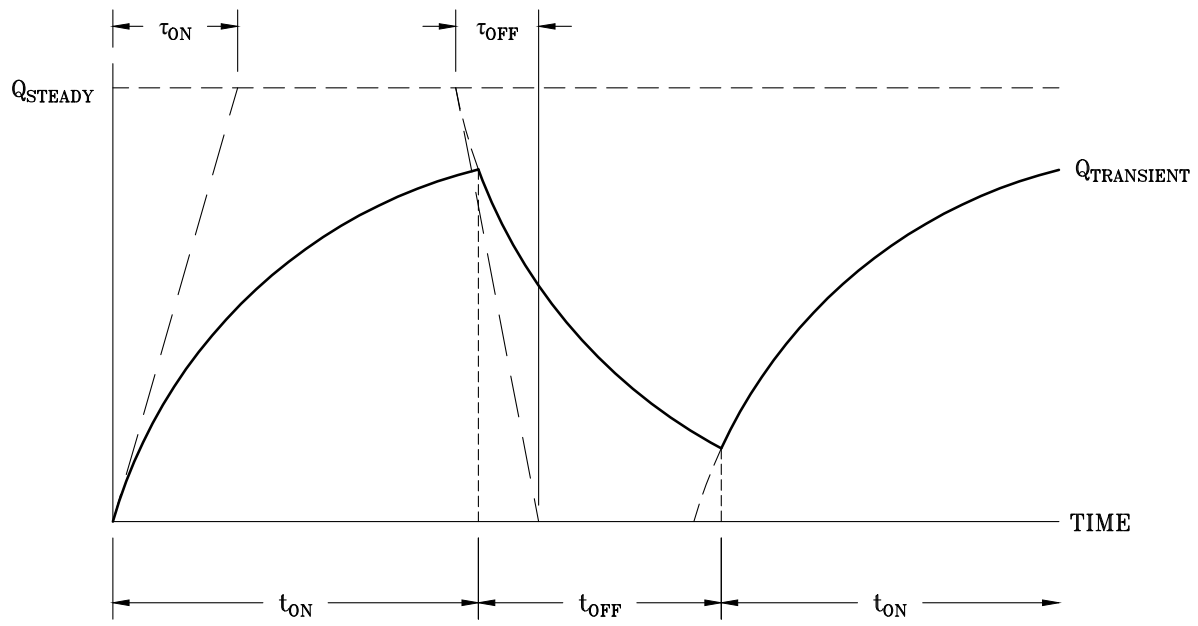

Figure 4.1: Transient heat pump model approach by Afjei et al. [81]

\subsubsection{Context for this work}

A custom water to water heat pump was tested experimentally. The heat pump was provided by Ecologix, and was a model GX employing R134a refrigerant. Its catalogue number was W2W420-1-NI-S004. The heat pump had a refrigerant charge of $1.22 \mathrm{~kg}(2 \mathrm{lb} 11 \mathrm{oz})$. The compressor was single speed scroll compressor.

The aim of the experimental testing was to map the steady state performance of the heat pump at various operating conditions. Additionally, transient tests were also performed. These tests were then used to develop a simple empirical model.

This model is to be used to simulate the energy demands of the active/passive radiant floor collection system described in Chapter 1.

\subsection{Experimental setup}

Two water storage tanks were used to store condenser and evaporator water at desired temperatures. An in-line electrical heater was used to heat the evaporator water as required, and a heat exchanger was used to cool the condenser water. The water temperatures supplied by the in-line electrical heater and chilled water heat exchanger were varied to maintain a given return temperature setpoint to the heat pump using PID controllers.

Figure 4.2 shows a schematic of the apparatus used for testing the heat pump. 


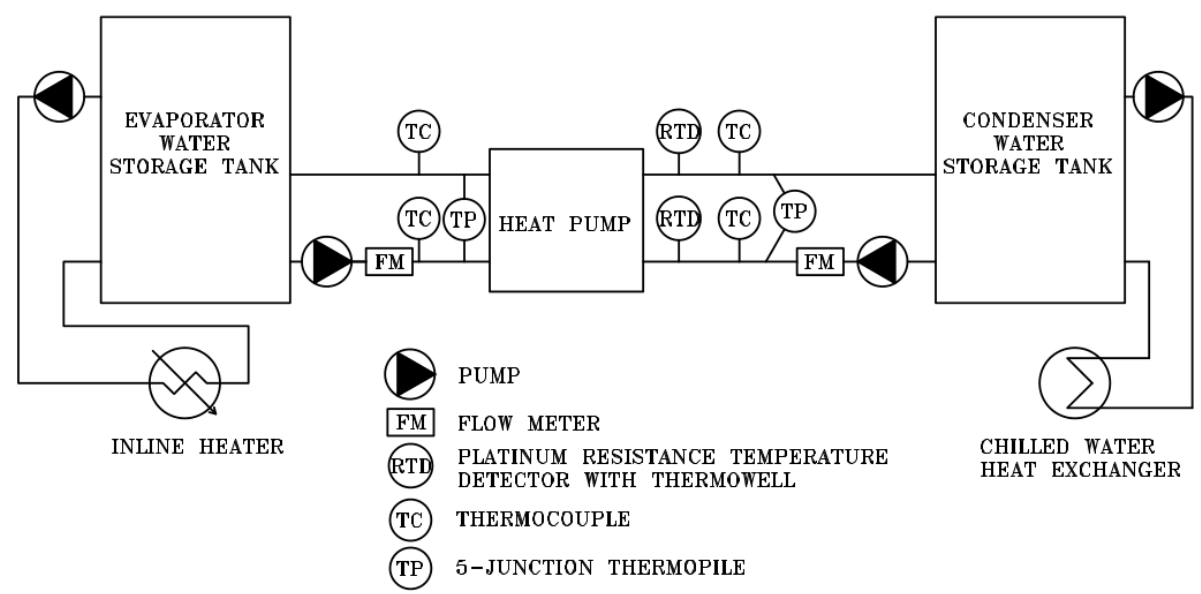

Figure 4.2: Heat pump experiment apparatus schematic

\subsubsection{Uncertainty analysis}

The bias and precisions errors of a multiple-sample measurement can be calculated using the method defined by Moffat [63]. The bias error $B$ for a single measurement $X$ with multiple sources of errors $j$ is found using Equation 3.10. When multiple measurements $X_{i}$ are used to calculate derived values $I$, Equation 3.12 is used to calculate the bias error for those derived values. The precision error $S$ is found using Equation 4.2 when $\mathrm{N}$ samples of a similar measurement are taken, and an average value is calculated from those measurements. Similarly to the propagation of bias error when a derived value is calculated, the precision error can be calculated for derived value using Equation 4.3.

$$
\begin{gathered}
S_{X}=\left\{\sum_{j=1}^{N} \frac{\left(X_{j}-\bar{X}_{j}\right)^{2}}{N-1}\right\}^{1 / 2} \frac{1}{\sqrt{N}} \\
S_{I}=\left\{\sum_{i=1}^{n}\left(\frac{\partial I}{\partial X_{i}} S_{i}\right)^{2}\right\}^{1 / 2} \text { where } I=f\left(X_{i}\right)
\end{gathered}
$$

The bias and precision errors can then be added together to find the total uncertainty with Equation 4.4 at $95 \%$ confidence interval, with $t$ being the Student's t multiplier using the two-tailed distribution at $95 \%$ confidence interval. In the case of the experiment discussed here, there were 99 degrees of freedom, therefore $t$ was 
Table 4.1: Thermocouple bias error sources

\begin{tabular}{lcc}
\hline Bias Error Sources & Calibration & $\begin{array}{c}\text { Experiment } \\
\text { Read and CJC }\end{array}$ \\
\hline Bias Error Values $\left({ }^{\circ} \mathrm{C}\right)$ & 0.27 & 0.38 \\
\hline
\end{tabular}

found to be 1.984 .

$$
\left(U_{I}\right)_{0.95}=\left\{\left(B_{I}\right)^{2}+\left(t S_{I}\right)^{2}\right\}^{1 / 2}
$$

\subsubsection{Temperature measurements}

Thermocouples were installed in the water lines on the supply and return sides of the condenser and evaporator. Additionally, thermopiles were installed on the condenser and evaporator water lines, as well as platinum resistance thermometers (Pt100) on the supply and return sides of the condenser.

The thermocouple wire spool was calibrated by Geoff Johnson [64]. A National Instruments cFP-TC-125 module was used to measure the $\mathrm{mV}$ signal from the thermopiles. The bias error (as discussed in Section 4.2.1) of the thermocouples was $0.47^{\circ} \mathrm{C}$ for the range of temperatures in the evaporator water. The bias error of the thermocouples on the condenser side was also $0.47^{\circ} \mathrm{C}$ for the range of temperatures. For the condenser temperatures, this bias error is only valid for the range of temperatures seen in the transient experiments discussed later as the Pt100s were used in the steady state experiments. The sources of bias error for the thermocouples are listed in Table 4.1. The calibration bias error includes the maximum regression residual, the reference junction drift, the Pt100 bias, and the electromotive force (emf) read error from the DAQ. The experiment read and cold junction compensation (CJC) bias error included the DAQ cold junction measurement error, as well as the DAQ emf bias error.

To accurately measure the difference in temperature between the inlet and outlet of the heat pump at both the condenser and evaporator, 5-junction thermopiles were used. The thermopliles were calibrated by Geoff Johnson [64]. A National Instruments cFP-TC-125 module was used to measure the $\mathrm{mV}$ signal from the thermopiles. The bias error from the thermopile was $0.16{ }^{\circ} \mathrm{C}$. The sources of bias error for the 
Table 4.2: Thermopile bias error sources

\begin{tabular}{lccc}
\hline Bias Error Sources & $\begin{array}{c}\text { Calibration } \\
\text { curve max. } \\
\text { residual }\end{array}$ & Calibration bias & $\begin{array}{c}\text { emf } \\
\text { measurement }\end{array}$ \\
\hline Bias Error Values $\left({ }^{\circ} \mathrm{C}\right)$ & 0.114 & 0.046 & 0.040 \\
\hline
\end{tabular}

Table 4.3: Pt100 bias error sources

\begin{tabular}{lccc}
\hline Bias Error Sources & Sensor & $\begin{array}{c}\text { Resistance } \\
\text { measurement }\end{array}$ & Calibration fit \\
\hline Bias Error Values $\left({ }^{\circ} \mathrm{C}\right)$ & 0.02 & 0.02 & 0.008 \\
\hline
\end{tabular}

thermopile are shown in Table 4.2.

In order to ensure correct measurements, the thermopile measurements were compared with the thermocouple measurements on both the condenser water and evaporator water. A discrepancy was found between the readings from the thermopile and the thermocouples on the condenser water side. Pt100s in thermowells were installed to investigate the problem. A Fluke 1524 reference thermometer was used to read the resistance from the Pt100s. It was found that the thermopile on the condenser water side was defective. The thermocouples however, were found to be accurate. Previous work by Geoffrey Johnson, a member of the SBES lab, had shown that the thermowells had no significant impact on steady state measurements with the Pt100s. The Pt100s were left in the apparatus, and were used for the steady state experiments. The bias error for the Pt100s was $0.03{ }^{\circ} \mathrm{C}$ each. The sources of bias errors for the Pt100s are shown in Table 4.3.

\subsubsection{Flow meters}

The condenser and evaporator water volumetric flow rates were measured with positive displacement flow meters (Brooks models BM10, and BM40 respectively). A National Instruments cFP-CTR-502 data acquisition module was used to count pulses coming from the flow meters. The bias error of the flow meter was $1 \%$ of measured flow rate. If it is assumed that one pulse is missed or one too many pulse is counted, at the end or beginning of the measurement period, this would yield a bias uncertainty of $0.006 \mathrm{~L} \mathrm{~s}^{-1}$ for the condenser and $0.014 \mathrm{~L} \mathrm{~s}^{-1}$ for the evaporator for each 


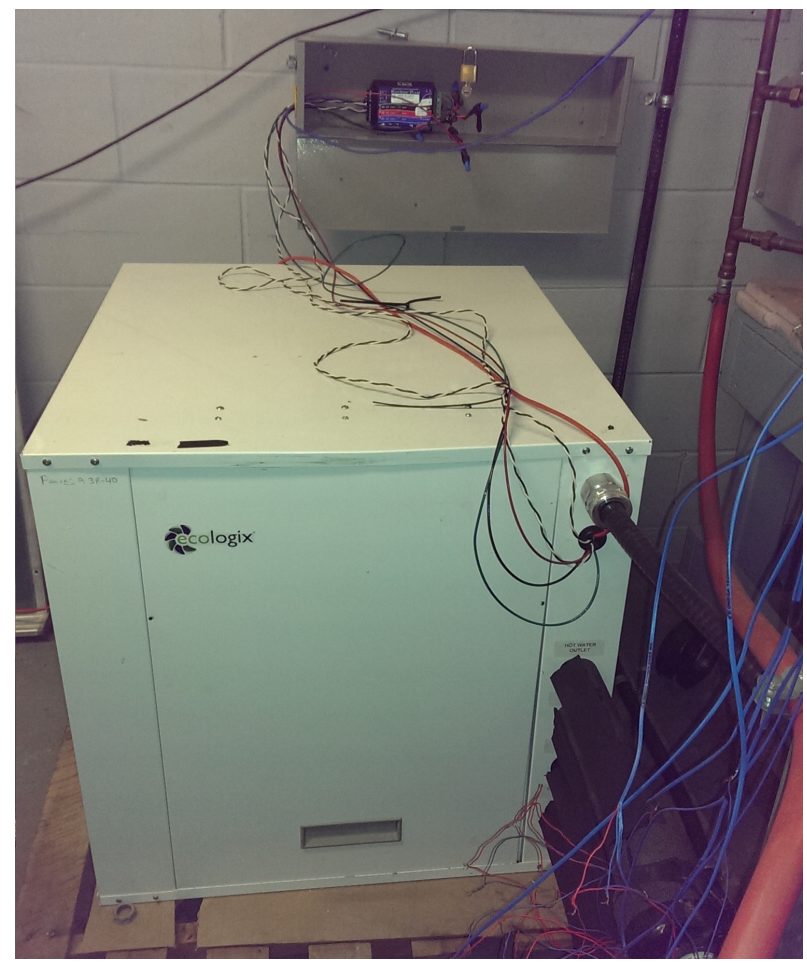

Figure 4.3: Heat pump in SBES lab

individual measurement (every 5 seconds). For the steady state measurement in its entirety (10 minutes) this bias becomes negligeable.

\subsubsection{Electrical power measurement}

The electrical power draw was measured using a WattNode Pulse WNB-3D-240-P (seen directly above the heat pump in Figure 4.3) with two 30 Amp current transformers (Model CTS-0750-030 LF) (as shown in Figure 4.4). If it is assumed that one pulse is missed or one too many pulse is counted at the end or beginning of the measurement period, this pulse would yield an uncertainty of $540 \mathrm{~W}$ for each individual measurement (every 5 seconds). For the steady state measurement in its entirety (10 minutes) this uncertainty becomes negligible.

A National Instruments cFP-CTR-502 data acquisition module was used to count pulses coming from the WattNode. The total uncertainty for the electrical consumption measurements was less than $3.5 \%$ of the measured value. 


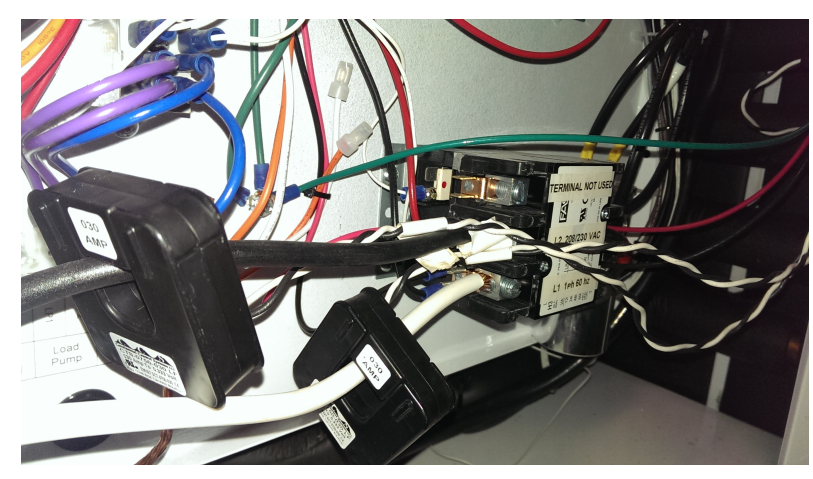

Figure 4.4: Current transformers

\subsection{Steady state tests}

The heat pump was tested at steady nominal recommended water flow rates, and average condenser and evaporator water temperatures. Once steady state conditions (or as close as possible) were achieved, 100 data points were taken every 5 seconds (for a total of $8.33 \mathrm{~min}$ ). The heat pump operating conditions that were tested were as follows:

- Condenser average water temperature: $27,31,37,43,49,55,61^{1}\left[{ }^{\circ} \mathrm{C}\right]$

- Evaporator average water temperature: $7^{1}, 10,15,20,25\left[{ }^{\circ} \mathrm{C}\right]$

- Flow rates: $0.57 \mathrm{~L} \mathrm{~s}^{-1}$ (Nominal flow rate as per manufacturer's recommendations)

Additional flow rates were tested for limited water temperatures combinations. These were:

- Condenser average water temperature of $27{ }^{\circ} \mathrm{C}$ and evaporator average water temperature of $10{ }^{\circ} \mathrm{C}$

- Condenser average water temperature of $61{ }^{\circ} \mathrm{C}$ and evaporator average water temperature of $20{ }^{\circ} \mathrm{C}$

- Flow rates:0.44 and $0.70 \mathrm{~L} \mathrm{~s}^{-1}$

\footnotetext{
${ }^{1}$ The combination of $7{ }^{\circ} \mathrm{C}$ evaporator water temperature and $61^{\circ} \mathrm{C}$ condenser water temperature was not tested
} 


\subsubsection{Experimental results}

The condenser and evaporator heat transfer can be calculated from the measurements using Equation 4.5.

$$
Q=\dot{V} \rho C_{p} \Delta T
$$

where $\dot{V}$ is the volumetric flow rate $\left(\mathrm{m}^{3} \mathrm{~s}^{-1}\right), \rho$ is the water density $\left(\mathrm{kg} \mathrm{m}^{-3}\right), C_{p}$ is the water specific heat $\left(\mathrm{J} \mathrm{kg}^{-1} \mathrm{~K}^{-1}\right)$, and $\Delta T$ is the difference between the inlet and outlet temperatures $\left({ }^{\circ} \mathrm{C}\right)$.

The density and specific heat vary with temperature. Data from CRC Handbook of Chemistry and Physics [65] was used to fit sixth order polynomials for both properties. The resulting residuals were negligible. The CRC Handbook of Chemistry and Physics quotes uncertainties of $0.001 \%$ and $0.1 \%$ for density and specific heat at 1 atm.

The experimental results for the condenser and evaporator heat transfer rates are shown in Figures 4.5 and 4.6 with error bars. The uncertainty of the condenser heat transfer rate was calculated to be less than $1.3 \%$. The uncertainty of the evaporator heat transfer rate was calculated to be less than $5 \%$ for all cases. The electrical power consumption results are shown in Figure 4.7. The error bars are not shown for clarity. The uncertainty in the electrical power measurements was between $81 \mathrm{~W}$ and $187 \mathrm{~W}$.

The heating coefficient of performance $\left(C O P_{h}\right)$ for each of these points can also be calculated with Equation 4.6. The results can be seen in Figure 4.8.

$$
C O P_{h}=Q_{\text {condenser }} / P_{\text {elec }}
$$

The cooling coefficient of performance $\left(C O P_{c}\right)$ can be calculated by subtracting unity from $C O P_{h}$.

\subsubsection{Influence of flow rate on performance}

The heat pump was tested at two additional flow rates for two steady state test points. This was to determine whether water flow rate influenced the performance of the heat pump. Table 4.4 shows the percentage difference in heat transfer rates and 


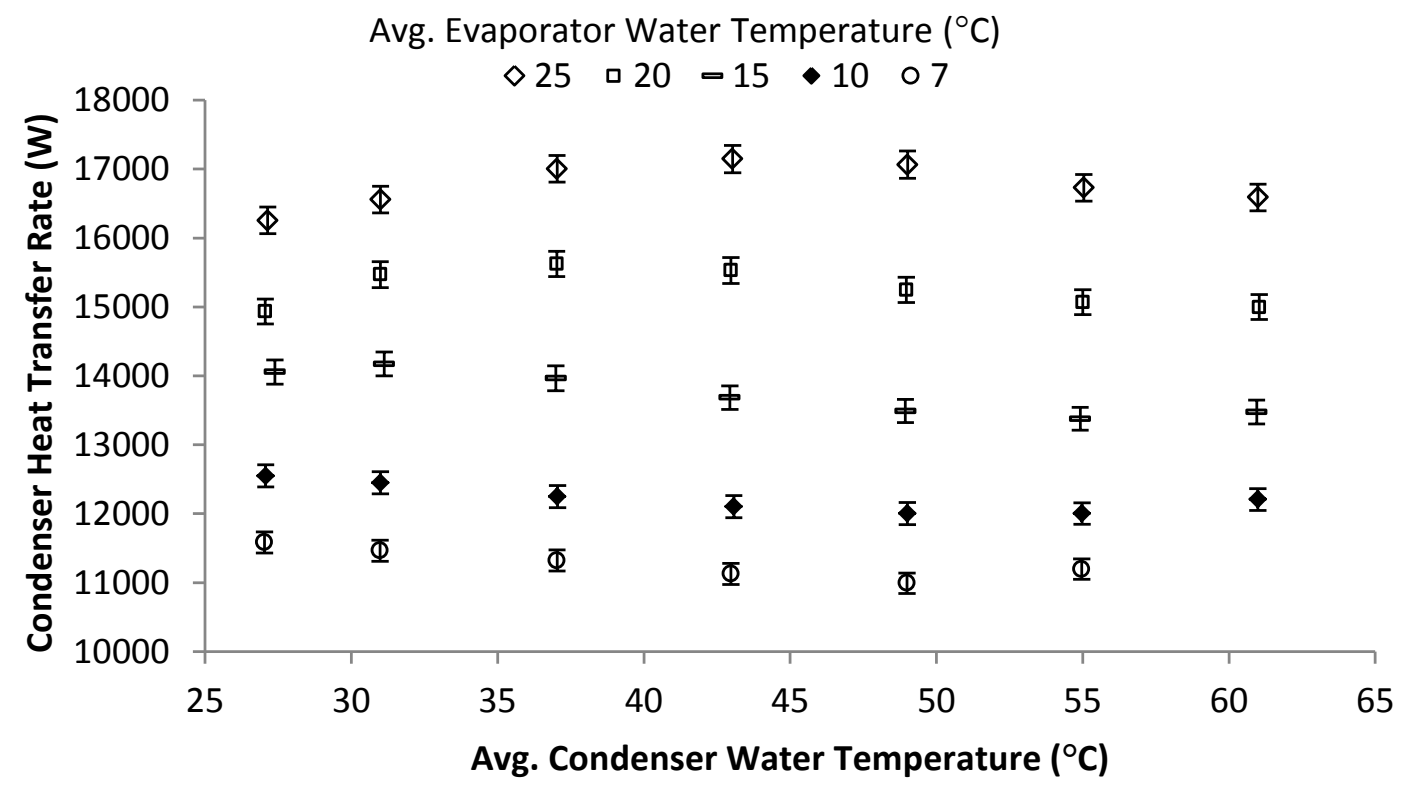

Figure 4.5: Condenser heat transfer rates - steady state experimental results

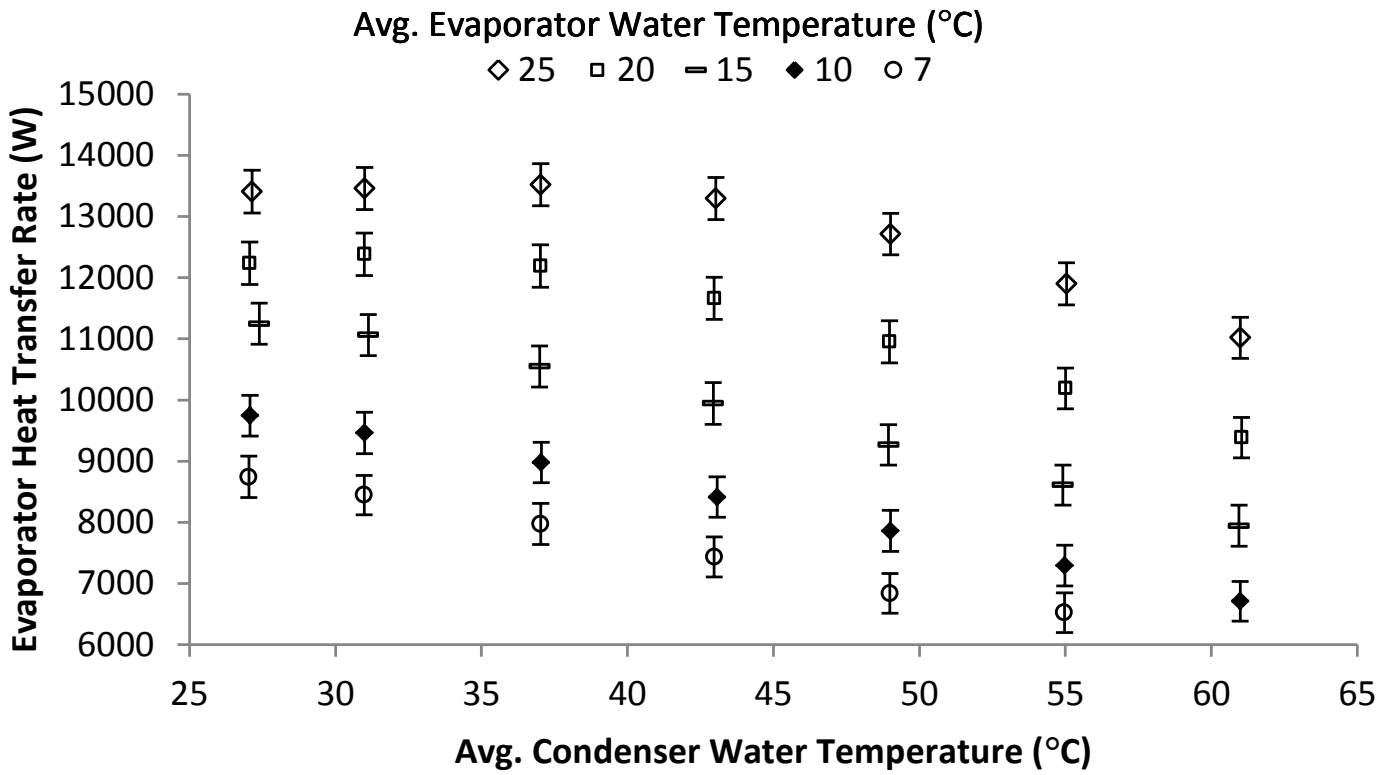

Figure 4.6: Evaporator heat transfer rates - steady state experimental results 


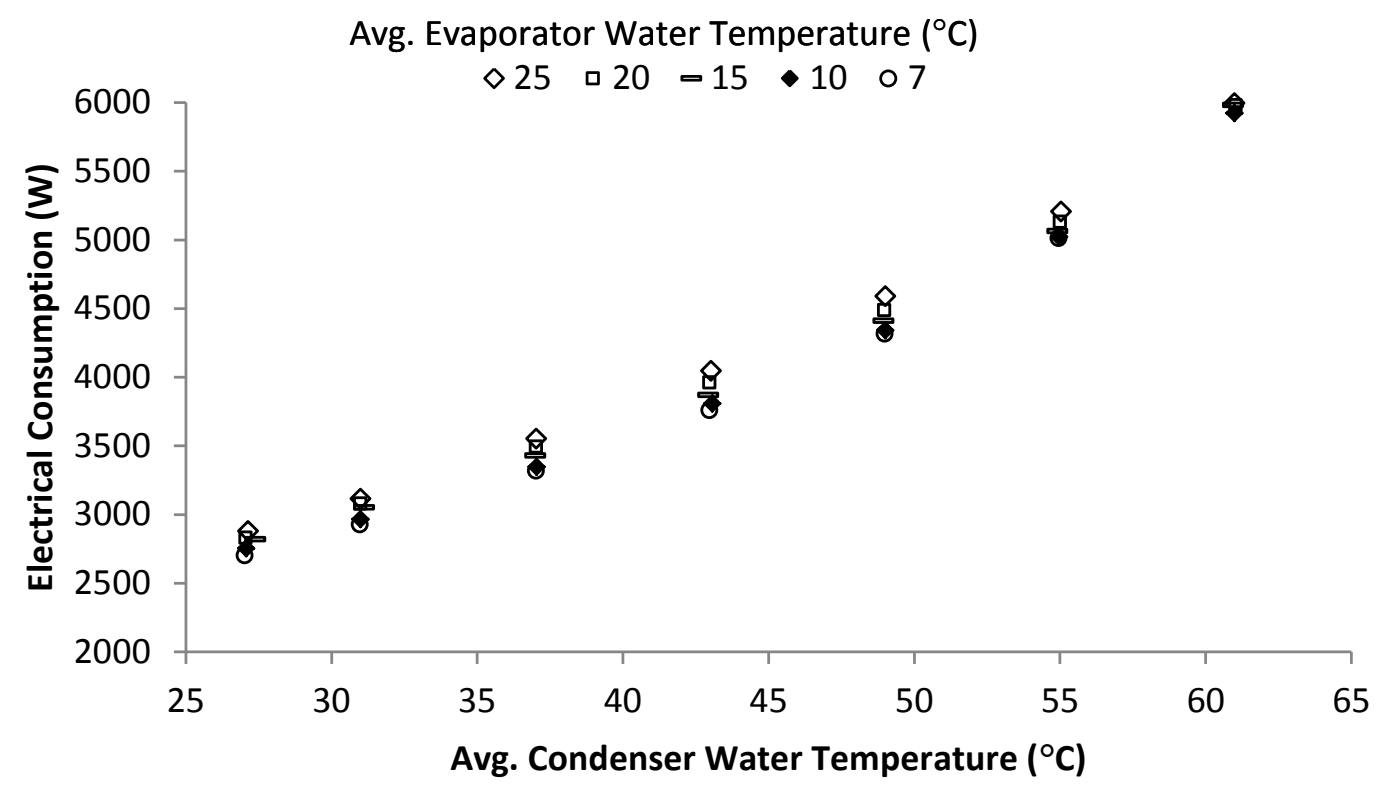

Figure 4.7: Electrical power consumption - steady state experimental results

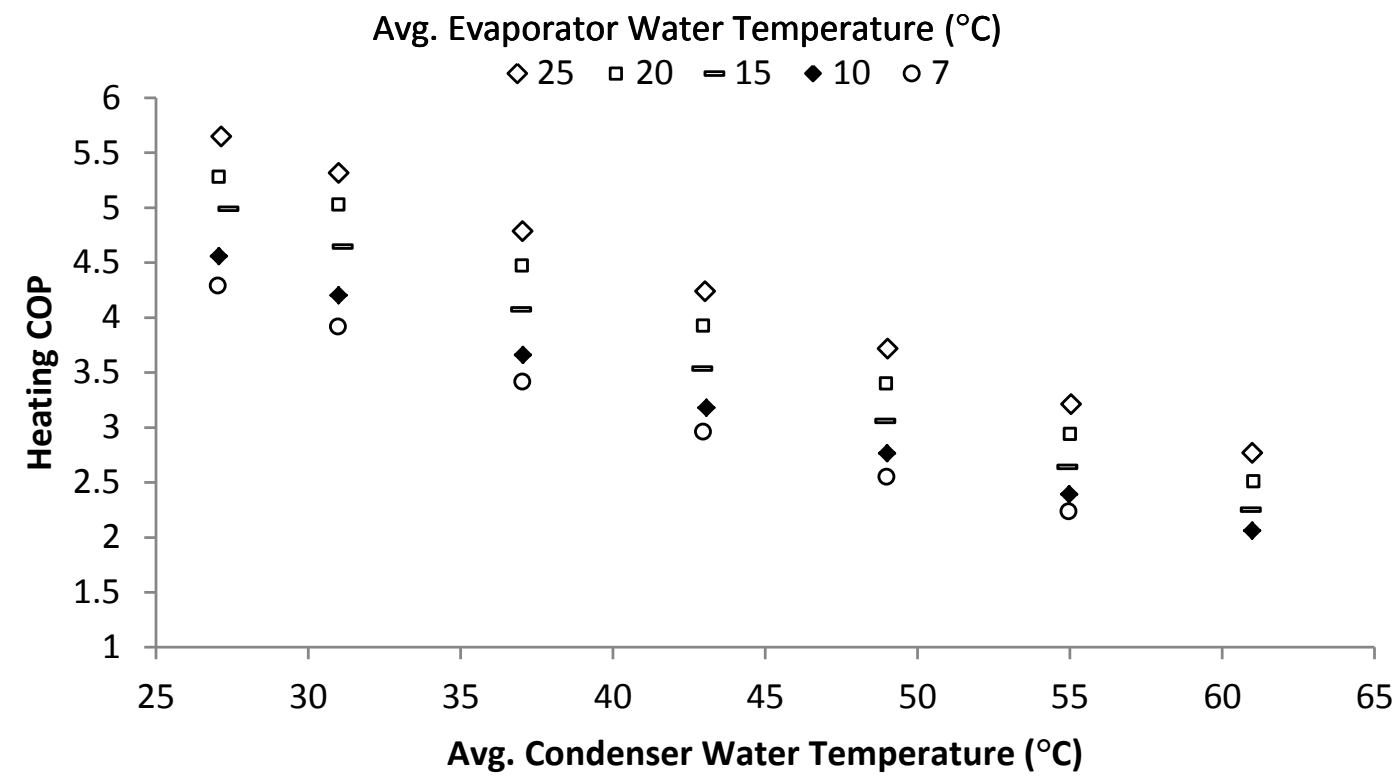

Figure 4.8: Heating COP - steady state experimental results 
Table 4.4: Percent difference in performance at different flow rates

\begin{tabular}{|c|c|c|c|c|c|c|}
\hline \multirow{2}{*}{$\begin{array}{c}T_{\text {condenser }}{ }^{\mathrm{a}} \\
\left({ }^{\circ} \mathrm{C}\right)\end{array}$} & \multirow{2}{*}{$\begin{array}{l}T_{\text {evap }}^{\mathrm{b}} \\
\left({ }^{\circ} \mathrm{C}\right)\end{array}$} & \multirow{2}{*}{$\begin{array}{c}\text { Condenser } \\
\text { Flow Rate } \\
\text { (L/s) }\end{array}$} & \multirow{2}{*}{$\begin{array}{c}\text { Evaporator } \\
\text { Flow Rate } \\
(\mathrm{L} / \mathrm{s})\end{array}$} & \multicolumn{3}{|c|}{$\begin{array}{c}\text { Percentage } \\
\text { Difference }\end{array}$} \\
\hline & & & & $Q_{\text {condenser }}$ & $Q_{\text {evap }}$ & $P_{\text {elec }}$ \\
\hline \multirow{3}{*}{27} & \multirow{3}{*}{10} & $\begin{array}{c}0.57 \\
\text { (Nominal) }\end{array}$ & $\begin{array}{c}0.57 \\
\text { (Nominal) }\end{array}$ & - & - & - \\
\hline & & 0.70 & 0.70 & 0.86 & 0.86 & -1.2 \\
\hline & & 0.44 & 0.44 & -1.0 & -1.9 & 0.39 \\
\hline \multirow{3}{*}{61} & \multirow{3}{*}{20} & $\begin{array}{c}0.57 \\
\text { (Nominal) }\end{array}$ & $\begin{array}{c}0.57 \\
\text { (Nominal) }\end{array}$ & - & - & - \\
\hline & & 0.70 & 0.70 & 1.3 & 0.97 & -0.91 \\
\hline & & 0.44 & 0.45 & 0.015 & -1.2 & 1.6 \\
\hline
\end{tabular}

power consumption between the nominal flow rate results and the higher and lower flow rates. These results show that for changes in flow rates greater than $20 \%$, there is a very small difference in the performance of the heat pump. These changes are within the experimental uncertainty.

\subsection{Transient tests}

A set of transient experiments were performed to characterize the startup characteristics of the heat pump. The heat pump was started from a cold state (room temperature, previously not active for an entire day), and after various periods of cool down time following approximately 30 minutes cycles. Figure 4.9 shows these cycles back to back on the same graph. The first cycle was a cold start. During the experimental phase, these cycles did not actually occur back to back as Figure 4.9 suggests. The data shown in Figure 4.9 is stitched up from a series of three different experiments: the cold start cycle, the 180 minute cycle, and the remaining three cycles. In all experiments, the flow rates were maintained at approximately $0.57 \mathrm{~L} / \mathrm{s}$ 
on the evaporator and condenser sides. The inlet condenser water temperature was approximately $29{ }^{\circ} \mathrm{C}$ and the inlet evaporator water temperature was approximately $17^{\circ} \mathrm{C}$.

Because of thermal mass in the thermowells used with the Pt100s, thermocouples were used for the transient tests in the condenser water. Thermocouples were directly in contact with water so did not have additional thermal mass. Thermocouples had a higher uncertainty than the Pt100s however. For the transient cycles in Figure 4.9, the maximum uncertainty of all of the data points for the condenser heat transfer rate was $1653 \mathrm{~W}$. In comparison, the maximum evaporator heat transfer rate uncertainty was $606 \mathrm{~W}$ with the use of the 5-junction thermopile. The maximum uncertainty of individual electrical power measurements was $549 \mathrm{~W}$. Most of this uncertainty is caused by the potential for lost pulses due to the short sampling time. As will be discussed later, the uncertainty of a single measurement is not critical however.

\subsection{TRNSYS model}

An empirical model was developed and implemented in TRNSYS. The model is based on a typical performance map of steady state test points. The transient nature of the startup of the heat pump was also included in the model.

\subsubsection{Linear regression of empirical data}

The statistical software $\mathrm{R}$ was used to fit the steady state experimental data through polynomial equations using linear regression. The equations were of the form shown in Equation 4.7. This equation is similar in form to an equation used by Stoecker and Jones [83] for modelling chillers. Only terms with $95 \%$ statistical significance were kept. These line fits gave maximum absolute residuals of $215 \mathrm{~W}, 139 \mathrm{~W}$, and $38 \mathrm{~W}$ for $Q_{\text {condenser }}, Q_{\text {evap }}$, and $P_{\text {elec }}$ respectively. Table 4.5 shows the coefficients to be used in Equation 4.7. 


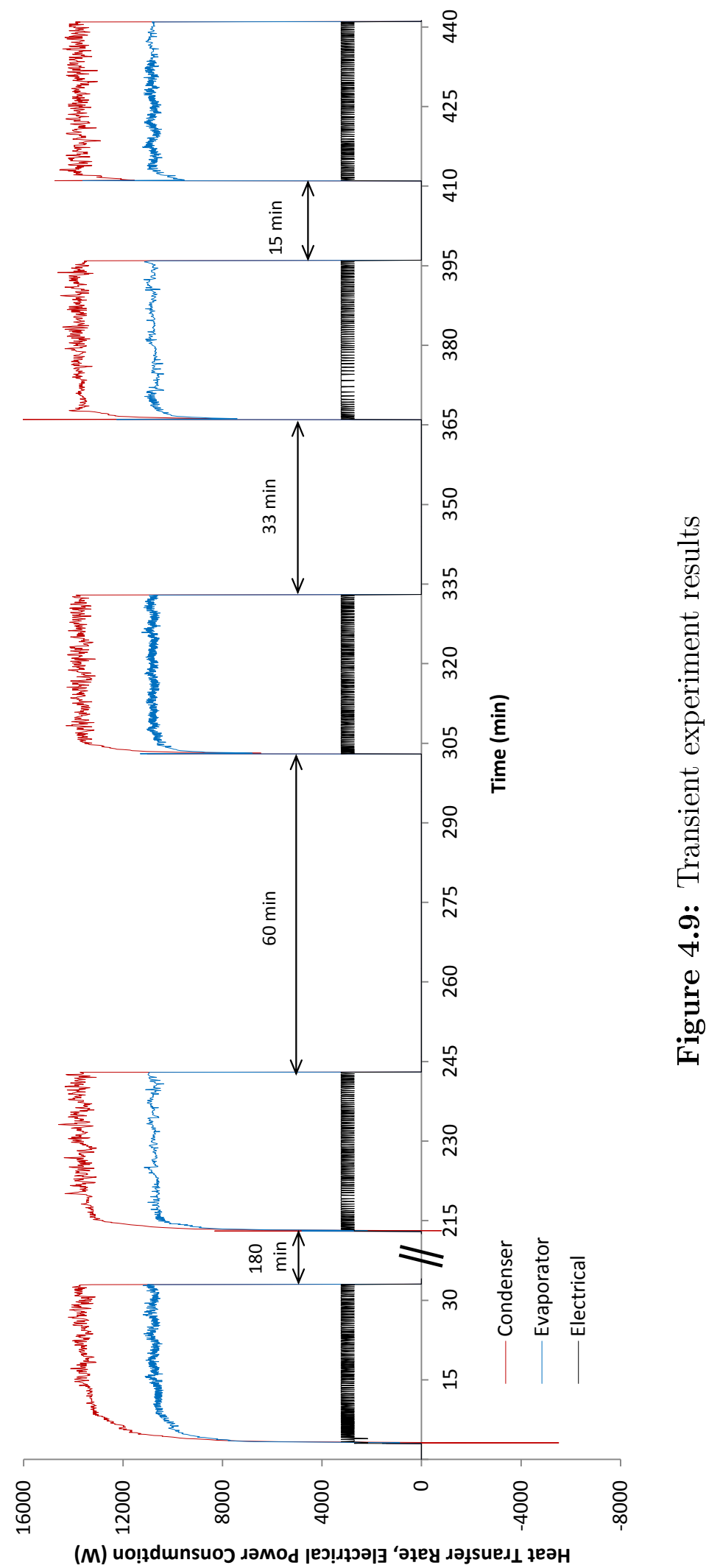


Table 4.5: Steady state heat pump equations coefficients

\begin{tabular}{lccc}
\hline Coefficients & $Q_{\text {condenser }}$ & $Q_{\text {evap }}$ & $P_{\text {elec }}$ \\
\hline$\Psi_{A}$ & 7615 & 7572 & 960.7 \\
$\Psi_{B}$ & 200.3 & 0 & 99.38 \\
$\Psi_{C}$ & 195.7 & 293.3 & -40.30 \\
$\Psi_{D}$ & -11.40 & -12.90 & 0 \\
$\Psi_{E}$ & -7.612 & -2.825 & -2.181 \\
$\Psi_{F}$ & 0.08412 & 0.03634 & 0.03072 \\
$\Psi_{G}$ & 0 & 0 & 0 \\
$\Psi_{H}$ & 13.59 & 9.899 & 2.623 \\
$\Psi_{I}$ & -0.2442 & -0.2173 & -0.03088 \\
$\Psi_{J}$ & 0.2687 & 0.3037 & 0 \\
\hline
\end{tabular}

$$
\begin{gathered}
Q_{\text {condenser }}, Q_{\text {evap }}, \text { or } P_{\text {elec }}=\Psi_{A}+\Psi_{B} \cdot T_{\text {condenser }}+\Psi_{C} \cdot T_{\text {evap }}+\Psi_{D} \cdot T_{\text {evap }}^{2}+\Psi_{E} \cdot T_{\text {condenser }}^{2} \\
+\Psi_{F} \cdot T_{\text {condenser }}^{3}+\Psi_{G} \cdot T_{\text {evap }}^{3}+\Psi_{H} \cdot T_{\text {condenser }} \cdot T_{\text {evap }}+\Psi_{I} \cdot T_{\text {condenser }}^{2} \cdot T_{\text {evap }} \\
+\Psi_{J} \cdot T_{\text {evap }}^{2} \cdot T_{\text {condenser }}
\end{gathered}
$$

where; $T_{\text {condenser }}$ and $T_{\text {evap }}$ are the average condenser and evaporator water temperature taken as $\left(T_{\text {in }}+T_{\text {out }}\right) / 2$.

\subsubsection{Steady state model}

With the equations defined in Section 4.5.1, a steady state model was developed. The steady state model requires the inputs and returns the outputs shown in Table 4.6.

Equation 4.7 is based on the average condenser and evaporator water inlet/outlet temperatures. As only the inlet temperatures are known, an iterative process was used to solve Equation 4.7 for $Q_{\text {condenser }}, Q_{\text {evap }}$, and $P_{\text {elec }}$. At each time step, for the first iteration, the average condenser and evaporator water temperatures are assumed to be equal to the inlet temperatures and $Q_{\text {condenser }}, Q_{\text {evap }}$, and $P_{\text {elec }}$, are calculated. 
Table 4.6: Heat pump model inputs and outputs

\begin{tabular}{ll}
\hline \multicolumn{1}{c}{ Inputs } & \multicolumn{1}{c}{ Outputs } \\
\hline Control Signal $(-)$ & Condenser water heat gain $\left(\mathrm{kJ} \mathrm{hr}{ }^{-1}\right)$ \\
Condenser water flow rate $\left(\mathrm{kg} \mathrm{hr}^{-1}\right)$ & Condenser water outlet temperature $\left({ }^{\circ} \mathrm{C}\right)$ \\
Condenser water temperature $\left({ }^{\circ} \mathrm{C}\right)$ & Evaporator water heat removal $\left(\mathrm{kJ} \mathrm{hr}{ }^{-1}\right)$ \\
Evaporator water flow rate $\left(\mathrm{kg} \mathrm{hr}^{-1}\right)$ & Evaporator water outlet temperature $\left({ }^{\circ} \mathrm{C}\right)$ \\
Evaporator water temperature $\left({ }^{\circ} \mathrm{C}\right)$ & Electrical consumption $\left(\mathrm{kJ} \mathrm{hr}{ }^{-1}\right)$ \\
\hline
\end{tabular}

The outlet water temperatures are then calculated with Equation 4.5. New average water temperatures are then calculated for the condenser water and evaporator water. This process is repeated until the average condenser temperature changes by less than $0.001{ }^{\circ} \mathrm{C}$ between two iterations.

\subsubsection{Steady state model applied to transient test}

In order to test the adequacy of the steady state model discussed in Section 4.5.2, the model results were compared with experimental data discussed in Section 4.4. Figures 4.10 through 4.14 show the percentage error between the steady state model and the experiment in total energy transfer in the condenser and evaporator and the electricity consumption since the beginning of the various cycles. Figure 4.10 is the cold start cycle where the heat pump had been sitting idle in over 24 hours. The following figures correspond to cycles with progressively shorter idle time, as seen in Figure 4.9. The energy was calculated at every 3 minutes, which will be the time step of the full model simulations. Equations 4.8 through 4.10 were used to calculate the energy transfer/consumption since beginning of the various cycles. The left Reinmann sum is used to approximate the integral in for both the experimental and modelled data. The experimental data is available every 5 seconds, whereas the modelled data is available every 3 minutes, the length of one model time step. Equation 4.11 calculates the percentage error between the modelled and experimental results.

$$
E_{\text {condenser }}=\int_{t=0}^{t=\varphi} Q_{\text {condenser }} d t
$$




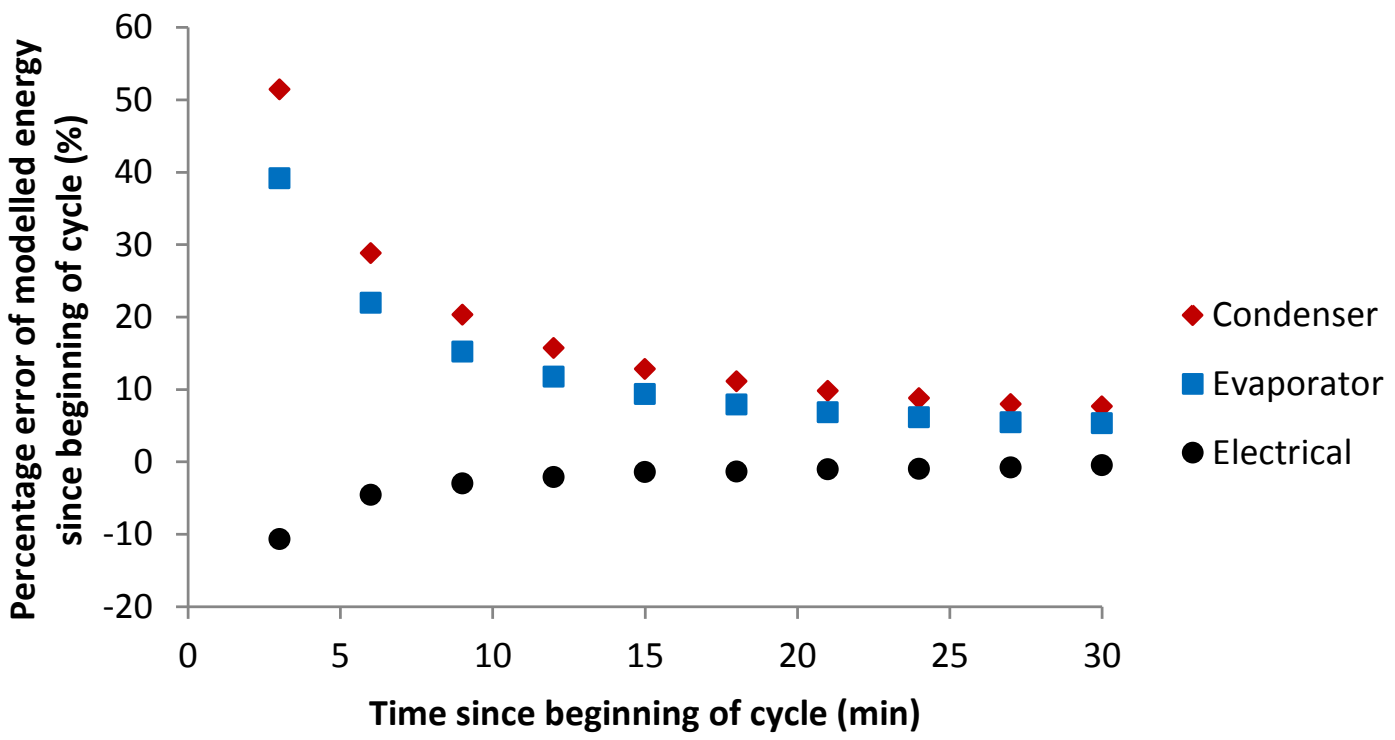

Figure 4.10: Percentage difference in energy between steady state model and experiment since start of cycle - cold start

$$
\begin{aligned}
E_{\text {evap }} & =\int_{t=0}^{t=\varphi} Q_{\text {evap }} d t \\
E_{\text {elec }} & =\int_{t=0}^{t=\varphi} P_{\text {elec }} d t
\end{aligned}
$$

where $\varphi$ is the time since the beginning of the cycle (in seconds).

$$
\text { \%error }=100 \cdot \frac{E_{\text {model }}-E_{\text {experiment }}}{E_{\text {experiment }}}
$$

The results show that the error fell with shorter time periods between cycles. This may be caused by the fact that the heat pump was already warmed up, and that refrigeration migration back to the evaporator may not have had time to fully occur for shorter time periods. For shorter time periods between cycles, a steady state model seemed appropriate. Additionally, the total error went down as the longer the cycle lasted as the heat pump approached steady state and the initial transient errors became smaller relative to the total energy of the cycle. However, it is clear that the steady state model is not appropriate if flexibility in idle time between cycle and 


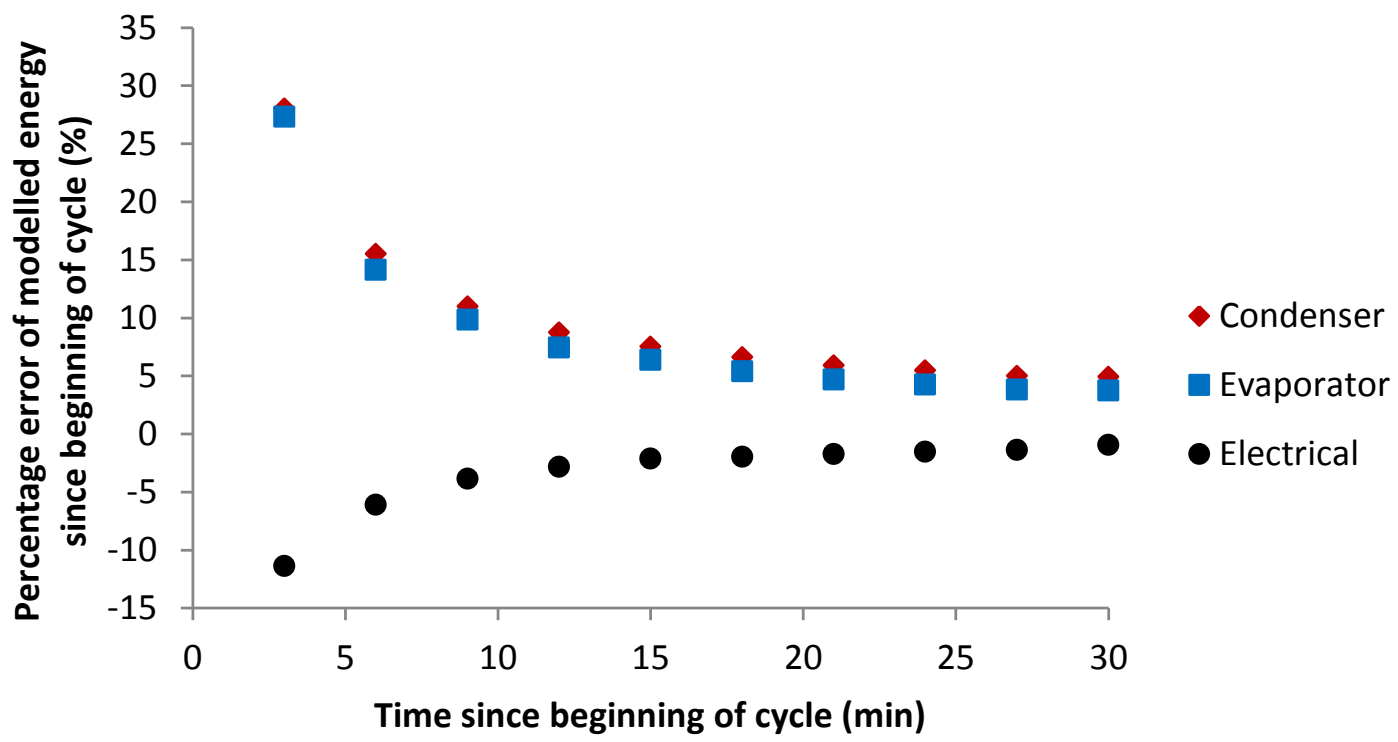

Figure 4.11: Percentage difference in energy between steady state model and experiment since start of cycle - 3 hours since last cycle

cycle length is required. 


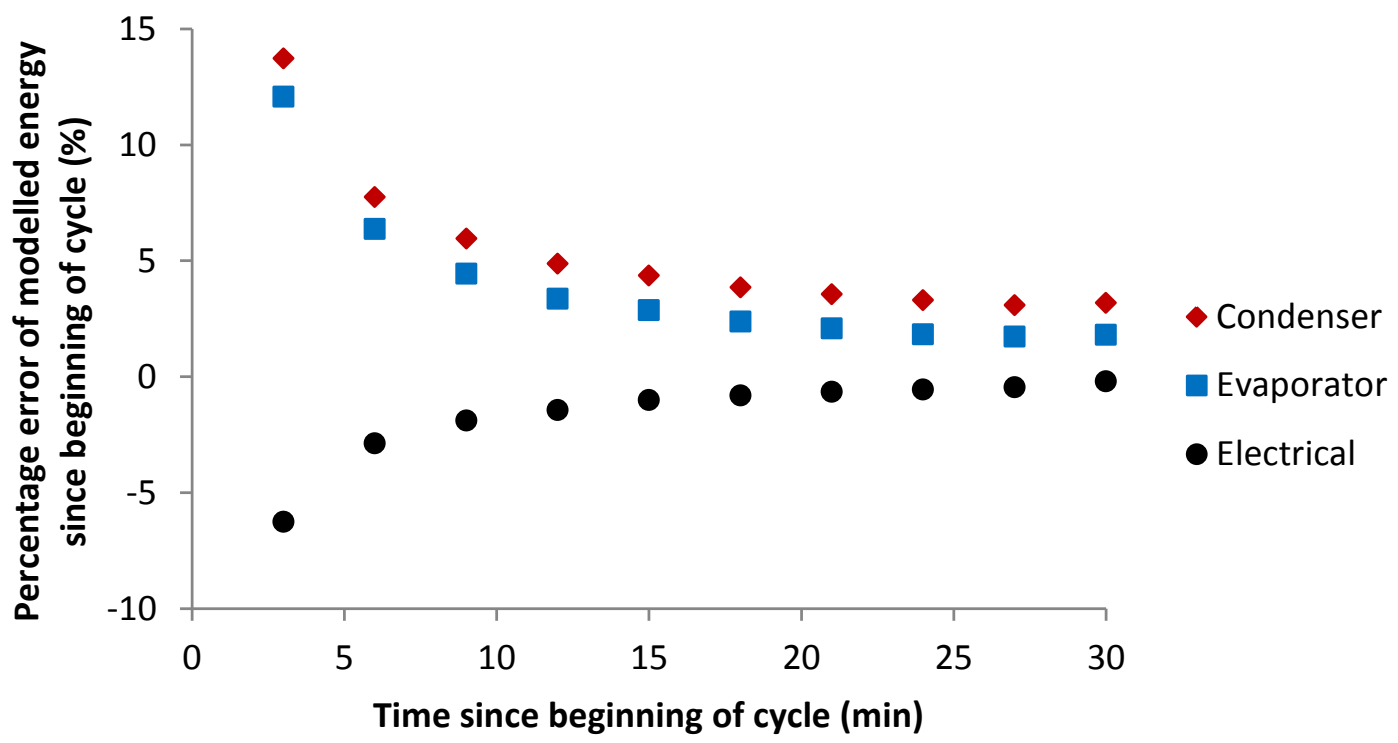

Figure 4.12: Percentage difference in energy between steady state model and experiment since start of cycle - 1 hour since last cycle

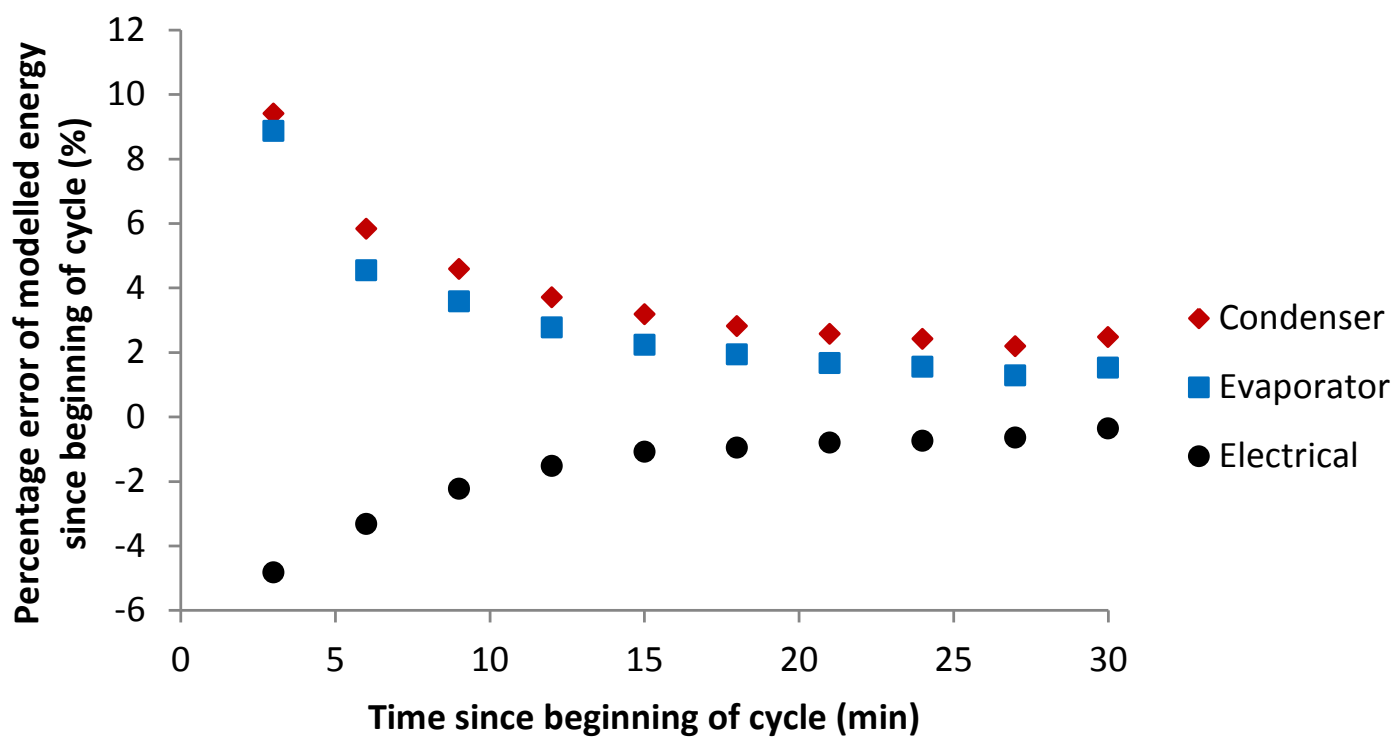

Figure 4.13: Percentage difference in energy between steady state model and experiment since start of cycle - 33 minutes since last cycle 


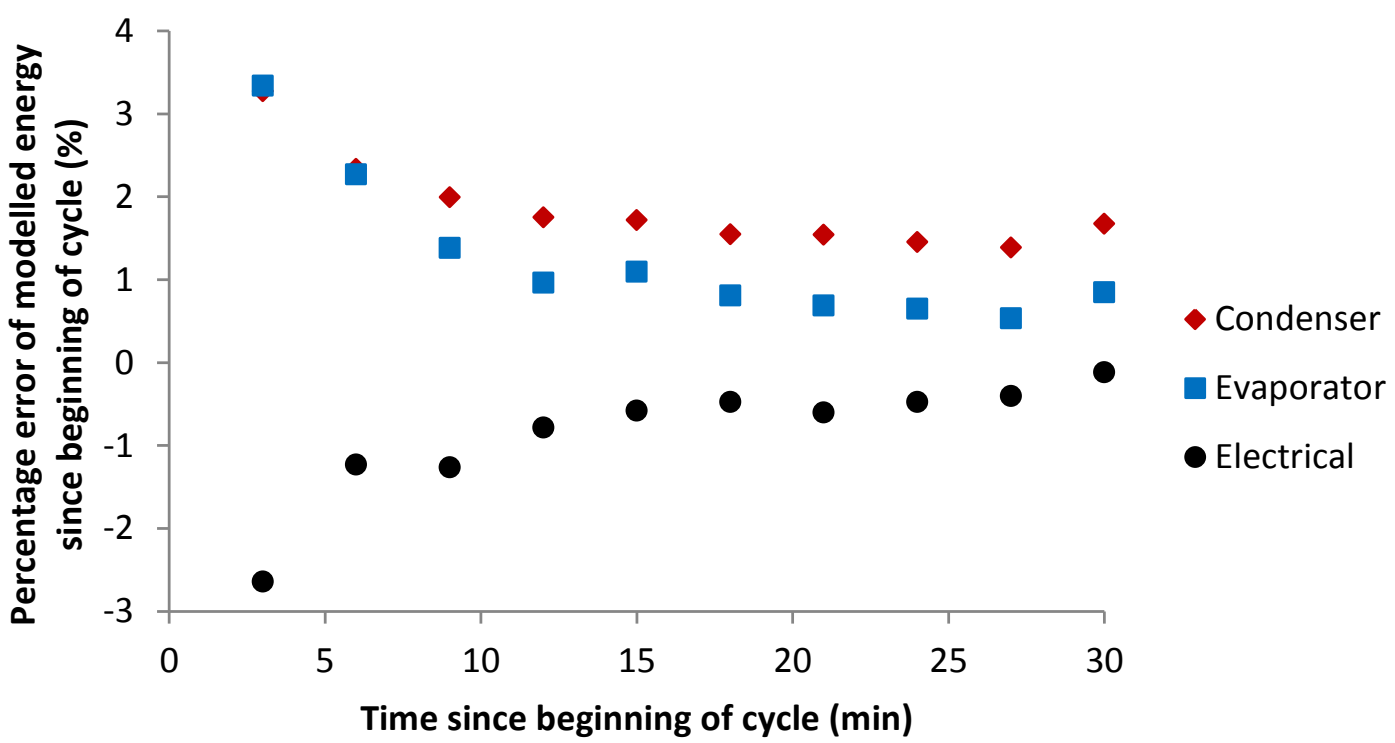

Figure 4.14: Percentage difference in energy between steady state model and experiment since start of cycle - 15 minutes since last cycle

\subsubsection{Development of transient heat pump model}

A simple transient model was applied to the the steady state Equations 4.7 and corresponding coefficients. This model was based on the assumption that condenser and evaporator startup transient heat transfer rates can be modelled with Equation 4.12.

$$
\frac{d Q_{\text {transient }}}{d t}=\frac{1}{\tau}\left[Q_{\text {transient }}-Q_{\text {steady }}\right]
$$

where, $Q_{\text {transient }}$ is the transient heat transfer rate for either the condenser or the evaporator, and $Q_{\text {steady }}$ is the corresponding steady state heat transfer rate as calculated with 4.7. When discretized, this equation yields Equation 4.13.

$$
Q_{\text {transient }}=Q_{\text {steady }}\left(1-e^{-\Delta t / \tau}\right)+Q_{\text {transient }, t-1} \cdot e^{-\Delta t / \tau}
$$

where the subscript $t-1$ denotes the previous time step. The time constant $\tau$ is a function of the amount of time since the end of the last cycle. This time constant $\tau$ can be assumed to change with a rate of change proportional to the difference between the current time constant $\tau$ and the time constant for a cycle with an infinitely large 
amount of time since the last cycle. This can be seen in Equation 4.14.

$$
\frac{d \tau}{d t}=\frac{1}{\Lambda}\left[\tau-\tau_{\text {coldstart }}\right]
$$

where, $\Lambda$ is a coefficient (in seconds) that describes the rate of change of the time constant $\tau$ between cycles and $\tau_{\text {coldstart }}$ is the time constant for a cycle started after a large amount of time since the last cycle (i.e. cold start cycle). Discretizing this equation yields Equation 4.15

$$
\tau=\tau_{\text {coldstart }}\left(1-e^{-\Delta t / \Lambda}\right)+\tau_{t-1} \cdot e^{-\Delta t / \Lambda}
$$

The value of $\tau$ is not necessarily zero at the end of a cycle, therefore an additional parameter is defined. This parameter $\tau_{0}$ is the value of $\tau$ immediately following the end of a cycle.

Another way to define $\tau_{\text {coldstart }}$ is that if the heat pump starts cold (i.e. had never been used previously), the output of the condenser (or evaporator) would rise with the a time constant $\tau_{\text {coldstart }}$. If the heat pump starts immediately following a previous ON cycle (i.e. heat pump was OFF for an infinitely small amount of time), the output of the condenser (or evaporator) would rise with a time constant $\tau_{0}$. During periods when the heat pump is OFF, $\Lambda$ is a time constant that describes how $\tau$ (the heat pump time constant) changes with time from $\tau_{0}$ to $\tau_{\text {coldstart }}$.

\section{Transient model solution methodology}

The transient model is solved iteratively. For the first iteration, (and if the heat pump is $\mathrm{ON}$ ) the inlet condenser and evaporator temperatures are used to evaluate the steady state condenser and evaporator heat transfer rates and the compressor electrical power (Equation 4.7). Then, the transient condenser and evaporator heat transfer rates are calculated with Equation 4.13 based on the corresponding time constants. An average water temperature is then calculated for the condenser and evaporator and the steady state values from Equation 4.7 can be recalculated. This is iterated until convergence. When $Q_{\text {transient }}$ reaches $99.9 \%$ of $Q_{\text {steady }}$, the transient model is switched off, $Q_{\text {steady }}$ is used for the rest of the cycle, and $\tau$ is reset to $\tau_{0}$. Between two ON cycles, Equation 4.15 is used to calculate the time constant $\tau$ based on the elapsed time since the previous cycle. 


\section{Finding unknown parameters}

Three parameters were unknown for each the condenser and the evporator: $\Lambda$, $\tau_{\text {coldstart }}$, and $\tau_{0}$. These were found using the experimental data from Figure 4.9. A genetic algorithm was used to minimize the error between the transient model and the experimental data. The objective function is shown in Equation 4.16.

$$
f=\sqrt{\sum_{\substack{\Gamma=E_{\text {condenser }} \\ E_{\text {evap }} \\ E_{\text {elec }}}} \sum_{i=0}^{N}\left(\frac{\Gamma_{\text {model }}-\Gamma_{\text {experiment }}}{\Gamma_{\text {experiment }}}\right)^{2}}
$$

where $\mathrm{N}$ is the total number of 3 minutes time steps for which the heat pump is ON during cycles that are used to evaluate the unknown parameters. Only three of the five cycles were used to evaluate the unknown parameters: cold start, 1 hours idle, and 15 minutes idle. The other two cycles ( 3 hours idle, and 33 minutes idle) were used for validation. $E$ is the total energy (heat or electrical) in Joules since the beginning of the cycle of interest. At the end of each cycle, $\mathrm{E}$ is reset to zero. $\mathrm{E}$ can be defined by the following equations:

$$
\begin{aligned}
E_{\text {condenser }} & =\int_{t=180 s \cdot i}^{t=180 s \cdot i+\Delta t} Q_{\text {condenser }} d t \\
E_{\text {evap }} & =\int_{t=180 s \cdot i}^{t=180 s \cdot i+\Delta t} Q_{\text {evap }} d t \\
E_{\text {elec }} & =\int_{t=180 s \cdot i}^{t=180 s \cdot i+\Delta t} P_{\text {elec }} d t
\end{aligned}
$$

where $\Delta t$ is the 3 minute time step (180 seconds), the $180 \mathrm{~s}$ is to convert the time step $i$ into time $t$ in seconds.

The left Reinmann sum was used to approximate both the experimental and the modelled energy (Equations 4.17 through 4.19) over a 3 minute time step. The experimental data was taken every 5 seconds while the modelled data was taken every three minutes.

As mentioned at the end of Section 4.4, the uncertainty of the individual measurements of the transient experiment was of secondary concern for the accuracy of the transient portion of the model. This can be explained by the fact that the transient part of the model only dealt with time response (various time constants) and not 
Table 4.7: Parameters for transient heat pump model

\begin{tabular}{lcc}
\hline Parameters & $\begin{array}{c}\text { Condenser } \\
(\mathbf{h r})\end{array}$ & $\begin{array}{c}\text { Evaporator } \\
\text { (hr) }\end{array}$ \\
\hline$\Lambda$ & 3.744 & 2.544 \\
$\tau_{\text {coldstart }}$ & 0.048 & 0.041 \\
$\tau_{0}$ & 0.018 & 0.017 \\
\hline
\end{tabular}

magnitudes of heat transfer $(Q)$. This meant that the transient experiment needed to be accurate in the time response, and that the uncertainty of the magnitude of the measurements was not a primary concern.

\section{Results of transient heat pump model}

Solving the optimization problem described above gave the parameters seen in Table 4.7. These parameters can then be used to validate the transient model.

Figures 4.15 through 4.19 show the results of the transient model with the optimized parameters. As mentioned previously, only three of the five cycles were used to evaluate the unknown parameters: cold start, 1 hours idle, and 15 minutes idle. The other two cycles ( 3 hours idle, and 33 minutes idle) were used for validation. Nevertheless, the results of the validation cycles are also shown here.

The transient model showed a great improvement over the steady state model. The most drastic example is that the cold start error for energy exchanged in the condenser after the first model time step (3 minutes) went down from above $50 \%$ to less than $2 \%$. In all cases, except the 15 minutes case, the condenser and evaporator error was greatly reduced for the first few time steps. There was no change to the error of the electrical requirements as the model for the compressor demand is strictly based on steady state values. Contrary to the heat transfer rates in the condenser and evaporator, the compressor startup transient response is not well described with time constants. Due to refrigerant migration, compressor power usually peaks within seconds of the start of the cycle before settling to a lower power condition at steady 


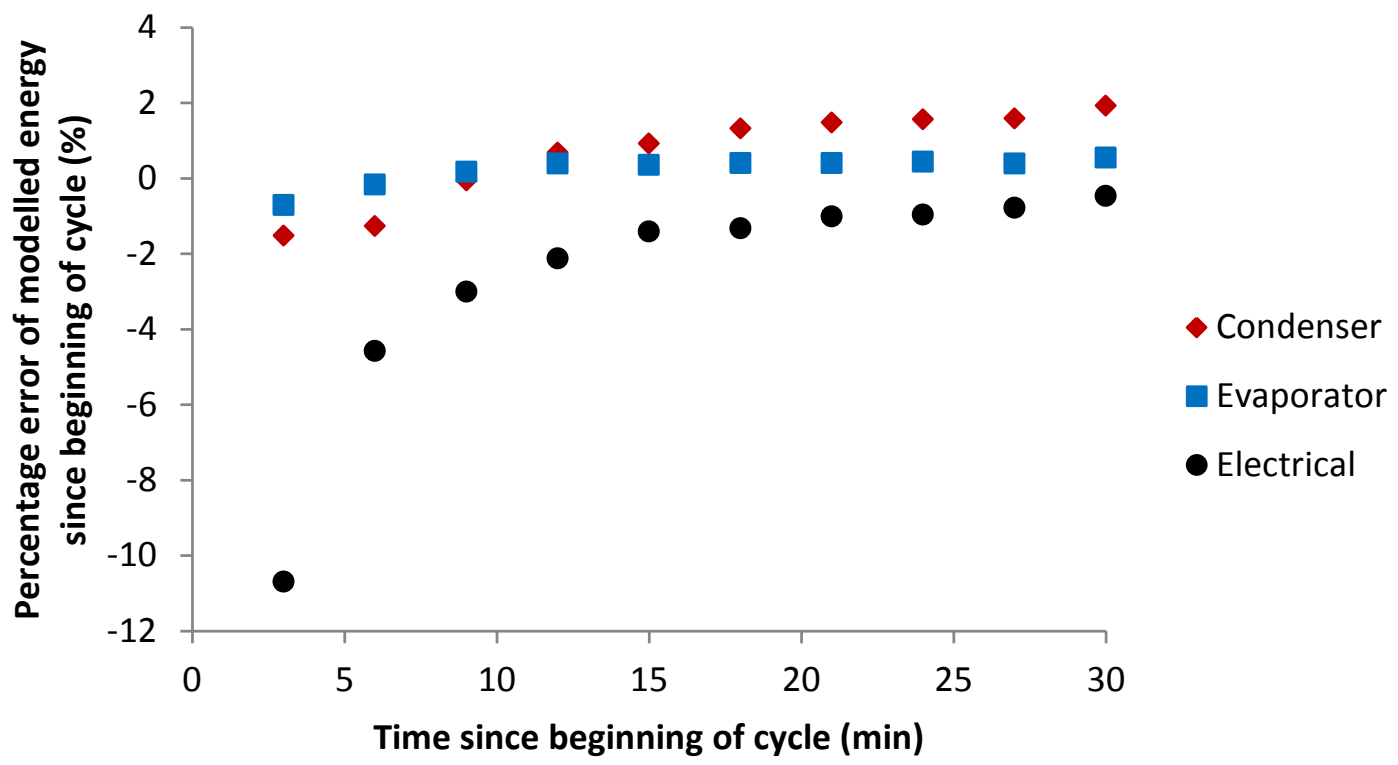

Figure 4.15: Percentage difference in energy between transient model and experiment since start of cycle - cold start

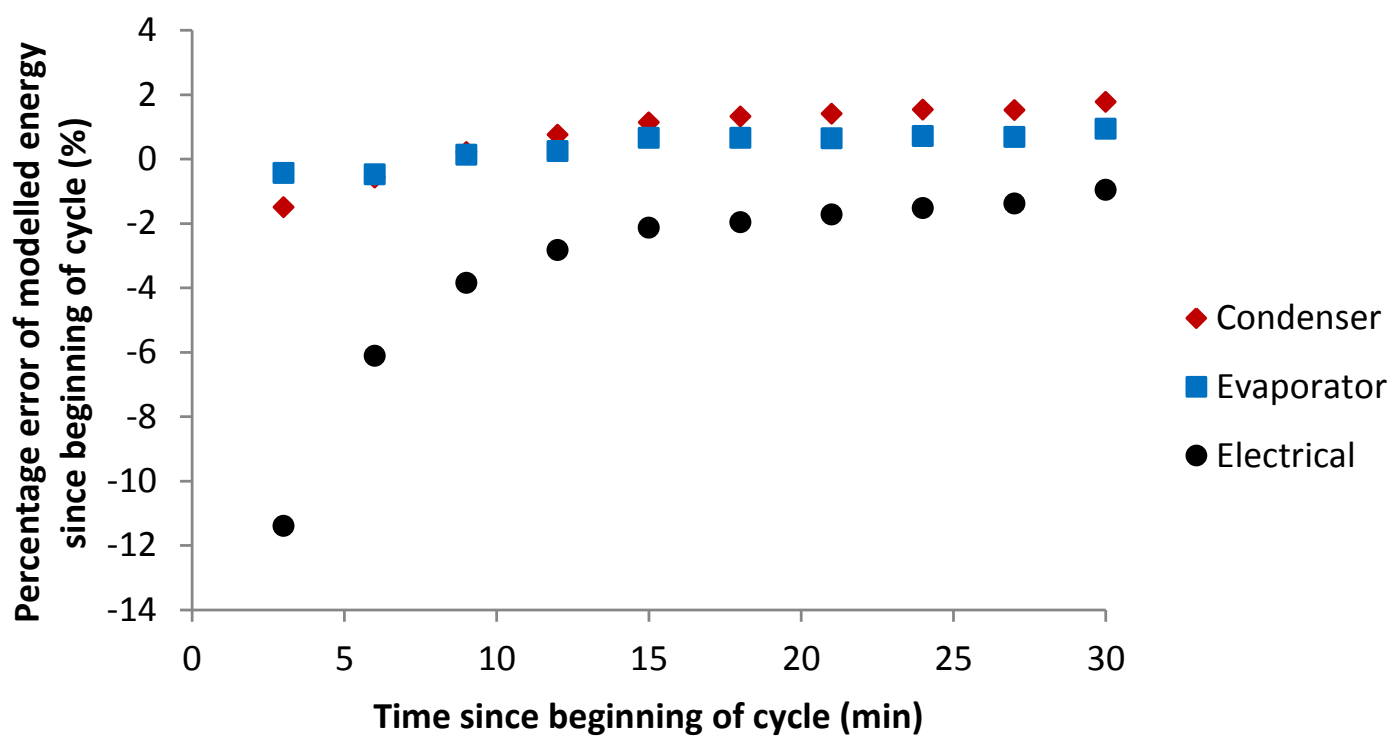

Figure 4.16: Percentage difference in energy between transient model and experiment since start of cycle - 3 hours since last cycle 


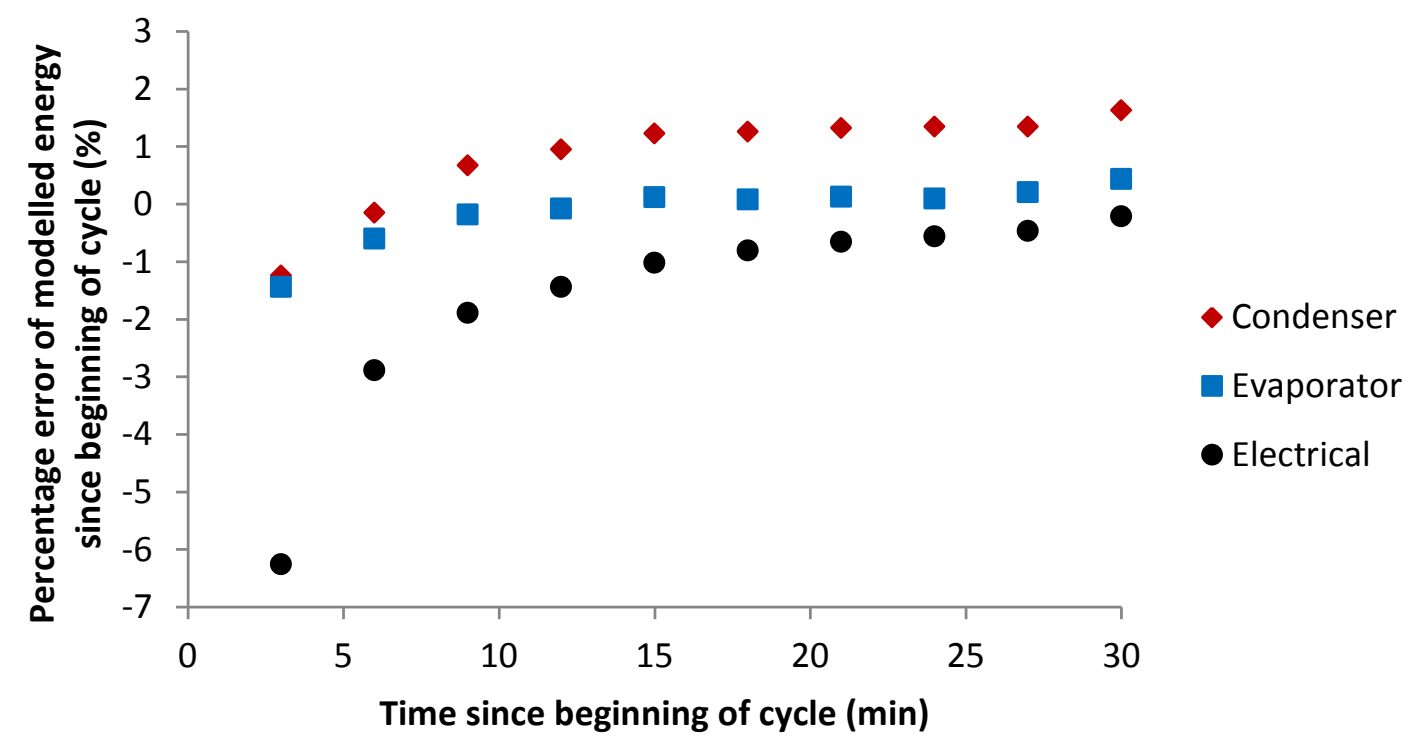

Figure 4.17: Percentage difference in energy between transient model and experiment since start of cycle - 1 hour since last cycle

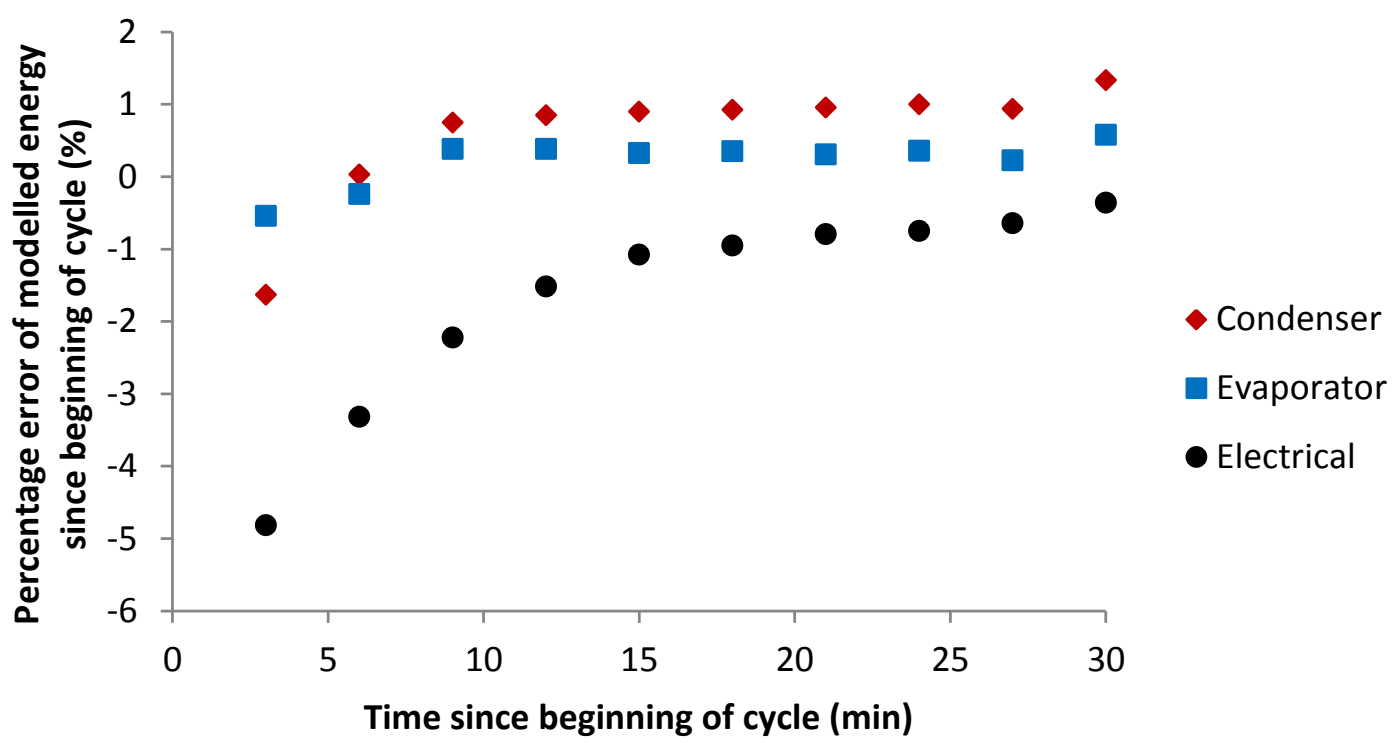

Figure 4.18: Percentage difference in energy between transient model and experiment since start of cycle - 33 minutes since last cycle 


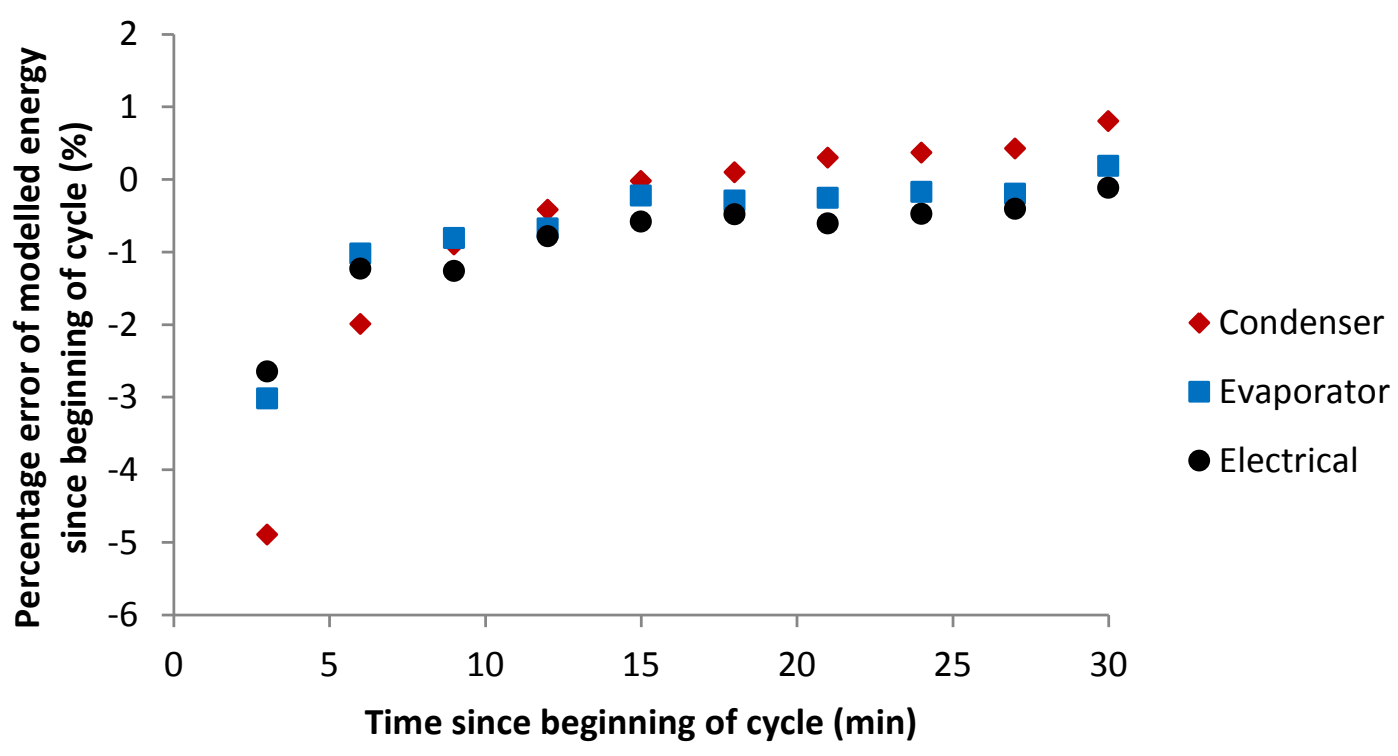

Figure 4.19: Percentage difference in energy between transient model and experiment since start of cycle - 15 minutes since last cycle

state.

There was no discernable computational time difference between a simple test case run for a year at a 3 minute time step between the transient model and the steady state model. Additionally, the TRNSYS Type 927 steady state heat pump model [84] was run for the same test case with similar computational time.

\subsection{Closing remarks}

A $11 \mathrm{~kW}$ (nominal cooling) water-water heat pump was tested experimentally and an empirical model was derived. It was shown that a steady state performance map model was inadequate to model the heat pump due to startup transient effects. A transient model was developed based on a performance map approach coupled with time constants for the condenser and evaporator heat transfer rates. Such time constant was not developed for the compressor electrical consumption. The time constants were dependent on the elapsed time since the heat pump was last switched from energized to de-energized. This approach gave better results than the steady state model alone for the condenser and evaporator heat transfer rates. This approach was 
shown to work well for a single speed scroll compressor, but is not expected to work for a heat pump with variable speed compressor due to internal controls in the heat pump and the possible changes in time constant with operating speeds.

Often, other components of heating and cooling systems such as boilers and air source heat pumps, are also modelled with steady state models. This work shows that there may be a case to be made for revisiting some of the assumptions that building simulationists sometimes make about the use of steady state models.

Further work could be undertaken in the future:

- The transient nature of the electrical consumption should be investigated further to allow for a transient model for the compressor.

- Further transient tests should be run at various inlet temperatures to verify the time response over a wide range of temperatures.

- Investigation of the prediction differences between the steady state and transient models in an actual system should be completed.

- Experimental investigation of the condenser and evaporator heat transfer rates following switching off of the heat pump and continuing operation of pumps would provide some insight into whether the pumps should be set on timer as opposed to turning off with the heat pump.

The model presented in this chapter is an improvement over the typical steady state models used in BPS. Despite the recommendations for future work, the author believes that the model presented in this chapter is fit for use in simulation of the active/passive solar collection system presented in Chapter 1. 


\section{Chapter 5}

\section{Controls of radiant floor heating with high solar gains}

\subsection{Introduction}

Some of the earliest experimental work on radiant panel heating was performed by Algren and Ciscel [85]. They measured the time constant of a radiant slab on grade (without slab insulation) with the use of a small experimental building. Slab on grade radiant floors are a type of embedded-tube system built directly on grade. Time constant is defined here as the time it takes for a system given a step input to reach approximately $63.2 \%$ of its steady-state value. They found a time constant of almost 4 hours for the floor surface temperature, and about 5 hours for the air temperature. These long time constants show that thermal mass in embedded-tube systems can be significant. Due to these potentially long response times, appropriate controls of radiant floors are crucial, especially when the heating or cooling load is highly variable. For residential applications, a large amount of south facing glazing could result in high variability in solar gains, especially during the shoulder seasons. Adequate controls are important in that case, in order to prevent overheating.

Single family housing in Canada consists mostly of timber frame construction. Except for slab on grade, or basement floors, concrete slabs are not typical. Additionally, embedded-tube systems (where the tubes are embedded in a concrete or gypsum cement slab) have a long response time so they take longer to react to sudden changes in setpoints. For these reasons, AFTP radiant floors are becoming more popular for single family housing in Canada. Since they are less massive then the embedded tube systems, the AFTP radiant floor systems are easier to control, especially when the 
heating or cooling load varies greatly with time.

Controls of radiant floors can be divided into two broad categories: reactive controls, and predictive controls. Reactive controls make decisions based on current conditions. Predictive controls attempt to anticipate future conditions, and make decisions based on these predicted future conditions. In practice, reactive controls are most commonly used today. Due to their relative complexity, predictive controls are still mostly an academic research topic and are implemented in few actual residential buildings.

\subsubsection{Objective}

The aim of this work is to investigate the appropriateness of simple reactive controls for radiant floor heating in Canadian housing, for various types of hydronic radiant floor systems, when high levels of solar radiation are present. Additionally, various types of radiant floor constructions, including a type of low mass AFTP radiant floor system, will be compared. In order to properly evaluate various control methods, various radiant floor contructions were evaluated in order to account for varying time response. Radiant floor cooling was not considered for this work.

\subsection{Literature Review}

\subsubsection{Reactive radiant floor heating controls}

Because of high thermal mass in typical embedded pipes radiant floor installations, reactive controls of radiant floor systems can be challenging. Work by Leigh and MacCluer [86] on radiant floor controls without solar gains has shown that radiant floor heating can be controlled effectively with supply temperature modulation. In this case, the supply temperature setpoint was defined based on the ambient air temperature and the indoor air temperature. MacCluer [87] proposed two methods of supply temperature modulation based on indoor and ambient temperatures. They did not however investigate how high solar gains variation may affect the adequacy of those control methods. Equation 5.1 shows the supply temperature setpoint for the outdoor temperature reset controller (TR).

$$
T_{\text {supply }}=S \cdot\left(T_{\text {setpoint }}-T_{\text {outdoor }}\right)+T_{\text {setpoint }}
$$


where $S$ is a dimensionless reset slope defined in [88], and $T_{\text {outdoor }}$ is the outdoor temperature and $T_{\text {setpoint }}$ is the indoor air setpoint temperature.

Although unconditionally stable, this simple equation can't account for changes in internal gains and may not be adequate in certain situations. An indoor temperature feedback can be added to Equation 5.1 to improve the its response. This can take the form of a reset slope modifier, or an intercept modifier as shown in Equations 5.2 and 5.3.

$$
T_{\text {supply }}=\left[S+g \cdot\left(T_{\text {setpoint }}-T_{a}\right)\right] \cdot\left(T_{\text {setpoint }}-T_{\text {outdoor }}\right)+T_{\text {setpoint }}
$$

where $g$ is a positive gain, small compared to $\mathrm{S}$, and $T_{a}$ is the interior air temperature.

$$
T_{\text {supply }}=S \cdot\left(T_{\text {setpoint }}-T_{\text {outdoor }}\right)+F \cdot\left(T_{\text {setpoint }}-T_{a}\right)+T_{\text {setpoint }}
$$

where $F$ is a positive gain.

Equations 5.2 and 5.3 are not unconditionally stable due to the feedback component. One has to exercise care when setting gains $g$ or $F$ to ensure a quick response and stability. The intercept modifier (Equation 5.3) does have an advantage over the reset slope modifier (Equation 5.2) in that its stability is not dependent on load but on the gain $F$. The controller defined by Equation 5.3 is commonly called outdoor temperature reset with indoor temperature feedback (TRIF). The supply water temperature is usually controlled by mixing the return water with supply water in adequate proportions. These types of controller can be categorized as proportional, since the output of the controller is directly proportional to the difference between the setpoint temperature and outdoor temperature, and the setpoint temperature and indoor temperature, or a mix of both.

Kim and Olesen recommend that instead of controlling the supply temperature, as in Equations 5.1 through 5.3, the average water temperature be controlled [89]. In that case, the same form of the equations can be used, but $T_{\text {supply }}$ should be changed to $T_{\text {average }}=\left(T_{\text {supply }}+T_{\text {return }}\right) / 2$. The supply temperature can be solved for by measuring the return temperature. Additionally, Kim and Olesen recommend the use of individual room controls with zone valves and thermostats for better comfort, and reduced energy consumption. They also suggest to control the room as a function of the operative temperature, and not the air temperature. This method however, requires a sensor sensitive to location and orientation. 
Forms of proportional controls based on floor surface temperature are also possible [90]. Although they have not been widely investigated in the literature, the industry frequently uses forms of floor temperature proportional controls [91]. However, instead of measuring the surface temperature, a sensor is typically placed in or underneath the floor cover, or embedded in the concrete or cement layer [92].

Gibbs [93] compared pulse-width-modulation (PWM), outdoor temperature reset with indoor temperature feedback, and outdoor temperature reset with PWM. A PWM controller regulates the flow with a zone valve (similar to a on-off control). The length of the heating (or cooling) cycle is proportional to the error (defined as the difference between the air temperature and the setpoint). Gibbs stated that the outdoor reset with PWM was the better system. This study did not account for solar gains.

Athienitis and Chen [94] modelled and experimented with an electrical resistance radiant floor with night setback in a room with approximately $19 \%$ south facing window to floor area. The peak solar gains were not calculated, but can be estimated for a clear double pane window to be approximately $120 \mathrm{~W} \mathrm{~m}^{-2}$ (per floor area). They found that proportional controls resulted in improved performance of the system compared to on-off controls. They also found that a thermostat setpoint night setback reduced demand but that an air temperature setpoint that followed a square wave profile (i.e. sudden change in setpoint temperature) lead to a very high increase in peak heating load during cold days. Following this research, Athienitis [95] found that with proper controls, solar gains can be used to reduce the peak load, total demand, and maximum surface temperature. Athienitis and Chen [96] then studied the effects of thermal mass on an electrical radiant floor system. They found that some thermal mass ( $5 \mathrm{~cm}$ thick concrete) was effective at storing passive thermal energy, but that a low night setpoint and smooth change to a higher daytime setpoint was required. In this case a semi-sinusoidal daily setpoint temperature profile was used. The nighttime setpoint they used was $15^{\circ} \mathrm{C}$, and may be too low for applications in residential buildings. Additionally, large temperature swings during cold sunny days (from $18^{\circ} \mathrm{C}$ to $27^{\circ} \mathrm{C}$ between 8:00 and 14:00) could be problematic. They also found that it may be more difficult to control systems with higher thermal mass $(10 \mathrm{~cm}$ thick concrete) due to larger overshoots when solar gains are present. For the same system, Chen and Athienitis [97] studied the effect of cover material on performance. They found that a thick carpet increases the response time of the floor temperature, 
and increases energy consumption.

Olesen [98] ran experiments in a test room with three different heating systems: a $2.0 \mathrm{~m} \times 0.55 \mathrm{~m}$ radiator panel placed directly under the only window in the room, a $5 \mathrm{~mm}$ thick capillary radiant floor system, and a $70 \mathrm{~mm}$ thick slab embeddedtube radiant floor system. The floor cover was carpet in all cases. Electrical heated blankets were placed on two locations on the floor to simulate solar, occupant, and lighting gains. The peak simulated solar gains in the space were equivalent to 15 $\mathrm{W} \mathrm{m}^{-2}$ of floor area. The average water temperature in both types of radiant floors was controlled based on the outdoor temperature. For the capillary tube system, the water flow rate was constant for the entire occupied period. For the embeddedtube system, the supply flow rate was modulated based on the room temperature. The increase in temperature in the room caused by solar gains was estimated to be around $1.4{ }^{\circ} \mathrm{C}$ for the radiator case, and $1.0^{\circ} \mathrm{C}$ for the embedded-tubes system. Olesen concluded that all three systems investigated were capable of controlling the indoor conditions adequatly. Additionally, the total energy consumption of the three systems was found to be within $5 \%$ of each other.

Cho and Zaheer-uddin [59] ran an experiment comparing four reactive radiant floor heating controllers: air temperature based on-off, PI control, slab temperature based on-off, and a new two-parameter on-off control. The two-parameter on-off control acts on a pump with a constant supply temperature, but aims at keeping both the slab temperature and the air temperature within a specified range. For this experiment, windows were covered with aluminium foil, thus blocking solar gains. The slab was $100 \mathrm{~mm}$ thick. It was found that the PI controller was the best at keeping a steady slab and air temperature, but that the two-parameter controller was better than only basing the on-off controller on the slab or air temperature. In a follow up study [99], they further explored the time interval at which the two-paramter controller would switch between controlling for air temperature and slab temperature sequentially. They found that, as long as the switching intervals were under 40 minutes, the twoparameter switching model was better at reducing the slab temperature variations compared with on-off controls based on air temperature.

Rekstad et al. [100] experimented with a AFTP radiant floor system. Although not mentioned explicitely, it does not appear that solar gains were present. The control method they proposed pulsed the water flow with the help of a zone valve. The duty cycle was based on ambient temperature. This is one of only a few papers 
that the author has found in the literature where a AFTP radiant floor system is investigated. The other papers did not investigate controls.

\subsubsection{Predictive radiant floor heating controls in housing}

In recent years, research focus has shifted to predictive controls for radiant floors. Predictive controls use modelling and prediction of future weather to optimize current control events. For sake of brevity, only the most relevant papers regarding predictive controls of radiant floors are discussed here.

Zaheer-Uddin et al. [101] modelled a simple zone with radiant floor heating. A $100 \mathrm{~mm}$ embedded-tube slab was used, with no floor cover. They used outdoor temperature forcast to find optimal operation of the radiant floor for the next 24 hours. The controller modulated the energy input to the boiler and the supply flow rate. The zone temperature was kept within $0.5^{\circ} \mathrm{C}$ of the setpoint temperature. For this study, it was not clear how much solar gains, if any, were included.

Cho and Zaheer-Uddin [102] studied a conventional intermittent control strategy experimentally, and compared it with a predictive control strategy. They found that there could be energy savings between 10 and $20 \%$ with the use of the predictive control startegy. Lee et al. [103] studied predictive controls of a radiant floor slab using a neural network model experimentally and with simulation. The supply temperature was constant, and the flow rate was tuned on or off by the controller. In simulations the test rooms only had North facing windows, so the solar gains were small. It is not clear how much solar radiation was introduced in the space during the experiments. The slab thickness was not given. They compared the predictive controller to a onoff controller and found the predictive controller had reduced zone air temperature overshoots and energy consumption.

Candanedo et al. used modelling to study model predictive controls (MPC) for a passive house with high amounts of south facing glazing [104]. The slab thickness was $63.5 \mathrm{~mm}$, and the south facing glazing to floor area ratio was $13.5 \%$. The peak solar gains per floor area were approximately $92 \mathrm{~W} \mathrm{~m}^{-2}$. The controller used a simplified transfer function model to predict the best course of action based on future weather. This included actuating blinds and delivering of a specific heat output to the floor slab. They found that controlling only the floor heat output resulted in overheating, but that when blinds were also controlled, the indoor temperatures were comfortable. They did not compare the predictive controller to a more typical reactive controller 
such as an on-off controller, or a temperature reset controller.

Candanedo and Athienitis modelled a solar house with a solar source heat pump and radiant floor [105]. They used similar controls as described in [104] for the radiant floor output but did not control blinds. The slab thickness was $150 \mathrm{~mm}$. The south facing glazing to floor area ratio was $21 \%$, and the peak solar gains per floor area were approximately $70 \mathrm{~W} \mathrm{~m}^{-2}$. The air temperature in the space was maintained between 18 and $25^{\circ} \mathrm{C}$. The predictive controller was not compared to a reactive one.

\subsubsection{Radiant floor models}

Litterature reviews for embedded-tube and AFTP systems can be found in Chapters 2 and 3 , and no further discussion will be provided here.

\subsection{Control schemes examined}

The objective of the work was to compare common, simple reactive controllers for use in single detached housing. The heat producing equuipment was not modelled, so the controls were idealized (the required supply temperature was assumed to always be available, and exact). All controls were implemented with and without nighttime and daytime (during unoccupied periods) temperature setbacks. The following controllers were investigated:

- On-Off: With On-Off controls, the supply temperature to the radiant floor is constant (supply temperature discussed in Section 5.7). A thermostat turns a pump (or a zone valve) on or off based on the zone air temperature. For this study, the occupied air temperature setpoint in the zone was $22^{\circ} \mathrm{C}$, with a thermostat deadband of $1{ }^{\circ} \mathrm{C}$. This ON-OFF thermostat measured air temperature only. The $22{ }^{\circ} \mathrm{C}$ temperature setpoint was selected because it is a a typical value that could be found in a house. This also leads to comfortable conditions according to the Predicted Mean Vote (PMV) model (discussed in Section 5.7).

- Pulse Width Modulation (PWM): A PWM can be used to control either the heat generation equipment, or the flow to the floor. In this case, the PWM controller was used to control flow to the floor. Similar to a On-Off controller, the supply temperature of the PWM system is fixed (discussed in Section 5.7), and the flow of water is turned on or off based on the air temperature in the zone. 


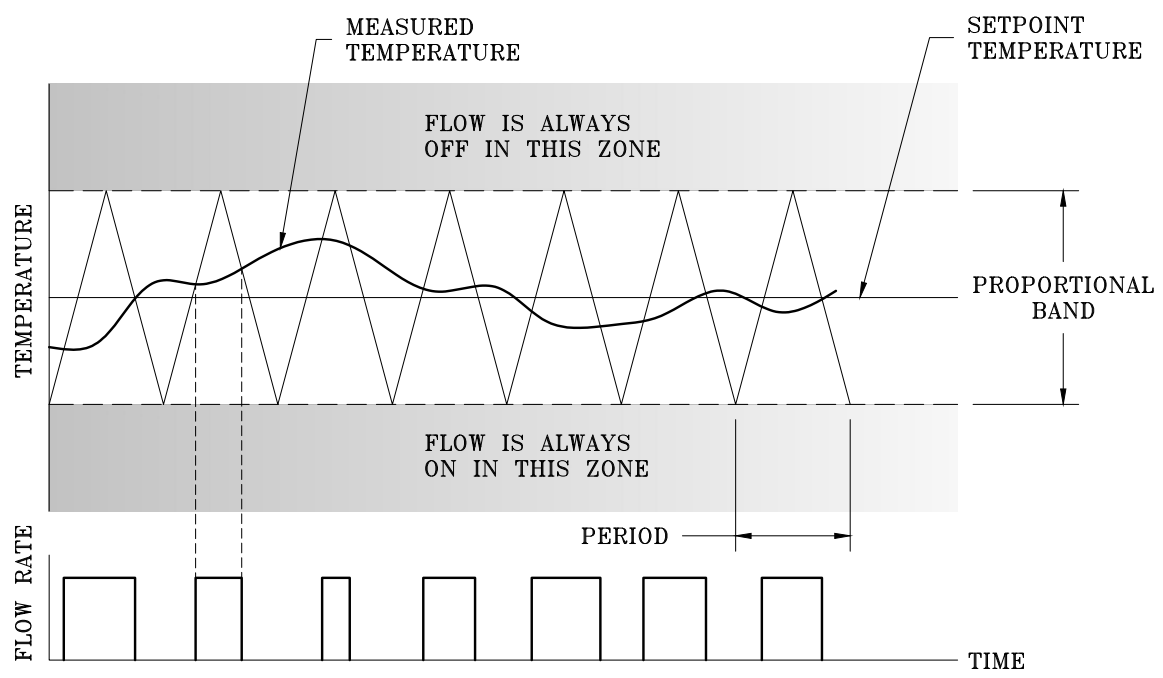

Figure 5.1: Example of pulse width modulation for heating mode. Adapted from Siegenthaler [106]

In order to choose how long to pulse the water flow in the floor, the controller generates a triangular wave with a pre-defined period (typically 10-15 minutes) and proportional band [106]. This amplitude is analogous the deadband of a ON-OFF thermostat, and is typically around $1{ }^{\circ} \mathrm{C}$. Figure 5.1 shows the working principle of PWM for heating mode. A zone valve is opened or closed (or pump turned on or off), based on whether the measured temperature is below or above the controller generated triangular wave of a set amplitude and period. If the measured temperature is above the triangular wave, the pump or zone valve or off. If the measured temperature is below the triangular wave, the pump or zone valve is on, allowing warm water to flow in the radiant floor. For this type of controller, the ratio of 'off' time to the period is approximately proportional to the measured temperature within the proportional band.

- Temperature Reset: The temperature reset controller is based on outdoor temperatures. The supply temperature delivered to the floor was defined in Equation 5.1. The flow rate can be controlled in many ways, but for this study, an ON-OFF thermostat, measuring air temperature only, with $1{ }^{\circ} \mathrm{C}$ deadband was used. The occupied setpoint for the thermostat was $22{ }^{\circ} \mathrm{C}$. 
- Temperature Reset with indoor temperature feedback: With this controller, the supply temperature is a function of the zone air temperature and the outdoor air temperature. Equation 5.3 defines the relationship. The flow rate can be controlled in many ways, but for this study, an ON-OFF thermostat, measuring air temperature only, with $1{ }^{\circ} \mathrm{C}$ deadband was used. The occupied setpoint for the thermostat was $22^{\circ} \mathrm{C}$.

- Temperature Reset with indoor temperature feedback - average temperature (TRIF-Avg): This controller is the same as the previous one, except that the average water temperature is controlled as opposed to the supply temperature. The controller outputs the average temperature $T_{\text {average }}=$ $\left(T_{\text {supply }}+T_{\text {return }}\right) / 2$ based on the outdoor and indoor air temperatures. The supply temperature can then be solved for if the return temperature is measured.

- Temperature Boost: This controller is a variation of an On-Off controller. If nightime setback is used, a long recovery time is usually necessary, and Olesen recommends the use of boost heating during this recovery period [10]. This is done by using a higher water temperature during setback recovery periods than during normal operation. This recovery period is the period before the occupied period when the setpoint temperature is increased to the desired 'occupied' value to prepare for the occupants use of the space.

- Proportional Integral Derivative: The Proportional-Integral-Derivative (PID) controller is a feedback loop type of controller. Equation 5.4 describes the operation of the controller. The controller attempts at reducing the error between the setpoint and the controlled variable. The proportional component calculates the current error, the integral component accounts for the past error, and the derivative component attempts to account for future error. For this study, water flows through the floor loops continuously for the PID controller. PID controllers can also be used with zone valves.

$$
v(t)=P+I+D=K\left(e(t)+\frac{1}{\xi_{i}} \int_{0}^{t} e(\tau) d \tau+\xi_{d} \frac{d e(t)}{d t}\right)
$$

where $v(t)$ is the output of the controller, $P$ is the proportional part, $I$ is the integral part, $D$ is the derivative part, $K$ is the gain, $e$ is the error (measured value - 
setpoint), $t$ is the time, $\xi_{i}$ is the integral time, and $\xi_{d}$ is the derivative time.

Each controller was tested with and without nightime temperature setback (except for the Temperature Boost case, wich was only tested with temperature setback). The occupied air setpoint temperature was $22{ }^{\circ} \mathrm{C}$ and the setback setpoint temperature was $17{ }^{\circ} \mathrm{C}$.

\subsection{Simulation approach}

The work presented here was performed with the ESP-r/TRNSYS co-simulator [24]. The building and the radiant floor system were represented in ESP-r, while the controls were represented in TRNSYS.

The first floor of a single-family detached home was represented in ESP-r. This model was based on the main floor in the Urbandale CHEeR presented in Chapter 3. All modelled glazing was triple pane with two low-e coatings, and argon filled. The center of glass nominal U-value was $0.9 \mathrm{~W} \mathrm{~m}^{-2} \mathrm{~K}^{-1}$ and the nominal SHGC was 0.6. The exterior walls were timber construction with $140 \mathrm{~mm}$ batt insulation in the cavity and $38 \mathrm{~mm}$ of continuous insulation. The exterior walls nominal R-value was approximately $4.2 \mathrm{~m}^{2} \mathrm{~K} \mathrm{~W}^{-1}\left(\mathrm{U}=0.238 \mathrm{~W} \mathrm{~m}^{-2} \mathrm{~K}^{-1}\right)$. The dimensions of the house were $12.09 \mathrm{~m}$ by $5.99 \mathrm{~m}$. Two south facing glazing areas were modelled: $10.9 \mathrm{~m}^{2}$ (15\% south-facing glazing to floor area ratio), and $4.32 \mathrm{~m}^{2}$ (6\% south-facing glazing to floor area ratio). The first floor area was $72.4 \mathrm{~m}^{2}$. Radiant floor systems covered $54.6 \mathrm{~m}^{2}$ of the first floor. Horizontal surfaces were added to the living space near the south facade to account for interaction between furniture and solar radiation. These horizontal surfaces were located at heights varying between $0.61 \mathrm{~m}$ and $0.9 \mathrm{~m}$ from the floor. The total area of this living space was $45.6 \mathrm{~m}^{2}$. The horizontal area of surfaces to account for furniture was $11.7 \mathrm{~m}^{2}$. Figure 5.2 shows a floor plan of the modelled zone. The white areas are the furniture surfaces.

The convective heat transfer coefficient between the floor and the zone air was calculated with a correlation by Awbi and Hatton [72]. This does not account for the effects of partition walls and furniture in the space. In other words, convective the heat transfer coefficient between the floor and the zone air is calculated as if the entire zone contained no internal partitions or furniture, and is applied on the entirety of the floor.

Additional mass was added in a internal partition wall to account for mass of all 


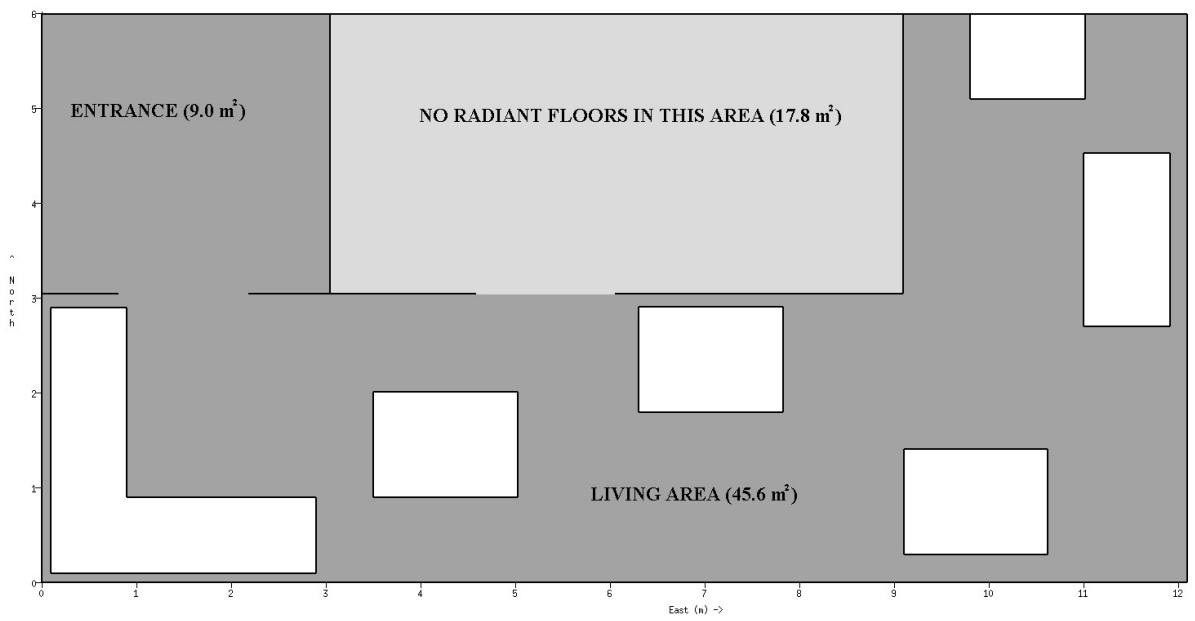

Figure 5.2: Floor plan of modelled zone

furniture in the space. The total mass of all furniture in the zone was calculated as per guidelines by Hendron and Engebrecht which stated that "The internal mass of furniture and contents shall be equal to $8 \mathrm{lb} \mathrm{ft}^{-2}$ of conditioned floor space" [107]. Since no specific heat value was mentioned in the guidelines, a value of $1150 \mathrm{~J} \mathrm{~kg}^{-1} \mathrm{~K}^{-1}$ was used.

The Alberta Infiltration Model [108] was used to calculate the infiltration based on the energy tight setting in ESP-r. This setting assumes a blower door test of 1.5 $\mathrm{ACH}$ at $50 \mathrm{~Pa}$. An energy recovery ventilator with sensible and latent effectiveness of 0.6 and 0.7 respectively provided $82 \mathrm{~kg} \mathrm{~h}^{-1}$ of fresh air to the zone and was modelled in TRNSYS.

The period modelled was one week in early February, using the Ottawa CWEC weather file. That week had the particularity of having mostly sunny days. Figure 5.3 shows the solar gains in the space for the $6 \%$ south-facing glazing to floor area ratio (normal glazing) and 15\% south-facing glazing to floor area ratio (high glazing), as well as the ambient dry bulb temperature. The peak solar gains per floor area are $111 \mathrm{~W} \mathrm{~m}^{-2}$ for the high glazing case, and $47 \mathrm{~W} \mathrm{~m}^{-2}$ for the normal glazing case. The first day of the simulation (following the one day of warmup, not shown on Figure 5.3) was a Wednesday. Wednesday and Sunday had considerable cloud cover while the other days were mostly clear sunny days.

Due to the generally open concept of the first floor of the house, it was modelled as a single zone. There were four parallel radiant floor loops on the first floor. The second 


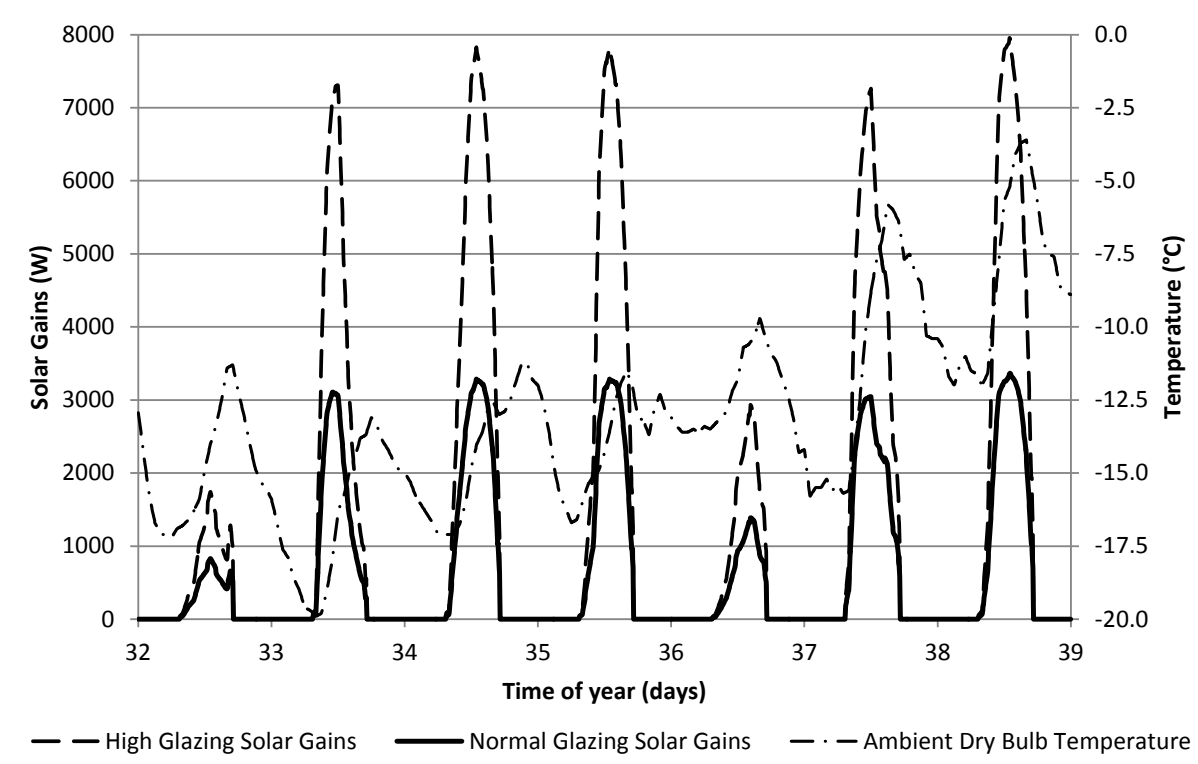

Figure 5.3: Solar gains in the space and ambient temperature

floor and basement were not modelled. Constant temperature boundary conditions were used to approximate heat transfer to those zones.

Four different radiant floor constructions were modelled: tube-in-subfloor (a type of AFTP system), thin embedded-tubes (3.8 cm slab thickness), thick embeddedtubes with the tubes at the bottom of the slab, thick embedded-tubes with the tubes near the top of the slab. Details of the construction for the tube-in-subfloor system is shown in Table 5.1 and the construction of the embedded systems are shown in Table 5.2. A section of an embedded-tubes construction can be seen in Figure 5.4 and a section of a tube-in-subfloor system can be seen in Figure 5.5. The tubes were made of crosslinked polyethylene, with a conductivity of $0.38 \mathrm{~W} \mathrm{~m}^{-1} \mathrm{~K}^{-1}$, a specific heat of $550 \mathrm{~J} \mathrm{~kg}^{-1} \mathrm{~K}^{-1}$, and a density of $938 \mathrm{~kg} \mathrm{~m}^{-3}$. The inner diameter of the tubes was $0.0127 \mathrm{~m}$ with a wall thickness of $0.00166 \mathrm{~m}$. The floor surface longwave emissivity and solar absorptivity were 0.847 and 0.65 . The inside facing walls had a longwave emissivity of 0.9 and a solar absorptivity of 0.278 .

Non-HVAC electrical gains were taken from measured data by Johnson and Beausoleil-Morrison (house H14) [109]. That study was an extension of work done 


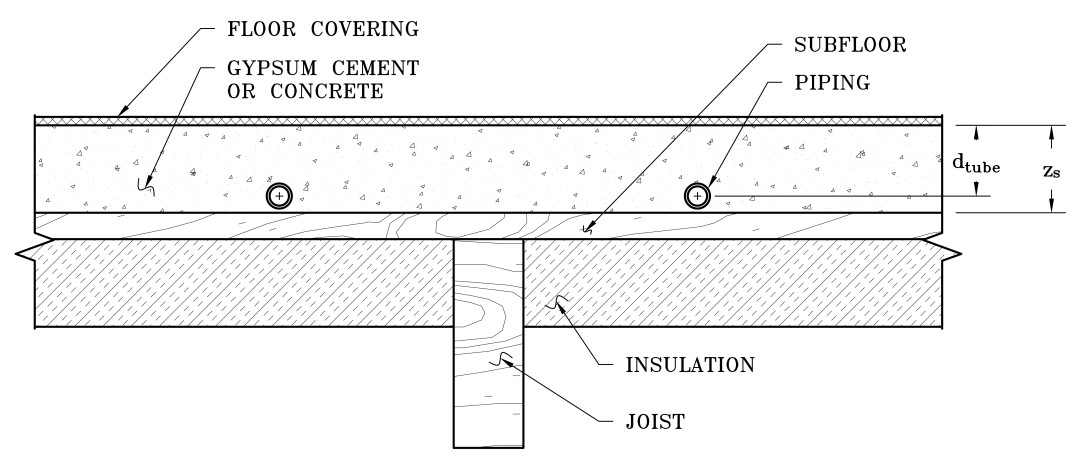

Figure 5.4: Embedded tubes construction

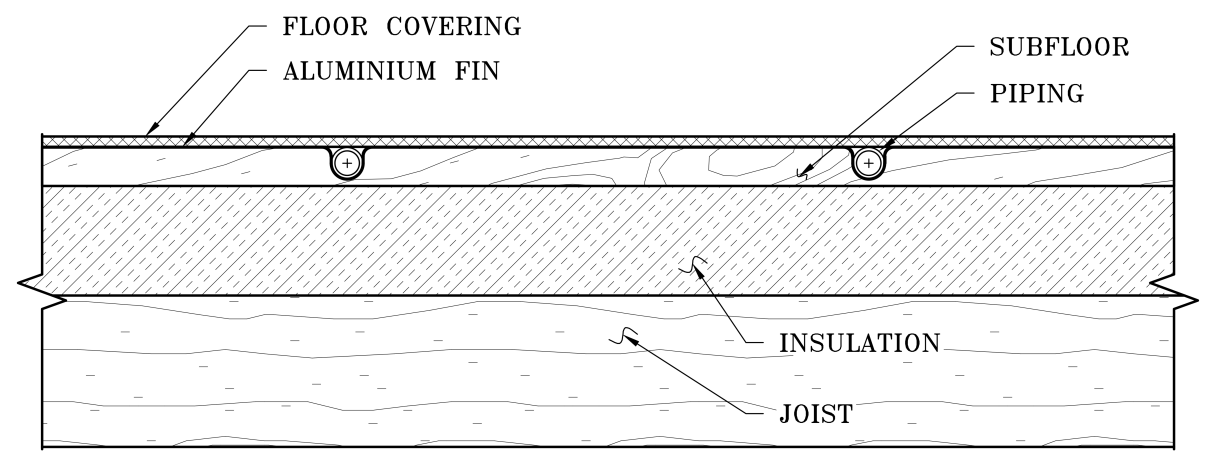

Figure 5.5: Tube-in-subfloor construction 
Table 5.1: Tube-in-subfloor construction

\begin{tabular}{lcccc}
\hline Layer & $\begin{array}{c}\text { Specific heat } \\
\left(\mathrm{J} \mathrm{kg}^{-1} \mathrm{~K}^{-1}\right)\end{array}$ & $\begin{array}{c}\text { Density } \\
\left(\mathrm{kg} \mathrm{m}^{-3}\right)\end{array}$ & $\begin{array}{c}\text { Conductivity } \\
\left(\mathrm{W} \mathrm{m}^{-1} \mathrm{~K}^{-1}\right)\end{array}$ & $\begin{array}{c}\text { Thickness } \\
(\mathrm{m})\end{array}$ \\
\hline Insulation & 960 & 100 & 0.036 & 0.076 \\
Subfloor & 1880 & 450 & 0.1 & 0.0279 \\
Fin & 900 & 2700 & 234 & 0.0006 \\
Thinset mortar & 780 & 1860 & 0.72 & 0.0032 \\
Backer board & 840 & 1461 & 0.277 & 0.0064 \\
Thinset mortar & 780 & 1860 & 0.72 & 0.0032 \\
Tile & 750 & 2336 & 1.6 & 0.0080 \\
\hline
\end{tabular}

Table 5.2: Embedded tube construction

\begin{tabular}{lcccc}
\hline Layer & $\begin{array}{c}\text { Specific heat } \\
\left(\mathrm{J} \mathrm{kg}^{-1} \mathrm{~K}^{-1}\right)\end{array}$ & $\begin{array}{c}\text { Density } \\
\left(\mathrm{kg} \mathrm{m}^{-3}\right)\end{array}$ & $\begin{array}{c}\text { Conductivity } \\
\left(\mathrm{W} \mathrm{m}^{-1} \mathrm{~K}^{-1}\right)\end{array}$ & $\begin{array}{c}\text { Thickness } \\
(\mathrm{m})\end{array}$ \\
\hline Insulation & 960 & 100 & 0.036 & 0.076 \\
Subfloor & 1880 & 450 & 0.1 & 0.0190 \\
Gypsum Cement & 938.5 & 1840 & 0.7142 & See note $^{\mathrm{a}}$ \\
Tile & 750 & 2336 & 1.6 & 0.0080 \\
\hline
\end{tabular}

a Three different embedded-tube systems were evaluated: one with a 3.8 cm thick gypsum cement layer, the other two with an $8 \mathrm{~cm}$ gypsum cement layer. The thicknesses and locations of the tubes are defined in Table 5.3.

Table 5.3: Slab thicknesses and tube locations

\begin{tabular}{ccc}
\hline & $z_{s}(\mathrm{~cm})^{\mathrm{a}}$ & $d_{\text {tube }}(\mathrm{cm})^{\mathrm{a}}$ \\
\hline Slab A & 3.8 & 3.0 \\
Slab B & 8.0 & 7.2 \\
Slab C & 8.0 & 3.0 \\
\hline
\end{tabular}

${ }^{\mathrm{a}} z_{s}$ and $d_{\text {tube }}$ are the thickness of the slab and the distance between the center of the tubes and the top of the slab. These are defined in Figure 5.4. 
Table 5.4: Occupant Schedule

\begin{tabular}{lccccc}
\hline & before 7:00 & $7: 00-8: 00$ & 8:00-17:00 & 17:00-22:00 & after 22:00 \\
\hline Weekday & Unoccupied & Occupied & Unoccupied & Occupied & Unoccupied \\
Weekend & Unoccupied & Occupied & Occupied & Occupied & Unoccupied \\
\hline
\end{tabular}

by Saldanha and Beausoleil-Morrison [110]. The average annual non-HVAC electrical load of the 23 houses evaluated in both studies was 19 GJ. In comparison, H14 had a total non-HVAC annual load of 15.5 GJ. These electrical loads were applied to the zone as intenal gains for the week of interest. The electrical data consumption for house H14 was chosen because of its near average energy consumption and because large applicances were sub-metered. This allowed applying the proper appliances internal gains in the zone. The kitchen related internal gains (stove and dishwasher) and $50 \%$ of all other non-HVAC internal gains were assumed to be going to the first floor. The clothes dryer internal gains were ignored, as they were assumed to be going to the basement. Sensible load fractions as defined by Hendron and Engebrecht [107] were used for the stove and dishwasher. Additionally, outdoor air ventilation was applied to the space at a rate of $0.056 \mathrm{~kg} \mathrm{~s}^{-1}$ for the stove (for range hood operation) when in use. Internal gains for two occupants were added to the space following the schedule found in Table 5.4. The occupant's sensible and latent loads were $70 \mathrm{~W}$ and $45 \mathrm{~W}$ per occupant.

\subsection{Tube spacing}

Radiant floor systems are typically sized for steady state conditions. In order to compare similar radiant floor systems, it was decided to compare systems that had a similar steady-state output. This was done by varying the tube spacing of the various floor constructions to get approximately the same steady state output.

Steady-state simulations were run for the $6 \%$ south facing glazing to floor area ratio with the four different floor constructions. A constant supply water temperature of $55{ }^{\circ} \mathrm{C}$ and a mass flow rate of $0.1 \mathrm{~kg} \mathrm{~s}^{-1}$ were used. The weather file was manipulated to keep the outdoor temperature constant at $-20{ }^{\circ} \mathrm{C}$ and to remove all solar radiation. The high difference between the supply temperature and outdoor temperature were meant to provide a high heat flux in order to accurately characterize the effective 
Table 5.5: Effective steady state conductance for various floor constructions

\begin{tabular}{lcc}
\hline & Tube Spacing $(\mathrm{mm})$ & Effective Conductance $\left(\mathrm{W} \mathrm{m}^{-2} \mathrm{~K}^{-1}\right)$ \\
\hline AFTP System & 304.8 & 2.841 \\
Slab A & 152.4 & 2.680 \\
Slab B & 152.4 & 2.304 \\
Slab C & 152.4 & 2.665 \\
\hline
\end{tabular}

conductance. These temperatures were not meant to be typical values. No internal gains were present in the space. The results are shown in Table 5.5. The effective

conductance is $C_{\text {eff }}=\frac{q}{T_{\text {supply }}-T_{z o n e}}$, taken at steady-state. Where $q$ is the heat flux to the zone above.

Commercial tube-in-subfloor products (or other type of AFTP systems) are available with either $304.8 \mathrm{~mm}$ (12 in) or $152.4 \mathrm{~mm}$ (6 in) tube spacing. Common tube spacing for embedded-tube systems are $152.4 \mathrm{~mm}$ (6 in), $228.6 \mathrm{~mm}$ (9 in), or 304.8 mm (12 in) but other spacings are possible. Simulation results showed that the tubein-subfloor (AFTP system) with a spacing of $304.8 \mathrm{~mm}$ has a slightly higher effective conductance than that of slabs $\mathrm{A}$ and $\mathrm{C}$ with a spacing of $152.4 \mathrm{~mm}$ (6 in). The effective conductance of slab B (the case with the tubes near the bottom of the slab) is much lower however. A smaller spacing would be unlikely in practice, due to the large amount of tubing required. Additionally, in a serpentine layout, the bend radius of the pex tubing would not allow for a smaller tube spacing. For that reason, a spacing of $152.4 \mathrm{~mm}$ (6 in) was picked for all of the slab cases, as opposed to a smaller spacing.

For the remainder of the study, the spacings shown in Table 5.5 were used.

\subsection{Response time}

The response of various floor constructions was evaluated by providing a step input supply temperature increase to the floor. During the entire duration of the simulations, the water flow rate was $0.1 \mathrm{~kg} \mathrm{~s}^{-1}$, and no internal gains were present in the space. The weather file was manipulated to keep the outdoor temperature constant at $-20{ }^{\circ} \mathrm{C}$ and to remove all solar radiation. The supply temperature was set to $20{ }^{\circ} \mathrm{C}$ 
Table 5.6: Time constant for various floor constructions

\begin{tabular}{lc}
\hline & Time constant $(\mathrm{h})$ \\
\hline AFTP System & 3.75 \\
Slab A & 5.55 \\
Slab B & 9.20 \\
Slab C & 8.20 \\
\hline
\end{tabular}

for two days to ensure equilibrium, then the supply temperature is abruptly changed to $55^{\circ} \mathrm{C}$.

A time constant was then calculated based on the zone air temperature response. A time constant is defined for linear first order system as the time taken for the system to reach $63.2 \%$ of the final increase in value. Although a building is not a linear first order system, the time constant is a simple and well known way to compare response times of various systems that is sometimes used for buildings. The results of the step input results are shown in Table 5.6. These results show that the room with the AFTP system responds the quickest, followed by the $3.8 \mathrm{~cm}$ slab (Slab A). The embedded-tube case with the tubes near the bottom of the slab (Slab B) was the slowest to respond with a time constant almost 2.5 times that of the AFTP system.

\subsection{Parametric Analysis}

A parametric analysis was performed on each controller. The variables that were varied for each controller are shown in Table 5.7. The PID controller is not included in Table 5.7 and will be discussed later. Also not shown in Table 5.7 are the setback recovery times. These were varied between 2.0 and 4.5 hours at 0.5 hour increments. Each of these analyses was performed for all four floor constructions and two south facing glazing areas mentioned previously. Additionally, the controllers were tested with and without temperature setback (with various recovery times).

A single 'tuned' solution for each controller/south facing window area/floor construction combination was picked amongst the various solutions from the parametric analysis. Because each controller has different possible settings (such as supply temperature, reset slope, setback recovery time) a standard way to define which settings 
Table 5.7: Parametric analysis

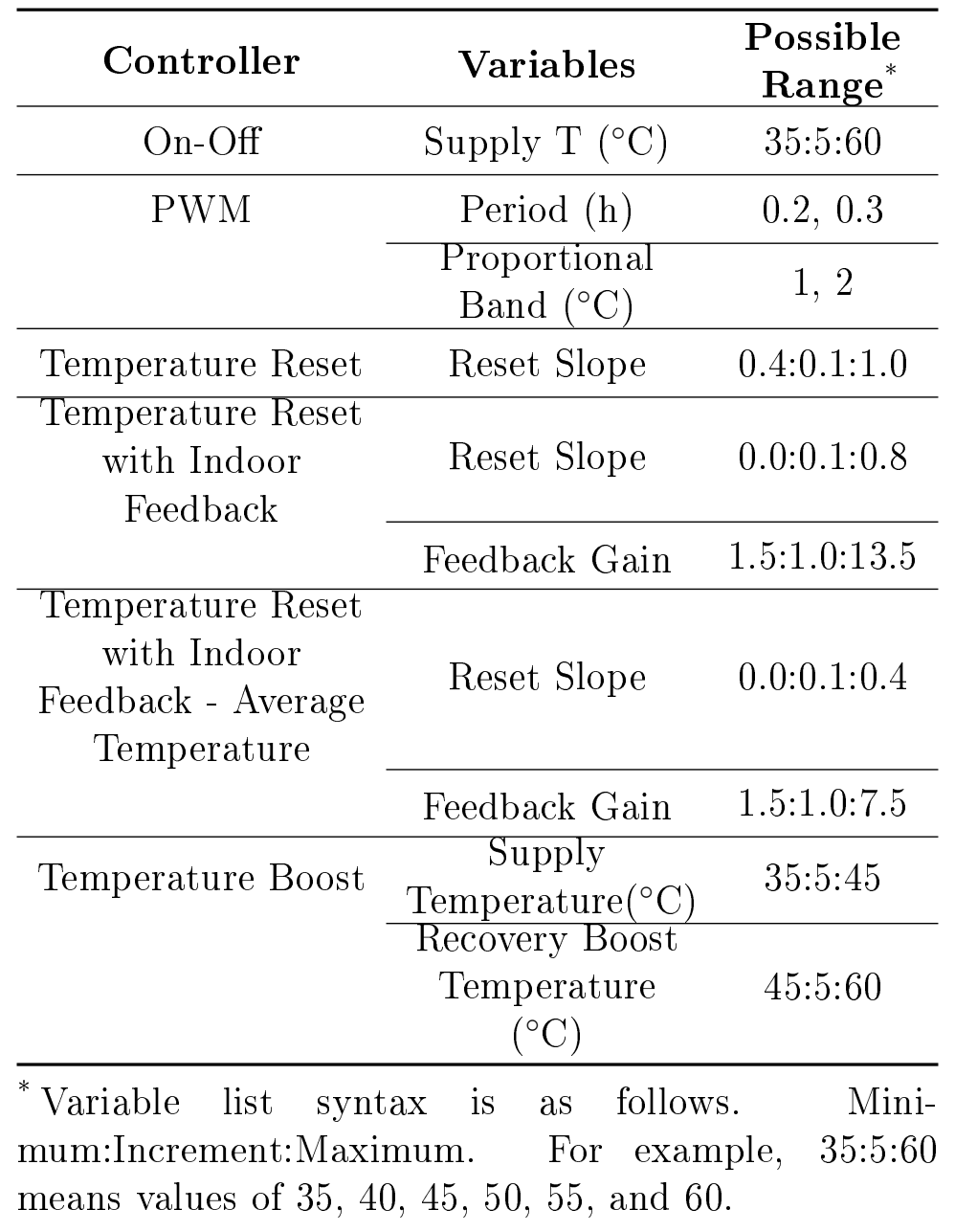


were the best for each case was devised. This allowed a fair comparison between all controllers.

Thermal comfort during occupied periods was deemed the most important factor to consider. The modelling of thermal comfort of the occupants was accomplished with the Predicted Mean Vote (PMV) model developed by Fanger [111], and implimented with code by van Schijndel [112]. ASHRAE standard 55 [113] recommends maintaining the PMV within a range of -0.5 to 0.5 . In this range, less than approximately $10 \%$ of occupants are typically dissatisfied with thermal conditions. The model inputs are the dry bulb temperature, the mean radiant temperature (MRT), the relative humidity, the metabolic rate, the external work, air velocity, and clothing insulation. A mean radiant sensor was used in ESP-r to measure the mean radiant temperature near the center of the living area. The predicted mean value (PMV) was calculated at each occupied time step. The air velocity was set to $0.15 \mathrm{~m} \mathrm{~s}^{-1}$, the occupants were assumed to have a metabolism level of $1.1 \mathrm{MET}$ with a clothing value of 1.0, and the relative humidity in the zone was assumed to be $35 \%$. A time step was assumed to be comfortable when the PMV was between -0.5 and 0.5 . The entire week was split into three periods: weekday mornings, weekday evenings, and weekend. For each of those periods, the percentage of time when the conditions in the zone were comfortable was calculated.

The morning period was relatively short compared with the other periods of the week ( 5 hours compared to 25 hours for evenings, and 30 hours for weekend) but it was deemed crucial to ensure comfort of the occupants, and to ensure that the setback recovery period was long enough. Looking at the parametric study results, it became apparent that underheating in the morning could help mitigate overheating in the evening and weekends for the case with high south facing glazing. It was decided that this is not an acceptable solution and that occupants would want to be comfortable while getting ready for their day. Using the other periods (evenings and weekends) as a primary benchmark for choosing the best controller settings could bias against morning comfort. Additionally, for the low glazing cases, it could be seen that if specific controller settings were able to maintain comfort in the morning, comfort was also likely maintained for the other periods. The morning period was a good predictor of comfort for all periods in that case.

An objective function, as one would use for an optimization problem, was developed to account for both the comfort and the heating energy use. The idea was to 
calculate this objective function for all of the cases, and pick the optimally tuned controllers. This objective function has to maximize comfort while minimizing heating energy use. It was decided that if all defined periods (morning, weekends, evenings) are comfortable according to the PMV model $95 \%$ of the time, then the only objective would be to minimize heating energy use. If not, then the objective function has to maximize all around comfort (and especially morning to ensure no bias against morning periods). In that case, a very small component of the objective function allowed for minimization of heating energy use. This part of the objective function was very small and only came into play if comfort levels were almost the same between the compared controllers. Table 5.8 describes the objective function.

For the PID controller, because of the large possible solution space for optimal tuning, a sweep of that solution space was deemed unreasonable. MATLAB's genetic algorithm was used to tune the controller with the objective function described in Table 5.8.

Table 5.8: Objective function

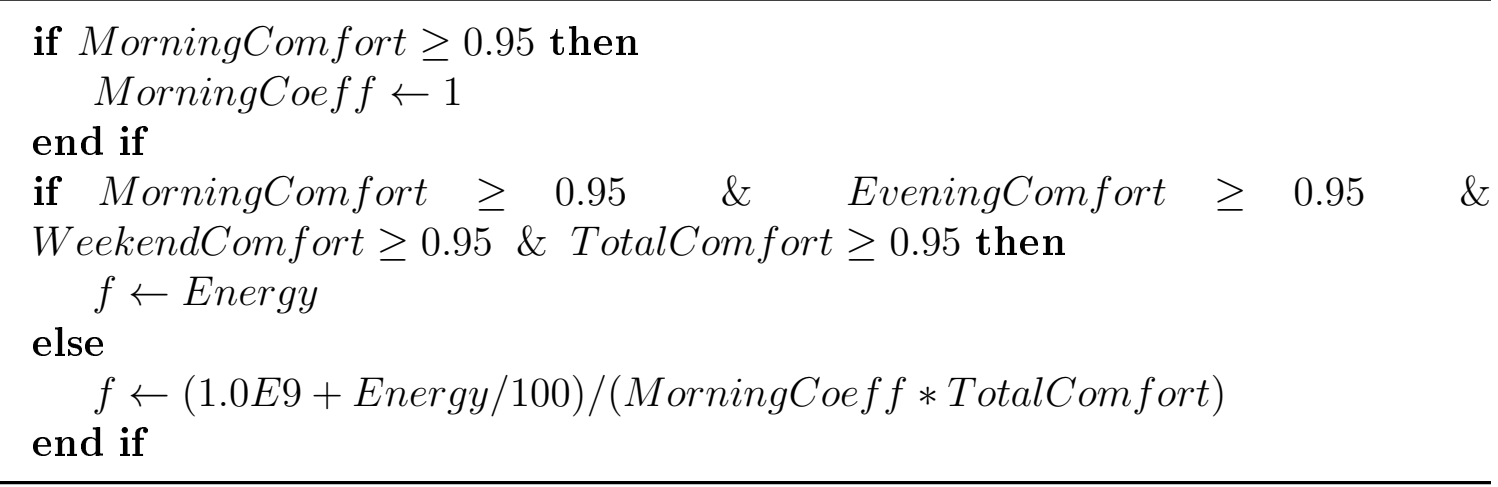

In Table 5.8, MorningComfort, EveningComfort, WeekendComfort, and TotalComfort are the percentage of times when occupants are considered comfortable according to PMV calculations for the mornings, evenings, weekend periods, and for the entire occupied periods (between 0 and 1). Energy is the amount of heating energy used over the week (in Joules). $f$ is the objective function. 


\subsubsection{Predictive controller}

In addition to the reactive controllers discussed previously, one predictive controller was modelled for slab C for the case of $15 \%$ south facing glazing to floor area ratio. This predictive controller was in fact set up as a large optimization problem with 85 different independent variables. These variables corresponded to supply temperatures every two hours. A spline is fitted through those points to find the supply temperatures at every other time step between the two hour intervals. The MATLAB genetic algortihm was used to solve for the optimal solution using the objective function as defined by Table 5.8. A new mutation scheme was defined for the genetic algorithm. This mutation scheme mutates blocks of adjacent 'genes' (in this case supply temperatures) by the same random amount. This made the supply temperature profiles less noisy than the default mutation schemes provided in MATLAB.

Since this predictive controller had exact knowledge of future boundary conditions (e.g. weather, occupancy, internal gains) and thermal response of the building model to changes in various inputs and boundary conditions, this controller was in a sense perfect, and therefore unrealistic. It does provide however a comparison point for the reactive controllers.

\subsection{Results}

The values of the parameters for the tuned controllers can be found in Appendix D.

\subsubsection{6\% South Facing Glazing to Floor Area Ratio without Setback}

For the cases where typical amounts south facing glazing were present, and no temperature setback, all 'tuned' controllers and floor constructions performed well, as they could all provide comfortable conditions for the occupants above $95 \%$ of the occupied period, for any floor construction.

Figures 5.6 and 5.7 show the heating demand and average supply temperature for 'tuned' controllers for each floor construction. The floor construction with the lowest heating energy requirement was the AFTP, using the TRIF-Avg controller (626.3 MJ). It also had the lowest average supply temperature requirement $\left(30{ }^{\circ} \mathrm{C}\right)$. The TRIF-Avg, TRIF, and PID controllers provided very similar results for all floor 
constructions.

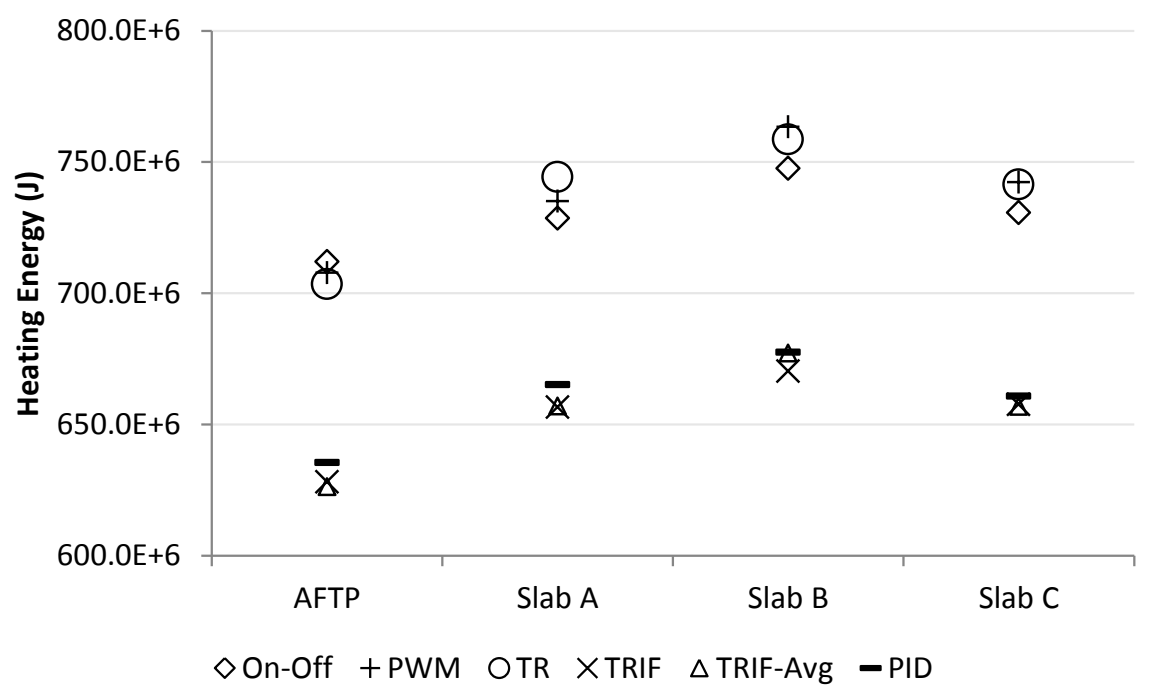

Figure 5.6: Heating demand of various floor constructions with typical solar gains without temperature setback

\section{Reset slope}

For all results, including the ones in the following sections, one interesting result for the TRIF and TRIF-Avg is that the reset slope of the tuned controller was zero for most of the cases (regardless of floor construction, glazing area, and presence of temperature setback). A few cases for slab B and C had a tuned reset slope of 0.1 . This means that most of the TRIF and TRIF-Avg controller cases were purely proportional controllers. For the cases where the reset slope was zero, the portion of the controller that is a function of outside temperature was removed from the controller. For the cases where the reset slope was 0.1, the reset portion of the controller played a relatively small part of the controller during cold days.

For the purposes of this thesis, controllers with a reset slope of zero are still called TRIF and TRIF-Avg even though the Temperature Reset part of the controller is not applied. This is because tuning of the controllers was run for a range of reset slopes, including zero and positive non-zero values, and the tuned results arrived at a zero reset slope. In other words, the cases with zero reset slope controllers were the results of tuning of the TRIF (or TRIF-Avg) controllers where the reset slope happened to 


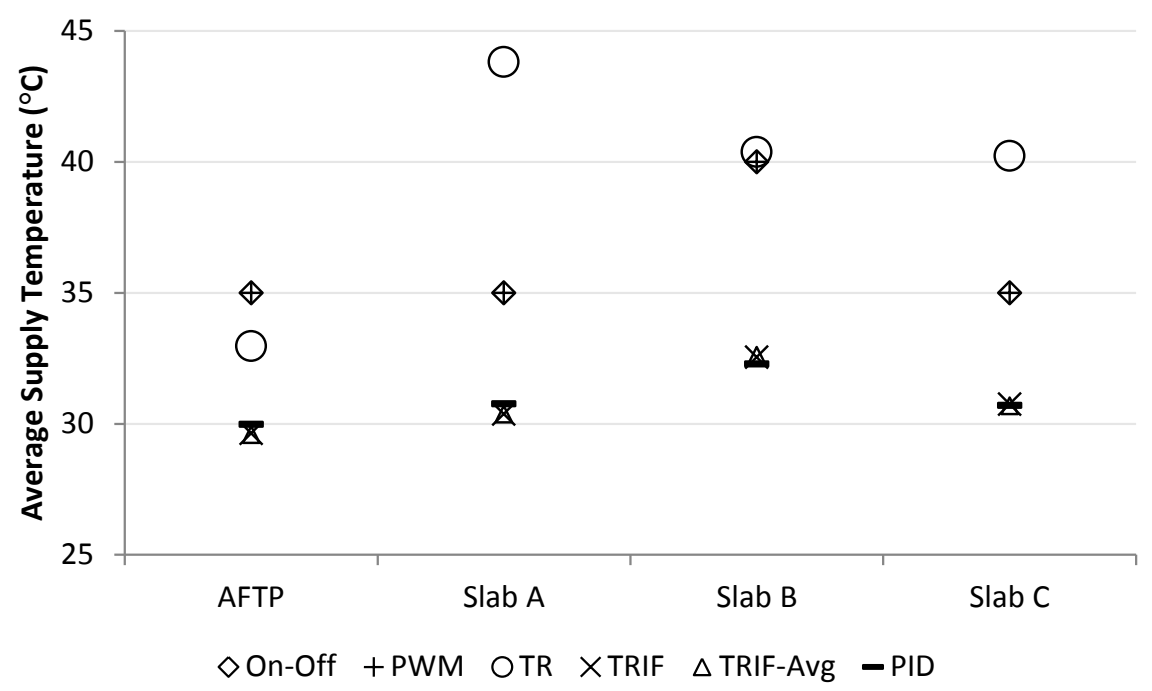

Figure 5.7: Average supply temperature of various floor constructions with typical solar gains without temperature setback

be zero (the minimum logical value possible for such a controller). 


\subsubsection{6\% South Facing Glazing to Floor Area Ratio with set- back}

If temperature setback is used with typical amounts of south facing area, all 'tuned' controllers and floor constructions performed well as they could all provide comfortable conditions for the occupants over $95 \%$ of the occupied period.

Figures 5.8 and 5.9 show the heating demand and the average supply temperature for the 'tuned' controller for each floor construction. Once again, the floor construction with the lowest heating energy requirement was the AFTP, using the TRIF-Avg controller (576.8 MJ). This was followed by Slab A (626.0 MJ), Slab C (640.0 MJ) and Slab B (667.3 MJ) (with TRIF). Generally, the lowest average supply temperature requirements come with the TRIF-Avg, PID, and TRIF controllers. There was a $25 \%$ percentage difference between the energy requirement of the lowest (AFTP with TRIF-Avg) and highest (Slab B with PWM) heating demand in the various construction/controller configurations.

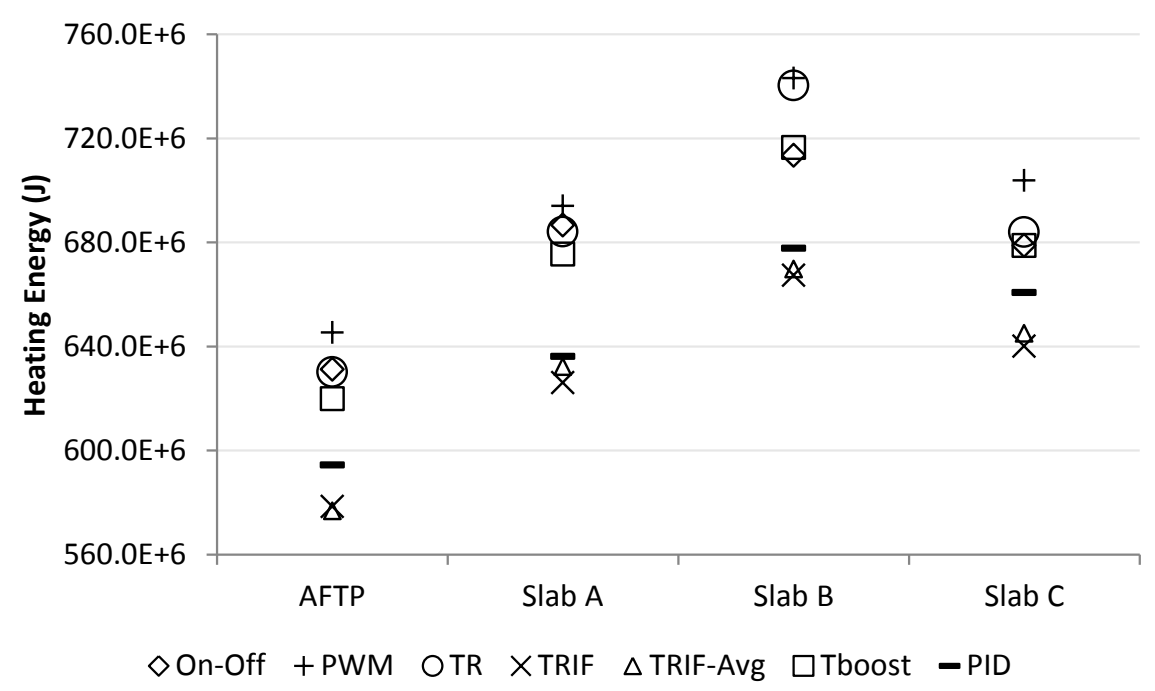

Figure 5.8: Heating demand of various floor constructions with typical solar gains and temperature setback 


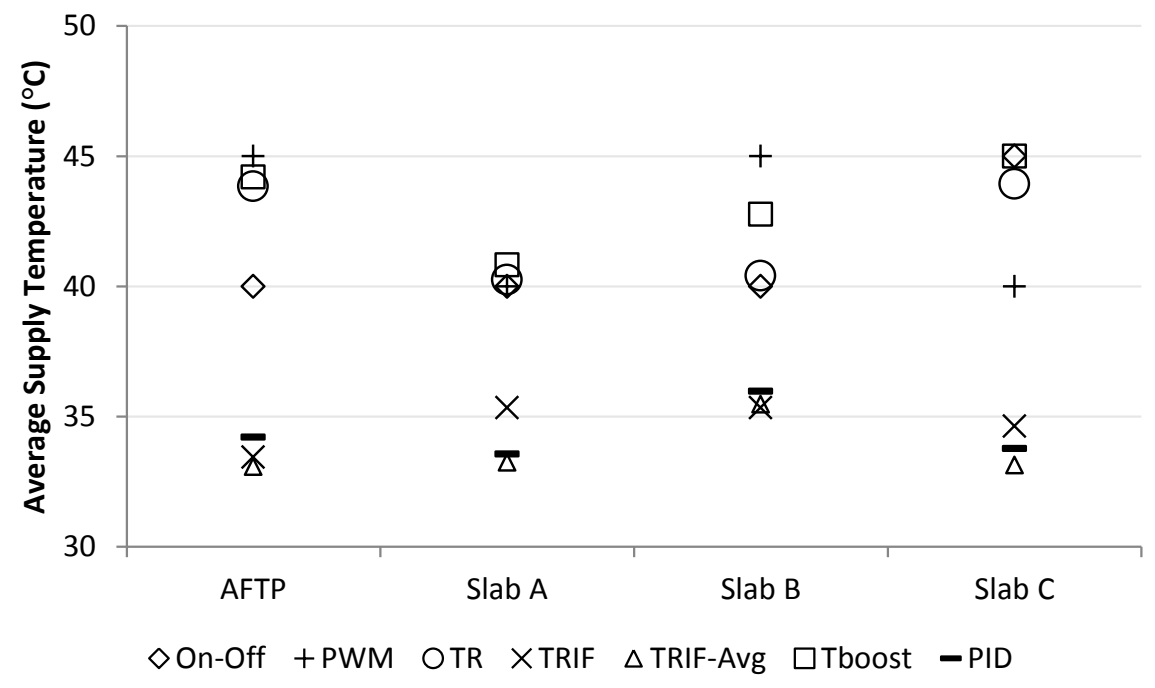

Figure 5.9: Average supply temperature of various floor constructions with typical solar gains and temperature setback

\subsubsection{5\% South Facing Glazing to Floor Area Ratio without Setback}

For cases with large amounts of south facing glazing and no temperature setback, overheating occured during weekends and evenings. In all cases, morning periods were comfortable $100 \%$ of the time. Figure 5.10 shows the percentage of time in comfortable range for the entire occupied period for the various floor construction and control strategies. In this case, the worst performing controller was the PWM for all cases. The best performing controller was the PID for the slab cases. For the AFTP, the best performing controller were the TRIF-Avg and TRIF. As can be seen from Figure 5.10, higher thermal mass in the floor appears to have some beneficial effects in increasing the thermal comfort. This is likely due to the fact that more solar gains could be stored in the additional thermal mass, thus reducing the peak temperatures in the zone.

Figure 5.11 shows the heating demands and Figure 5.12 shows the average supply temperatures of the various control strategies. The lowest energy demand is the combination of TRIF-Avg and AFTP. The lowest average supply temperature is also a combination of TRIF-Avg and AFTP. There was a $24 \%$ percentage difference between the energy requirement of the lowest (AFTP with TRIF-Avg) and highest (Slab B 


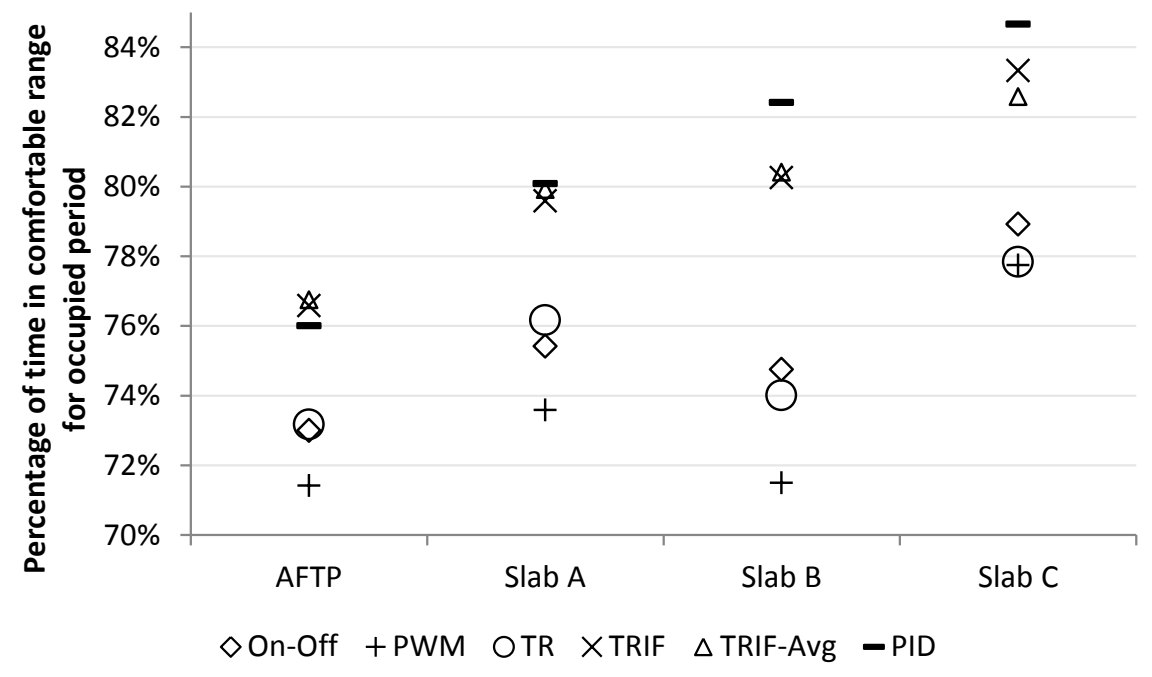

Figure 5.10: Comfort of various floor constructions with high solar gains and without temperature setback

with On-Off) heating demand in the various construction/controller configurations. 


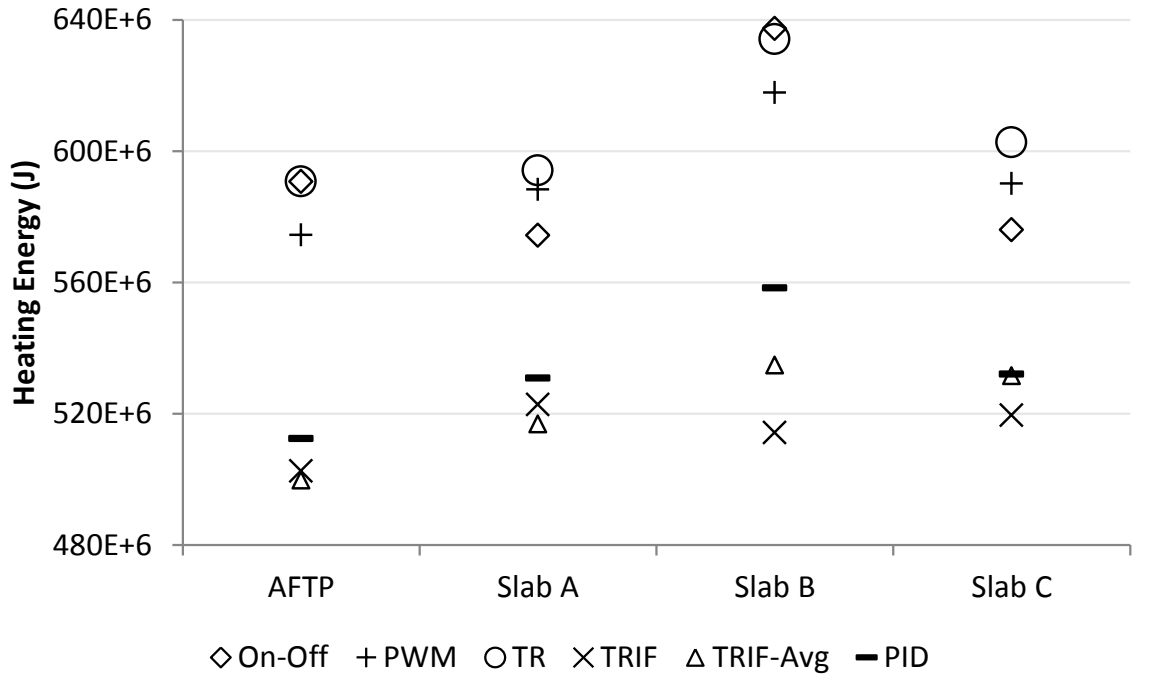

Figure 5.11: Heating demand of various floor constructions with high solar gains and without temperature setback

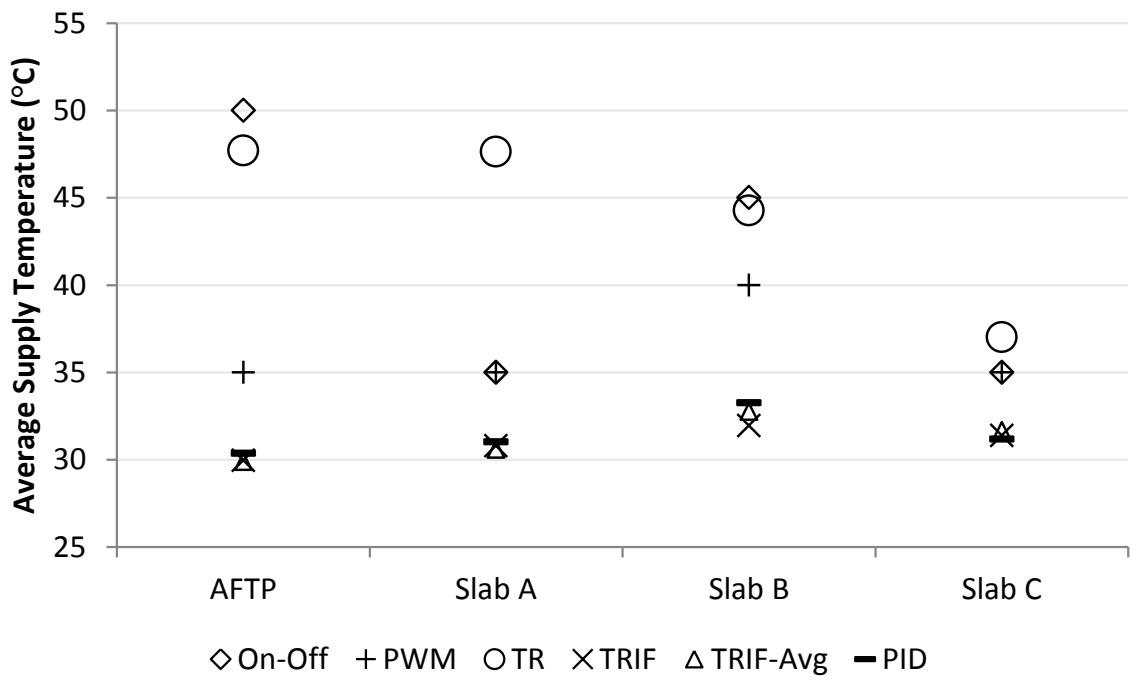

Figure 5.12: Average supply temperature of various floor constructions with high solar gains and without temperature setback 


\subsubsection{5\% South Facing Glazing to Floor Area Ratio with Set- back}

For cases with large amounts of south facing glazing with temperature setback, overheating occured during weekends and evenings. In all cases, morning periods were comfortable at least $95 \%$ of the time. Figure 5.13 shows the percentage of time in the comfortable range for the entire occupied period. That figure shows that generally, floors with more thermal mass yield better comfort (less overheating), except for the case of Slab B for some controllers. This is likely due to the fact that the tube in Slab $\mathrm{B}$ are at the bottom of the slab. During setback recovery, the entire thickness slab needs to be warmed up before the room temperature is affected. Once solar gains start heating the space, the slab is already warm and keeps heating the space, thus increasing overheating. This effect is not as important with Slab C because, although they have the same thickness, the tubes in Slab C are closer to the surface so the entire slab does not need to be warmed up before heating the space. Of the reactive controllers, the TRIF and TRIF-Avg controllers are found to be the best for comfort for the AFTP, slab A and slab B. TRIF-Avg, TRIF and PID provide similar comfort for Slab C.

Figures 5.14 and 5.15 show the heating demand and average supply temperatures for the various control strategies. The heating demand is the lowest in the AFTP floor. This is due to the faster response time of the AFTP system. Because it responds faster, the AFTP system setback recovery time can be shorter, and less extra stored heat is used to heat the space at night during the setback period. As discussed above however, the low thermal mass also allows more overheating later during the day. There was a $30 \%$ percentage difference between the energy requirement of the lowest (AFTP with TRIF-Avg) and highest (Slab B with PWM) heating demand in the various construction/controller configurations. 


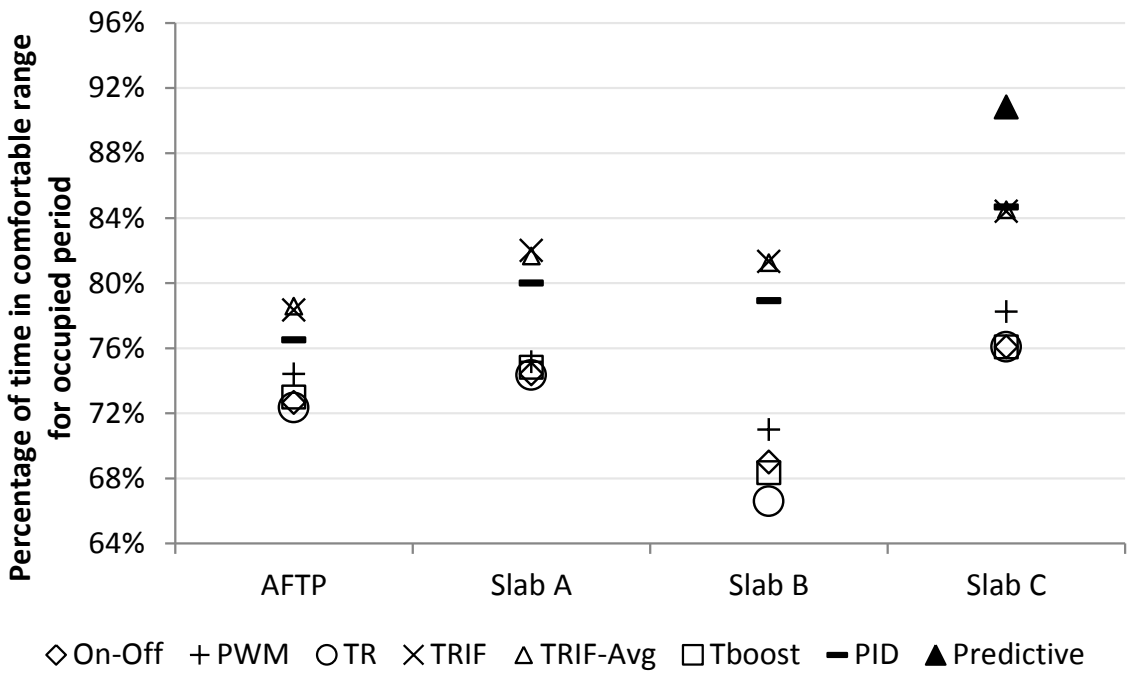

Figure 5.13: Comfort of various floor constructions with high solar gains and temperature setback

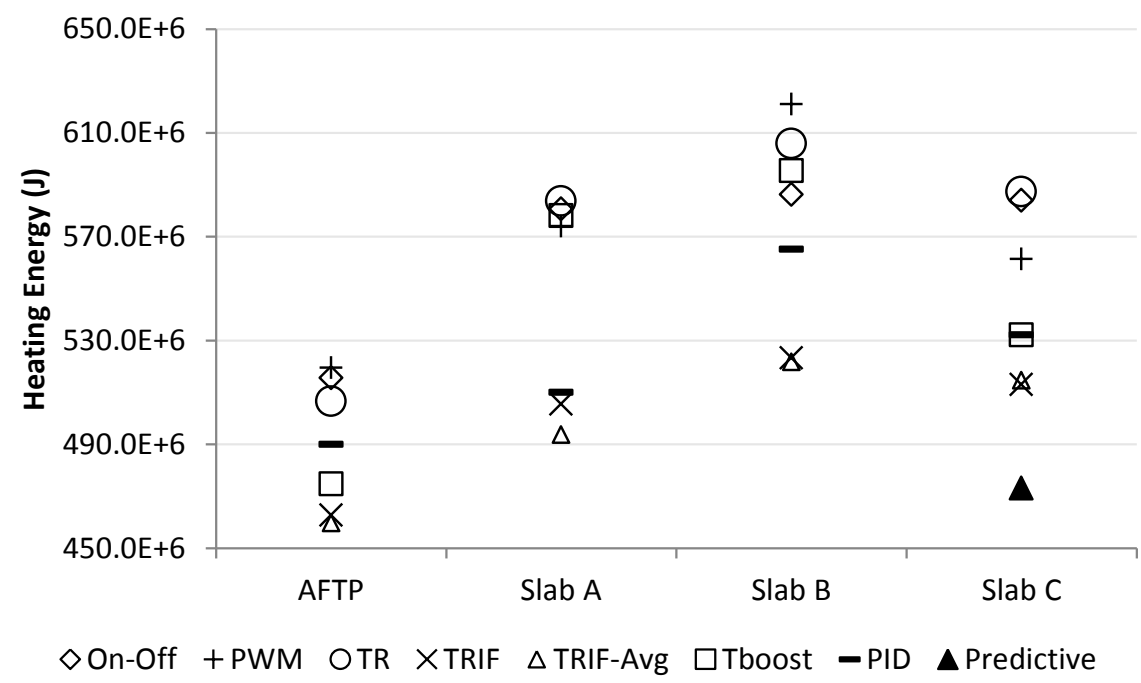

Figure 5.14: Heating demand of various floor constructions with high solar gains and temperature setback 


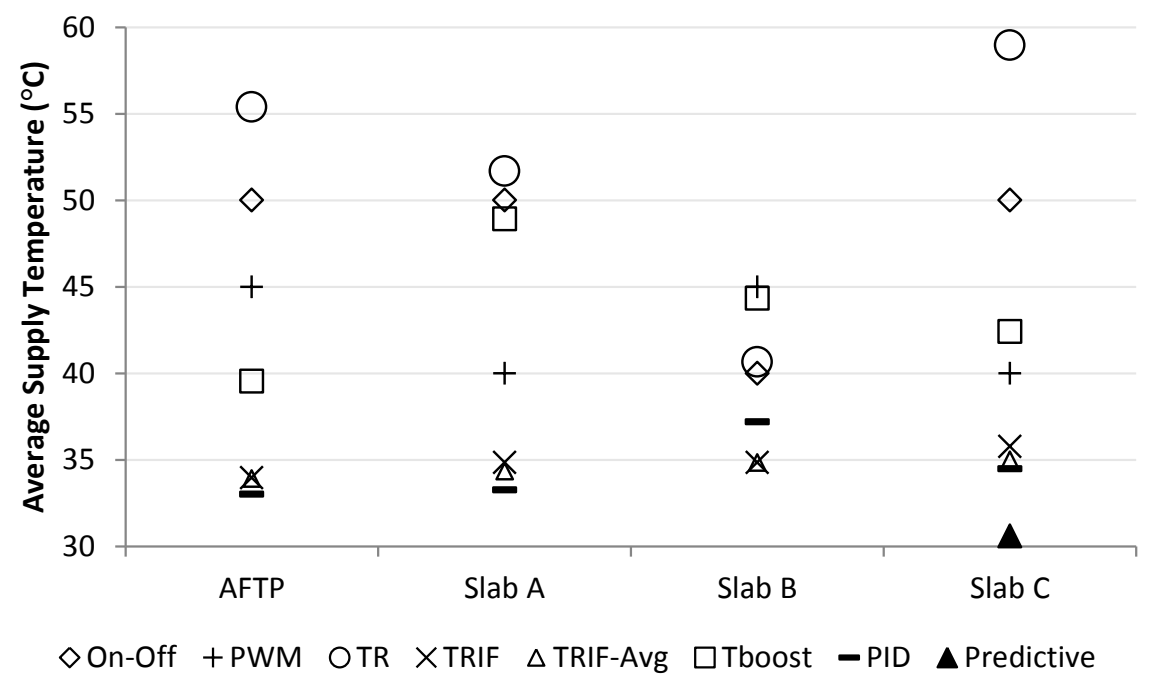

Figure 5.15: Average supply temperature of various floor constructions with high solar gains and temperature setback 


\section{Predictive controller}

As expected, the predictive controller modelled for a single case (Slab C, high solar gains and temperature setback) performed better than all reactive controllers. The comfort was increased from $85 \%$ (PID) to $91 \%$. For that same case, the average supply temperature was reduced from $34.5{ }^{\circ} \mathrm{C}$ (PID) to $30.6{ }^{\circ} \mathrm{C}$, and the heating energy demand was reduced from 532.1 MJ to 473.1 MJ (a 12\% difference).

The specific controller implemented here was for comparison purposes but would be difficult in its current state to implement in a real building due to the solution time of the optimization function required. Other researchers have investigated much more computationally efficient ways of solving this type of problem. Many predictive controllers do however require a certain expertise to implement, and are currently still mostly applied in research projects.

\subsubsection{Setback recovery time}

The setback recovery time for the 'tuned' controllers varies between 2 and 4.5 hours. These were the maximum and minimum recovery times evaluated for this study. It is likely that some controllers would have performed slightly better with a longer recovery period. However, a close look at the results showed that the controllers that were tuned with a recovery time of 4.5 hours were only marginally improved compared with the same controller with a recovery time of 4.0 hours. The same is true for a tuned controller with a recovery time of 2.0 hours. In that case, it was seen that the controller was improved only marginally compared with the same controller with a recovery time of 2.5 hours. It was therefore decided to maintain the solution space to the range between 2.0 hours and 4.5 hours in order to reduce the already high computational cost.

\subsection{Concluding remarks}

A week of simulations were run for four different radiant floor constructions and seven different reactive controllers in the main floor of a house in heating-only mode with and without air temperature setpoint setback. The comfort and heating demand were recorded for each combination of floor construction and controller. For each combination, tuned controllers were used as basis for comparison. 
The main findings are that for a zone with a typical amount of south facing glazing (for this study, 6\% south-facing glazing to floor area ratio), a lighter floor construction (such as the above-floor tube and plate, or thin slab) tends to require lower average supply temperatures and total heating energy for the same comfort conditions. In cases with higher solar gains (for this study, 15\% south-facing glazing to floor area ratio), floors with higher thermal mass tend to provide better comfort to the occupants. This is especially true is the tubes are located near the surface of the floor. In a high solar gains case with nighttime setback, a thick slab with tubes deep in the floor perform worse than lighter floors both in terms of comfort and energy requirements.

In general, the more complex the controller, the better it seems to perform. The PID, TRIF, and TRIF-Avg controllers perform better in most cases. Also, the tuned TRIF and TRIF-Avg most often yielded a purely proportional controller the reset slope was equal to zero). This may be due to the fact that the house used was well insulated, so the heat losses were low compared to the variations in occupant, electrical and solar heat gains. Additionally, the simulations were run for only one specific week of the year. This means that the ambient temperature range and other boundary conditions were limited to the range of conditions during that week.

While the PID controller performed well, it was not found to be significantly better than other controllers in any of the cases. Since PID controllers can be problematic to tune in the field, the author sees no advantage in using this type of controller in housing for radiant heating.

The one case where a predictive controller was investigated, this controller performed much better than any of the other controllers. This controller was however not a realistic controller and was provided only for comparison purposes. The controller was 'perfect' and used the same building model to make decisions that it was meant to control. Additionally, the solution time for this specific 'controller' was such that it is impossible to implement in a building. There are however many types of predictive controllers that could be implemented. However, these are generally complex and have yet to be implemented in real buildings without close monitoring from highly qualified researchers.

One aspect that should be further investigated is the influence of the amount of furniture in the space. Another is the discretization of the floor surface to account for the exact location where solar gains are absorbed and the local influence on the 
floor. Also, other controllers could be investigated, such as one based on the floor surface temperature. 


\section{Chapter 6}

\section{Evaluation of active/passive solar collection system}

\subsection{Introduction}

As discussed in Chapter 1, solar gains can be used to reduce heating demand in houses during winter and shoulder seasons in Canada. This is usually done by using an optimal area of south facing glazing. Increasing south facing window area beyond the optimal point can result in overheating during sunny days while increasing heat losses at night.

With the use of radiant floors, a heat pump, and storage tanks, it is possible to collect those solar gains incident on the floor in zones with a large amount of south facing windows and store the heat for DHW or space heating. Figure 1.2 shows a schematic of such a system with cooling and heating of two zones.

The work presented in this chapter is an investigation of the performance of an active/passive radiant floor solar collection system. This was accomplished with building performance simulation. This work builds upon the work presented in the previous chapters. Validated AFTP and embedded-tube radiant floor models and the new transient water-water heat pump model were used. Initial results of this work were presented at the 6th International Building Physics Conference [114].

\subsection{Models}

In order to evaluate the system as shown in Figure 1.2, the TRNSYS/ESP-r cosimulator [24] was used. The building envelope and radiant floors were represented in 
ESP-r, while the rest of the mechanical system was represented in TRNSYS. Additionally, a typical house representation was developed in order to compare a conventional HVAC system with the solar collection system. All simulations were run with a 3 minute time-step for an entire year with CWEC climate files [115].

\subsubsection{Building model}

A single-family detached home was represented in ESP-r. This home was loosely based on the Urbandale CHEeR presented in Chapter 3. The house representation consisted of an unconditioned basement, and two conditioned floors. The dimensions of the house were $12 \mathrm{~m}$ by $6 \mathrm{~m}$. The exterior walls were timber construction with $140 \mathrm{~mm}$ batt insulation in the cavity and $38 \mathrm{~mm}$ of continuous insulation. The exterior walls nominal R-value was approximately $4.2 \mathrm{~m}^{2} \mathrm{~K} \mathrm{~W}^{-1}\left(\mathrm{U}=0.24 \mathrm{~W} \mathrm{~m}^{-2} \mathrm{~K}^{-1}\right)$. The attic was insulated with $320 \mathrm{~mm}$ of batt insulation and had an R-value of $9.0 \mathrm{~m}^{2} \mathrm{~K} \mathrm{~W}^{-1}$. The basement heat loss was modelled with the BASESIMP model [116]. The above grade basement walls construction was made of $10 \mathrm{~mm}$ of parging, $76 \mathrm{~mm}$ EPS board, $200 \mathrm{~mm}$ concrete, and $38 \mathrm{~mm}$ fiberglass. This is equivalent to an overall R-value of $3.5 \mathrm{~m}^{2} \mathrm{~K} \mathrm{~W}^{-1}\left(\mathrm{U}=0.29 \mathrm{~W} \mathrm{~m}^{-2} \mathrm{~K}^{-1}\right)$. The below grade walls were made of the same construction as the above grade basement walls without the parging layer. The below grade and above grade had effectively the same R-value. The basement floor was made of a $51 \mathrm{~mm}$ EPS board, and a $100 \mathrm{~mm}$ concrete slab. This gives an R-value of 1.6 $\mathrm{m}^{2} \mathrm{~K} \mathrm{~W}^{-1}\left(\mathrm{U}=0.61 \mathrm{~W} \mathrm{~m}^{-2} \mathrm{~K}^{-1}\right)$.

All modelled glazing was triple pane with two low-e coatings, and argon filled. The center of glass nominal U-value was $0.9 \mathrm{~W} \mathrm{~m}^{-2} \mathrm{~K}^{-1}$ and the nominal SHGC was 0.6. Window frames were modelled as a separate surface. Two south facing glazing areas were modelled: $20.7 \mathrm{~m}^{2}$ (14.4\% south-facing glazing to floor area ratio) and 6.9 $\mathrm{m}^{2}$ (4.8\% south-facing glazing to floor area ratio). The south façade for the $20.7 \mathrm{~m}^{2}$ and $6.9 \mathrm{~m}^{2}$ glazing areas are shown in Figures 6.1 and 6.2. In those figures, the dark grey area is the roof, the light grey area is the basement, and the white areas are the glazed portions.

The solar absorptivities of the floor tiles, walls/ceilings, and furniture were set to $0.79,0.30$, and 0.50 . The solar absorptivities of the floor tiles and walls/ceilings were measured by Pr. Michael Collins at the University of Waterloo with the use of 


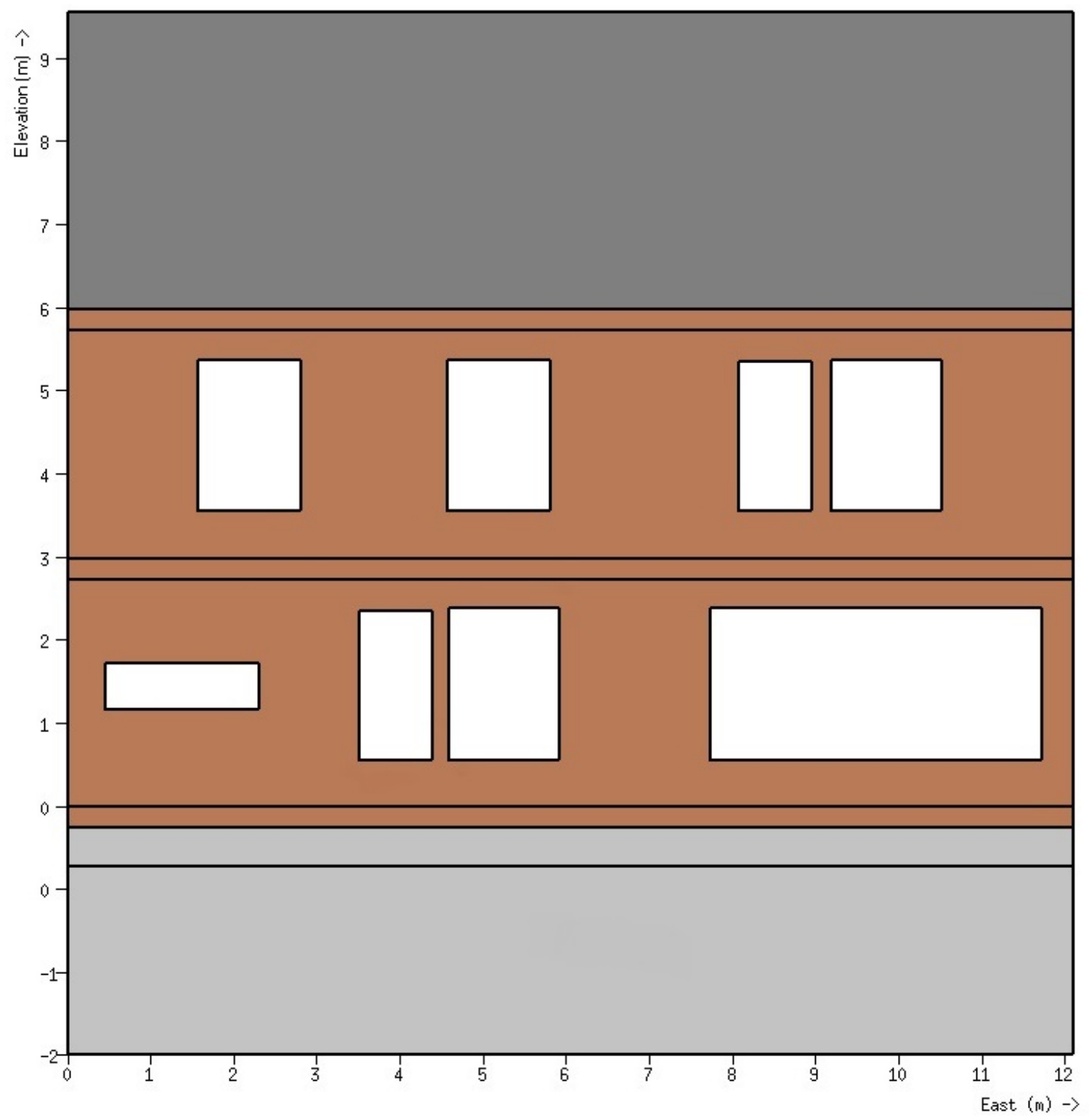

Figure 6.1: South elevation with high glazing area 


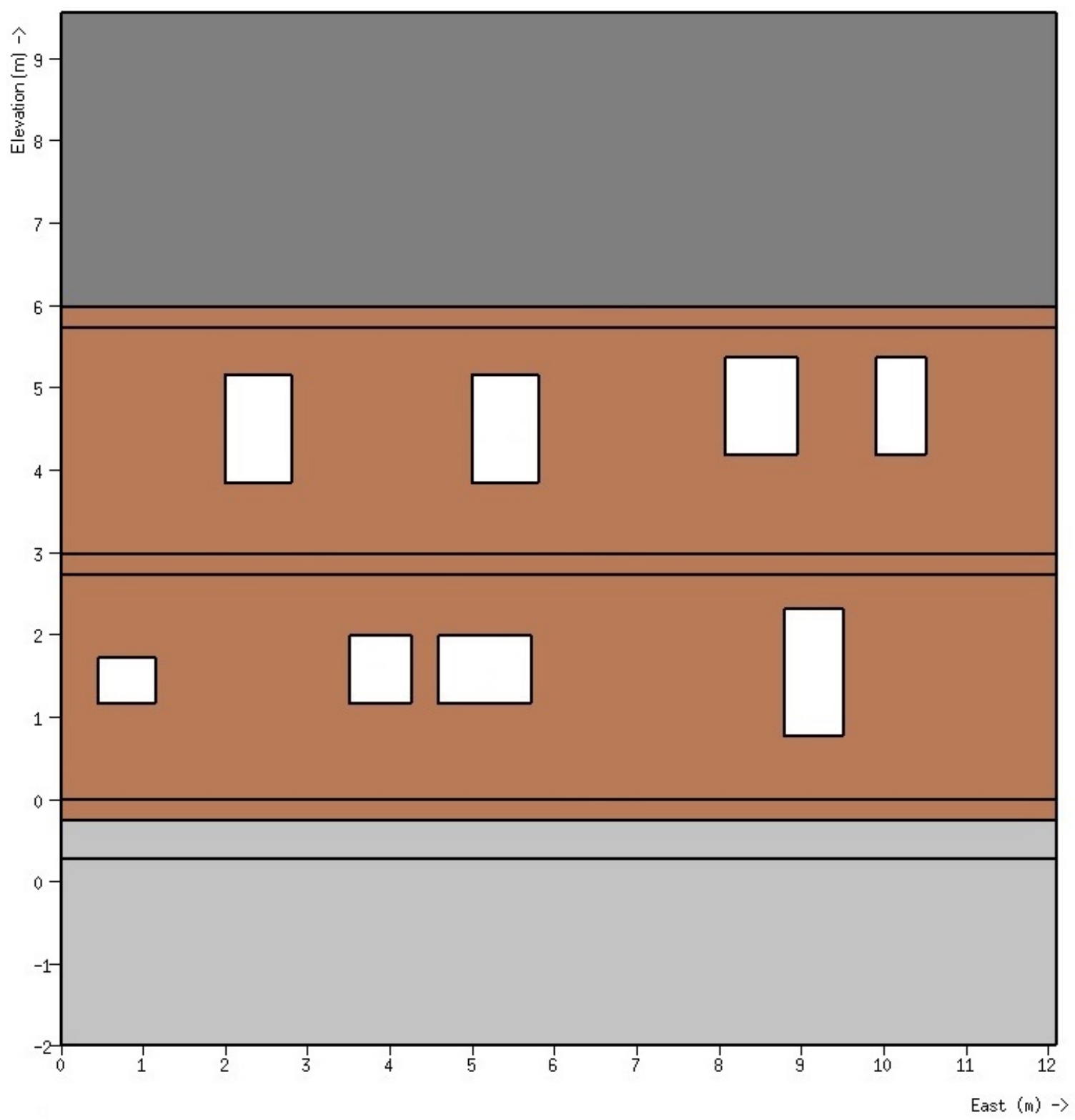

Figure 6.2: South elevation with low (typical) glazing area 
a Varian Cary 5000 Ultra-violet/visible light/near-infrared spectrophotometer. The value for the furniture surfaces was chosen at 0.50 due to the large range of possible material finishes and their corresponding solar absorptivities (e.g. white paint 0.30, white marble 0.46 , black felt 0.82 [117]). The exterior walls were assumed to be bare wood finish with a solar absorptivity set to 0.50 . This value was picked based on a report by Akbari et. al. [118] who state reflectivity of bare wood roof shakes to be between 0.40 and 0.55 (i.e. absorptivity between 0.45 and 0.6 ). The roof solar absorptivity was set to 0.90, based on the report by Akbari et. al. [118] who reported absorptivity values for typical asphalt shingles between 0.85 and 0.96 . The longwave emissivities of the floor tiles, walls/ceilings, and furniture were set to 0.80, 0.83, and 0.83. The longwave emissivity values for the floor tiles and walls/ceilings materials were measured by Pr. Michael Collins at the University of Waterloo with a Gier Dunkle DB-100 reflectometer. The exterior walls longwave emissivity was set to 0.83 (reported values in the literature for bare wood between 0.80 and 0.90 [118]). The roof longwave emissivity was set to 0.90 (reported values in the literature for asphalt shingles between 0.80 and 0.90 [118]).

The Alberta Infiltration Model [108] was used to calculate the infiltration based on the energy tight setting in ESP-r. This setting assumes a blower door test of $1.5 \mathrm{ACH}$ at $50 \mathrm{~Pa}$. An energy recovery ventilator with sensible and latent effectiveness of 0.6 and 0.7 respectively provided $198 \mathrm{~kg} \mathrm{~h}^{-1}$ of fresh air to the house and was modelled in TRNSYS. The ventilator was assumed to consume $85 \mathrm{~W}$.

Due to the generally open concept of the first floor of the house, it was modelled as a single zone. There were six parallel radiant floor loops on the first floor. The first floor area was $72.4 \mathrm{~m}^{2}$. Radiant floor systems covered $54.6 \mathrm{~m}^{2}$ of the first floor. Horizontal surfaces with thermal mass were added to the living space near the south facade to account for interaction between furniture and solar radiation. The thermal properties of the furniture surfaces were made to be equivalent to that of a $25.4 \mathrm{~mm}$ thick sheet of gypsum board. The aim of the surfaces was to account for interaction between the furniture and solar radiation and there is a need for better understanding of the proper amount of detail required in modelling furniture in building energy simulation, as these effects are often ignored. The simplifications used here are an attempt at accounting for the furniture in the space. Additional thermal mass was added to the first floor to account for the thermal mass of furniture not included in the surfaces explicitly modelled. This is discussed below. These horizontal surfaces 


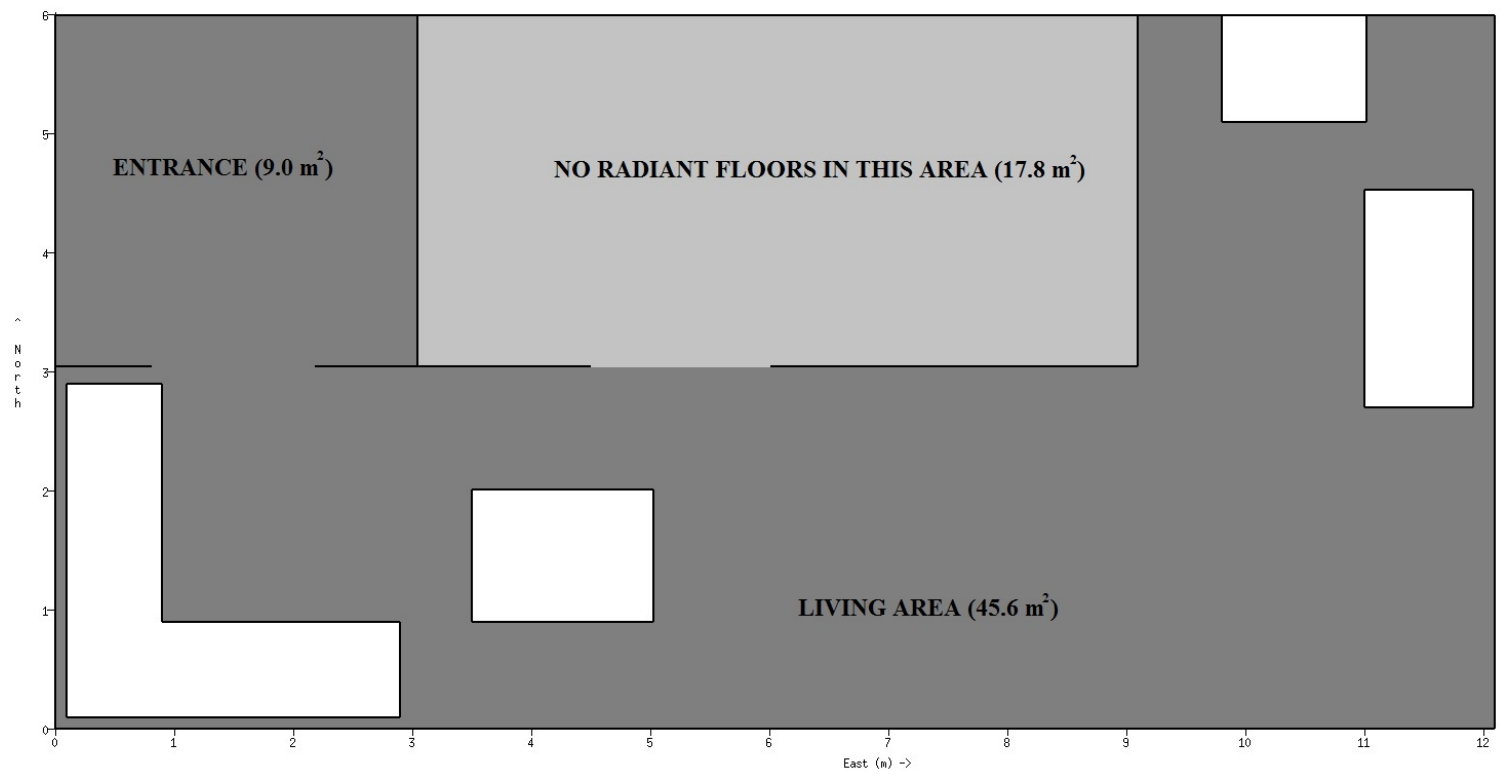

Figure 6.3: Floor plan of first floor zone

were located at heights varying between $0.61 \mathrm{~m}$ and $0.9 \mathrm{~m}$ from the floor. The total area of this living space was $45.6 \mathrm{~m}^{2}$. The horizontal area of surfaces to account for furniture was $8.32 \mathrm{~m}^{2}$. Figure 6.3 shows a floor plan of the first floor zone. The white areas are the furniture surfaces.

The second floor consists of three bedrooms and a hallway. Each of the bedrooms and the hallway were modelled as separate zones. Each of the second floor zones contains a single parallel radiant floor loop. Radiant floor systems covered the entirety of the second floor area $\left(72.4 \mathrm{~m}^{2}\right)$. Horizontal surfaces were added to the bedrooms to account for interaction between furniture and solar radiation. Thermal properties for these surfaces are the same of those included in the first floor zone. These horizontal surfaces were located at heights varying between $0.1 \mathrm{~m}$ and $0.7 \mathrm{~m}$ from the floor. Figure 6.4 shows a floor plan of the second floor zones. The white areas are the furniture surfaces. It is important to note that the surfaces added to account for the furniture on the main and second floor had no influence on the convective heat transfer coefficient on the floor. These surfaces did however include some thermal mass. The thermal mass of each of the furniture surfaces was estimated based on the type of furniture the surface was intended to represent.

Additional mass was added in internal partition walls on the first floor between 


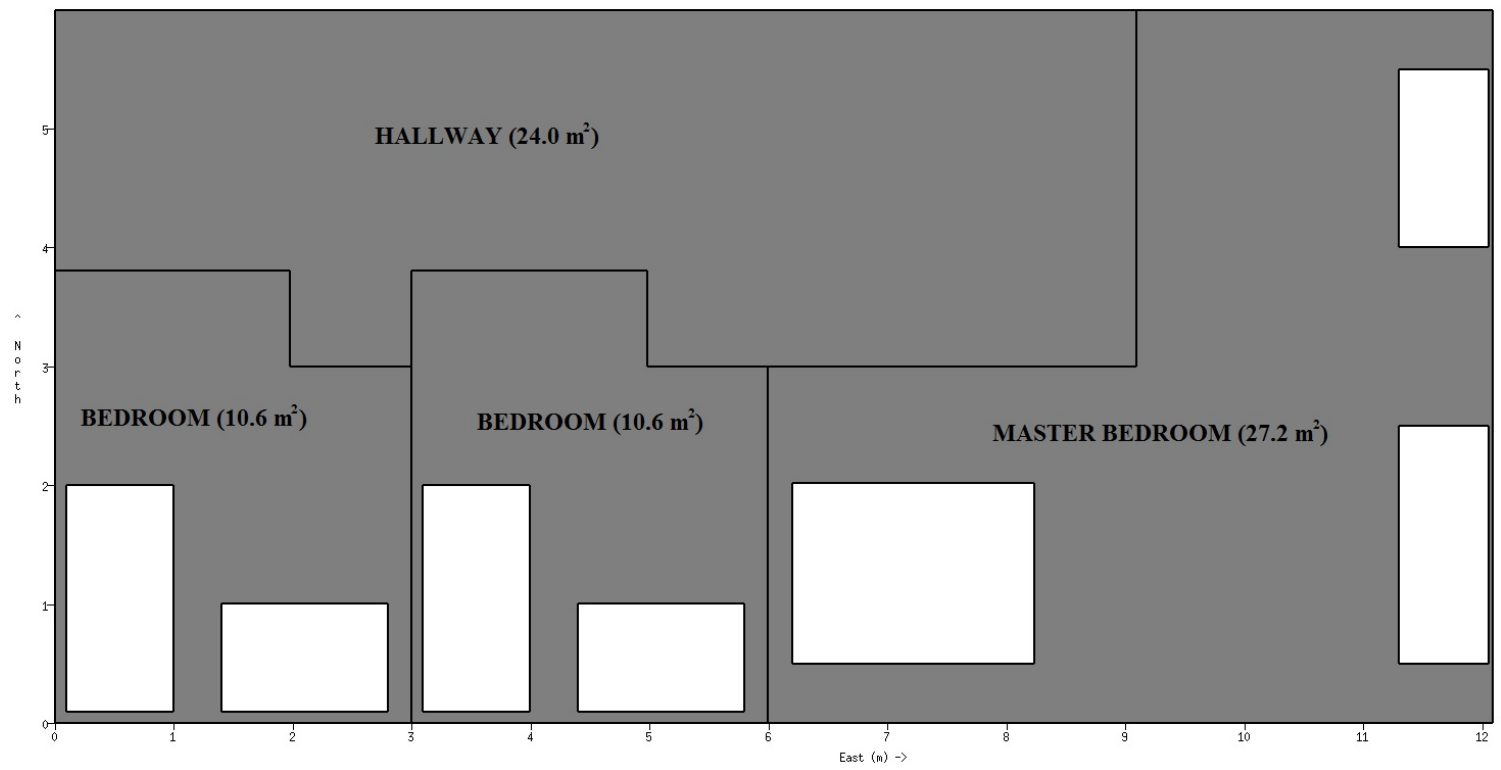

Figure 6.4: Floor plan of first floor zone

the living space and area without radiant floor, and on the second floor between the hallway and the master bedroom to account for mass of all potential furniture in the space. The total mass of all furniture in the house was calculated as per guidelines by Hendron and Engebrecht which stated that "The internal mass of furniture and contents shall be equal to $8 \mathrm{lb} \mathrm{ft}^{-2}$ of conditioned floor space" [107]. Since no specific heat value was mentioned in the guidelines, a value of $1150 \mathrm{~J} \mathrm{~kg}^{-1} \mathrm{~K}^{-1}$ was used.

Two types of radiant floors were used: the AFTP, and the embedded tube. The new model described in Chapter 3 was used to simulate the AFTP radiant floor system. The model by Laouadi with modifications as described in Chapter 2 was used to simulate the embedded-tube radiant floor model.

The construction of the AFTP radiant floor is shown in Table 3.7. Two constructions of embedded-tube radiant floors were evaluated (Slab A, and Slab C), and are shown in Table 6.1.

Casement windows were modelled to open when indoor temperature was above $25{ }^{\circ} \mathrm{C}$ provided that the outdoor air temperature was at least $11{ }^{\circ} \mathrm{C}$ and $1{ }^{\circ} \mathrm{C}$ lower than the indoor temperature. Windows were shut when the indoor air temperature dropped to $21{ }^{\circ} \mathrm{C}$. This was to allow for some natural ventilation in the summer and shoulder seasons. Additionally, between May 1st and September 30th, indoor roller blinds were pulled down if the direct normal solar radiation intensity reached 
Table 6.1: Construction of embedded tube floor

\begin{tabular}{lcccc}
\hline Material & $\begin{array}{c}\text { Thickness } \\
(\mathrm{m})\end{array}$ & $\begin{array}{c}k \\
\left(\mathrm{~W} \mathrm{~m}^{-1} \mathrm{~K}^{-1}\right)\end{array}$ & $\begin{array}{c}\rho \\
\left(\mathrm{kg} \mathrm{m}^{-3}\right)\end{array}$ & $\begin{array}{c}C_{p} \\
\left(\mathrm{~J} \mathrm{~kg}^{-1} \mathrm{~K}^{-1}\right)\end{array}$ \\
\hline Insulation & 0.02489 & 0.029 & 45 & 1450 \\
Subfloor & 0.01905 & 0.100 & 450 & 1880 \\
Gypsum Cement & $z_{s}{ }^{\mathrm{a}}$ & 0.7142 & 1840 & 938.5 \\
Mortar & 0.0032 & 0.72 & 1860 & 780 \\
Tile & 0.009 & 1.5 & 2089 & 730 \\
\hline
\end{tabular}

a The thickness of the slab $z_{s}$ and the depth of the tubes $d_{t u b e}$ for Slab $\mathrm{A}$ and $\mathrm{C}$ are found in Table 5.3.

$400 \mathrm{~W} \mathrm{~m}^{-2}$, and pulled back up once it reached $200 \mathrm{~W} \mathrm{~m}^{-2}$. This was to prevent overheating during sunny summer days.

Non-HVAC electrical gains were taken from measured data by Johnson and Beausoleil-Morrison [109] (house H14). That work was a continuation of a similar study by Saldhana and Beausoleil-Morrison [110]. The average annual non-HVAC electrical load of the 23 combined houses evaluated in both studies was 19 GJ. House H14 had a total non-HVAC annual load of 15.5 GJ. This house was chosen because its annual non-HVAC load was near the average of all houses, and because many of the appliances were sub-metered, allowing for a better allocation of internal gains in the various zones.

The kitchen related electrical loads (stove and dishwasher) and $50 \%$ of all other non-HVAC electrical loads were applied to the first floor as internal gains. The clothes dryer electrical loads were applied to the basement as internal gains. Sensible load fractions as defined by Hendron and Engebrecht [107] were used for the stove, dishwasher, and clothes dryer. Additionally, outdoor air ventilation was applied to the space at a rate of $0.056 \mathrm{~kg} \mathrm{~s}^{-1}$ for each of the stove (for range hood operation) and the clothes dryer when in use. The remainders of the non-HVAC electrical loads were applied equally between the other zones, including the basement as internal gains. Internal gains for four occupants were added to the space. An occupant internal gain consisted of $70 \mathrm{~W}$ of sensible gain and $45 \mathrm{~W}$ of latent gain. Half of the sensible gain was convective and the other half radiative. During the weekdays, the main floor received gains from four occupants between 7:00 and 8:00, and 18:00 and 22:00. 
During the weekends and holidays, the main floor received gains from two occupants between 9:00 and 22:00. The bedrooms received occupant gains at night between 22:00 and 7:00 during the week and 22:00 and 9:00 during the weekends and holidays.

\subsubsection{Plant model - solar collection system}

The plant was modelled in TRNSYS. Figure 1.2 shows a schematic of the plant system. Zone 1 and 2 are the first and second floor respectively. The radiant floor supply temperatures were controlled with a floor surface temperature reset controller in cooling mode and an outdoor temperature reset with indoor temperature feedback controller in heating mode. A floor surface temperature reset controller is similar to an outdoor temperature reset controller, except that the monitored variable is the floor surface temperature, and the setpoint variable becomes the required surface temperature (in this case $19{ }^{\circ} \mathrm{C}$ in cooling mode). A simple aquastat, measuring the cold tank temperature, with a setpoint of $12{ }^{\circ} \mathrm{C}$ and a dead band of $2{ }^{\circ} \mathrm{C}$ was used to turn the water-water heat pump on and off. The air temperature set points for cooling were $25.5{ }^{\circ} \mathrm{C}$ between May 1st and September $30 \mathrm{th}$, and $24{ }^{\circ} \mathrm{C}$ the rest of the year. This was because occupants were expected to wear less clothing during the summer months, therefore be able to tolerate a higher temperature. Additionally, a lower setpoint during the spring, fall, and winter might help with the performance of the system by allowing more heat to be collected while maintaining comfortable conditions. This additional heat is not required during the summer months. The heating set point was $22^{\circ} \mathrm{C}$ for the entire year.

The heat pump was modelled with the transient empirical model described in Chapter 4 for a $11 \mathrm{~kW}$ nominal cooling R134a water-water heat pump. In Chapter 4, the time response of a heat pump was investigated. The time constants for the heat pump were much smaller than the time constant of the radiant floors discussed in Chapter 5. In the active/passive solar collection system, the heat pump cycles on for minutes whereas the radiant floors may cycle for hours. Although the short-term transient response of the heat pump has little impact on the the thermal response of the radiant floors, modelling the transient effects of the heat pump will affect the overall energy consumption.

All pumps were assumed to draw $100 \mathrm{~W}$ of power when turned on. This assumption was derived from lab tests on a Grundfos UPS 26-99FC 3-speed circulation pump which drew this much power on its highest setting. This test was performed 
during testing of the heat pump in Chapter 4. However, real piping circuits will yield different power consumptions.

The cylindrical water storage tanks were modelled using Type 534 [84]. Type 534 uses a one-dimensional multinode approach to model the stratification of the water in tank. The cold tank had a volume of $0.454 \mathrm{~m}^{3}$ (height $1.575 \mathrm{~m}$ ) and three hot water tank volumes were investigated: $3 \mathrm{~m}^{3}, 2 \mathrm{~m}^{3}$, and $1 \mathrm{~m}^{3}$ (height $2.3 \mathrm{~m}$ ). The cold tank volume was kept at $0.454 \mathrm{~m}^{3}$ for all simulations to prevent short cycling of the heat pump. Ten nodes were used for both tanks. Wills had found that using more than ten nodes made little difference to the results of a solar thermal simulation [119], so this number of nodes was used. In Type 534, a parameter is used to describe an additional conductivity parameter between nodes. This parameter accounts for the conduction between nodes due to tank wall conductivity. This was set to zero as the storage tanks were assumed to be made of polyethylene or similar material (as for an open tank system) and the additional thermal conduction through the tank walls was calculated to be small compared to the thermal conduction in the water. The hot tank insulation R-value was $5.0 \mathrm{~m}^{2} \mathrm{~K} \mathrm{~W}^{-1}$ while the cold tank R-value was 2.9 $\mathrm{m}^{2} \mathrm{~K} \mathrm{~W}^{-1}$.

Water was drawn from the tanks to supply both sides of the heat pump. Similarly, water was drawn directly from the tanks to heat and cool the house. In heating mode, if the supply temperature required by the controller was not met by the hot tank, an auxiliary electrical heater was used to bring the water to temperature. The heat pump had a maximum condenser water temperature average temperature of $60{ }^{\circ} \mathrm{C}$ above which it would shut off. A dry cooler was used to cool down the hot water tank if required. The maximum temperature at the bottom of the hot tank was set to $55^{\circ} \mathrm{C}$ during the heating season, whereas it was set to $45^{\circ} \mathrm{C}$ in the cooling season. These set points determined when the dry cooler was activated. The higher set point in the heating season was to allow for more heat storage, while the lower set point in the cooling season was to increase the coefficient of performance (COP) of the heat pump.

During periods of domestic hot water demand, a heat exchanger in the hot tank heated the incoming mains water to $45^{\circ} \mathrm{C}$. If this temperature was not achieved due to low tank temperature, an auxiliary electrical heater was used to bring the water to temperature. Type 1243a [84] was used to provide a domestic hot water draw schedule based on ASHRAE 90.2. A total of $190 \mathrm{~L} \mathrm{day}^{-1}$ was used in the model. 


\subsubsection{Plant model - typical house}

The plant was modelled in TRNSYS. A gas furnace with a heating capacity of $6 \mathrm{~kW}$ and $92 \%$ constant efficiency was modelled. An air conditioning unit was modelled with TRNSYS Type 921 [84], using manufacturer's data for a ducted air conditioning unit. The domestic hot water tank was modelled with TRNSYS Type 534. The tank volume was $0.200 \mathrm{~m}^{3}$, and the $\mathrm{R}$-value was $3 \mathrm{~m}^{2} \mathrm{~K} \mathrm{~W}^{-1}$. A gas heater with a constant efficiency of $90 \%$ provided heat to the tank, which had a setpoint temperature of $55^{\circ} \mathrm{C}$. The fan was assumed to consume $300 \mathrm{~W}$, and only ran when the air conditioning unit or gas furnace were called for cooling or heating. Fresh air ventilation was handled separately by the energy recovery ventilator as discussed earlier.

\subsubsection{Thermal comfort}

The modelling of thermal comfort of the occupants was accomplished with the Predicted Mean Vote (PMV) model developed by Fanger [111], and implemented with code by van Schijndel [112] as a post-processor using ESP-r predictions of MRT, dry bulb temperature, and relative humidity. ASHRAE standard 55 [113] recommends maintaining the PMV within a range of -0.5 to 0.5 . In this range, less than approximately $10 \%$ of occupants are typically dissatisfied with thermal conditions. The comfort was assessed on the main floor during occupied periods. The model inputs are the dry bulb temperature, the mean radiant temperature (MRT), the relative humidity, the metabolic rate, the external work, air velocity, and clothing insulation. A MRT sensor was modelled in the center of the living space, $1.4 \mathrm{~m}$ above the floor. The metabolic rate was set to 1.1 MET, the external work was set to 0 MET, air velocity was set to $0.1 \mathrm{~m} \mathrm{~s}^{-1}$. Clothing insulation was set to 1.0 clo (equivalent to an outfit of trousers, long-sleeved shirt, single-breasted suit jacket or sweater, and t-shirt) from January to the end of May and September to the end of December, but if PMV was higher than 0.5, this level was allowed to drop to 0.75 clo (take off the long-sleeve shirt for example). Since the occupants are in their house, it is assumed that they are able to dress according to the temperature in the house. A drop of 0.25 clo is roughly equivalent to removing a sweater. In June, July, and August, the occupants are assumed to have a clo level of 0.57 (equivalent to an outfit of trousers and short-sleeved shirt), but are allowed to remove 0.25 clo (changing into a t-shirt and shorts) if the PMV is higher than 0.5 , or add 0.25 clo if the PMV is lower than 
-0.5. ASHRAE reports floor surface temperatures to be comfortable between $19^{\circ} \mathrm{C}$ and $29^{\circ} \mathrm{C}$ for people wearing normal indoor footwear [16]. For people with bare feet, ASHRAE reports varying comfortable surface temperature ranges based on the floor materials [16]. For this work, it was attempted to maintain the floor surface temperature between $19^{\circ} \mathrm{C}$ and $29^{\circ} \mathrm{C}$. However, further work is required to study the impact of floor surface material on the energy performance and thermal comfort of barefoot occupants.

\subsection{Results}

\subsubsection{Daily results}

To illustrate the daily workings of the system during sunny days at various times of the year, examples of the results were plotted for the active/passive solar collection system with $20.7 \mathrm{~m}^{2}$ south-facing glazing glazing for February 2nd, July 21st, and November 15th in Ottawa with the AFTP radiant floor. These plots are shown in Figures 6.5 through 6.7. Only the results for the main floor are shown for clarity.

For February 2nd, Figure 6.5 shows that for the first 8 hours of the day, heat to the main floor is provided with the auxiliary heat system. The auxiliary heat shown in that figure is larger than the heat delivered to the main floor because auxiliary heat is also utilized for second floor heating, domestic hot water draws, and losses in the tank. The solar radiation starts heating the house during the day, forcing the cooling system to start at approximately 10:30. The cooling water flowing to the main floor warms the cold water tank, therefore the water-water heat pump is also promptly activated. This produces a rise in the hot water tank temperature. The cooling of the main floor and coincident hot water tank temperature rise occur between approximately 10:30 and 15:30. During this time, the hot water tank temperature rises from $28{ }^{\circ} \mathrm{C}$ to $48{ }^{\circ} \mathrm{C}$. Just before 17:00, heat is called to the main floor and since the hot water tank is charged, no auxiliary heat is required until 1:30 the next day. 


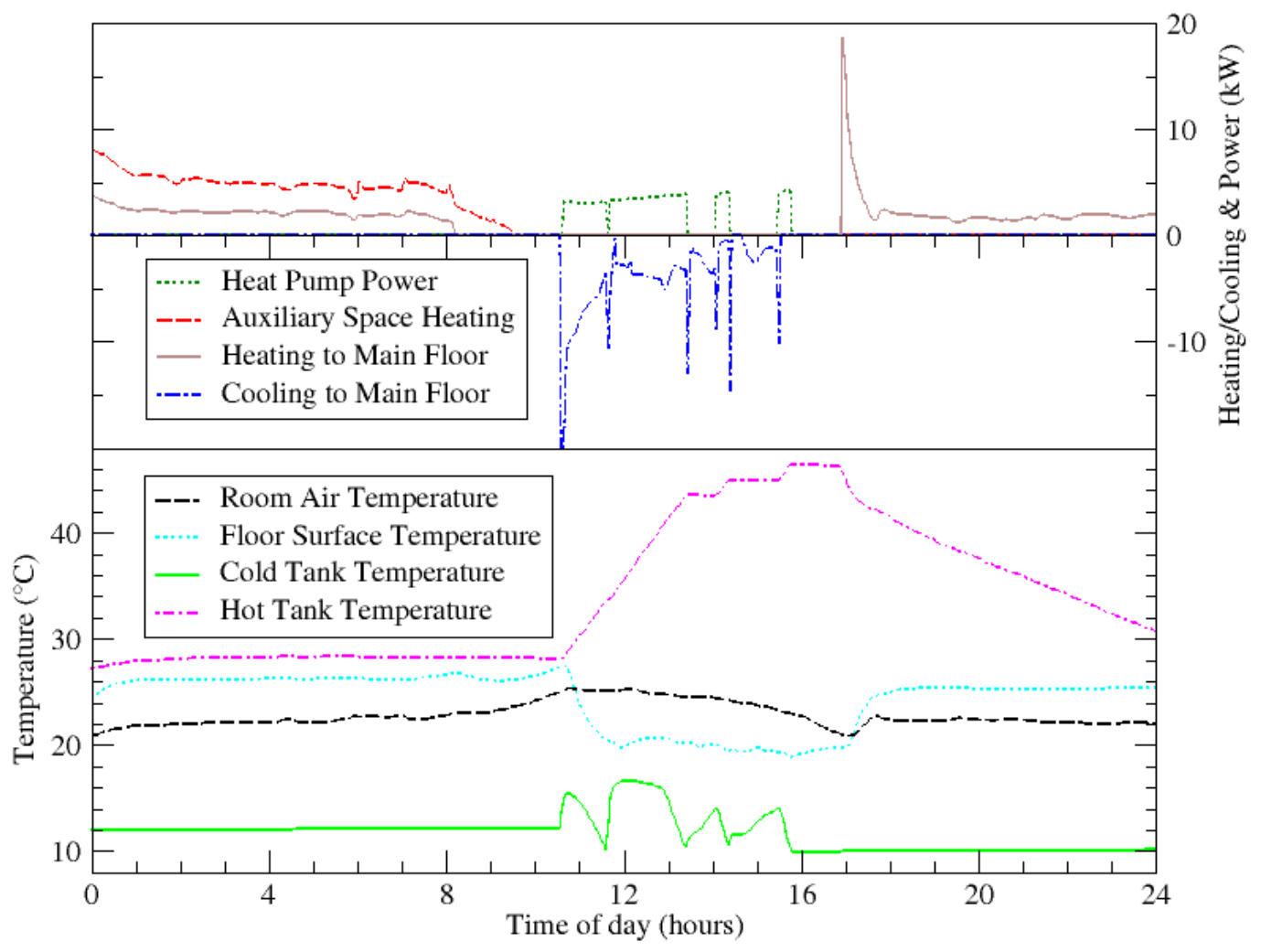

Figure 6.5: Results for February 2nd - Ottawa

On July 21st, heating is not required and the hot water tank remains above $44^{\circ} \mathrm{C}$ for the entire day. The required temperature for domestic hot water was $45{ }^{\circ} \mathrm{C}$ therefore very little domestic hot water auxiliary heat (not shown here for clarity), if any, is required for that day. The indoor air temperature reaches a temperature of $27{ }^{\circ} \mathrm{C}$ at around noon, but the floor temperature is maintained at around $19{ }^{\circ} \mathrm{C}$. Given the geometry of the space and the humidity in the house (ranging between 43 and $65 \% \mathrm{RH}$ for that day), the comfort model shows that occupants would be comfortable most of the day. It is however too warm in the early part of the day (before the floor has been cooled). Other days around that period have problems with overheating, therefore better controls should be investigated. One simple way to improve this might be to lower the cooling temperature setpoint. Additionally, a small air coil could be added to take care of periods of high cooling demand. This coil could also take care of any latent cooling. The cooling to the coil could be 
provided by the same cold water supplied to the floors. Another interesting point is the large variability in cooling response. The controler was meant to maintain a floor temperature at a constant $19{ }^{\circ} \mathrm{C}$. Even though the floor is maintained at the correct temperature, it is likely that the gain on the floor temperature reset controller is too high so the controller becomes unstable.

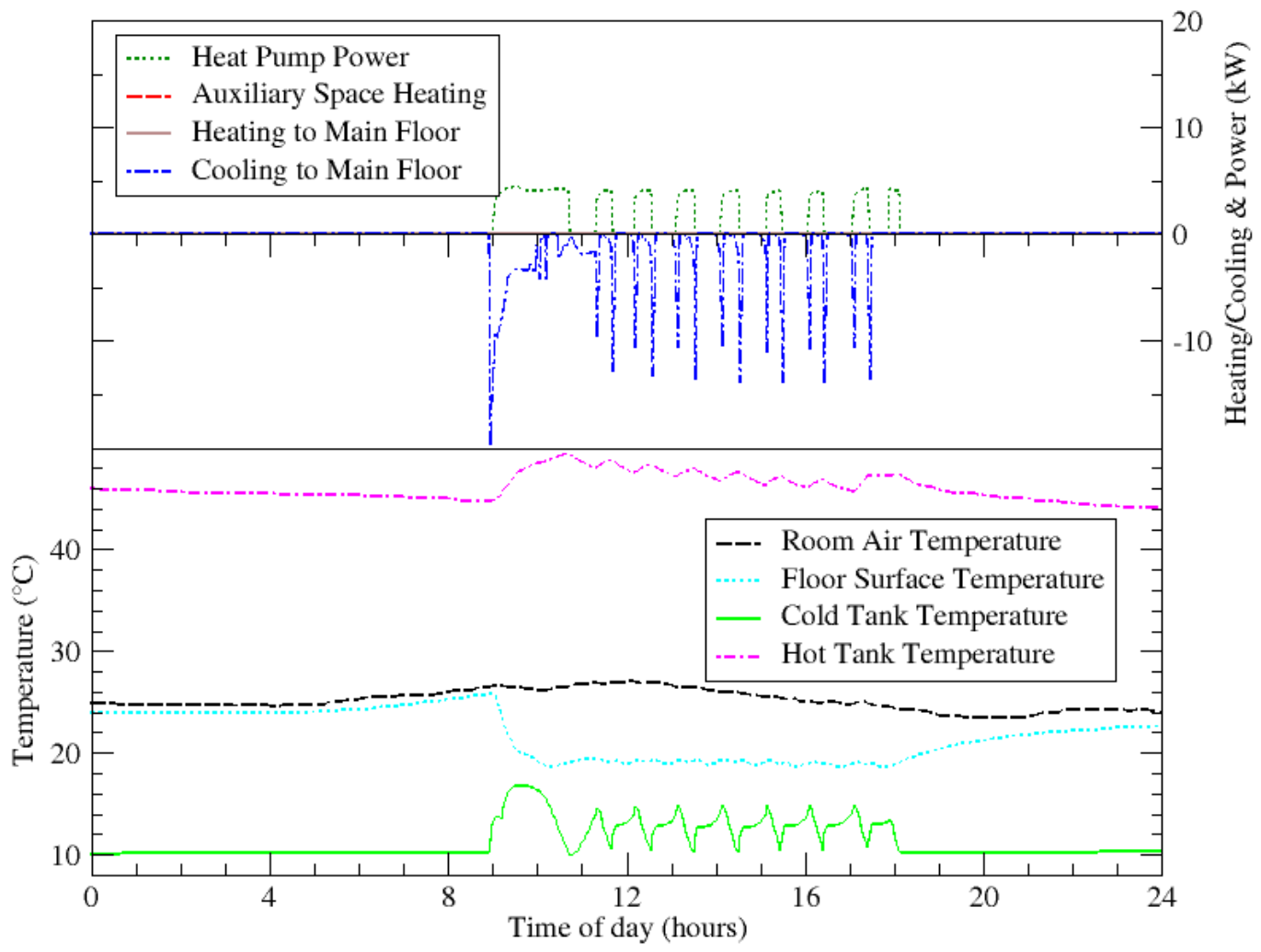

Figure 6.6: Results for July 21st - Ottawa

On November 15th, heating was required at the beginning of the day, and some heat was drawn from the hot water tank while the auxiliary heater provided the rest. The spike in auxiliary heating at 8:00 is due to the second floor heating turning on (not shown here) and the tank being depleted. Shortly after 9:00, the space requires cooling and the heat pump turns on. This increases the hot storage tank temperature from 24 to $38^{\circ} \mathrm{C}$. At 15:30, heating is required in the space again, and heat is taken from the hot storage tank so no auxiliary heat is required. 


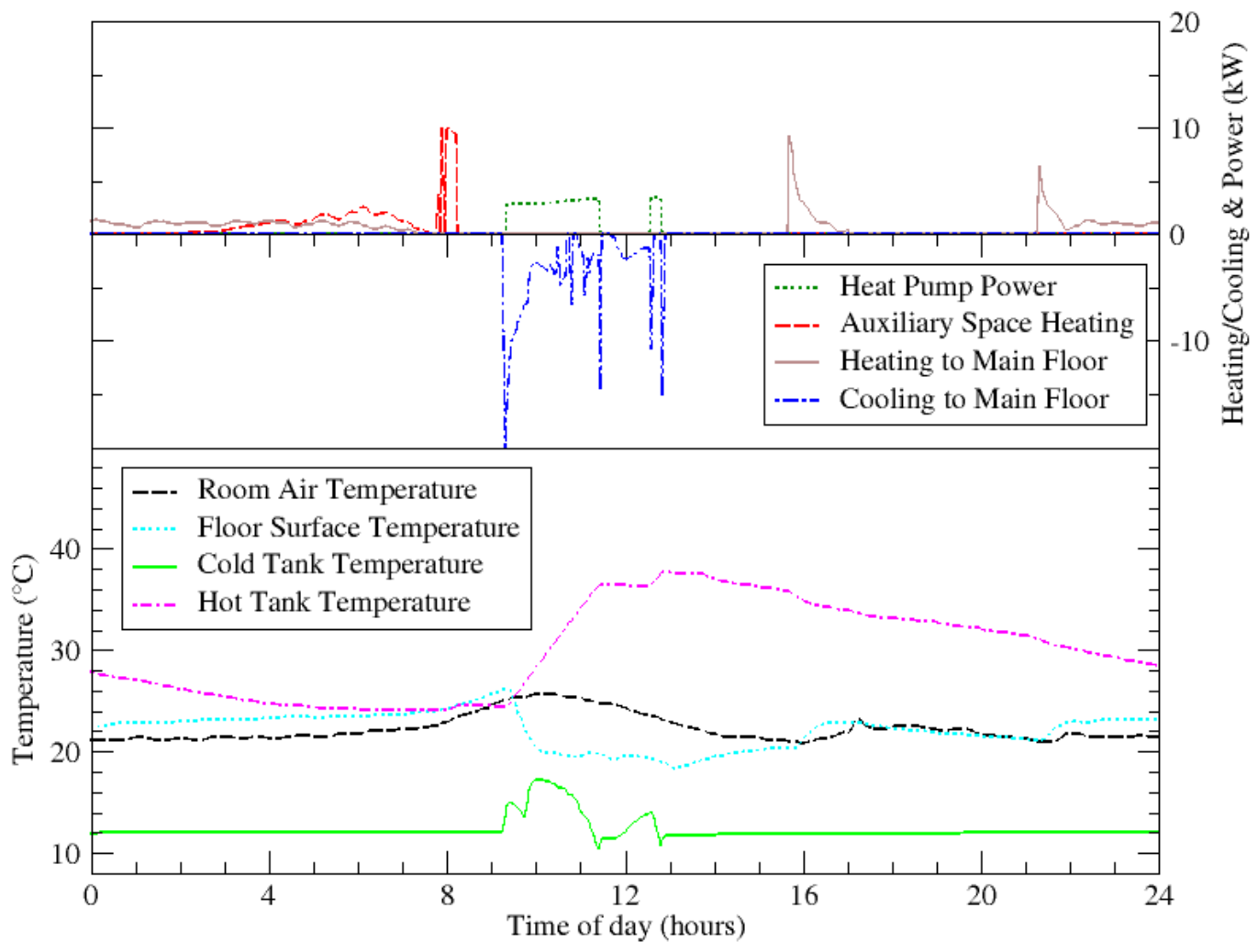

Figure 6.7: Results for November 15th - Ottawa

One interesting result is the potential for using better floor heating and cooling controls. An argument can be made that the floor was cooled for too long on February 2nd and November 15th. If the cooling had stopped at an earlier 'optimal' point, the heat pump consumption would have decreased and the need for heating would have been delayed, thus increasing the overall performance of the system. Additionally, the simple heat pump controls could be improved. Currently, a simple aquastat with a deadband is used to control the heat pump. A better option may be an algorithm that allows the cold storage to float depending on the house and hot tank temperatures. The cold storage tank could always be at the highest temperature required by the floors at any given time, unless the hot storage tanks are depleted. If this happened, the heat pump could turn on until the cold storage tank reaches its the low temperature limit (around $10{ }^{\circ} \mathrm{C}$ ) to give the hot storage tank an extra charge. 


\subsubsection{Annual results}

The $6.9 \mathrm{~m}^{2}$ south-facing glazing case was simulated along with a typical HVAC system, as described in Section 6.2.3, to represent a more typical house. The $20.7 \mathrm{~m}^{2}$ south-facing glazing case was modelled with the solar collection system described in Section 6.1. The purpose of the large amount of glazing in this case was to allow as much solar gains as possible in the space for use by the solar collection system. If this much glazing were to be used with a conventional HVAC system, overheating would occur on sunny days, even during the coldest days of the year. For this reason, only the $6.9 \mathrm{~m}^{2}$ glazing case was paired with the typical HVAC case. For comparison, a case with $6.9 \mathrm{~m}^{2}$ south-facing glazing area and the solar collection system was also simulated.

Figures 6.8 and 6.9 show annual results for Ottawa and Calgary. The solar collection systems shown here are with the AFTP radiant floor systems. End-uses are reported for each category. For example, Air Conditioning represents the electricity use for the conventional air conditioner, expressed in GJ, and Furnace represents the natural gas consumption, expressed in GJ, using the Higher Heating Value. Note that the very close similarity between the annual even though their climates might look quite different at first glance. Figure 6.10 shows the average monthly temperature and average daily direct normal solar radiation from the CWEC weather files for Ottawa and Calgary. The temperature is lower in Ottawa in January, and February, while it is colder in Calgary the rest of the year. However, the amount of direct normal solar radiation is higher in all months in Calgary except February and March. These differences in climates, especially during the winter and shoulder seasons, seem balance each other out to produce similar total energy demand over the year.

The monthly energy demands for Ottawa and Calgary are shown in Figures 6.11 and 6.12 for a hot storage tank volume of $2 \mathrm{~m}^{3}$ and a south-facing window area of $20.7 \mathrm{~m}^{2}$. For Ottawa (Figure 6.11), the highest auxiliary heating demand occurs in January. This is due to the cold weather and low amount of solar radiation. By the month of May, there is almost no need for auxiliary heating, until the month of November. In the months between June and August, a relatively large amount of heat is being rejected to the environment because there is no use for all of the heat collected. A small amount of heat is also rejected during the cold months, but this is because of short term effects. For example, on warm days with high amounts of sun, some heat might need to be rejected because the hot storage tank temperature 


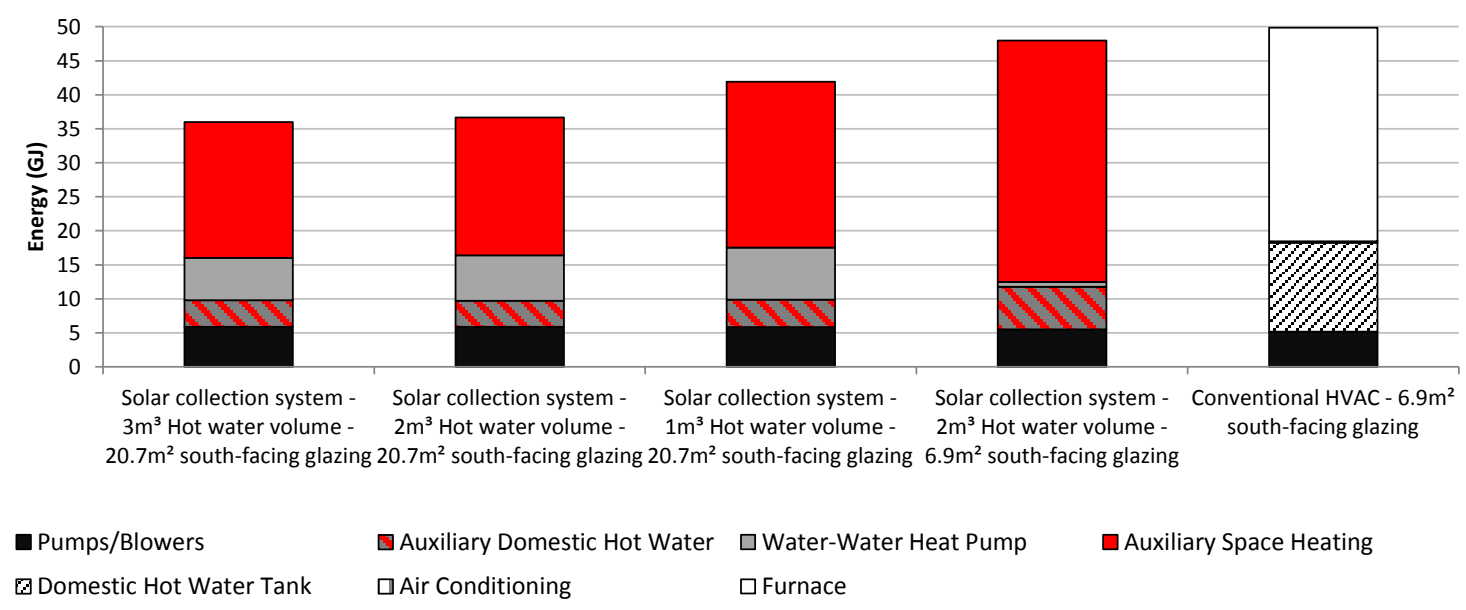

Figure 6.8: Annual simulation results for Ottawa - AFTP

reaches the heat pump high temperature limit. This happens infrequently, but signals the need for better sizing and control of the system. Interestingly, in May no heat is rejected, and the heat pump is barely used. This might have to due with the relatively mild temperatures and high solar angles (average at solar noon of $64^{\circ}$ ). This combination makes the house relatively comfortable with little intervention from the HVAC system.

For Calgary (Figure 6.12), the highest auxiliary demand was in December. In Calgary, December is the second coldest month, and the month with the least available solar radiation. The heat rejected in Calgary is slightly more evenly spread throughout the year in Calgary than in Ottawa. This might have to do with the year-round slightly milder temperatures. There is not as much need for space heating in the winter, therefore the hot water tank reaches the high temperature limit more often. In the summer, there is not as much need for cooling as the ambient temperatures are lower so the heat pump is not used as much. Even though there is significantly more solar radiation in the summer in Calgary, the average solar altitude of the sun during those months makes its impact less important than during the winter months.

Figures 6.8 and 6.9 show that the solar collection system required less energy with a larger hot water storage tank, but the improvements decreased significantly with a 


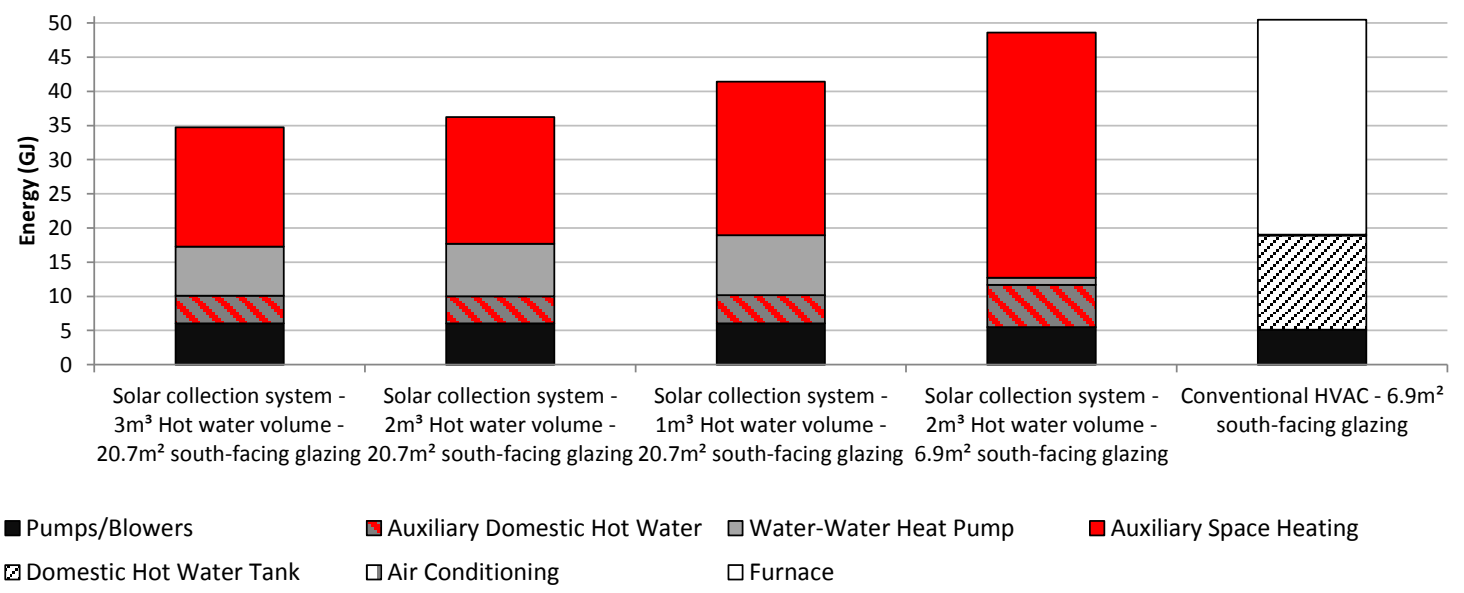

Figure 6.9: Annual simulation results for Calgary - AFTP

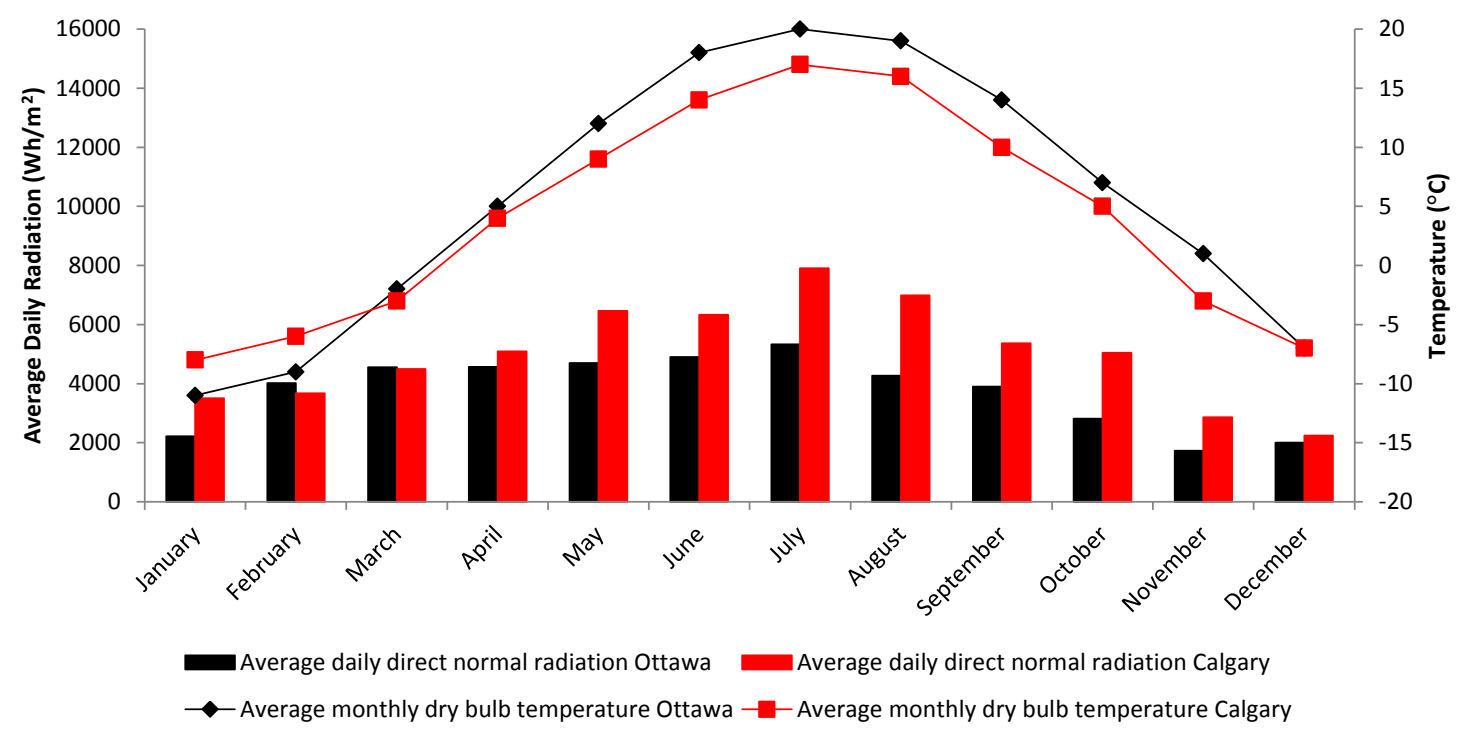

Figure 6.10: CWEC monthly average climate data 


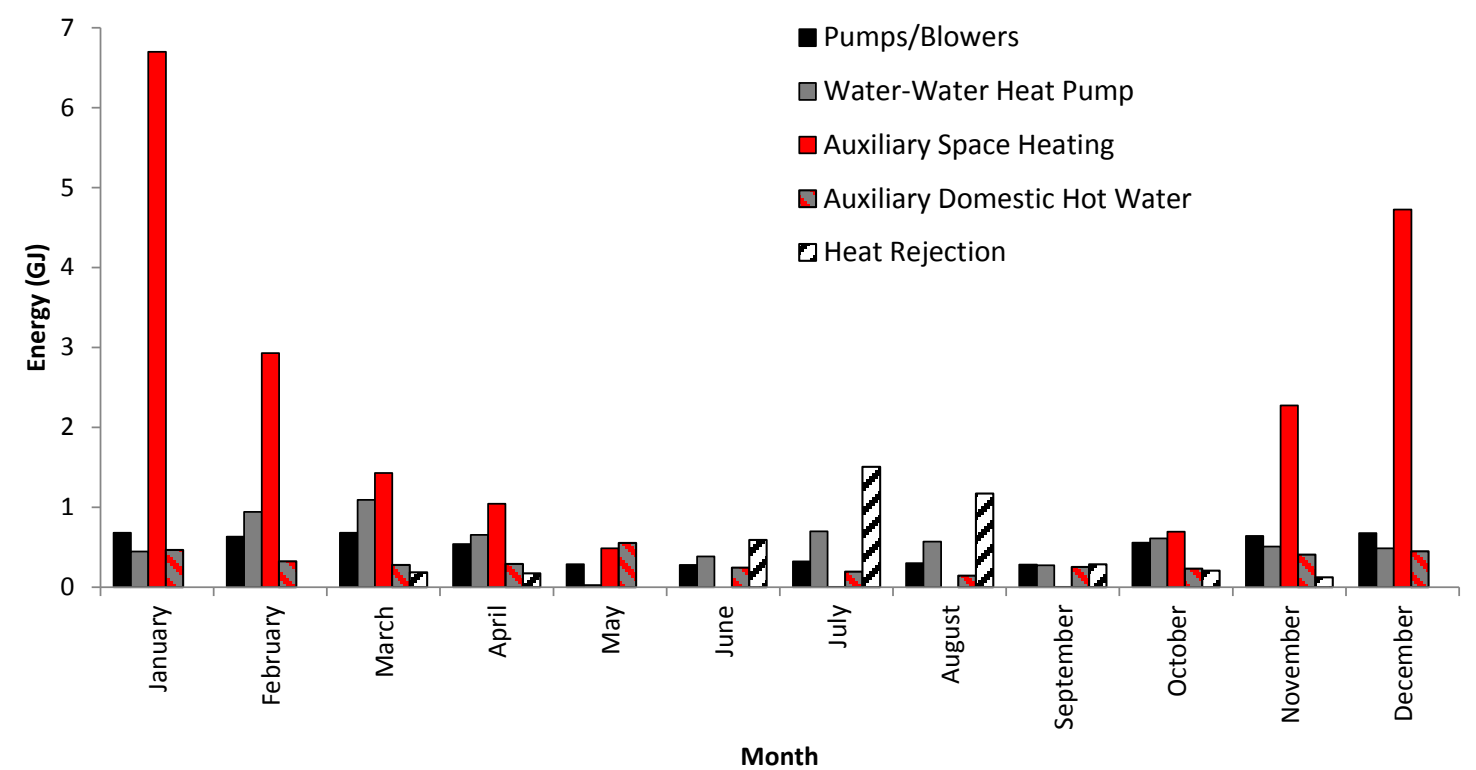

Figure 6.11: Monthly simulation results for Ottawa - AFTP, $2 \mathrm{~m}^{3}$ hot storage tank, high south-facing glazing

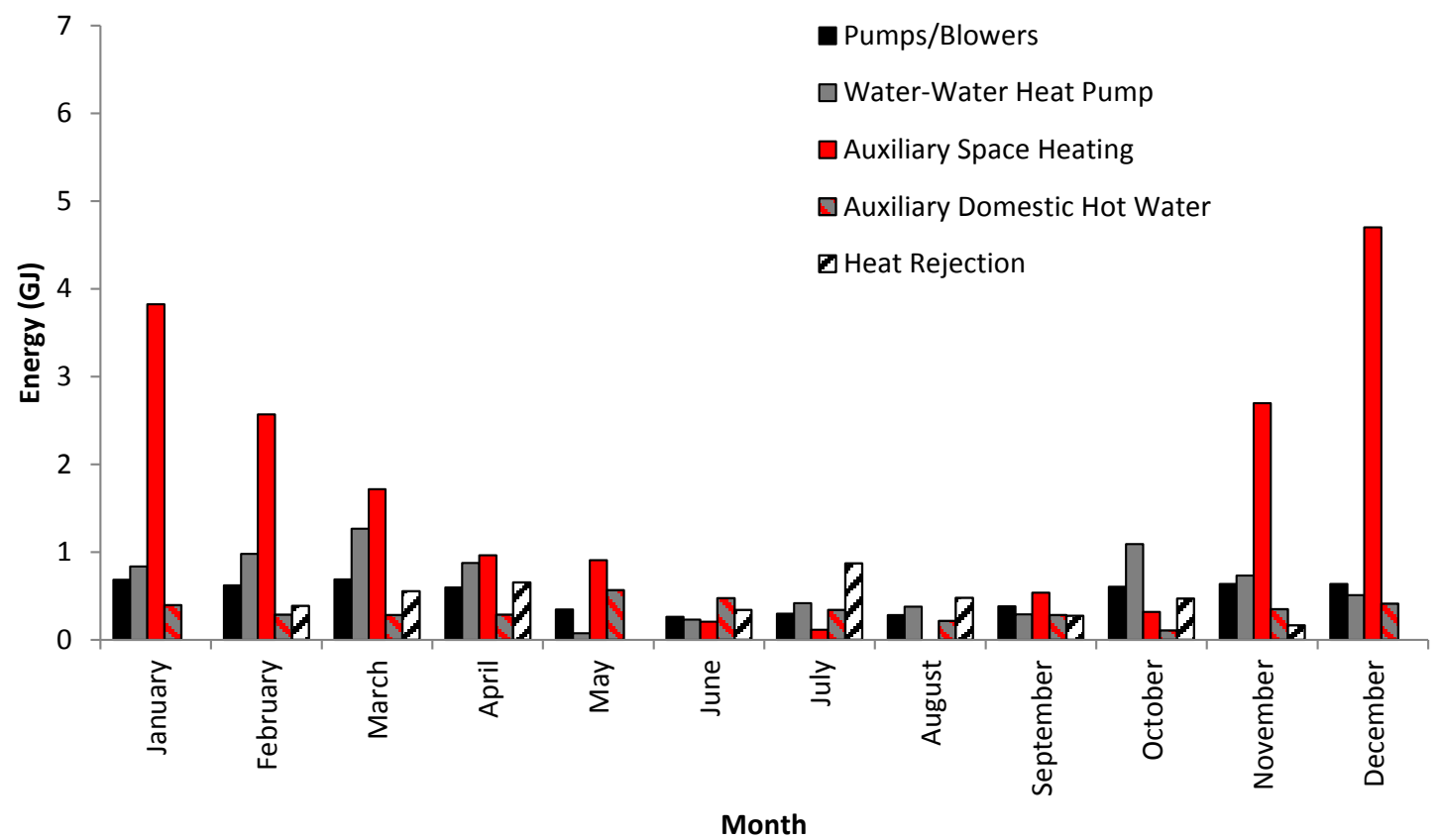

Figure 6.12: Monthly simulation results for Calgary - AFTP, $2 \mathrm{~m}^{3}$ hot storage tank, high south-facing glazing 
tank greater than $2 \mathrm{~m}^{3}$. Also, the high glazing cases used less energy than the typical glazing case. Compared with the conventional house HVAC and glazing coverage (6.9 $\mathrm{m}^{2}$ south-facing glazing), the solar collection system with $2 \mathrm{~m}^{3}$ hot water storage tank and higher glazing coverage $\left(20.7 \mathrm{~m}^{2}\right.$ south-facing glazing) required $25 \%$ less energy annually in Ottawa, and 27\% less energy annually in Calgary. Addidionally, there are no benefits to the passive/active solar collection system if a typical south-facing glazing area is used (in this case $6.9 \mathrm{~m}^{2}$ ). For the conventional HVAC system, the furnace energy demand is much lower than the auxiliary space heating demand for the solar collection system with the typical glazing area. The opposite is true of the domestic hot water energy demands. This is because, for the active/passive solar collection system, a portion of the auxiliary heat energy is contributes heating of domestic hot water. The single hot tank design means that when the auxiliary space heater is active, the return water carrying residual energy is stored in the hot water tank for domestic hot water heating or space heating.

It is important to note that the solar collection system as modelled here was an entirely electrical system, while the typical HVAC system uses primarily natural gas. The active/passive solar collection system could be made to use natural gas for auxiliary DHW heating and space heating. If this was done and a $92 \%$ efficiency was applied to the auxiliary heaters, the solar collection system would use approximately $21 \%$ less energy than the typical HVAC and glazing coverage in Ottawa, and $23 \%$ in Calgary.

Two additional cases were run in Whitehorse. These cases were for the passive/active solar collection system with $2 \mathrm{~m}^{3}$ hot water storage tank and the conventional HVAC and glazing coverage. The annual energy demands are shown in Figure 6.13. As expected in the Whitehorse climate, the house uses more heating energy. Additionally, the relative energy savings using the passive/active solar collection system are $14 \%$ in Whitehorse which is much lower than in Ottawa and Calgary $(25 \%$ and $27 \%$ respectively). This is likely due to the lower amount of sunlight during the winter months.

\section{Embedded tube radiant floor results}

Simulations were also performed for the passive/active solar collection system with embedded tube radiant floors Slab A and Slab C, as described in Table 6.1. These 


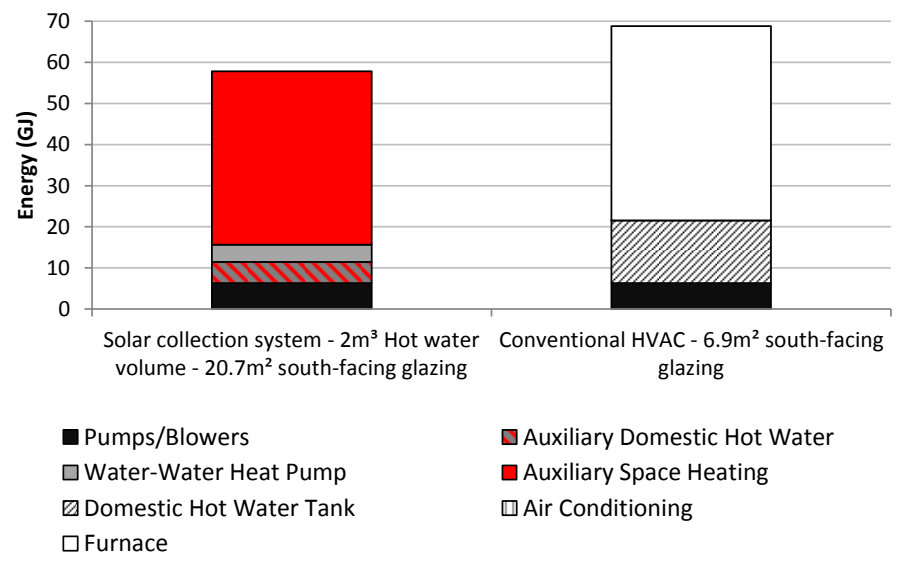

Figure 6.13: Annual simulation results for Whitehorse

simulations were run for the Ottawa climate and the results are shown in Figure 6.14 with the results for the AFTP floor for comparison. The same controls were used for the embedded tube radiant floors as for the previous simulations with the AFTP radiant floors. The results seem to show that heavier floors tend to require more energy. This might be due to the fact that, although the heavier floors can help mitigate overheating, once overheating has happened, more cooling is then required to bring back the space to an acceptable temperature. Furthermore, overcooling of the floor seen in the late afternoon in the AFTP system is made worse by the heavier embedded tube systems. Therefore, if an active cooling system is used to mitigate overheating during the heating season, lighter floors might be more appropriate. It is however possible that optimizing the controls of the radiant floors for the embedded tubes would change the results of the simulation making embedded tube systems more appropriate.

\subsubsection{Thermal comfort results}

The comfort of the occupants in the first floor living area was assessed during occupied hours for the Ottawa climate. All cases for the Ottawa climate discussed in this chapter were assessed. It was found that, for the adaptive comfort scheme discussed in Section 6.2.4, the PMV remained within the ASHRAE recommended range 96.6\% of the time for the worst case. 


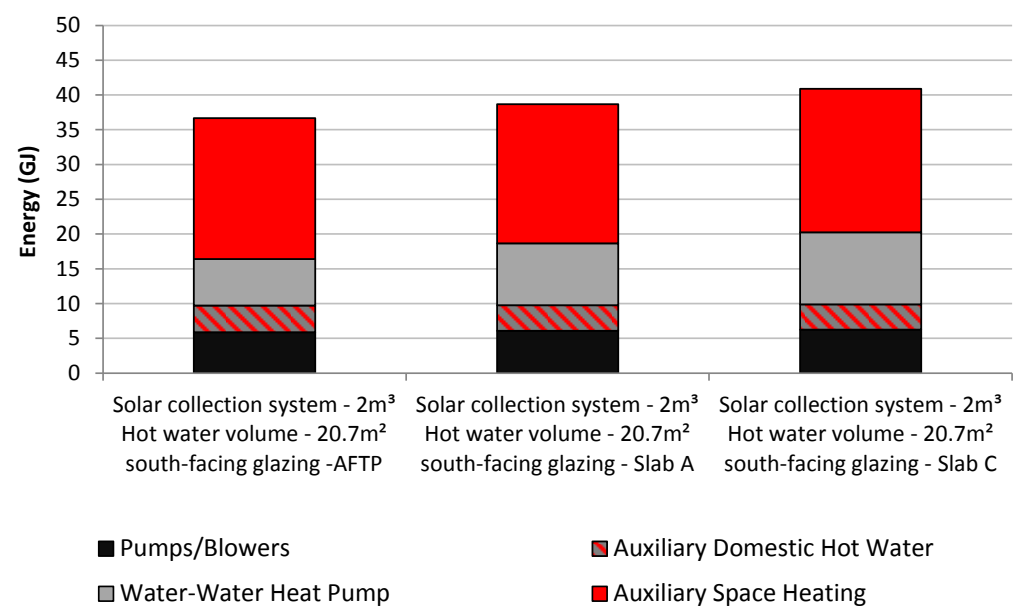

Figure 6.14: Annual simulation results for various floor constructions in Ottawa

\subsubsection{Latent heat removal}

In the Ottawa simulations, the dew point temperature occasionally rose above the floor surface temperature, especially in July and August. This was not an issue in Calgary as the climate is drier. In order to assess the possibility and effect of dehumidifying the space, a cooling coil was added to the rest of the active/passive solar collection system. This coil used chilled water from cold storage tank, and air drawn from the first and second floors to the coil. The fan is assumed to consume $300 \mathrm{~W}$ of electrical power. The cooling coil was set to activate when the relative humidity on the first floor went above $60 \%$. It shut off once the relative humidity dropped to $50 \%$. Simulation results with the $2 \mathrm{~m}^{3}$ hot storage tank and high south-facing window area showed that the coil can maintain acceptable dew point temperatures in the house. However, this required 5\% more energy over the year, but occupant comfort increased during the summer. More work is required to assess the latent heat removal requirements in the Ottawa climate. In particular, better controls, based on dew point temperature may be more appropriate.

\subsection{Concluding remarks}

In this chapter, a new concept of a solar gains collection system with radiant floors was described and assessed with the use of a detailed building energy simulation model. It was found that it is possible to reduce energy consumption in houses 
using this system, but many factors have the potential to influence its performance. Four parameters were explored here: the hot water storage tank volume, the south facing glazing to floor area ratio, the climate, and the floor construction. All of these parameters were shown to have a significant effect on the annual energy consumption of the system.

These preliminary simulation results showed that the solar collection system may reduce the HVAC and domestic hot water energy demand by as much as $27 \%$ when compared to a conventional HVAC system in a house with more typical window area.

This work was a proof of concept and further work will be required to refine the system, such as: investigating the effect of night time setback, investigating the removal of internal roller blinds, optimizing radiant floor supply temperature control, improving heat pump controls, investigating the sensitivity to the treatment of adding more 'furniture' in the space, and investigating the effect on the model results of splitting the radiant floors into multiple smaller discrete sections to better capture the variations in floor temperature in the space.

Additionally, empirical validation of these simulations of the complete system is required. To this end, a system similar to the one discussed in this chapter has been built in the CHEeR. This system will be discussed in the next chapter. 


\section{Chapter 7}

\section{Design and construction of active/passive radiant floor solar collection system in the Urbandale Center for Home Energy Research}

\subsection{Introduction}

The components necessary to operate the passive/active system have been installed and commissioned at the CHEeR. The author assisted with the design, installation, instrumentation, and commissioning of the system. Design of thermal components (e.g. heat pump sizing, storage tank sizing) was by the author. Design of plumbing system (e.g. pipe and pump sizing) was by Sarah Brown, an undergraduate research assistant. Construction of the system was completed by Sarah Brown, with help by Curtis Meister, a graduate student, both in the SBES research group. There was additional work by Chris Weissflog, Fred Barrett, and a few contractors . The involvement of the author during the construction phase was mostly in an advisory capacity, although hands-on help was provided at times. This system will be used in future work to test the system and to validate the simulations presented in Chapter 6 .

\subsection{Radiant floors}

An above-floor tube and plate system is used throughout the first and second floors. The radiant floor panels provided by Roth consisted of $25.4 \mathrm{~mm}$ of high density polystyrene foam overlayed with a $0.5 \mathrm{~mm}$ aluminium sheet. Grooves in the insulation 


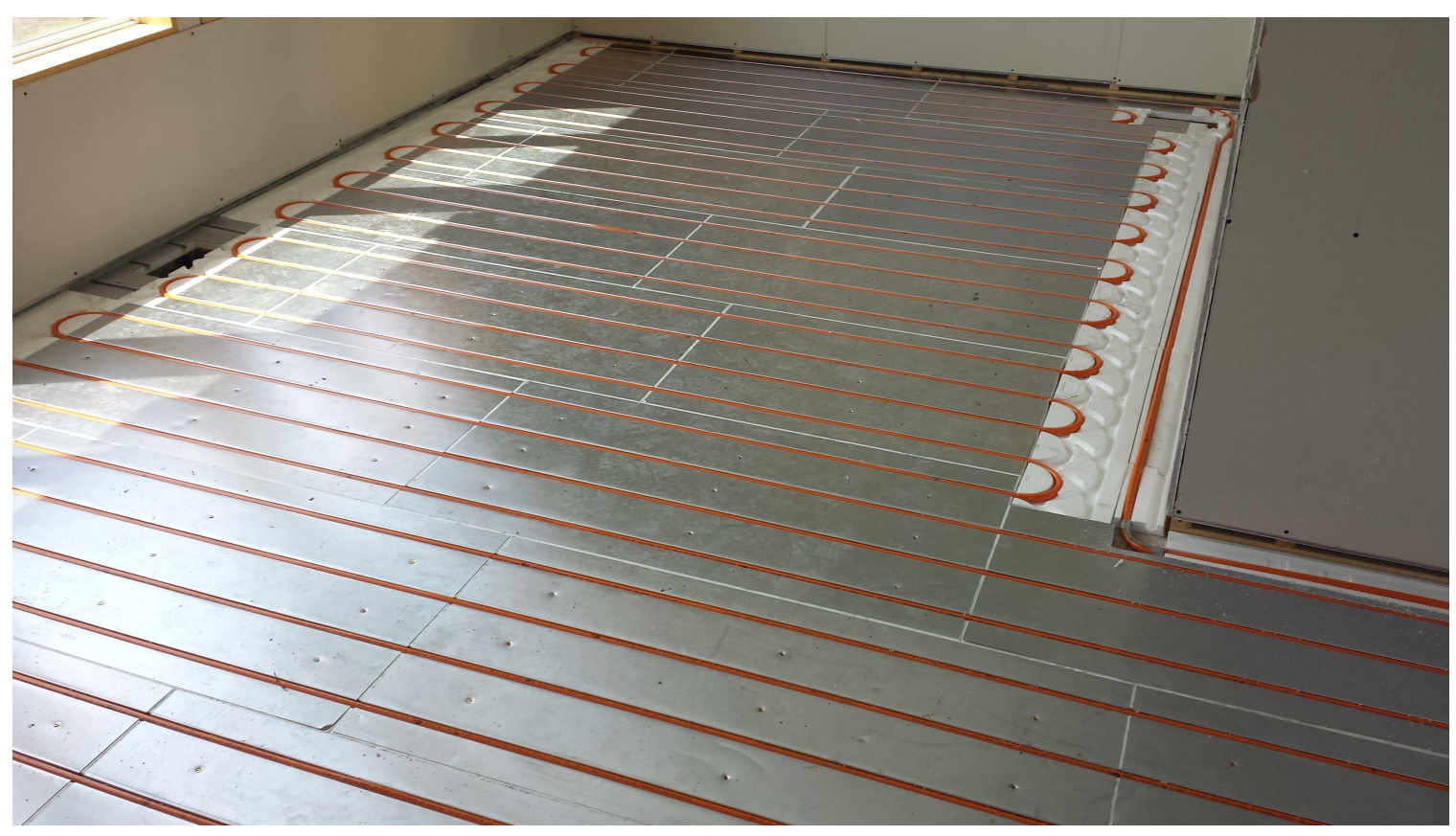

Figure 7.1: Roth radiant floor panels with tubes

and aluminium allow for $12.7 \mathrm{~mm}$ dia. pex tubes to be inserted every $152.4 \mathrm{~mm}$ (oncenter spacing). Figures 7.1 and 7.2 show the Roth radiant floor panels in the house during construction. Figure 7.2 shows the Roth radiant panels partly covered with thinset mortar and cement backing boards. The construction of the floor is shown in Table 7.1 .

Manifolds equiped with zone valves are located on the main and second floor (see Figure 7.3 for an example of a manifold). The zone valves open and close depending on the demand for heating or cooling. A differential pressure by-pass valve (located in the basement) is used between the supply and return pipe to ensure that the circulation pump operates at approximately constant flow rate regardless of how many zone valves are opened or shut in the manifolds. The main floor contains three separate radiant floor zones: the entrance (1 floor loop), the living area (4 floor loops), and the equipment room (one floor loop). The second floor contains four separate radiant floor zones: the hallway (one floor loop), the first bedroom (one floor loop), the second bedroom (one floor loop), and the master bedroom (three floor loops). Each of the zones are controlled by a separate thermostat. 


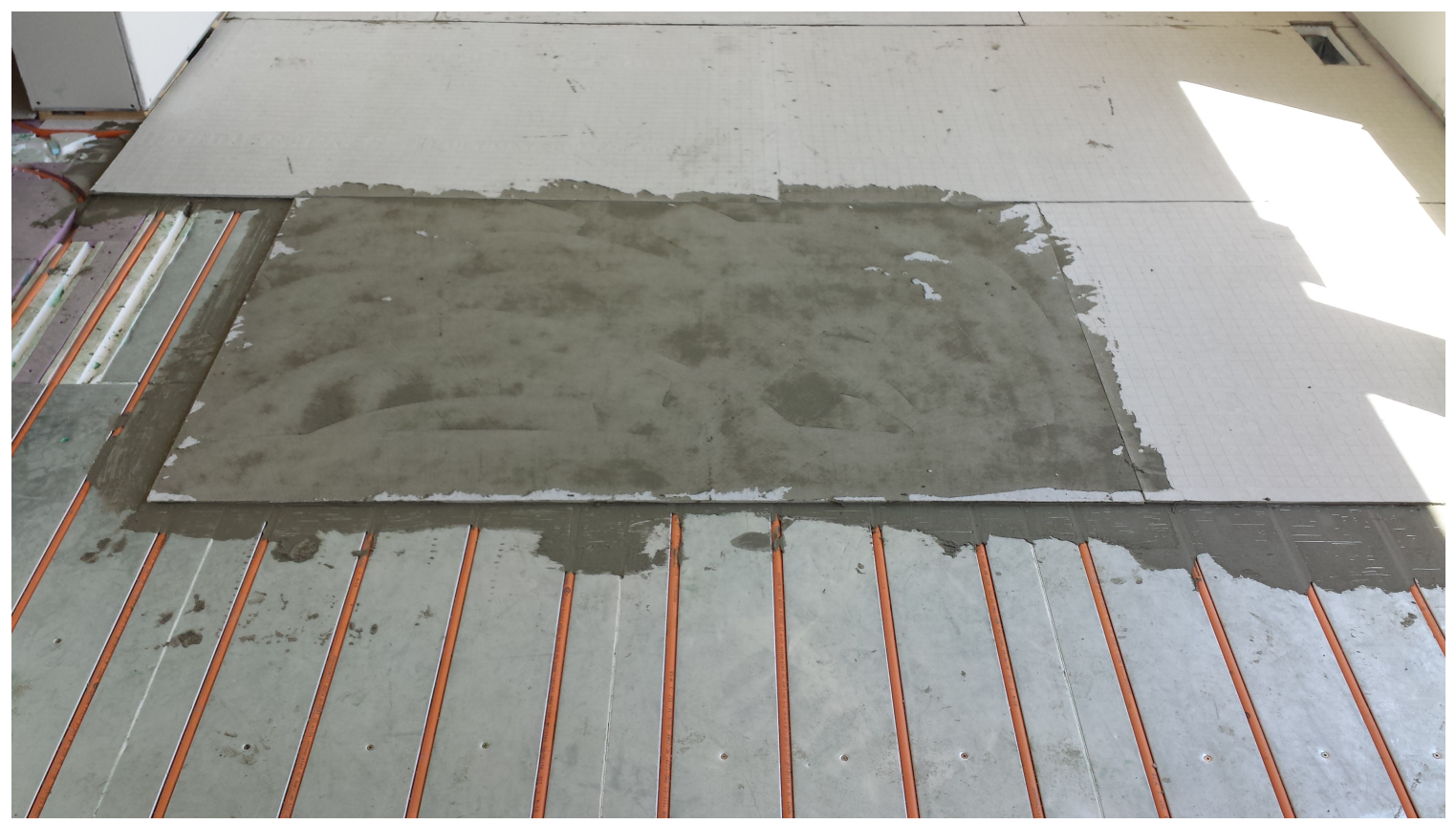

Figure 7.2: Roth radiant floor with backing boards and thinset mortar

Table 7.1: Construction of floor

\begin{tabular}{lc}
\hline Material & Thickness $(\mathrm{m})$ \\
\hline Plywood Subfloor & 0.0159 \\
Roth Panel $^{\mathrm{a}}$ & 0.0254 \\
Mortar & 0.0032 \\
Cement Backing Board & 0.0064 \\
Mortar & 0.0032 \\
Tile & 0.009 \\
\hline
\end{tabular}

${ }^{a}$ Roth panel is made of High Density Insulation overlaid with an aluminium sheet $(0.0005 \mathrm{~m}$ thick$)$. Tubes located in grooves in aluminium sheet. 


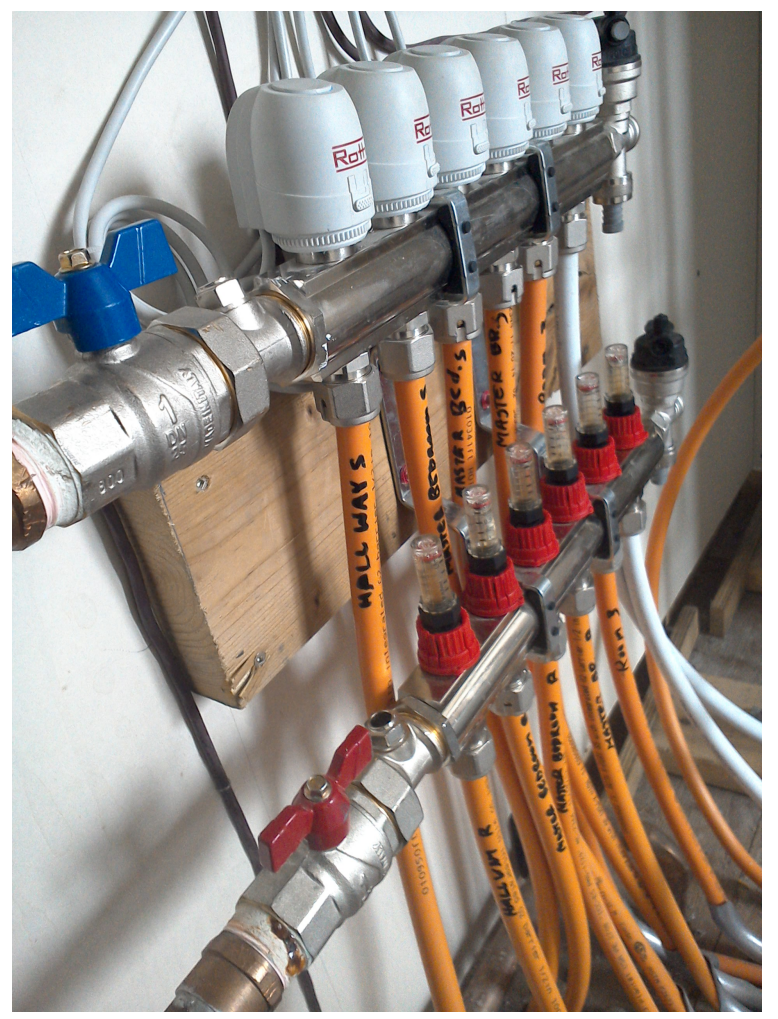

Figure 7.3: Manifold on second floor 
A Brooks BM-04 flow meter measures flow rate to the radiant floors, a type$\mathrm{T}$ thermocouple (from a calibrated spool) measures the supply temperature, and a thermopile (from a calibrated spool) measures the temperature differential across the radiant floors.

\subsection{Heat pump}

The heat pump described and tested in Chapter 4 is located in basement. Grundfos UPS 26-99FC pumps are used to move water between the condenser/evaporator heat exchangers and the hot and cold storage tanks. The flow rates in the condenser and evaporator heat exchangers are measured with Brooks displacement flow meters BM10 and BM14. Additionally, thermopiles and thermocouples (from calibrated spools) are used across the condenser and evaporator heat exchangers to measure the temperatures and temperature gradients across the heat exchangers. The electrical power draw was measured using a WattNode Pulse WNB-3D-240-P with two 30 Amp current transformers (Model CTS-0750-030 LF).

\subsection{Hot water storage}

The hot water storage consists of two THERMO 2000 RE119 tanks each with a volume of $450 \mathrm{~L}$, and one THERMO 2000 Turbomax 109 tank also with a volume of $450 \mathrm{~L}$, totalling a combined volume of $1350 \mathrm{~L}$. These storage tanks are shown in Figure 7.4. The Turbomax 109 tank contains two coil heat exchangers inside the tank (used with a solar collector loop for a separate project, and for domestic hot water loads) while the RE119 tanks do not contain any heat exchangers. Type-T thermocouples (from a calibrated spool) are used to measure the tank temperatures for control purposes. The water in the three tanks can be moved from one tank to the next with the help of a pump, actuated two-way valves and tees. This effectively turns the three distinct tanks into a single large tank. The hot water can be used for heating the floors or used to mimic domestic hot water via the domestic hot water mimicry system. 


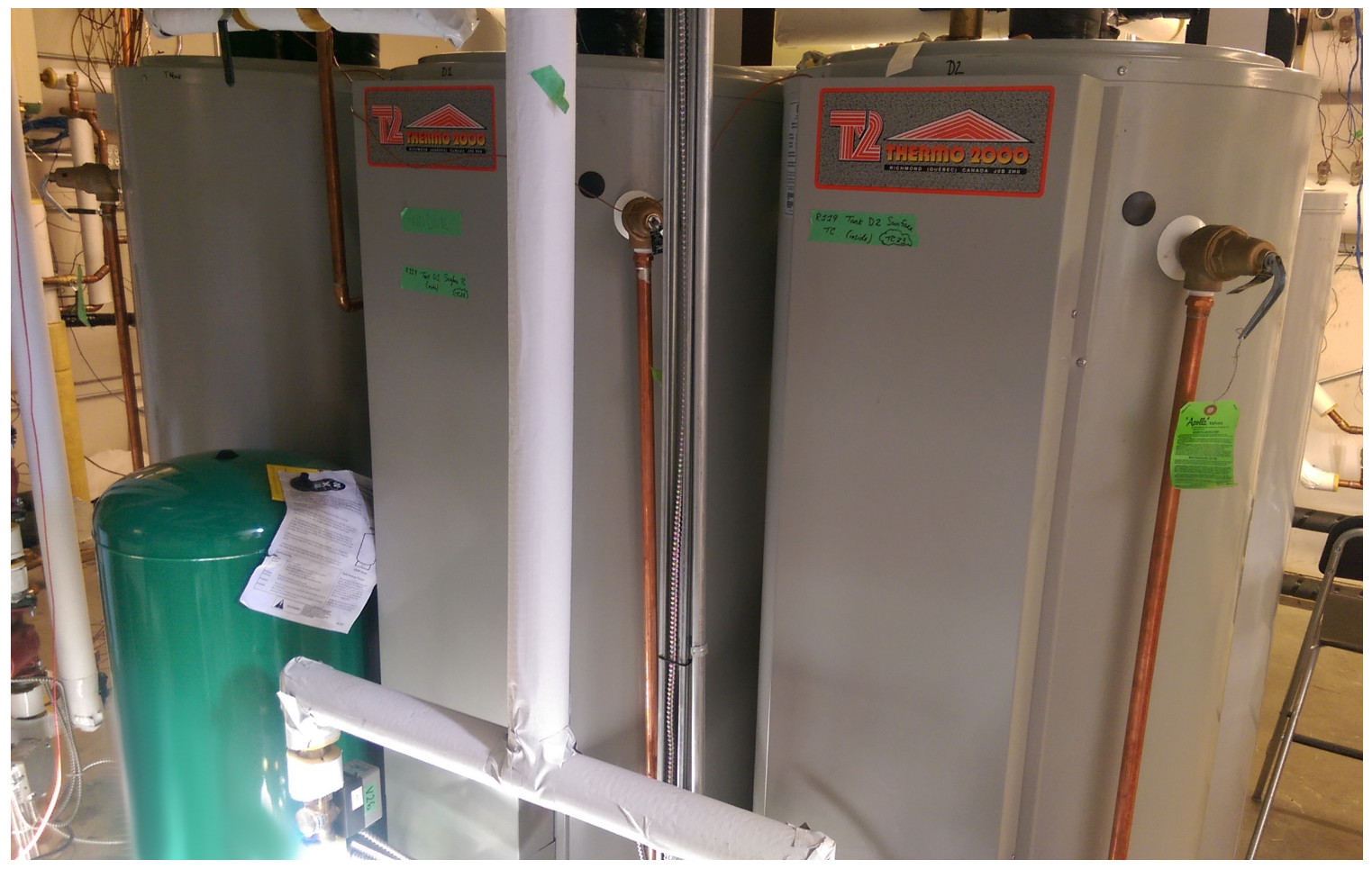

Figure 7.4: Hot storage tanks

\subsubsection{Domestic hot water mimicry system}

The domestic hot water mimicry system is a means to mimic the domestic hot water draws in the house without the need to waste water as the CHEeR house does not have access to mains water. Heat dissipating radiators located on the roof (Figure 7.5) are used at night to reduce the temperature of a storage tank overnight. Scheduled to mimic occupants, a set of five flow control valves is used to provide set amounts of low temperature water from the domestic hot water mimicry system storage to the hot water storage. Instead of water being dumped to a drain, this water is returned to the domestic water mimicry system storage. The aim is to ensure that the right amount of energy is removed from the hot storage tanks, at the right period of the day. The storage tanks and flow control valves of the domestic hot water mimicry system is shown in Figure 7.6. The drawback from this system is that although the right amount of energy is removed from the hot storage tanks, the water being supplied to the tank may not be at the correct temperature during the summer because the heat dissipating radiators can only provide water as cold as the night time ambient air temperature. This could affect how the tanks stratify, therefore the overal accuracy 


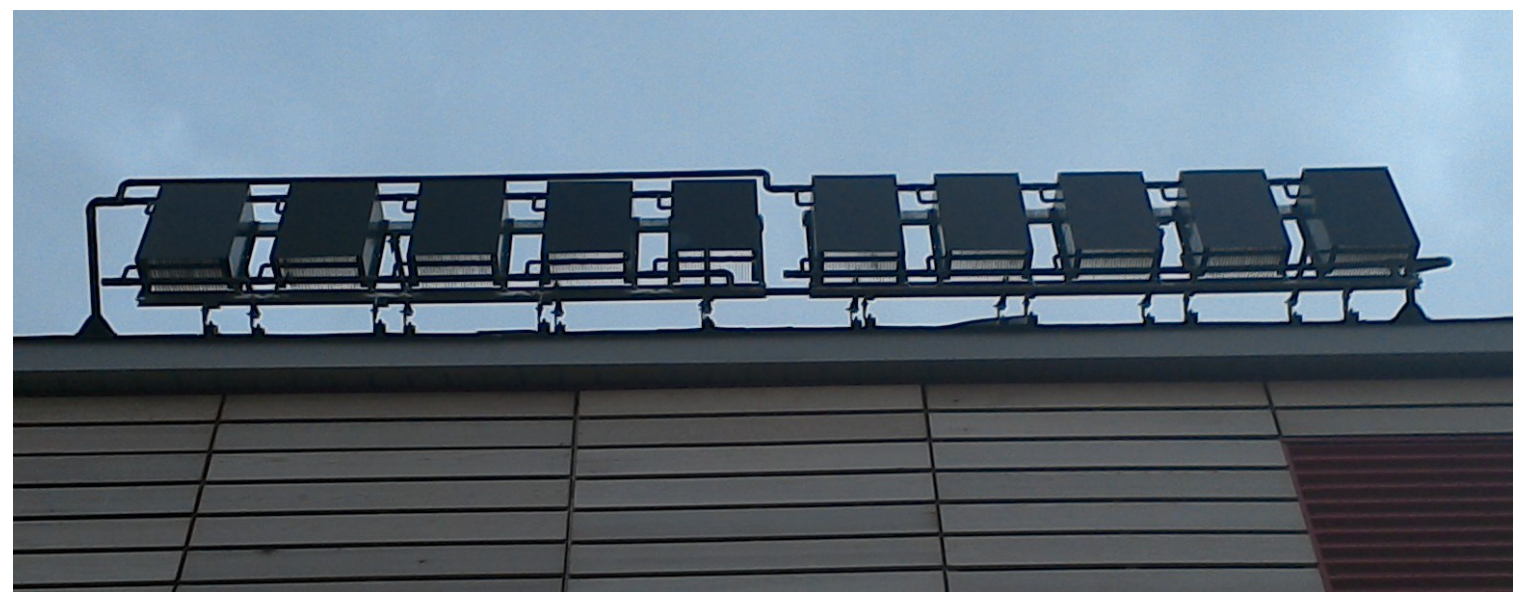

Figure 7.5: Heat dissipators

of the testing. In order to accurately simulate a real life scenario, the mimicry system should be able to provide water at the water mains temperature, which is typically lower than outdoor air temperature during the summer. In the future, a water-air heat pump, with the condenser unit dumping heat outdoors, might be required to correct this issue.

\subsection{Cold water storage}

The cold water storage consists of a THERMO 2000 RE119 tank with a volume of $450 \mathrm{~L}$ seen in Figure 7.7. Water is cooled by the heat pump through the evaporator heat exchanger. That cold water can then be sent to the floors during periods of cooling demand. A type- $T$ thermocouple (from a calibrated spool) measures the temperature of the tank.

\subsection{Heat dump}

In periods of high cooling demand, the hot water storage tanks may become too hot for the heat pump to keep running. In that case, some of the stored heat needs to be dumped to a cold reservoir. This can be outside air, or another any other reservoir colder than the hot storage tank. In the case of the CHEeR house, an underground 


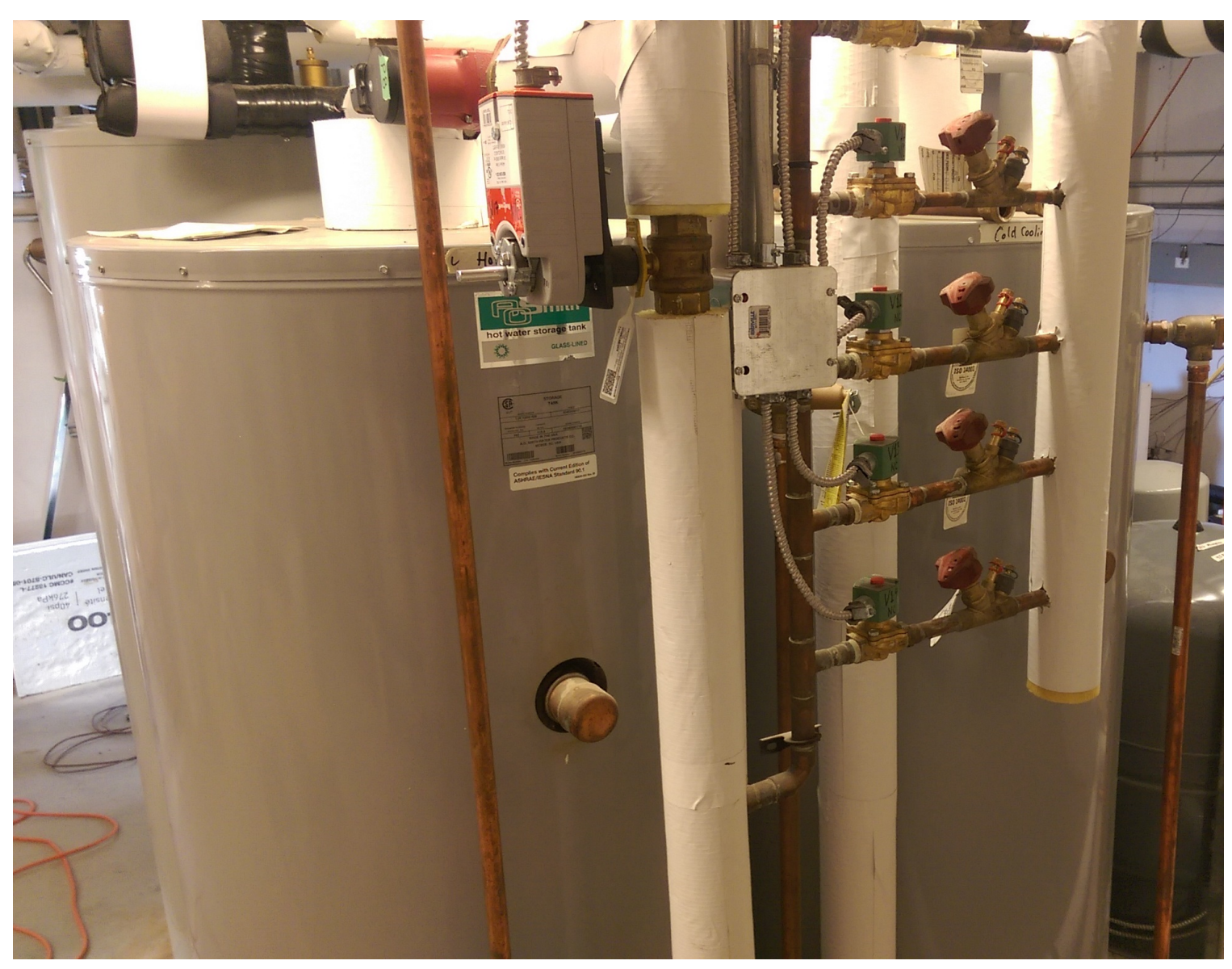

Figure 7.6: Domestic hot water mimicry system storage tanks and flow control valves 


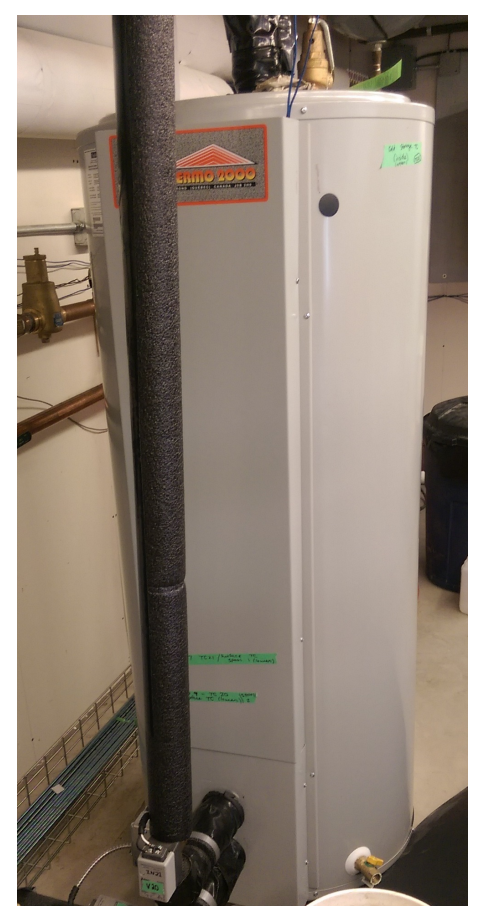

Figure 7.7: Cold storage tank

saturated sand storage system is currently not being used for any other project. It is at a low temperature and will act as the heat dump reservoir. One problem with this approach however is that this method of dumping heat cannot be used while the radiant floors are active due to the plumbing configuration. If initial testing of the system active/passive solar collection system shows promise, a dedicated heat dump system such as a dry cooler placed outdoors would be a better permanent solution.

\subsection{Electric backup heater}

If the heat pump cannot provide at the required temperature for space heating, a THERMO 2000 bth Ultra $12 \mathrm{~kW}$ electric backup heater is used (Figure 7.8). 


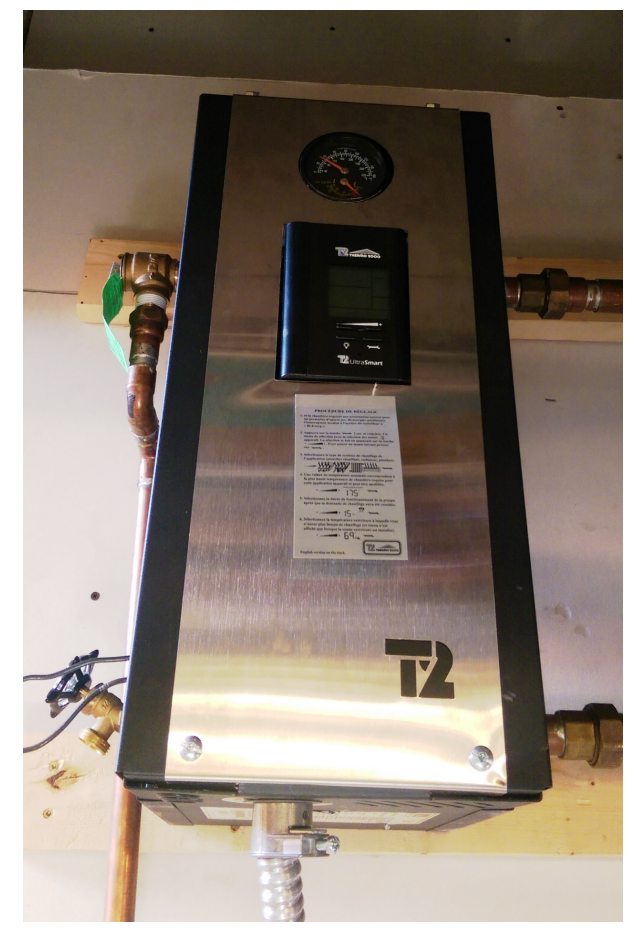

Figure 7.8: Electric backup boiler

\subsection{System operation}

\subsubsection{Cooling mode}

Figure 7.10 shows a schematic of the system in cooling mode with the heat pump operating. During periods of cooling demand, chilled water is pumped from the cold storage tank to the radiant floors (with legend in Figure 7.9). A motorized mixing valve (labeled $M 1$ ) is used to mix return water with supply water to control the water temperature being supplied to the floor.

The heat pump is controlled independently from the water supply to the radiant floor system. This means that the heat pump can be turned on while the radiant floor system is on, or not. When the heat pump is activated, circulation pumps in series between the hot storage tanks and the condenser heat exchanger are turned on. Initial undersizing of the pump required a second pump to be installed in series to obtain the required flow rate. A pump circulating water between the evaporator heat exchanger and the cold storage tank is also activated. 


\begin{tabular}{|c|c|c|c|}
\hline L & Ball Valve & $\psi_{\text {sopest }}$ & Pressure Relief Valve \\
\hline 采 & 3-Way Actuated Valve & $\hat{1}$ & Air Bleed \\
\hline$N$ & Check Valve & $\stackrel{-\cdots}{-\cdots}$ & $0.75 " N P S$ \\
\hline 东 & 2-Way Actuated Valve & $\longrightarrow$ & $1 " N P S$ \\
\hline N & Stop Check Valve & $\cdot-------\rightarrow$ & $1.25 " \mathrm{NPS}$ \\
\hline 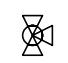 & Mixing Valve & $--------\longrightarrow$ & 1.5" NPS \\
\hline 承 & Balancing Valve & $\stackrel{0-7.5 \mathrm{psi}}{5}$ & Pressure Differential Bypass \\
\hline & Pump & $\stackrel{\text { HXG }}{\mathbb{B}}$ & Heat Exchanger \\
\hline & Flow Meter & ○ & Thermocouple \\
\hline & Air Separator & $\Gamma$ & Pipe Open to Atmosphere \\
\hline & Y Strainer & @ & Pressure Gauge \\
\hline & Expansion Tank & i & Drain/Hose Connection \\
\hline
\end{tabular}

Figure 7.9: Symbol legend for plumbing schematics 


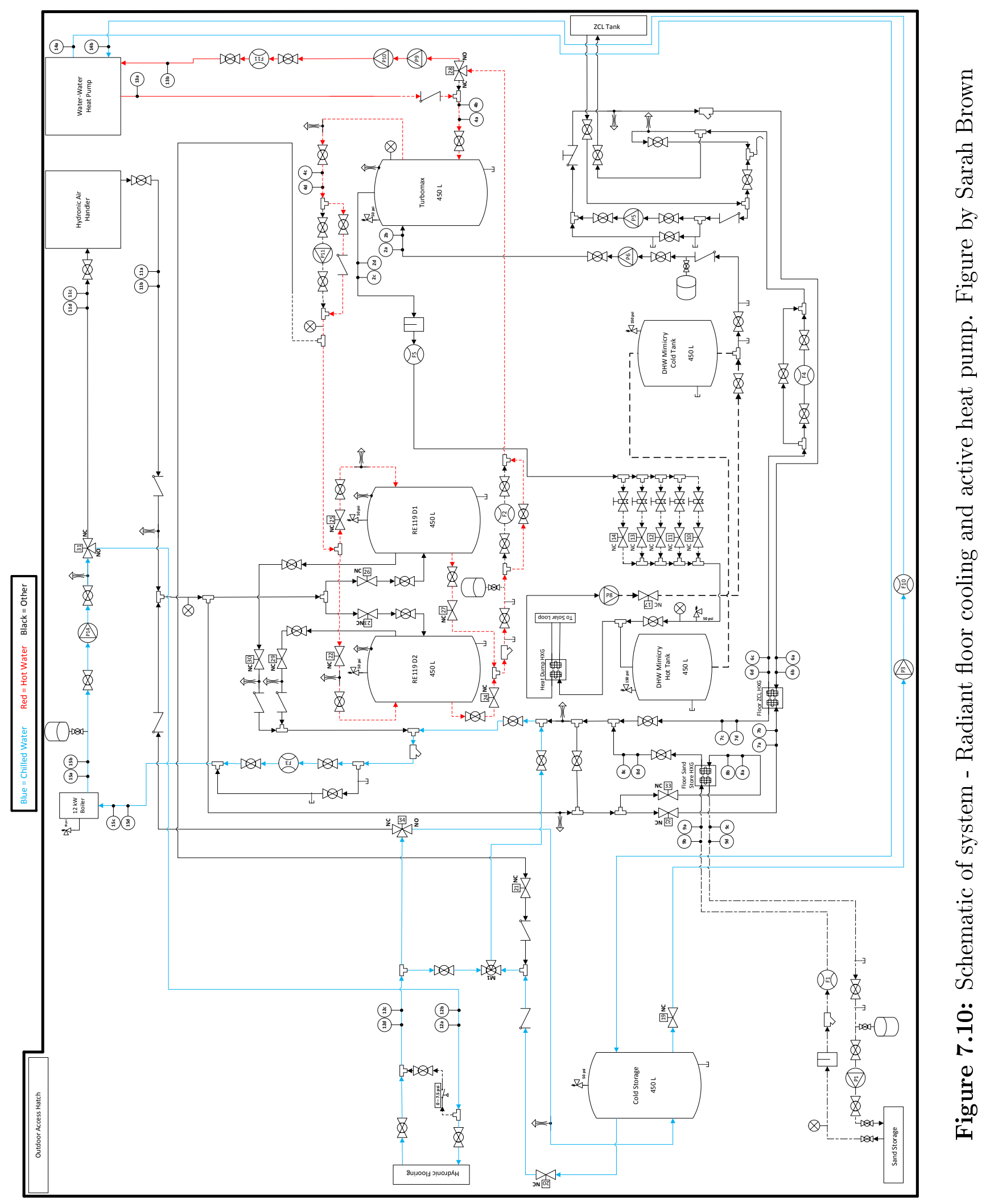




\subsubsection{Heating mode}

Figure 7.11 shows the schematic of the same system in heating mode. Hot water is taken out of the Turbomax tank and supplied to the floors. Motorized mixing valve M1 is used to mix return water with supply water to control the temperature of the water supplied to the floor, as is the case in cooling mode. The return water is sent to tanks D1 and D2, and then back to the Turbomax tank.

\subsubsection{Heating mode with domestic hot water draw}

Figure 7.12 shows the schematic of the system in heating mode during a simulated domestic hot water draw. In this case, the space heating water is drawn directly from D1 and D2.

\subsection{Concluding remarks}

This chapter discussed the active/passive solar collection system that was installed in the CHEeR house on the Carleton University Campus. The system will be tested in order to assess its performance. Additionally, experimental data will allow for a full scale model to be calibrated and validated so that further modelling efforts can lead to a better understanding of the important parameters affecting the performance of this type of system. This will likely lead to better controls, and design of the system. 


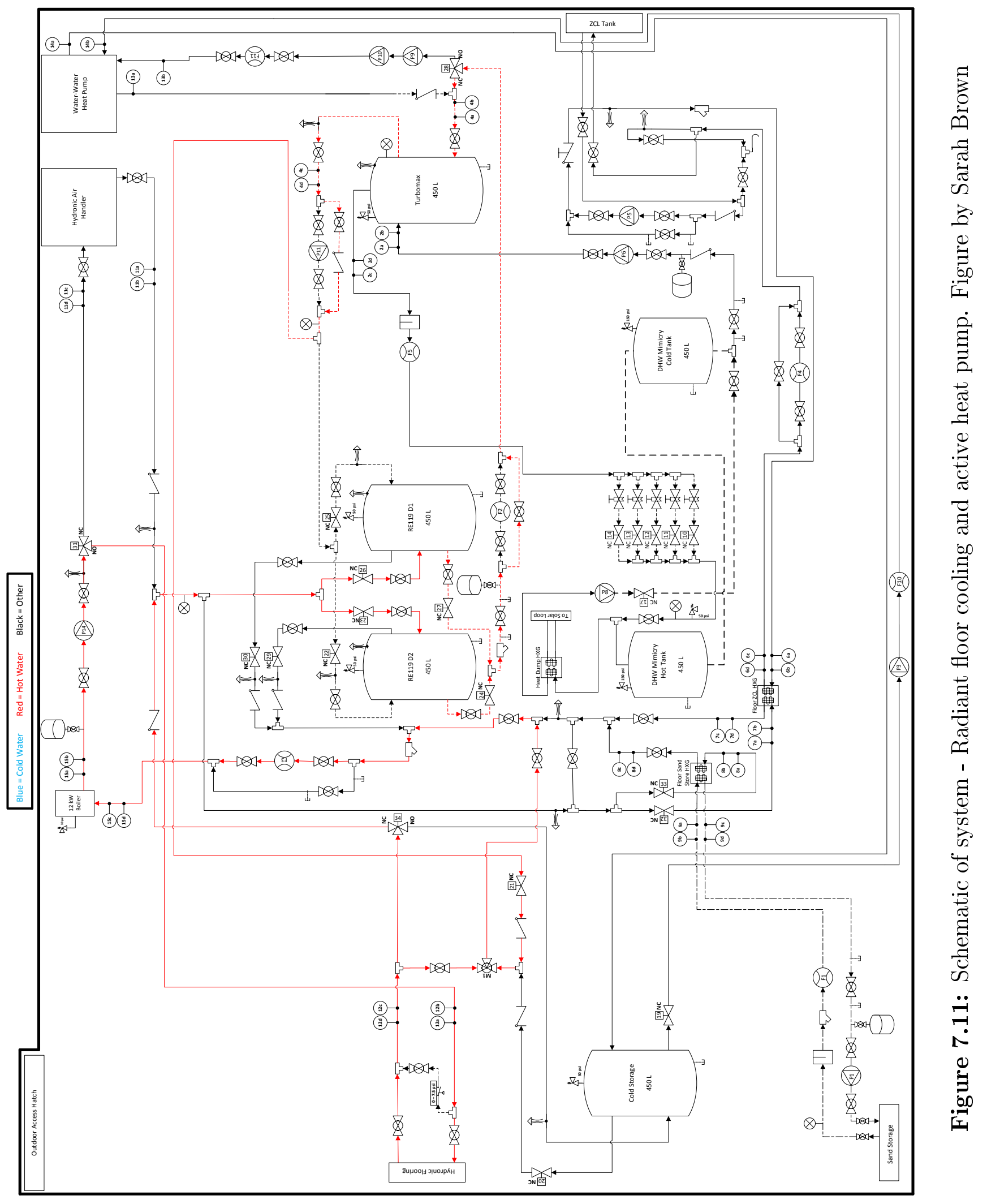




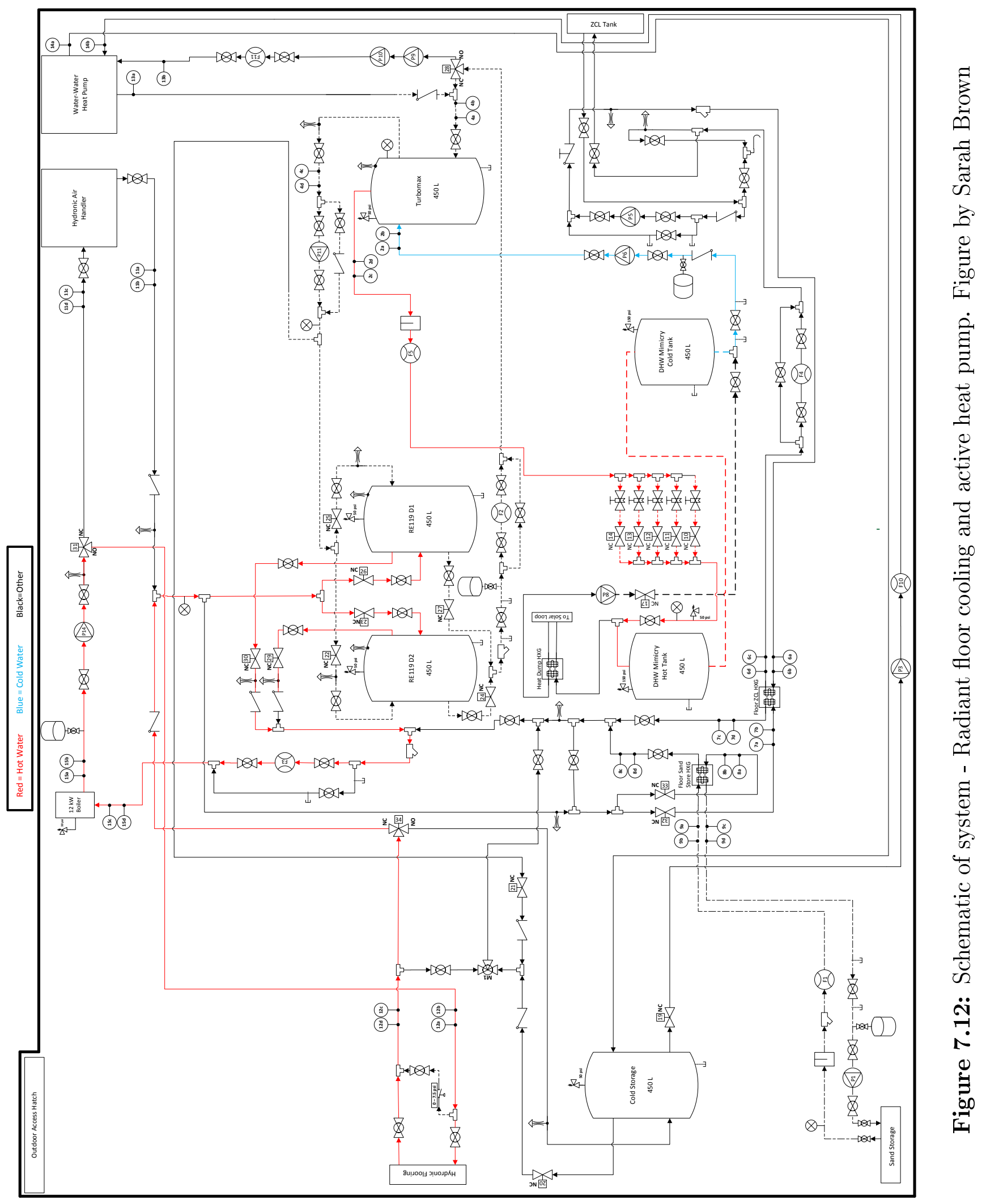




\section{Chapter 8}

\section{Conclusion}

In this thesis, an active/passive solar collection system for a house in a Canadian climate was described. This system used high south-facing window area to allow more solar gains in the house. Radiant floors, a heat pump, and storage tanks, were used to capture these solar gains by cooling the floor in periods of overheating. The aim of this work was to study the performance of such a system. In order to accurately model this system, many tasks needed to be addressed beforehand. First, models currently available in building performance simulation (BPS) tools were validated. Second, above-floor tube-and-plate radiant floor models were not available, so one was developed and validated. Third, a new transient model was developed for a water-water heat pump.

\subsection{Embedded-tube radiant floor inter-model com- parison}

Three BPS tools currently include hydronic embedded tube radiant floor models: TRNSYS, ESP-r, and EnergyPlus. None of these models had previously been properly validated. To be able to simulate the active/passive solar collection system with embedded tube radiant floors, confidence in the embedded tube radiant floor model must first be established. In Chapter 2, these models were compared with each other, and with a two dimensional (Finite Element Analysis) FEA model. Test cases based upon two floor constructions and two inner tube temperature profiles were created, and the inputs to the three BPS tools were made equivalent. The simulation predictions were compared with each other and with the FEA results. 
This analysis found serious issues with all three models. First, the TRNSYS model was unable to simulate one of the test cases, due to the model's limitation to thick slabs only. This required the use of the expert mode for the thin slab case, which is problematic due to the lack of explanation in the TRNSYS manual.

The ESP-r model employs a method which uses average thermal properties for the floor construction and then models the entire floor as a uniform slab. It was found that this could lead to important prediction errors when the construction layers have significantly different thermal properties. A solution was proposed and tested, and resulted in much better agreement between the ESP-r model and the FEA solution.

EnergyPlus' 1D model was found to significantly overestimate the heat transfer rate from the water to the floor for a given flow rate and supply water temperature. Furthermore, a coding error was found in the EnergyPlus 2D model, which caused a significant error in the results. As a result of this work, the EnergyPlus developers were made aware of this error, and it has since been corrected in the general distribution.

More generally, it was found that the three models showed similar results for all cases. Additionally, the ESP-r and EnergyPlus models were found to be sensitive to time-step. The ESP-r solution diverged from the FEA solution with a larger time-step due to its solution methodology (effectively the radiant floor model is one time-step behind the rest of the building model). The EnergyPlus solution gets closer to the FEA solution with larger time-steps, quite possibly due to the conduction transfer function coefficient truncation with shorter time-steps.

The ESP-r model was found to give acceptable results so it was used for simulation of the active/passive solar collection system with embedded-tube radiant floors.

\subsection{Above-floor tube and plate radiant floor model development}

The passive/active solar collection system can also utilize above-floor tube and plate (AFTP) radiant floors. Unfortunately, no complete model for this type of radiant floor has been found in the literature. A new model was therefore required in order to simulate the passive/active solar collection system with AFTP radiant floors.

Chapter 3 discussed the development of an AFTP radiant floor model for ESP-r, The model was compared with a two dimensional FEA solution with good results. 
Additionally, a full scale experiment was performed to validate the model. This experiment showed good results, and a parametric analysis showed that uncertainty in material properties and convective heat transfer coefficient could lead to a significant difference in simulation results. The model was found to be good, and could be used for simulation of the active/passive solar collection system with AFTP radiant floors.

\subsection{Heat pump experimental testing and empirical model}

Steady state heat pump models are typically used in building performance simulation. These models are typically empirical. Unfortunately, a water-water heat pump of appropriate cooling capacity and temperature range could not be found with reliable empirical data.

In Chapter 4, a custom 11kW (nominal cooling) water-water heat pump was tested experimentally and an empirical model was derived. Due to startup transient effects, it was found that a steady state performance map model was inadequate to model the heat pump even though this type of steady state model is commonly used in building simulation. A transient model was derived based on a steady state performance coupled with time constants for the condenser and evaporator heat transfer rates. The time constants were dependent on the elapsed time since the last heat pump cycle. This transient model was found to give more accurate results than the steady state model, and can be used for simulation of the active/passive solar collection system.

\subsection{Controls of radiant floor heating with high solar gains}

Control of radiant floors pose a specific problem in buildings. Due to their slow response, careful care must be taken designing and deploying controls for radiant floor systems. Much work has been done in the past regarding this topic. Two areas of research had not been considered however: the controls of radiant floor heating in housing with high solar gains, and the controls of AFTP radiant floors compared with embedded tube radiant floors. This was addressed in Chapter 5. 
Using simulation for a relatively sunny week in February in Ottawa, it was found that for a zone with a typical amount of south facing glazing, a lighter floor construction tends to require lower average supply temperatures, and total energy for similar comfort conditions. In cases with high solar gains (i.e. high amount of south facing glazing), floors with higher mass tend to provide better comfort by reducing overheating. However, in a high solar gain case with nightime setback, a thick slab with tubes deep in the floor performs worse than lighter floors, both in terms of comfort and energy requirements.

It was also found that more complex controllers tend to perform better. The better controllers were found to be the Proportional-Integral-Derivative (PID) controller and the outdoor temperature reset with indoor temperature feedback. However, the optimal settings for many of the outdoor temperature reset with indoor temperature feedback controllers turned out to be a simple proportional controller (with the outdoor reset slope being set to zero).

\subsection{Evaluation of active/passive solar collection sys- tem}

In Chapter 6, simulation was used to evaluate the performance of the active/passive solar collection system with radiant floors. Simulations were run for the Ottawa, Calgary, and Whitehorse climates, and various hot water tank volumes. Additionally, various floor constructions were used in the simulations. It was found that it is possible to considerably reduce the energy consumption in houses using this system. More specificaly, it was found that the active/passive solar collection system could reduce HVAC and domestic hot water loads by as much as $27 \%$. However, the simulations showed that many factors have an large influence on the energy consmption of the system. Furthermore, the system was not optimized, and it is possible that better controls or different equipment or window sizing could yield better results. 


\subsection{Design and construction of active/passive radi- ant floor solar collection system}

In order to verify the accuracy of the simulations discussed in Chapter 6 , the system was built in the CHEeR house on the Carleton University campus. Chapter 7 discusses the major components of the installed system and the various modes of operation. In the future, the system will be tested in order to assess its performance. Additionally, experimental data will allow for a full scale model to be calibrated and validated so that further modelling efforts can lead to a better understanding of the important parameters affecting the performance of this type of system.

\subsection{Major contributions}

To summarize, the major contributions to the literature from the work presented in this thesis are:

- The inter-model comparison of embedded tube radiant floor models: This work found major problems with all three models currently found in BPS tools, and provided correction for two of the three models. This work was published in the Journal of Building Performance Simulation [25].

- Development of above-floor tube and plate radiant floor model: A model for above-floor tube and plate radiant floor systems was developed and integrated to a BPS tool. This model was compared with a FEA solution and a full scale experiment. Some of this work was presented at the eSim2014 conference [56].

- Heat pump experimental testing and empirical model: This work showed that steady state models, commonly used in building performance simulation, was inadequate for heat pumps. Based on work by others, a new time constant model was developed to account for startup transients of the heat pump. This work was presented at the eSim2016 conference [74].

- Controls of radiant floor heating with high solar gains: Controls of hydronic radiant floor heating has previously been studied extensively. However, no studies had studied the effects of very high solar gains variation on the 
controlability of radiant floors. Additionally, various floor constructions were rarely compared, and AFTP constructions had never been studied. This work assessed seven different reactive controllers, four different floor constructions, and two south facing glazing areas.

- Evaluation of active/passive solar collection system: This work evaluated the performance of the active/passive solar collection system using building performance simulation. This new type of system had never been assessed before. Although the system was not optimized, this proof of concept is a good starting point for further studies. Preliminary results of this work were presented at the 6th International Building Physics Conference [114].

\subsection{Recommendations}

Many recommendations were made in the previous chapters of this thesis. They are summarized here.

First, additional test cases and carefully designed and executed experiments would be useful for further validating the embedded-tube models described in Chapter 2. Second, the behaviour of the water-water heat pump described in Chapter 4 should be further investigated. Particularly, the transient nature of the compressor power consumption should be examined, additional transient tests should be run over a wide range of water temperatures, and results from the transient model should be compared to the steady state model for an actual system. Third, the active/passive solar collection system discussed in Chapter 5 should be further examined. This includes investigating the influence of furniture in the space and the modelling resolution required. An analysis of the effects of the discretization of the floor surface on the simulation results should also be completed. Also, optimization of the controls and various components of the active/passive system should be carried out. Finally, a fullscale testing of the passive/active solar collection system is planned in the CHEeR, as described in Chapter 7 . 


\section{List of References}

[1] Natural Resources Canada, "Energy use data handbook table." http://oee.nrcan.gc.ca/corporate/statistics/neud/dpa/menus/ trends/handbook/handbook_aaa_ca.cfm, Accessed on April 20th 2015.

[2] D. Sander and S. Barakat, "Mass \& Glass: How Much? How Little," ASHRAE Journal, vol. 26, no. 11, pp. 26-31, 1984.

[3] S. Barakat, "Solar heat gains through windows in Canada," tech. rep., National Research Council of Canada DBR Paper No. 994, 1980.

[4] D. Sander and S. A. Barakat, "A method for estimating the utilization of solar gains through windows," ASHRAE Transactions, vol. 89, no. 1163, pp. 12-22, 1983.

[5] G. Proskiw, "Identifying affordable net zero energy housing solutions," tech. rep., Natural Resources Canada, 2010.

[6] I. Beausoleil-Morrison, "The adaptive simulation of convective heat transfer at internal building surfaces," Building and Environment, vol. 37, no. 8-9, pp. 791806, 2002.

[7] F. Alamdari and G. P. Hammond, "Improved data correlations for buoyancydriven convection in rooms," Building Services Engineering Research and Technology, vol. 4, no. 3, pp. 106-112, 1983.

[8] D. Fisher, An experimental investigation of mixed convection heat transfer in a rectangular enclosure. PhD thesis, University of Illinois at Urbana-Champaign, 1995.

[9] B. Olesen, "Possibilities and Limitations of Radiant Floor Cooling," ASHRAE Transactions, vol. 103, no. 1, pp. 42-48, 1997.

[10] B. Olesen, "Radiant floor heating in theory and practice," ASHRAE Journal, pp. 19-24, July 2002.

[11] P. Simmonds, W. Gaw, S. Holst, and S. Reuss, "Using radiant cooled floors to condition large spaces and maintain comfort conditions," ASHRAE Transactions, vol. 112, no. 1, pp. 695-701, 2000.

[12] M. De Carli and M. Tonon, "Effect of modelling solar radiation on the cooling performance of radiant floors," Solar Energy, vol. 85, no. 5, pp. 689-712, 2011. 
[13] Y. M. Li and J. Y. Wu, "Energy simulation and analysis of the heat recovery variable refrigerant flow system in winter," Energy and Buildings, vol. 42, no. 7, pp. 1093-1099, 2010.

[14] T. N. Aynur, "Variable refrigerant flow systems: A review," Energy and Buildings, vol. 42, no. 7, pp. 1106-1112, 2010.

[15] ASHRAE, 2008 ASHRAE Handbook: HVAC Systems and Equipment. Atlanta, USA: American Society of Heating Refrigerating and Air-Conditioning Engineers, 2008.

[16] ASHRAE, 2009 ASHRAE Handbook: Fundamentals. Atlanta, USA: American Society of Heating Refrigerating and Air-Conditioning Engineers, 2009.

[17] J. Mitchell and J. Braun, Principles of Heating, Ventilating, and Air Conditioning, in Buildings. Hoboken, USA: Wiley, 2013.

[18] D. B. Crawley, J. W. Hand, M. Kummert, and B. T. Griffith, "Contrasting the capabilities of building energy performance simulation programs," Building and Environment, vol. 43, no. 4, pp. 661-673, 2008.

[19] I. Beausoleil-Morrison, The adaptive coupling of heat and air flow modelling within dynamic whole-building simulation. PhD thesis, University of Strathclyde, 2000.

[20] P. Strachan, "ESP-r : Summary of Validation Studies," tech. rep., University of Strathclyde - Energy Systems Research Unit, Glasgow, 2000.

[21] J. L. M. Hensen, On the thermal interaction of building structure and heating and ventilating system of building structure. PhD thesis, Technische Universiteit Eindhoven, 1991.

[22] J. A. Clarke, Energy Simulation in Building Design. Oxford: ButterworthHeinemann, 2nd ed., 2001.

[23] TRNSYS, TRNSYS 17 Manual. 2012.

[24] I. Beausoleil-Morrison, F. Macdonald, M. Kummert, T. McDowell, and R. Jost, "Co-simulation between ESP-r and TRNSYS," Journal of Building Performance Simulation, vol. 7, no. 2, pp. 133-151, 2013.

[25] S. A. Brideau, I. Beausoleil-Morrison, M. Kummert, and A. Wills, "Inter-model comparison of embedded-tube radiant floor models in BPS tools," Journal of Building Performance Simulation, vol. 9, no. 2, pp. 190-209, 2016.

[26] I. Kilkis, S. Sager, and M. Uludag, "A simplified model for radiant heating and cooling panels," Simulation Practice and Theory, vol. 2, no. 2, 1994.

[27] A. Laouadi, "Development of a radiant heating and cooling model," Building and Environment, vol. 39, no. 4, pp. 421-431, 2004. 
[28] H. Ishino, "Research on calculation method of thermal design load in radiant heating and cooling systems," in International Building Performance Simulation Association Conference, (Kyoto, Japan), 1999.

[29] D. Carbonell, J. Cadafalch, and R. Consul, "A transient model for radiant heating and cooling terminal heat exchangers applied to radiant floors and ceiling panels," in ISES Solar World Congress 2011 Proceedings, (Kassel, Germany), 2011.

[30] L. Hulbert, H. Nottage, and C. Franks, "Heat flow analysis in panel heating or cooling sections," Heating, Piping and Air Conditioning, vol. 22, no. 4, pp. 117$122,1950$.

[31] H. Nottage, C. Franks, L. Hulbert, and L. Schutrum, "Heat Flow Analysis in Panel Heating or Cooling Sections. Case II - Floor Slab on Earth with Uniformly Spaced Pipes or Tubes at the Slab-Earth Interface," ASHVE Heating, Piping and Air Conditioning, vol. 25, no. 5, pp. 115-118, 1953.

[32] Z. Zhang and M. Pate, "A numerical study of heat transfer in a hydronic radiant ceiling panel," ASME Proceedings - Heat Transfer Division, vol. 62, pp. 31-37, 1986 .

[33] Z. Zhang and M. Pate, "A semi-analytical formulation of heat transfer from structures with embedded tubes," ASME Proceedings - Heat Transfer Division, vol. 78, pp. 17-25, 1987.

[34] Z. Zhang and M. Pate, "A new approach for designing heating panels with embedded tubes," ASHRAE Transactions, vol. 95, no. 1, pp. 231-238, 1989.

[35] X. Jin, X. Zhang, and Y. Luo, "A calculation method for the floor surface temperature in radiant floor system," Energy and Buildings, vol. 42, no. 10, pp. 1753-1758, 2010.

[36] J. Bohle and H. Klan, "Design of panel heating and cooling systems," ASHRAE Transactions, vol. 106, no. 1, pp. 677-683, 2000.

[37] S.-Y. Ho, "Simulation of the dynamic behaviour of a hydronic floor heating system," Master's thesis, University of Alberta, 1992.

[38] S. Ho, R. Hayes, and R. Wood, "Simulation of the Dynamic Behaviour of a Hydronic Floor Heating System," Heat Recovery Systems and CHP, vol. 15, no. 6 , pp. 505-519, 1995.

[39] T. Weber, G. Jóhannesson, M. Koschenz, B. Lehmann, and T. Baumgartner, "Validation of a FEM-Program (Frequency-Domain) and a Simplified RC-Model (Time-Domain) for Thermally Activated Building Component Systems (TABS) Using Measurement Data," Energy and Buildings, vol. 37, no. 7, pp. 707-724, 2005.

[40] H. Karlsson, "Embedded water-based surface heating part 1: Hybrid 3d numerical model," Journal of Building Physics, vol. 33, no. 4, pp. 357-391, 2010. 
[41] H. Karlsson, "Embedded water-based surface heating part 2: Experimental validation," Journal of Building Physics, vol. 34, no. 2, pp. 143-162, 2010.

[42] M. Tye-Gingras and L. Gosselin, "Investigation on heat transfer modeling assumptions for radiant panels with serpentine layout," Energy and Buildings, vol. 43, pp. 1598-1608, Jul 2011.

[43] B. Glück, Strahlungsheizung - Theorie und Praxis [Radiant Heating - Theory and Practice]. Karlsruhe, Germany: C.F. Müller, 1982.

[44] K. Fort, "Type 360: Floor heating and hypocaust," 2001. http://www. transsolar.com/__software/download/en/ts_type_360_en.pdf, accessed on July 19th, 2014.

[45] Thermal Energy Systems Specialists, TESSLibs 17, Volume 5: Ground Coupling Library Mathematical Reference. Madison, USA: Solar Energy Laboratory, University of Wisconsin-Madison, 2012.

[46] R. K. Strand, Heat Source Transfer Functions and their Application to Low Temperature Radiant Heating Systems. PhD thesis, University of Illinois, 1995.

[47] Lawrence Berkley National Laboratory, Simulation Research Group, 2012. EnergyPlus.

[48] S. Sattari and B. Farhanieh, "A parametric study on radiant floor heating system performance," Renewable Energy, vol. 31, no. 10, pp. 1617-1626, 2006.

[49] C. Chantrasrisalai, V. Ghatti, D. Fisher, and D. Scheatzle, "Experimental validation of the energyplus low-temperature radiant simulation," ASHRAE Transactions, vol. 109, no. 2, pp. 614-623, 2003.

[50] LISA Finite Element Analysis, Tutorials and Reference Guide, 2013.

[51] B. Delcroix, M. Kummert, A. Daoud, and M. Hiller, "Improved Conduction Transfer Function Coefficients Generation in TRNSYS Multizone Building Model," in 13th International IBPSA Conference Proceedings, (Chambéry, France), pp. 2667-2674, IBPSA, 26-28 August 2013.

[52] M. Koschenz and V. Dorer, "Interaction of an air system with concrete core conditioning," Energy and Buildings, vol. 30, no. 2, pp. 139-145, 1999.

[53] J. Clarke, P. Yaneske, and A. Pinney, The Harmonisation of Thermal Properties of Building Materials. BRE Publications, 1990. BEPAC Research Report.

[54] I. A. Macdonald, Quantifying the Effects of Uncertainty in Building Simulation. PhD thesis, University of Strathclyde, 2002.

[55] A. Athienitis and Y. Chen, "The effect of solar radiation on dynamic thermal performance of floor heating systems," Solar Energy, vol. 69, no. 3, pp. 229-237, 2000 .

[56] S. Brideau and I. Beausoleil-Morrison, "Model Development for Tube-inSubfloor Radiant Floor Heating and Cooling," in eSim2014, (Ottawa), 2014. 
[57] M. Yeo and K. Kim, "A Study on the Thermal Performance Simulation to Evaluate the Prefabricated Radiant Floor Heating Panels," in Proceedings of the 5th International IBPSA Conference, (Prague, Czech Republic), 1997.

[58] P. Kattan, K. Ghali, and M. Al-Hindi, "Modeling of under-floor heating systems: A compromise between accuracy and complexity," HVAC \& R Research, no. July, pp. 37-41, 2012.

[59] S.-H. Cho and M. Zaheer-uddin, "Temperature regulation of radiant floor heating systems using two-parameter on-off control: An experimental study.," ASHRAE Transactions, vol. 103, no. 1, pp. 966-982, 1997.

[60] Roth North America, "Panel system for radiant heating systems." http://www . roth-usa.com/products_radiant_panelsystem.cfm, accessed on September $14,2016$.

[61] Warmboard, "Warmboard-S." http://www . warmboard.com/warmboard-s, accessed on September 14, 2016.

[62] J. M. Tarara and G.-A. Hoheisel, "Low-cost Shielding to Minimize Radiation Errors of Temperature Sensors in the Field," vol. 42, no. 6, pp. 1372-1379, 2007.

[63] R. J. Moffat, "Describing the uncertainties in experimental results," Experimental Thermal and Fluid Science, vol. 1, no. 1, pp. 3-17, 1988.

[64] G. Johnson, "Design and commissioning of an experiment to characterize the performance of a lithium-bromide absorption chiller," Master's thesis, Carleton University, 2011.

[65] W. Haynes, ed., CRC Handbook of Chemistry and Physics. Boca Raton, USA: CRC Press, 94th ed., 2013. Section 6-1.

[66] L. Michalski, K. Eckersdorf, J. Kucharski, and J. McGhee, Temperature Measurement. Chichester, UK: John Wiley \& Sons, second ed., 2001.

[67] R. J. Moffat, CRC Handbook of Mechanical Engineering. Boca Raton, USA: CRC Press, second ed., 2004. Section 4.6.

[68] J. D. Spitler, Load Calculation Applications Manual. Atlanta, USA: ASHRAE, SI ed., 2010.

[69] M. M. Rathore and R. Kapuno, Engineering Heat Transfer. Sudbury, USA: Jones \& Bartlett Learning, second ed., 2010.

[70] ICC Evaluation Services, "Legacy Report: NER-405," tech. rep., 2014.

[71] E. García, A. de Pablos, M. Bengoechea, L. Guaita, M. Osendi, and P. Miranzo, "Thermal conductivity studies on ceramic floor tiles," Ceramics International, vol. 37, no. 1, pp. 369-375, 2011.

[72] H. Awbi and A. Hatton, "Natural convection from heated room surfaces," Energy and Buildings, vol. 30, no. 3, pp. 233-244, 1999. 
[73] A. J. N. Khalifa and R. H. Marshall, "Validation of heat transfer coefficients on interior building surfaces using a real-sized indoor test cell," International Journal of Heat and Mass Transfer, vol. 33, no. 10, pp. 2219-2236, 1990.

[74] S. Brideau, I. Beausoleil-Morrison, and M. Kummert, "Empirical Model of a 11 kW (Nominal Cooling) R134a Water-Water Heat Pump," in eSim2016, (Hamilton, Canada), 2016.

[75] J. Winkler, Development of a Component Based Simulation Tool for the Steady State and Transient Analysis of Vapor Compression Systems. PhD thesis, University of Maryland, 2009.

[76] W. D. Henderson, "The simulation of a heat pump heating a highly insulated dwelling," Building Services Engineering Research and Technology, vol. 3, no. 3, pp. 117-126, 1982.

[77] V. Goldschmidt, G. Hart, and R. Reiner, "A note on the transient performance and degradation coefficient of a field tested heat pump-cooling and heating mode," ASHRAE Transactions, vol. 86, no. 2, pp. 368-375, 1980.

[78] D. R. Tree and B. W. Weiss, "Two Time Constant Modeling Approach for Residential Heat Pumps," in International Refrigeration and Air Conditioning Conference, pp. 141-148, 1986.

[79] W. Mulroy and D. Didion, "Refrigerant migration in a split-unit air conditioner.," ASHRAE transactions, 1985.

[80] M. Kummert and M. Bernier, "Sub-hourly simulation of residential ground coupled heat pump systems," Building Service Engineering Research and Technology, vol. 29, no. 1, pp. 27-44, 2008.

[81] T. Afjei and M. Wetter, "Compressor heat pump including frost and cycle losses - Version 1.1, Model description and implementing into TRNSYS," 1997.

[82] F. Garde, F. Lucas, H. Boyer, and J. Brau, "Multiple Model Approach of a Residential Heat Pump for Integration in a Building Thermal Simulation Code Comparison with Experimental Results," ASHRAE Transactions, vol. 107, no. 1, pp. 14-25, 2001.

[83] W. Stoecker and J. Jones, Refrigeration and Air Conditioning. New York, USA: McGraw-Hill College, second ed., 1982.

[84] Thermal Energy System Specialists, TESSLibs 17, Component Libraries for the TRNSYS Simulation Environment. Madison, USA: Solar Energy Laboratory, University of Wisconsin-Madison, 2012.

[85] A. Algren and B. Ciscel, "Heating Panel Time Response Study," Heating. Piping and Air Conditioning, vol. 21, no. 3, 1949.

[86] S. Leigh and C. MacCluer, "A comparative study of proportional fluxmodulation and various types of temperature-modulation approaches for radiant floor-heating system control," ASHRAE Transactions, vol. 100, no. 1, pp. 1040-1053, 1994. 
[87] C. MacCluer, "The response radiant heating systems controlled by outdoor reset with feedback," ASHRAE transactions, vol. 97, no. 2, pp. 795-799, 1991.

[88] C. MacCluer, "Analysis and simulation of outdoor reset control of radiant slab heating systems," ASHRAE transactions, 1990.

[89] K. W. Kim and B. W. Olesen, "Radiant Heating and Cooling Systems: Part Two," ASHRAE Journal, vol. 57, no. 3, pp. $34-42,2015$.

[90] A. Hasan, J. Kurnitski, and K. Jokiranta, "A combined low temperature water heating system consisting of radiators and floor heating," Energy and Buildings, vol. 41, no. 5, pp. 470-479, 2009.

[91] tekmar Control Systems Ltd., "Control of Radiant Floor Heating Zones," 2002.

[92] tekmar Control Systems Ltd., "Slab Sensor 079 - Installation manual," 2007.

[93] D. Gibbs, "Control of multizone hydronic radiant floor heating systems," ASHRAE Transactions, vol. 100, no. 1, 1994.

[94] A. Athienitis and T. Chen, "Experimental and theoretical investigation of floor heating with thermal storage," ASHRAE Transactions, vol. 99, no. 1, 1993.

[95] A. Athienitis, "Numerical model of floor heating system," ASHRAE Transactions, vol. 100, no. 1, pp. 1024-1030, 1994.

[96] A. Athienitis and T. Chen, "Numerical study of thermostat setpoint profiles for floor radiant heating and the effect of thermal mass," ASHRAE Transactions, vol. 101, no. 1, pp. 939-948, 1997.

[97] Y. Chen and A. Athienitis, "A three-dimensional numerical investigation of the effect of cover materials on heat transfer in floor heating systems," ASHRAE Transactions, vol. 104, pp. 1350-1358, 1998.

[98] B. Olesen, "Comparative experimental study of performance of radiant floorheating systems and a wall panel heating system under dynamic conditions," ASHRAE Transactions, vol. 100, no. 1, pp. 1011-1023, 1994.

[99] S. Cho and M. Zaheer-uddin, "An experimental study of multiple parameter switching control for radiant floor heating systems," Energy, vol. 24, pp. 433444, 1999.

[100] J. Rekstad, M. Meir, and A. R. Kristoffersen, "Control and energy metering in low temperature heating systems," Energy, vol. 35, pp. 281-291, 2003.

[101] M. Zaheer-Uddin, G. Zheng, and S. Cho, "Optimal operation of an embeddedpiping floor heating system with control input constraints," Energy Conversion and Management, vol. 38, no. 7, pp. 713-725, 1997.

[102] S. Cho and M. Zaheer-uddin, "Predictive control of intermittently operated radiant floor heating systems," Energy Conversion and Management, vol. 44, no. 8, pp. 1333-1342, 2003. 
[103] J. Lee, I. Yang, S. Song, H. Kim, and K.-W. Kim, "A Study of the Predictive Control of the ONDOL System in Apartments," in Proceedings of the Yth International Building Performance Simulation Association (IBPSA) Conference, 1999.

[104] J. Candanedo, A. Allard, and A. Athienitis, "Predictive Control of Radiant Floor Heating and Transmitted Irradiance in a Room with High Solar Gains," ASHRAE Transactions, 2011.

[105] J. Candanedo and A. Athienitis, "Predictive control of radiant floor heating and solar-source heat pump operation in a solar house," HVACERR Research, vol. 17, no. 3, pp. 235-256, 2011.

[106] J. Siegenthaler, Modern hydronic heating: for residential and light commercial buildings. Clifton Park, NY: Delmar Cengage Learning, 3rd ed., 2012.

[107] R. Hendron and C. Engebrecht, "Building America House Simulation Protocols," Tech. Rep. October, U.S. Department of Energy, 2010.

[108] I. Walker and D. Wilson, "The Alberta infiltration model: AIM-2," tech. rep., University of Alberta, Edmonton, 1990.

[109] G. Johnson and I. Beausoleil-Morrison, "Electrical-end-use data from 23 houses sampled each minute for simulating micro-generation systems," Applied Thermal Engineering, 2016.

[110] N. Saldanha and I. Beausoleil-Morrison, "Measured end-use electric load profiles for 12 Canadian houses at high temporal resolution," Energy and Buildings, vol. 49, pp. 519-530, June 2012.

[111] P. O. Fanger, Thermal comfort. New York, USA: McGraw, 1970.

[112] J. van Schijndel, "Eindhoven University of Technology HAMLAB - Building Physics Toolbox," 1998. http://archbps1.campus.tue.nl/bpswiki/index. php/Hamlab, accessed on July 132016.

[113] ASHRAE, "ASHRAE 55-2004, Thermal environmental conditions for human occupancy," 2004.

[114] S. Brideau, I. Beausoleil-Morrison, and M. Kummert, "Collection and storage of solar gains incident on the floor in a house during the heating season," Energy Procedia, vol. 78, pp. 2274-2279, 2015.

[115] Environment Canada, "Canadian Weather year for Energy Calculation (CWEC)." ftp://ftp.tor.ec.gc.ca/Pub/Engineering_Climate_Dataset/ Canadian_Weather_year_for_Energy_Calculation_CWEC/ENGLISH/, accessed on January 15, 2015.

[116] I. Beausoleil-Morrison and G. Mitalas, "BASESIMP : a Residential-Foundation Heat-Loss Algorithm for Incorporating Into Whole-Building Energy-Analysis Programs," in Building Simulation 1997, (Prague, Czech Republic), 1997. 
[117] R. Siegel and J. R. Howell, Thermal Radiation Heat Transfer. New York: Taylor \& Francis, 4th ed., 2002.

[118] H. Akbari, C. Wray, T. Xu, and R. Levinson, "Inclusion of Solar Reflectance and Thermal Emittance Prescriptive Requirements for Residential Roofs in Title 24." http://www . energy .ca.gov/title24/2008standards/prerulemaking/ documents/2006-05-18_workshop/2006-05-17_RESIDENTIAL_ROOFS.PDF, accessed on September 19, 2016.

[119] A. Wills, "Design and co-simulation of a seasonal solar thermal system for a Canadian single-family detached house," Master's thesis, Carleton University, Ottawa, 2013. 


\section{Appendix A}

\section{Additional results for above-floor tube and plate radiant floor model}

This appendix presents additional results to the ones shown in Chapter 3. The results shown in Chapter 3 were for a floor in which the grooves were in a layer of insulation, and the tubes were $0.1524 \mathrm{~m}$ apart. In this appendix, the results are for a floor in which the grooves are in a wood layer (subfloor), and the tubes are $0.3048 \mathrm{~m}$ apart.

\section{A.1 Geometry, construction, and test cases}

The geometry is similar to the test case defined in Chapter 3, except that the grooves are in a wood layer (subfloor), and the tubes are $0.3048 \mathrm{~m}$ apart. Also, two different floor covers were tested: a tile cover, and a hardwood cover.

Table A.1 summarizes the construction of the floors.

The boundary conditions were the same in the ESP-r simulation and in the finite element simulation. The floor surface was given a convective heat transfer coefficient of $5 \mathrm{~W} \mathrm{~m}^{-2} \mathrm{~K}^{-1}$ with a constant zone air temperature at $15^{\circ} \mathrm{C}$. The tube inner temperature was set to $45^{\circ} \mathrm{C}$ for the first 500 minutes, after which it is set to $30^{\circ} \mathrm{C}$. In ESP-r, this was accomplished by providing an unrealistically high water flow rate at those temperatures such that the outlet temperature remained almost equal to the inlet temperature (within $0.01^{\circ} \mathrm{C}$ ). The bottom boundary condition was adiabatic. The initial floor temperature was set to $15^{\circ} \mathrm{C}$. No radiation heat transfer (long, or short wave) was considered. Time steps were $120 \mathrm{~s}$ for a total of 1280 minutes (21.33 hours). 
Table A.1: Construction of floor

\begin{tabular}{lcccc}
\hline Material & $\begin{array}{c}\text { Thickness } \\
(\mathrm{m})\end{array}$ & $\begin{array}{c}k \\
\left(\mathrm{~W} \mathrm{~m}^{-1} \mathrm{~K}^{-1}\right)\end{array}$ & $\begin{array}{c}\rho \\
\left(\mathrm{kg} \mathrm{m}^{-3}\right)\end{array}$ & $\begin{array}{c}C_{p} \\
\left(\mathrm{~J} \mathrm{~kg}^{-1} \mathrm{~K}^{-1}\right)\end{array}$ \\
\hline Insulation & 0.076 & 0.036 & 100 & 960 \\
Subfloor & 0.02794 & 0.1 & 450 & 1880 \\
Aluminium Fin $^{\mathrm{a}}$ & 0.000635 & 234.0 & 2700 & 900 \\
Hardwood $^{\mathrm{b}}$ & 0.01905 & 0.14 & 600 & 1210 \\
Mortar $^{\mathrm{c}}$ & 0.003175 & 0.72 & 1860 & 780 \\
Cement Backing Board $^{\mathrm{c}}$ & 0.00635 & 0.277 & 1461 & 840 \\
Mortar $^{\mathrm{c}}$ & 0.003175 & 0.72 & 1860 & 780 \\
Tile $^{\mathrm{c}}$ & 0.0127 & 1.1 & 2100 & 837 \\
\hline
\end{tabular}

a Tubes located in grooves in aluminium layer.

${ }^{\mathrm{b}}$ Hardwood cover.

c Tile cover.

\section{A.2 Results}

\section{A.2.1 Finite element mesh sensitivity}

The FEA mesh for the tile cover case is shown in Figure A.1. A mesh sensitivity analysis was performed with $120 \mathrm{~s}$ time steps. The total heat transfer from the floor to the surroundings was calculated for the first 78 minutes. The mesh refinement showed no significant changes in the results $(<0.3 \%)$ after 3800 nodes for the tile floor cover. Similar results were found for the hardwood cover at 3706 nodes. Those meshes were therefore used.

\section{A.2.2 ESP-r finite difference mesh sensitivity}

A mesh sensitivity was also performed in ESP-r with $120 \mathrm{~s}$ time steps. The total heat transfer from the floor to the surroundings was calculated for the first 78 minutes. The mesh refinement showed no significant changes in the results $(<0.3 \%)$ after 40 nodes. 


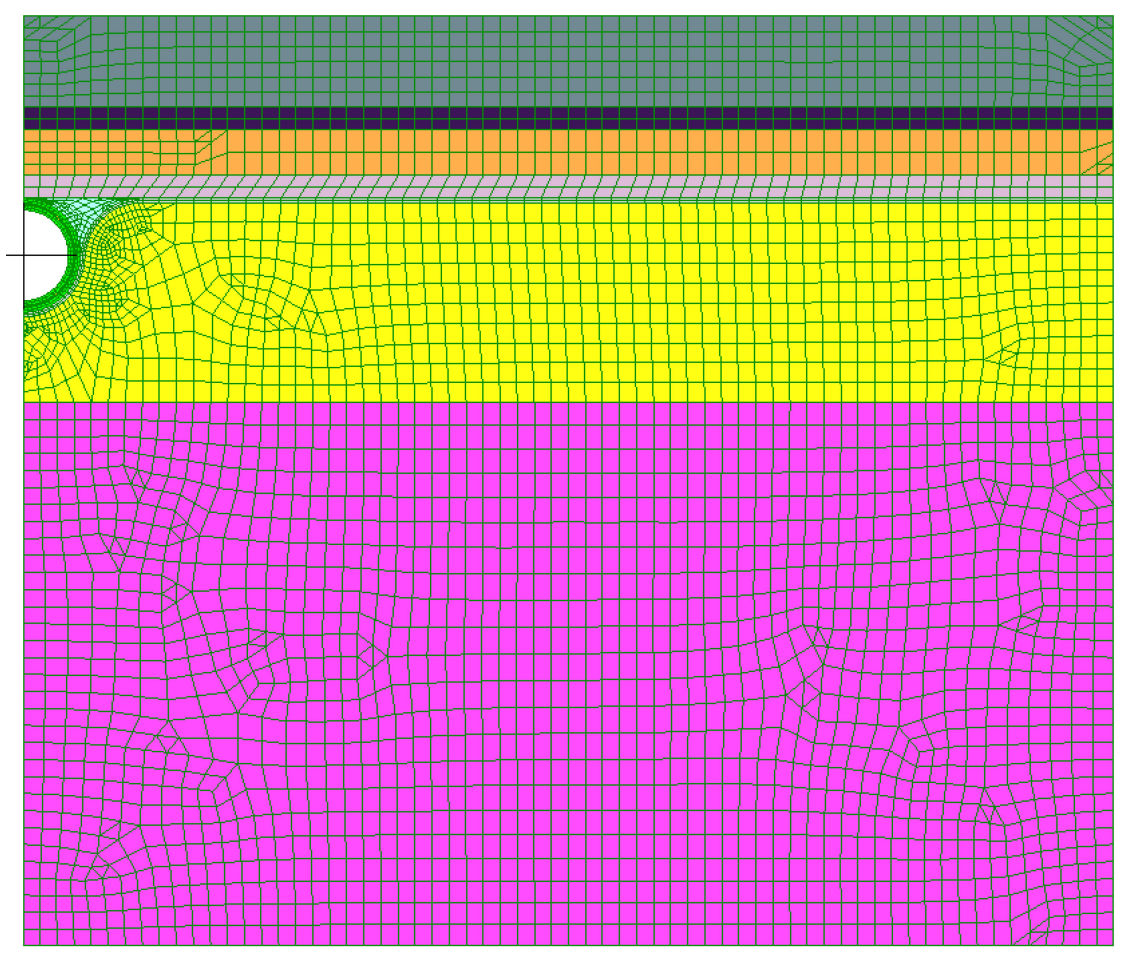

Figure A.1: Finite element mesh for tile cover

\section{A.2.3 Comparison}

The heat flux from the floor surface to the surroundings as calculated by the FEA model and the ESP-r model are shown in Figure A.2 for a tile floor cover. Forty data points were recorded with a root mean square deviation (RMSD) between the two models of $1.22 \mathrm{~W} \mathrm{~m}^{-2}$. The heat flux for the first 39 time steps for tile cover are shown in Figure A.3. For the first 39 time steps, the RMSD was $2.15 \mathrm{~W} \mathrm{~m}^{-2}$.

Similarly, simulations with the hardwood cover were run. Results for the full length of the simulation (1280 minutes) and for the first 39 time steps are seen in Figures A.4 and A.5. The RMSD was $0.90 \mathrm{~W} \mathrm{~m}^{-2}$ for the full length of the simulation and $1.83 \mathrm{~W} \mathrm{~m}^{-2}$ for the first 39 time steps. These results imply that the ESP-r model does not agree quite as well with the FEA model in highly transient periods compared to steady state periods. Nonetheless, the ESP-r results in transient and steady state periods are quite close to the FEA results. 


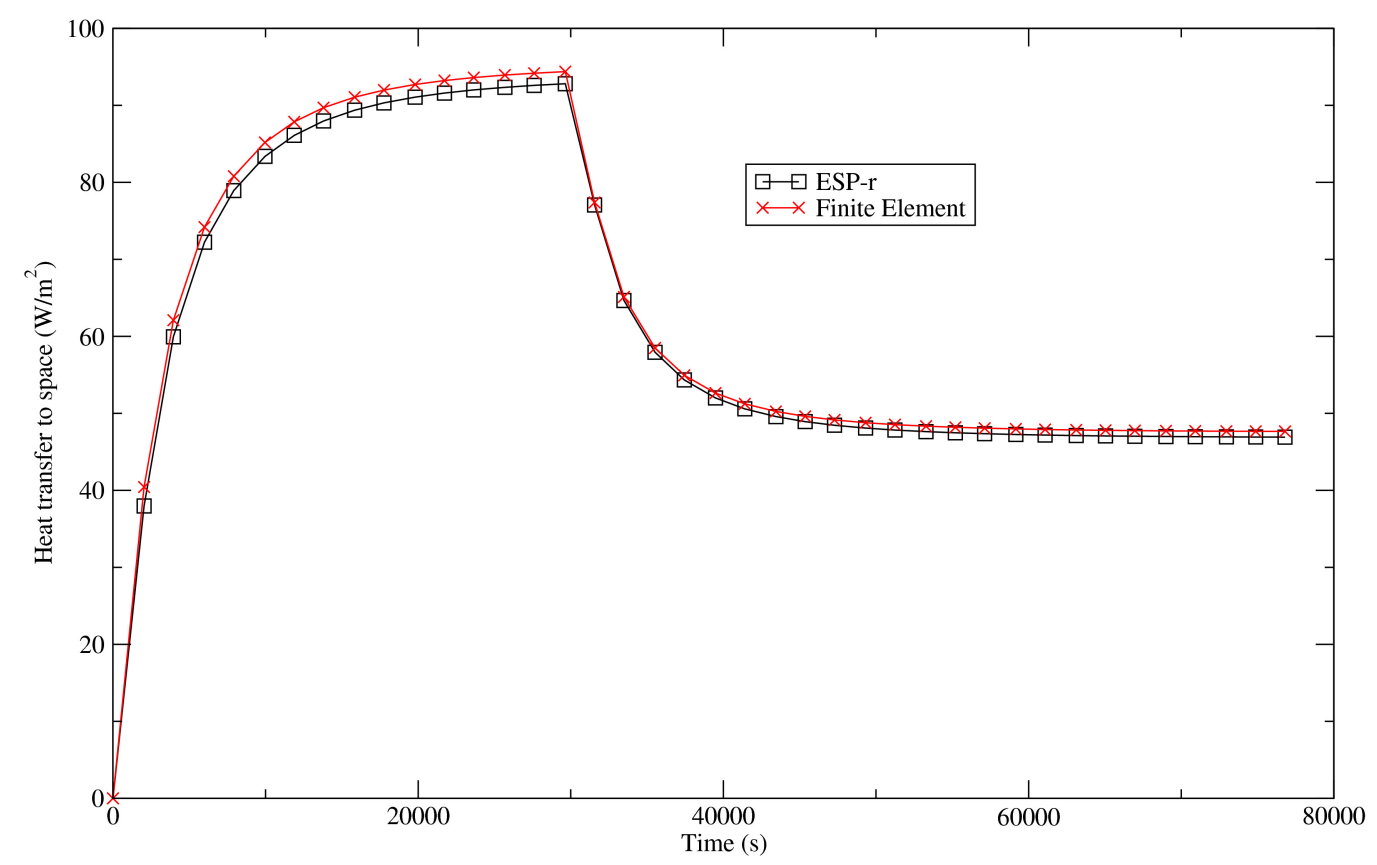

Figure A.2: Comparison of ESP-r model with finite element model for tile cover and 1280 minutes

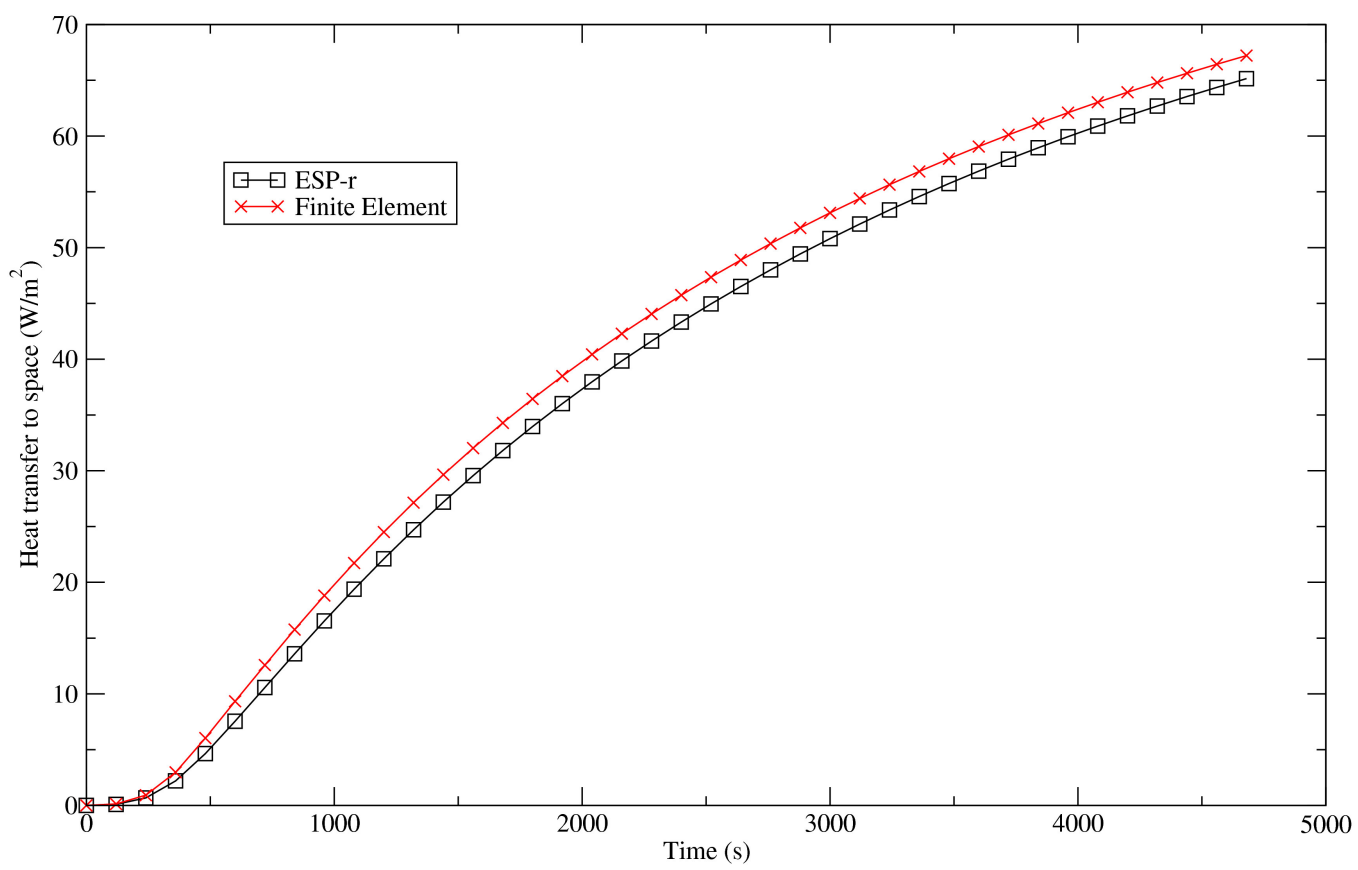

Figure A.3: Comparison of ESP-r model with finite element model for tile cover and first 39 time steps (78 minutes) 


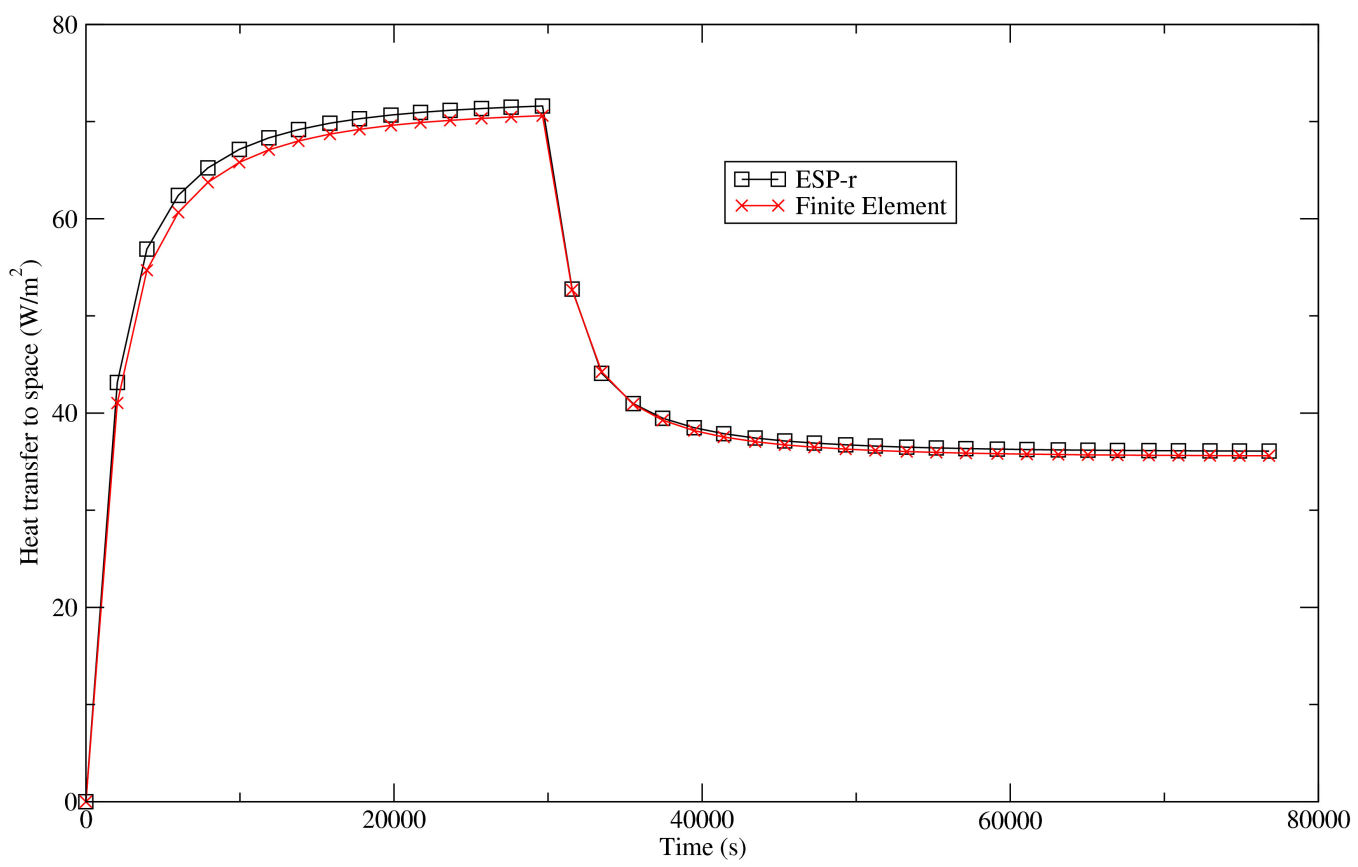

Figure A.4: Comparison of ESP-r model with finite element model for hardwood cover and 1280 minutes

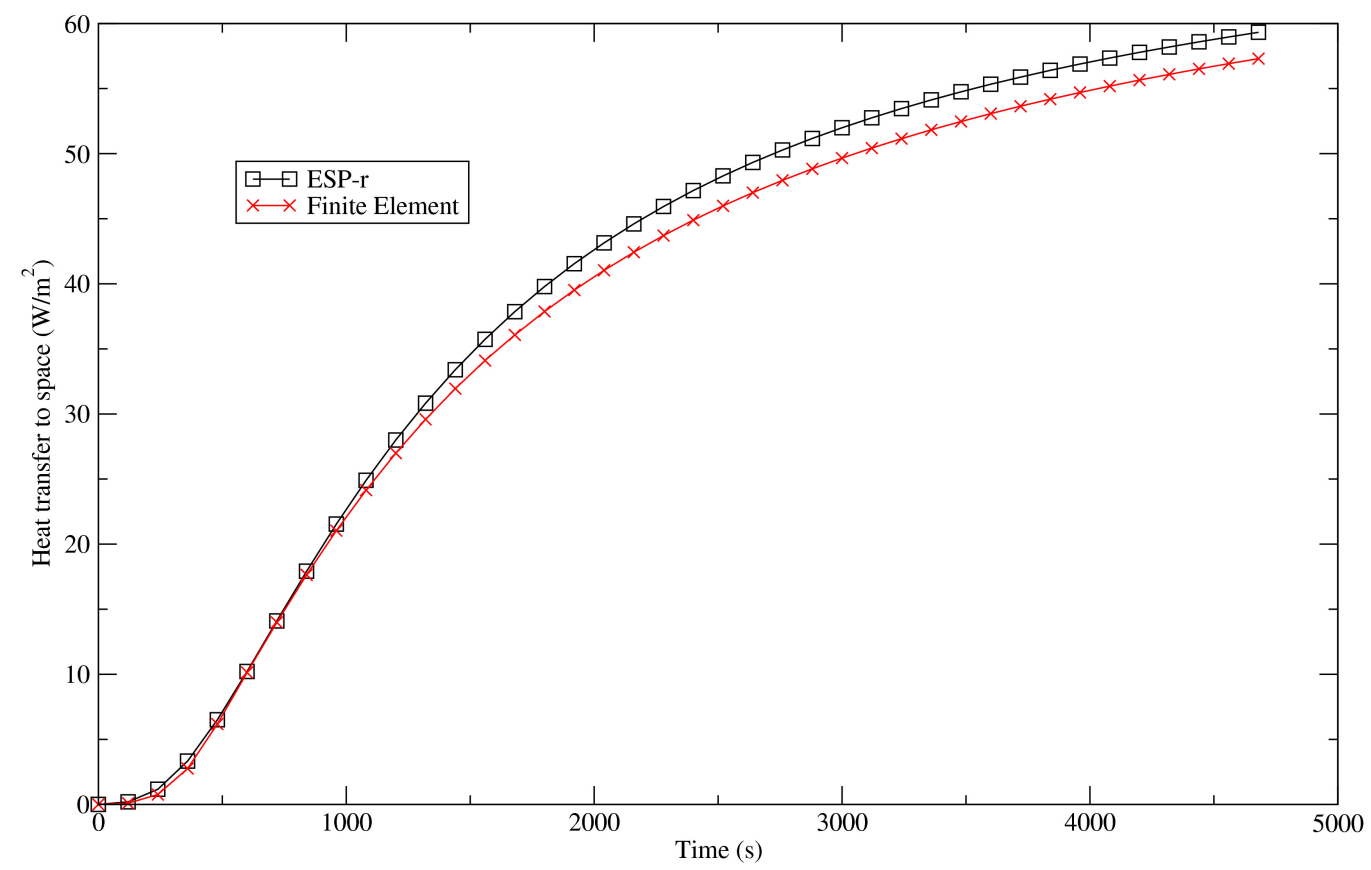

Figure A.5: Comparison of ESP-r model with finite element model for hardwood cover and first 39 time steps (78 minutes) 
Table A.2: RMSD for various parameters pertubation

\begin{tabular}{lcc}
\hline Parameter & $\begin{array}{r}\text { RMSD for parameter } \\
+10 \%\left(\mathrm{~W} \mathrm{~m}^{-2}\right)\end{array}$ & $\begin{array}{c}\text { RMSD for parameter } \\
-10 \%\left(\mathrm{~W} \mathrm{~m}^{-2}\right)\end{array}$ \\
\hline$k_{\text {cover }}$ & 0.987 & 1.15 \\
$(\rho C)_{\text {cover }}$ & 0.815 & 0.857 \\
$k_{\text {tube }}$ & 0.684 & 0.812 \\
$k_{\text {fin }}$ & 1.017 & 1.024 \\
$t_{\text {fin }}$ & 0.969 & 1.16 \\
$k_{\text {subfloor }}$ & 0.277 & 0.299 \\
$h_{\text {surface,top }}$ & 4.06 & 4.36 \\
\hline
\end{tabular}

\section{A.2.4 Parametric analysis}

A parametric analysis was performed with the ESP-r model with a tile floor cover. The parameters investigated were: cover conductivity, cover thermal mass, tube conductivity, fin conductivity, fin thickness, subfloor conductivity and surface convective heat transfer coefficient. Each parameter was varied by $+10 \%$ and $-10 \%$ and a RMSD was calculated for all data points between the base case and the varied parameter case. Simulations were run in ESP-r with the same conditions as described previously. Table A.2 shows the results.

Considering that the RMSD between the FEA model and the ESP-r model for the tile cover was $1.22 \mathrm{~W} \mathrm{~m}^{-2}$ for the full simulation (1280 minutes), it can be seen that varying some of the parameters by $10 \%$ would result in similar results. The fin thickness and conductivity, and the cover conductivity all have RMSD around 1 $\mathrm{W} \mathrm{m}^{-2}$ for a $10 \%$ change. The heat transfer coefficient is much higher at around 4 $\mathrm{W} \mathrm{m}^{-2}$. This is of interest because in a situation where one wants to model a building with a radiant floor, the various parameters related to floor are usually not known to a great level of certainty. This analysis shows that the difference between the FEA results and the ESP-r results is similar or smaller to the uncertainty one would get from the input parameters or heat transfer coefficient. 


\section{Appendix B}

\section{Laouadi radiant floor tube model}

As discussed in Chapter 3, the model for the heat transfer in the tube described by Laouadi was used in the AFTP model. This is a brief mathematical explanation of the pertinant information relevant to the AFTP model. The interested reader is refered to work by Laouadi [27] for further information.

Figure 3.5 shows an energy balance on a discrete 1D element of a tube in a floor.

Equation B.1 shows the resulting discretized tube conduction model for the fully implicit method.

$$
\left(\beta_{1}+\beta_{2} \Delta t\right) \bar{\Theta}-\beta_{1} \bar{\Theta}^{\text {old }}-\Delta t \gamma=0
$$

where:

$$
\begin{gathered}
\bar{\Theta}=\frac{1}{L} \int_{0}^{L} \Theta d z \\
\Theta=T_{f}-T_{t o} \\
\beta_{1}=\frac{(\rho C A)_{f}}{U P} \\
\beta_{2}=\frac{\chi_{1} L}{\chi_{1} L-1+e^{-\chi_{1} L}} \\
\gamma=\left(\frac{1-e^{-\chi_{1} L}}{\chi_{1} L-1+e^{-\chi_{1} L}}\right) \Theta_{i n}-\frac{\chi_{4}}{U P} \frac{d T_{t o}}{d t}
\end{gathered}
$$




$$
\begin{gathered}
\Theta_{i n}=T_{i n}-T_{t o} \\
\chi_{1}=\frac{U P}{\dot{m} C_{f}} \\
\chi_{4}=(\rho C A)_{f}+U P R_{\text {cond,tube }}(\rho C A)_{\text {tube }} \\
U P=\frac{1}{R_{\text {conv }, f}+R_{\text {cond }, \text { tube }}} \\
R_{\text {conv }, f}=\frac{1}{\pi D_{t i} h_{f}} \\
R_{\text {cond,tube }}=\frac{\ln \left(D_{t o} / D_{t i}\right)}{2 \pi k_{\text {tube }}}
\end{gathered}
$$

Equation B.13 is used to calculate the heat transferred to the floor.

$$
Q_{c}=U P L\left[\bar{\Theta}-R_{c o n v, f}(\rho C A)_{t u b e} \frac{d T_{t o}}{d t}\right]
$$

with $\bar{\Theta}$ being the average temperature difference between the fluid temperature and the tube outer temperature and $\frac{d T_{t o}}{d t}$ being discretized;

$$
\frac{d T_{t o}}{d t}=\frac{T_{t o}-T_{t o, t-1}}{\Delta t}
$$




\section{Appendix C}

\section{Additional results for AFTP radiant floor experiment}

This appendix discusses the results for test B, and should be read in conjunction with Chapter 3. Results for test B are very similar to test A so they will not be discussed in as much detail as test $\mathrm{A}$.

The results for the test B are shown in Figures C.3 through C.5.

The RMSD of the modelled vs experimental (corrected) floor surface temperature was $0.67^{\circ} \mathrm{C}$. The RMSD of the top and bottom floor surface heat flux were $2.95 \mathrm{~W} \mathrm{~m}^{-2}$ (8.1\% of average heat flux of $36.41 \mathrm{~W} \mathrm{~m}^{-2}$ ) and $1.67 \mathrm{~W} \mathrm{~m}^{-2}$ (34\% of average heat flux of $4.89 \mathrm{~W} \mathrm{~m}^{-2}$ ) respectively. Finaly, the RMSD of the water heat transfer rate was $28.0 \mathrm{~W}$ (4.8\% of average heat transfer of $581 \mathrm{~W})$.

As can be seen in Figure C.3, the model predicts the heat transfer rate between the water and the floor quite well. There is however an over-prediction of the heat transfer rate for the first hour. Following the first hour, the model consistently slightly underpredicts the heat transfer rate, but tends to capture the transient effects relatively well. Most of the data points are not within the experimental error bars.

Figure C.4 shows measured floor temperature, as well as the corrected (or undisturbed) floor temperature as per Equation 3.13. The modelled floor temperature and corrected results seem to agree very well. The modelled air temperature is not shown

as the measured experimental values were imposed on the model. The error bars are only shown every 6 time steps for clarity.

Figure C.5 shows the surface heat fluxes. As for test A, there is a lag between 


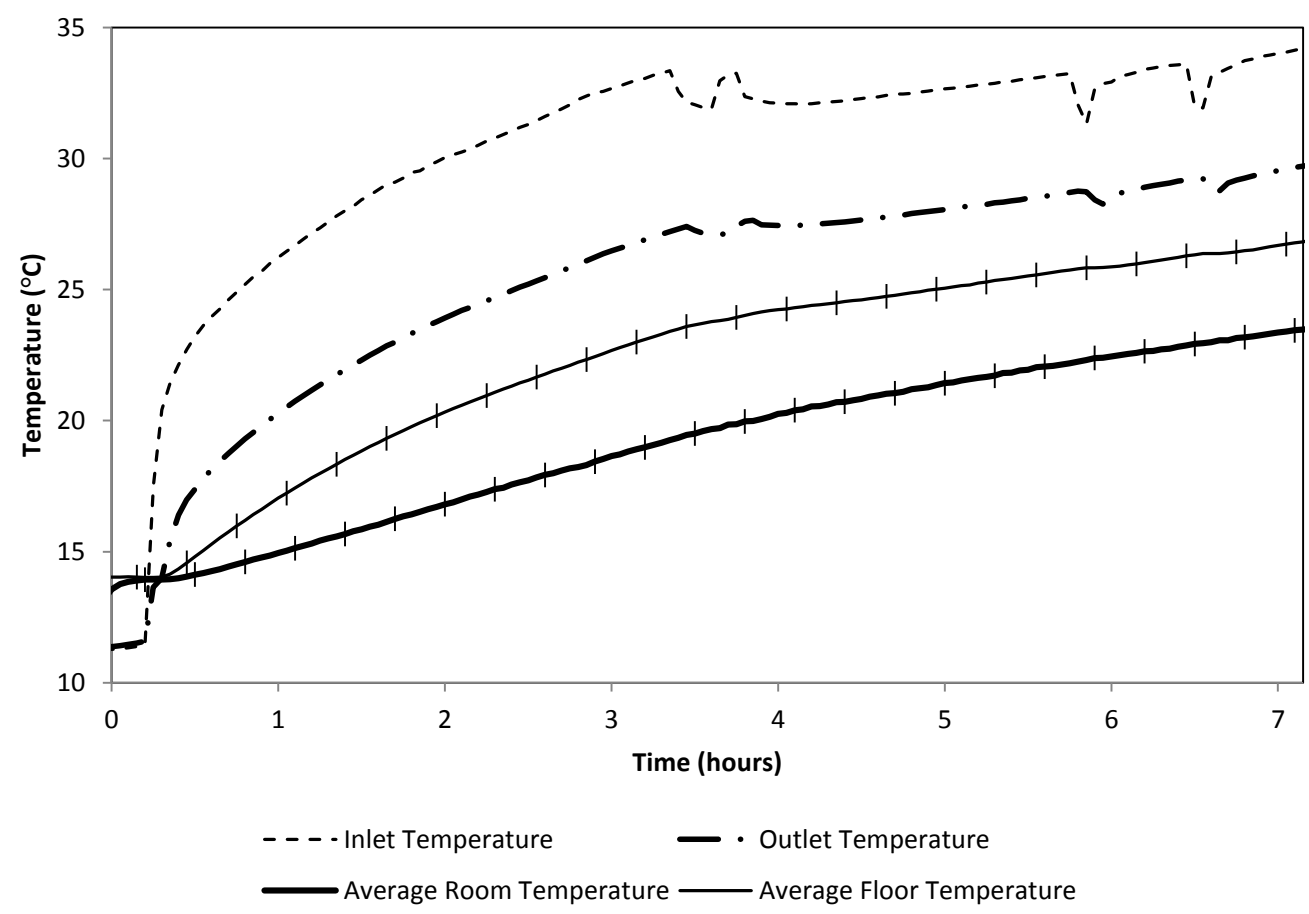

Figure C.1: Experimental data (temperatures) for test B

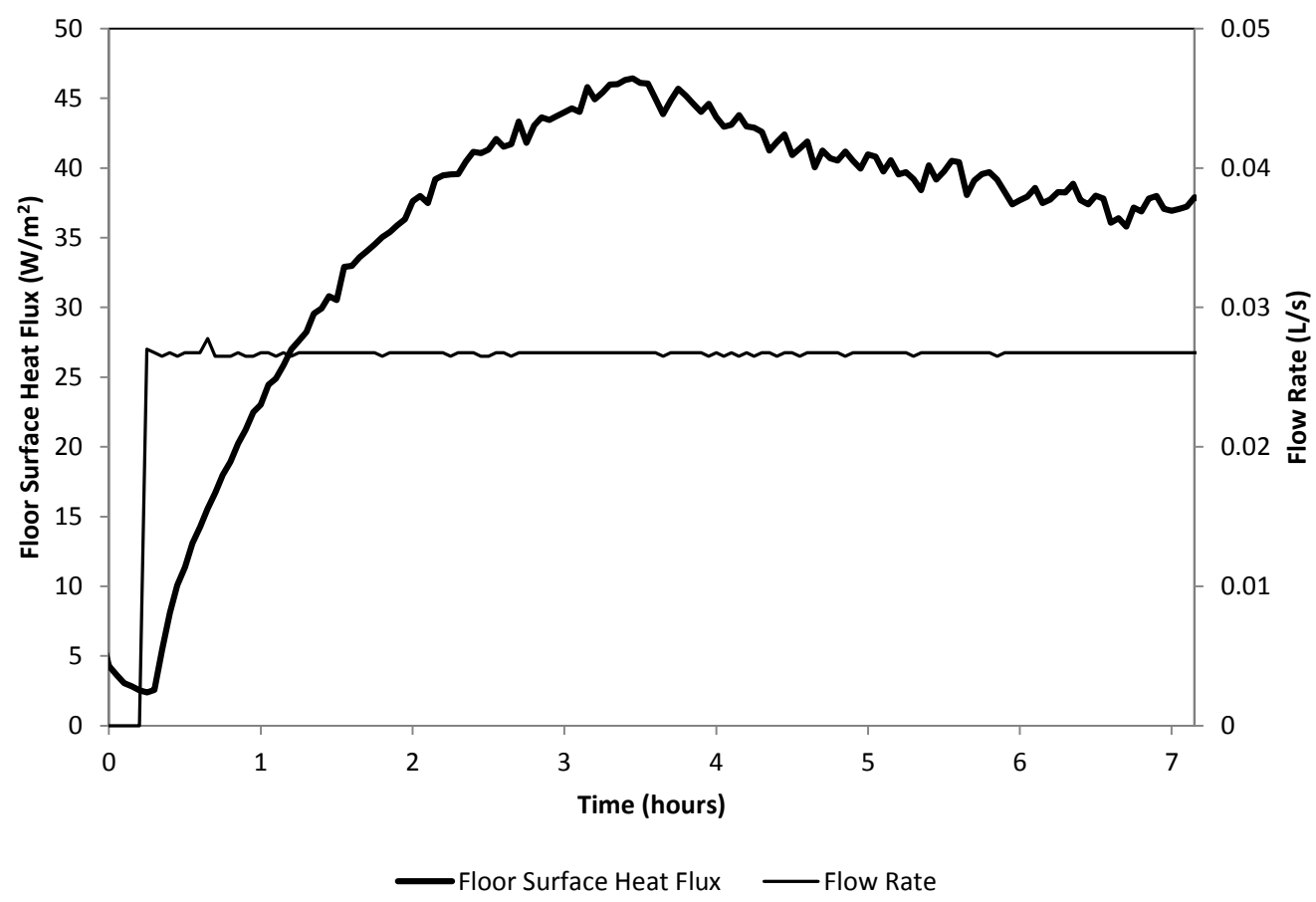

Figure C.2: Experimental data (heat flux and flow rate) for test B 


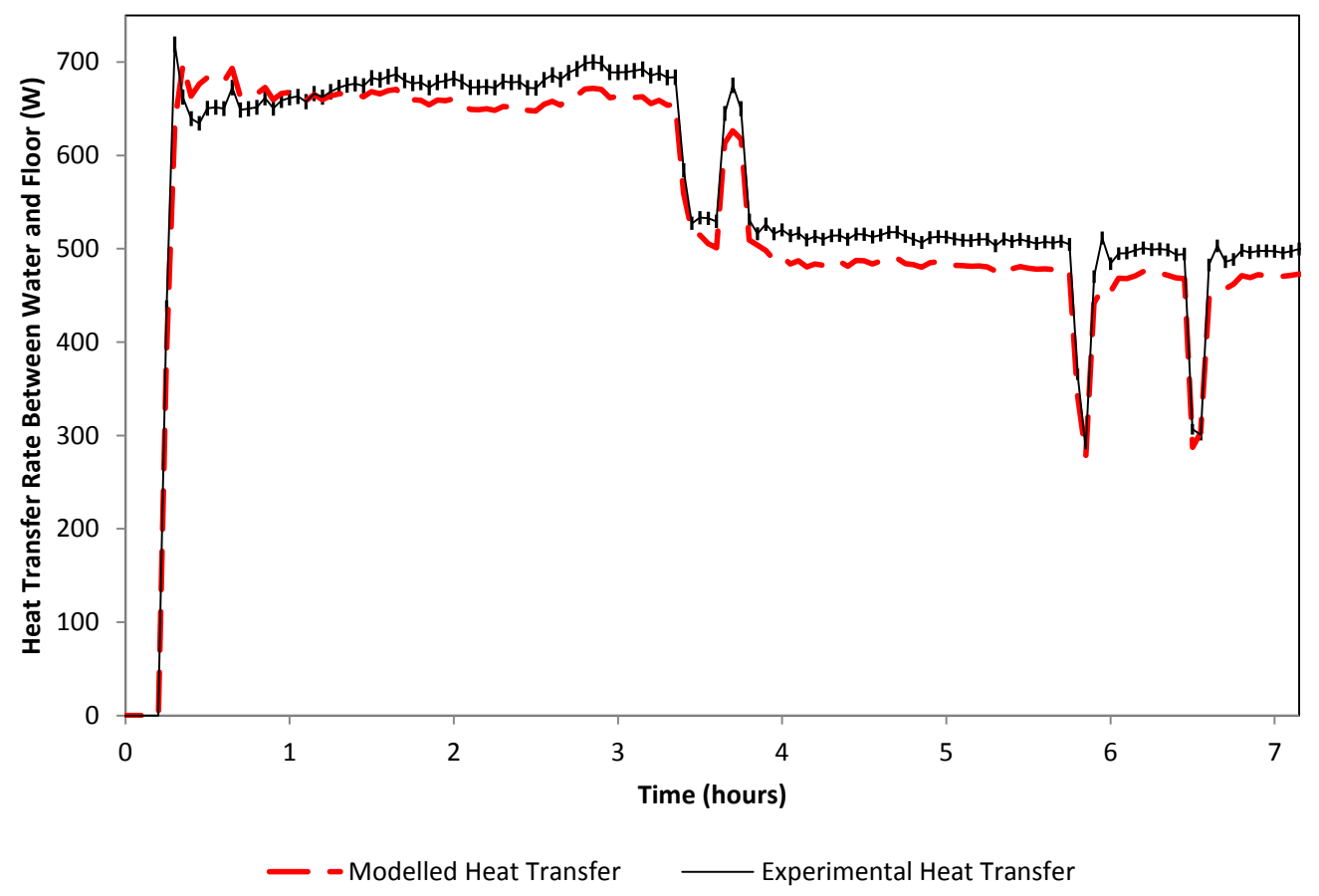

Figure C.3: Experimental vs Modelled Results - Test B: Water Heat Transfer Rate

the modeled top surface heat flux and the experimental value at the beginning of the test. Additionally, the heat flux below the subfloor is greatly inaccurate when evaluated in terms of percentage error. As mentioned earlier, the RMSD is $34 \%$ of the average. In absolute value however, it is very small due to the small amount of heat flux flowing downwards. The error bars for the heat flux from the subfloor are not shown for clarity as they were very small (less than $0.2 \mathrm{~W} \mathrm{~m}^{-2}$ ).

With the parameters described in Table 3.7, the model under-predicts the heat transfer from the water to the floor, from the top surface to the room, and from the bottom surface to the joist cavity.

\section{C.1 Sensitivity analysis}

Table C.1 shows the results of the RMSD for the various model outputs for test B. Those results show that the material properties can have an impact on the results, especially for the top surface heat flux. The corrected (or undisturbed) temperature, 


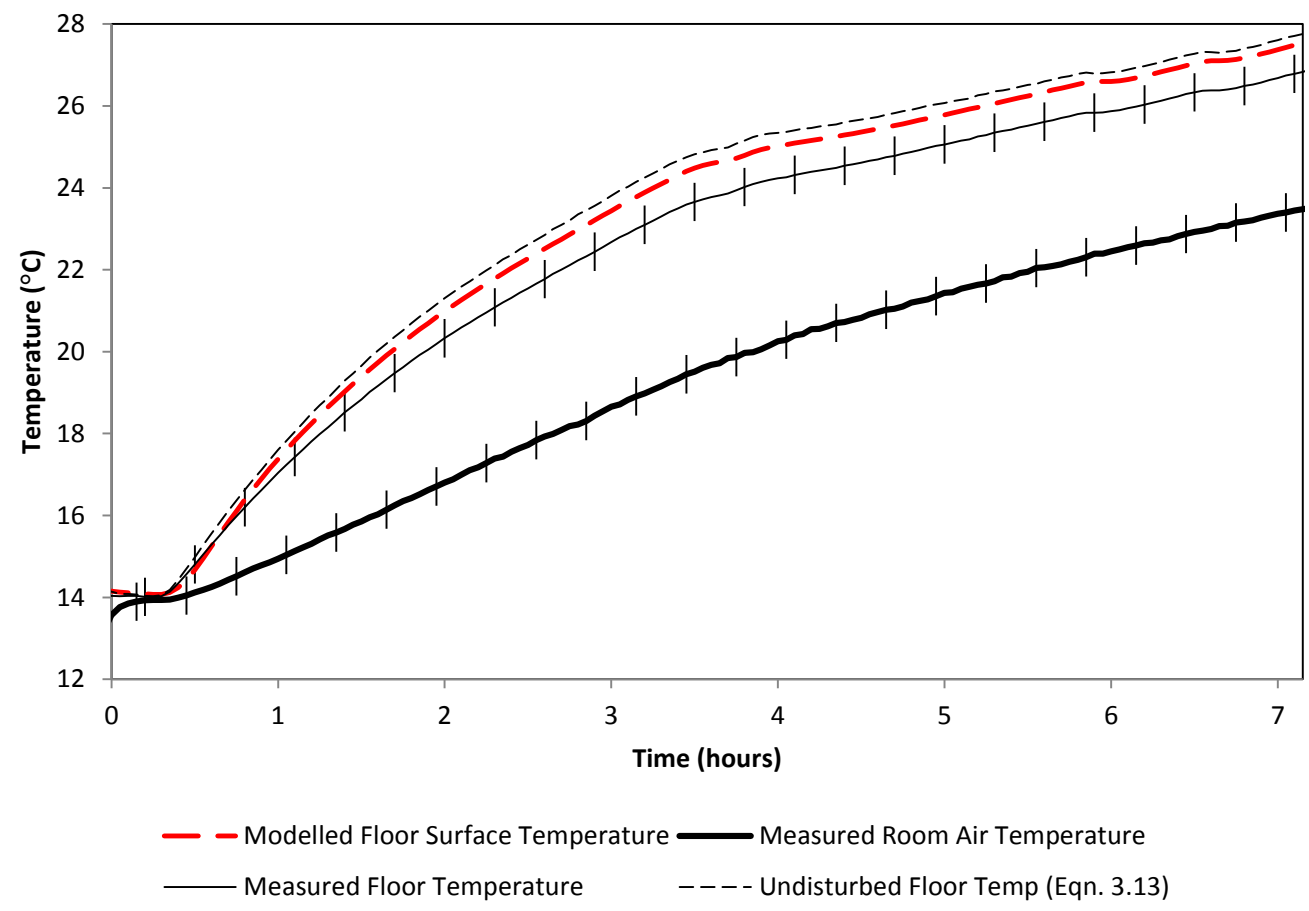

Figure C.4: Experimental vs Modelled Results - Test B: Air and Floor Surface Temperature

Table C.1: Material sensitivity - Test B

\begin{tabular}{|c|c|c|c|c|}
\hline & \multirow{3}{*}{$\begin{array}{c}\text { Average } \\
\text { Experiment } \\
\text { Value }\end{array}$} & \multicolumn{3}{|c|}{ RMSD: Experiment vs Model } \\
\hline & & Base & Low & High \\
\hline & & Case & Diffusivity & Diffusivity \\
\hline $\begin{array}{l}\text { Temperature Top Floor Surface } \\
\left({ }^{\circ} \mathrm{C}\right)\end{array}$ & 22.6 & 0.29 & 0.40 & 0.20 \\
\hline $\begin{array}{l}\text { Heat Flux Top Surface } \\
\left(\mathrm{W} \mathrm{m}^{-2}\right)\end{array}$ & 36.4 & 2.95 & 3.71 & 2.23 \\
\hline $\begin{array}{l}\text { Heat Flux Bottom Surface } \\
\left(\mathrm{W} \mathrm{m}^{-2}\right)\end{array}$ & 4.89 & 1.67 & 1.49 & 1.79 \\
\hline $\begin{array}{l}\text { Water to Floor Heat Transfer } \\
\text { (W) }\end{array}$ & 581 & 28.0 & 26.57 & 29.5 \\
\hline
\end{tabular}




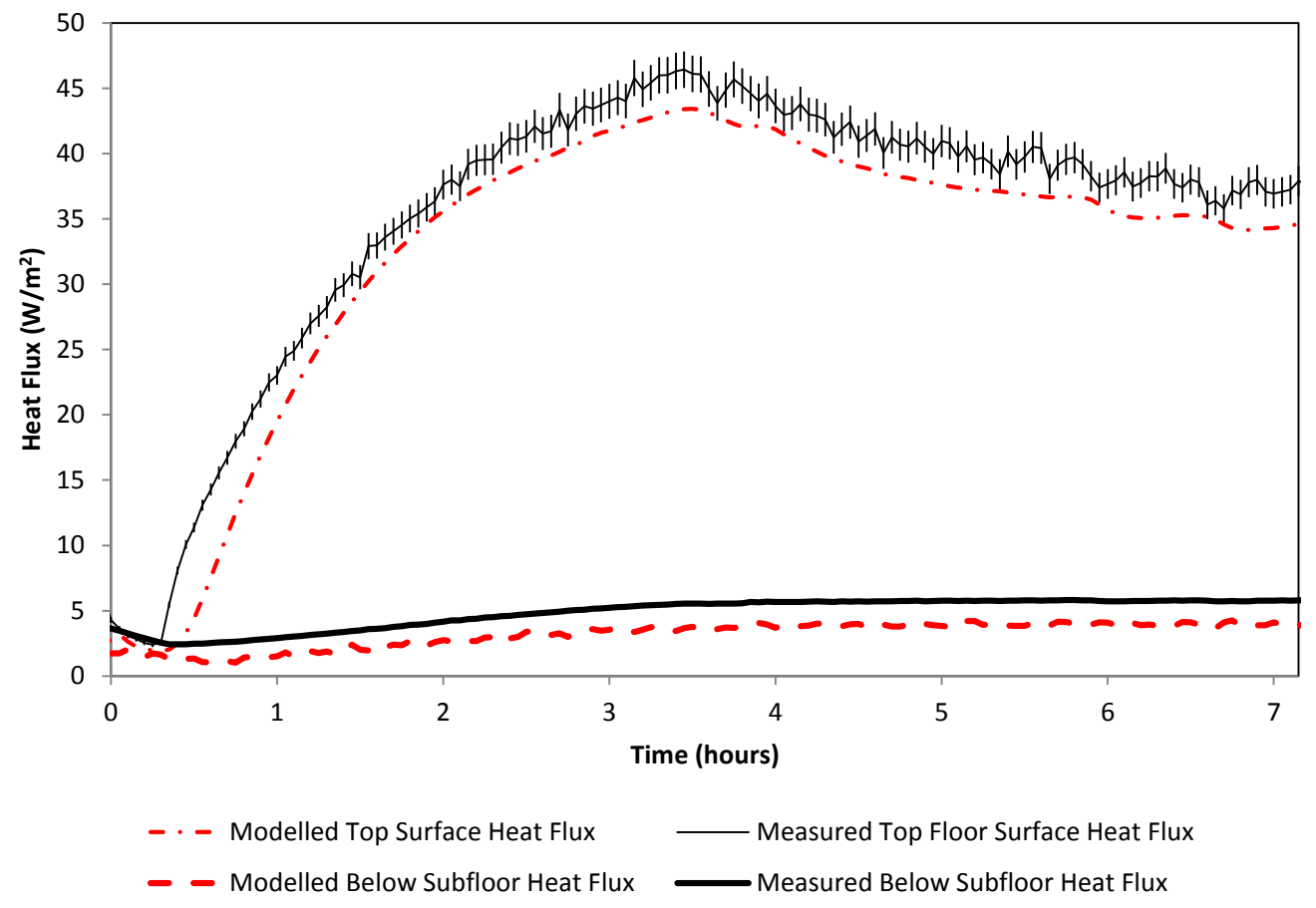

Figure C.5: Experimental vs Modelled Results - Test B: Heat Fluxes

as defined in Equation 3.13 is used here.

Table C.2 shows the RMSD between the experiment and the model with the various convective heat transfer coefficients (Awbi and Hatton is the base case). 
Table C.2: Convective heat transfer coefficient sensitivity- Test B

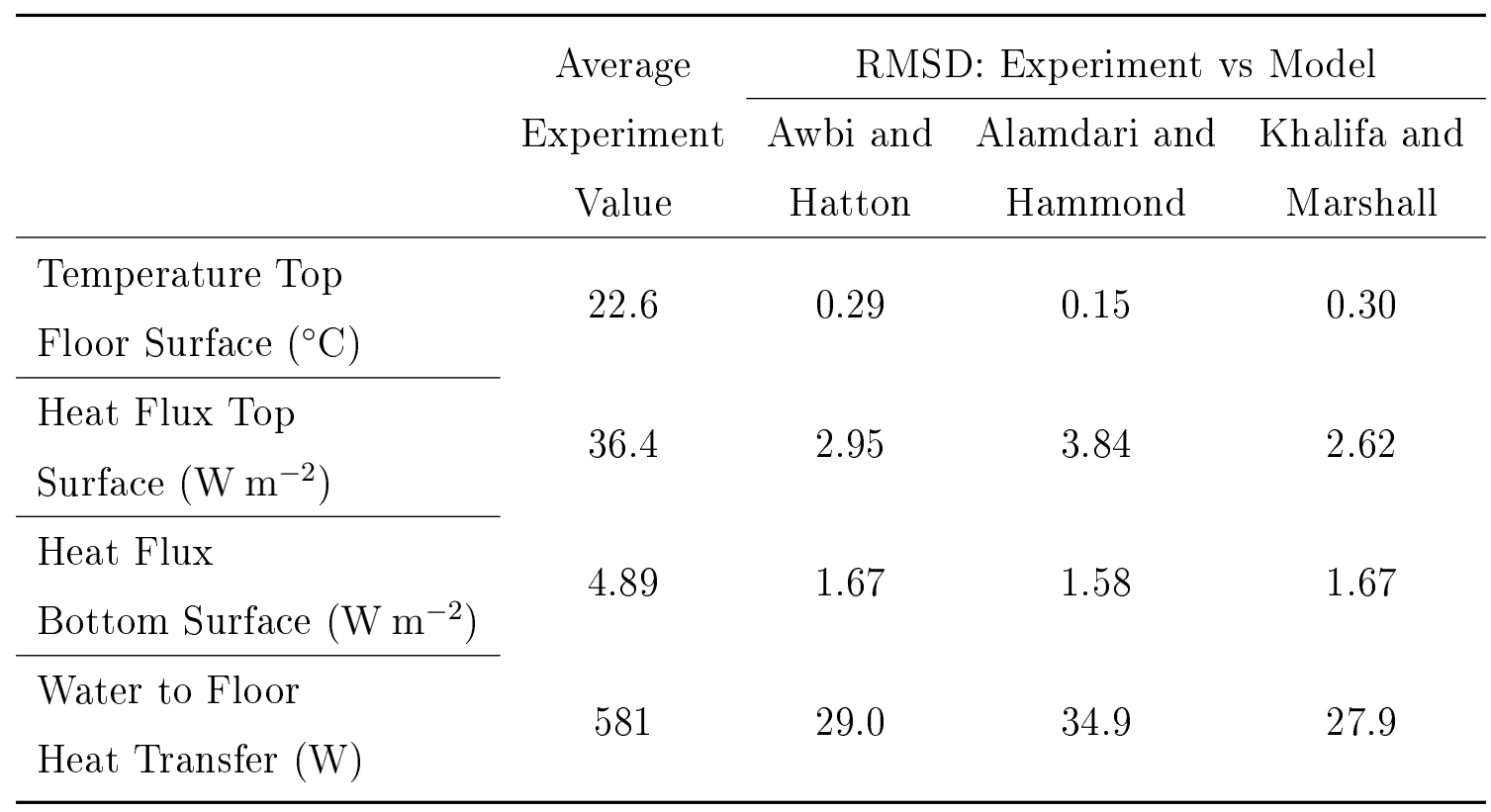




\section{Appendix D}

\section{Parameters of tuned radiant floor heating controllers}

This appendix shows the parameters for the tuned controllers discussed in Chapter 5. 
Table D.1: ON-OFF controls without temperature setback

\begin{tabular}{llc}
\hline Floor Type & Glazing Area & Supply Temperature $\left({ }^{\circ} \mathrm{C}\right)$ \\
\hline AFTP & Normal & 35 \\
AFTP & High & 50 \\
Slab A & Normal & 35 \\
Slab A & High & 35 \\
Slab B & Normal & 40 \\
Slab B & High & 45 \\
Slab C & Normal & 35 \\
Slab C & High & 35 \\
\hline
\end{tabular}

Table D.2: ON-OFF controls with temperature setback

\begin{tabular}{llcc}
\hline Floor Type & Glazing Area & Supply Temperature $\left({ }^{\circ} \mathrm{C}\right)$ & Setback Time (hours) \\
\hline AFTP & Normal & 40 & 3 \\
AFTP & High & 50 & 3 \\
Slab A & Normal & 40 & 3.5 \\
Slab A & High & 50 & 4 \\
Slab B & Normal & 40 & 4 \\
Slab B & High & 40 & 4 \\
Slab C & Normal & 45 & 2 \\
Slab C & High & 50 & 4.5 \\
\hline
\end{tabular}


Table D.3: PWM controls without temperature setback

\begin{tabular}{llccc}
\hline Floor Type & Glazing Area & $\begin{array}{c}\text { Supply } \\
\text { Temperature } \\
\left({ }^{\circ} \mathrm{C}\right)\end{array}$ & $\begin{array}{c}\text { Period } \\
\text { (hours) }\end{array}$ & $\begin{array}{c}\text { Proportional } \\
\text { Band }\left({ }^{\circ} \mathrm{C}\right)\end{array}$ \\
\hline AFTP & Normal & 35 & 0.2 & 1 \\
AFTP & High & 35 & 0.2 & 1 \\
Slab A & Normal & 35 & 0.2 & 1 \\
Slab A & High & 35 & 0.3 & 1 \\
Slab B & Normal & 40 & 0.3 & 1 \\
Slab B & High & 40 & 0.3 & 1 \\
Slab C & Normal & 35 & 0.3 & 1 \\
Slab C & High & 35 & 0.3 & 1 \\
\hline
\end{tabular}

Table D.4: PWM controls with temperature setback

\begin{tabular}{llcccc}
\hline Floor Type & Glazing Area & $\begin{array}{c}\text { Supply } \\
\text { Temperature } \\
\left({ }^{\circ} \mathrm{C}\right)\end{array}$ & $\begin{array}{c}\text { Period } \\
(\text { hours })\end{array}$ & $\begin{array}{c}\text { Proportional } \\
\text { Band }\left({ }^{\circ} \mathrm{C}\right)\end{array}$ & $\begin{array}{c}\text { Setback } \\
\text { Time } \\
(\text { hours })\end{array}$ \\
\hline AFTP & Normal & 45 & 0.2 & 1 & 2 \\
AFTP & High & 45 & 0.3 & 1 & 2 \\
Slab A & Normal & 40 & 0.2 & 1 & 3.5 \\
Slab A & High & 40 & 0.2 & 1 & 4.5 \\
Slab B & Normal & 45 & 0.2 & 1 & 3.5 \\
Slab B & High & 45 & 0.3 & 1 & 4.5 \\
Slab C & Normal & 40 & 0.3 & 1 & 3.5 \\
Slab C & High & 40 & 0.3 & 1 & 3.5 \\
\hline
\end{tabular}


Table D.5: TR controls without temperature setback

\begin{tabular}{llc}
\hline Floor Type & Glazing Area & Reset Ratio \\
\hline AFTP & Normal & 0.3 \\
AFTP & High & 0.7 \\
Slab A & Normal & 0.6 \\
Slab A & High & 0.7 \\
Slab B & Normal & 0.5 \\
Slab B & High & 0.6 \\
Slab C & Normal & 0.5 \\
Slab C & High & 0.4 \\
\hline
\end{tabular}

Table D.6: TR controls with temperature setback

\begin{tabular}{llcc}
\hline Floor Type & Glazing Area & Reset Ratio & Setback Time (hours) \\
\hline AFTP & Normal & 0.6 & 2 \\
AFTP & High & 0.9 & 2.5 \\
Slab A & Normal & 0.5 & 3 \\
Slab A & High & 0.8 & 4 \\
Slab B & Normal & 0.5 & 4.5 \\
Slab B & High & 0.5 & 4.5 \\
Slab C & Normal & 0.6 & 2 \\
Slab C & High & 1 & 4.5 \\
\hline
\end{tabular}


Table D.7: TRIF controls without temperature setback

\begin{tabular}{llcc}
\hline Floor Type & Glazing Area & Reset Ratio & Gain \\
\hline AFTP & Normal & 0 & 8.5 \\
AFTP & High & 0 & 8.5 \\
Slab A & Normal & 0 & 9.5 \\
Slab A & High & 0 & 10.5 \\
Slab B & Normal & 0 & 11.5 \\
Slab B & High & 0 & 8.5 \\
Slab C & Normal & 0 & 9.5 \\
Slab C & High & 0 & 11.5 \\
\hline
\end{tabular}

Table D.8: TRIF controls with temperature setback

\begin{tabular}{llccc}
\hline Floor Type & Glazing Area & Reset Ratio & Gain & Setback Time (hours) \\
\hline AFTP & Normal & 0 & 10.5 & 2 \\
AFTP & High & 0 & 9.5 & 2.5 \\
Slab A & Normal & 0 & 11.5 & 2 \\
Slab A & High & 0 & 11.5 & 3 \\
Slab B & Normal & 0.1 & 7.5 & 4.5 \\
Slab B & High & 0 & 9.5 & 4.5 \\
Slab C & Normal & 0 & 10.5 & 3 \\
Slab C & High & 0 & 12.5 & 3 \\
\hline
\end{tabular}


Table D.9: TRIF-Avg controls without temperature setback

\begin{tabular}{llcc}
\hline Floor Type & Glazing Area & Reset Ratio & Gain \\
\hline AFTP & Normal & 0 & 6.5 \\
AFTP & High & 0 & 6.5 \\
Slab A & Normal & 0 & 7.5 \\
Slab A & High & 0 & 7.5 \\
Slab B & Normal & 0.1 & 5.5 \\
Slab B & High & 0.1 & 5.5 \\
Slab C & Normal & 0 & 7.5 \\
Slab C & High & 0.1 & 5.5 \\
\hline
\end{tabular}

Table D.10: TRIF-Avg controls with temperature setback

\begin{tabular}{llccc}
\hline Floor Type & Glazing Area & Reset Ratio & Gain & Setback Time (hours) \\
\hline AFTP & Normal & 0 & 7.5 & 2.5 \\
AFTP & High & 0 & 7.5 & 2.5 \\
Slab A & Normal & 0 & 7.5 & 3.5 \\
Slab A & High & 0 & 7.5 & 3 \\
Slab B & Normal & 0.1 & 5.5 & 4.5 \\
Slab B & High & 0 & 7.5 & 4.5 \\
Slab C & Normal & 0 & 7.5 & 4.5 \\
Slab C & High & 0.1 & 5.5 & 3.5 \\
\hline
\end{tabular}


Table D.11: Temperature Boost controls

\begin{tabular}{llccc}
\hline Floor Type & Glazing Area & $\begin{array}{c}\text { Supply } \\
\text { Temperature } \\
\left({ }^{\circ} \mathrm{C}\right)\end{array}$ & $\begin{array}{c}\text { Boost } \\
\text { Temperature } \\
\left({ }^{\circ} \mathrm{C}\right)\end{array}$ & $\begin{array}{c}\text { Setback Time } \\
(\text { hours })\end{array}$ \\
\hline AFTP & Normal & 35 & 55 & 2 \\
AFTP & High & 35 & 45 & 2 \\
Slab A & Normal & 35 & 45 & 3 \\
Slab A & High & 45 & 50 & 4 \\
Slab B & Normal & 40 & 45 & 3 \\
Slab B & High & 35 & 50 & 3 \\
Slab C & Normal & 45 & 45 & 2 \\
Slab C & High & 40 & 45 & 2 \\
\hline
\end{tabular}

